\title{
Respiratory mechanics and lung structure in rodent models of emphysema
}

Margit Veronika Szabari, MD

$\mathrm{PhD}$ Thesis

Szeged

2015 
Graduate School of Multidisciplinary Medical Sciences

Department of Medical Physics and Informatics

University of Szeged, Hungary

Supervisor: Prof. Zoltán Hantos 


\section{List of papers included in this thesis:}

I. Z. Hantos, Á. Adamicza, T. Jánosi, M.V. Szabari, J. Tolnai and B. Suki: Lung volumes and respiratory mechanics in elastase-induced emphysema in mice. Journal of Applied Physiology, 105: 1864-1872 (2008)

II. J. Tolnai, M.V. Szabari, G. Albu, B.A. Maár, H. Parameswaran, E. Bartolák-Suki, B. Suki and Z. Hantos: Functional and morphological assessment of early impairment of airway function in a rat model of emphysema. Journal of Applied Physiology, 112: 1932-1939 (2012)

III. M.V. Szabari, J. Tolnai, B.A. Maár, H. Parameswaran, E. Bartolák-Suki, B. Suki and Z. Hantos: Lung structure and function relation in elastase-treated rats: a long-term follow up study. Respiratory Physiology \& Neurobiology, 215: 13-19 (2015)

IV. M.V. Szabari, H. Parameswaran, S. Sato, Z. Hantos, E. Bartolák-Suki and B. Suki: Acute mechanical forces cause deterioration in lung structure and function in elastase-induced emphysema. American Journal of Physiology. Lung Cellular and Molecular Physiology, 303: L567-L574 (2012)

List of papers related to the subject of this thesis:

V. B. Suki, S. Sato, H. Parameswaran, M.V. Szabari, A. Takahashi and E. BartolákSuki: Emphysema and mechanical stress-induced lung remodeling. Physiology, 28: 404-413 (2013) 


\section{List of abstracts related to the subject of this thesis:}

VI. M.V. Szabari, J. Tolnai, B.A. Maár, H. Parameswaran, E. Bartolák-Suki, B. Suki and Z. Hantos: Lung structure and function in a rat model of emphysema: $A$ longitudinal study. European Respiratory Journal, 40 Suppl. 56: 592s (2012)

VII. M.V. Szabari, J. Tolnai, B.A. Maár, H. Parameswaran, E. Bartolák-Suki, B. Suki and Z. Hantos: Lung structure and function relation in elastase-treated rats: a long-term follow up study. American Journal of Respiratory and Critical Care Medicine, 185: A6405 (2012)

VIII. M.V. Szabari, S. Sato, H. Parameswaran, E. Bartolák-Suki, Z. Hantos and B. Suki: Acute exposure to mechanical forces deteriorates lung structure and function in a mouse model of emphysema. European Respiratory Journal, 38 Suppl. 54: 864s (2011)

IX. Z. Hantos, J. Tolnai, M.V. Szabari, B.A. Maár and B. Suki: Alveolar bronchial morphometry in emphysematous rats. American Journal of Respiratory and Critical Care Medicine, 183: A2452 (2011)

X. J. Tolnai, Z. Hantos, M.V. Szabari, B.A. Maár and B. Suki: Airway opening in normal and emphysematous rats. American Journal of Respiratory and Critical Care Medicine, 183: A2448 (2011)

XI. M.V. Szabari, S. Sato, H. Parameswaran, E. Bartolák-Suki, Z. Hantos and B. Suki: Effects of mechanical stresses on the structure-function relations during the progression of elastase-induced emphysema. American Journal of Respiratory and Critical Care Medicine, 183: A2447 (2011)

XII. M.V. Szabari, J. Tolnai, B.A. Maár, B. Suki and Z. Hantos: Follow-up of lung function impairment in elastase-treated rats. European Respiratory Journal, 36 Suppl. 54: 48S (2010) 
XIII. Z. Hantos, M.V. Szabari, J. Tolnai, G. Albu and B. Suki: Lung volumes and respiratory mechanics in a rat model of emphysema. American Journal of Respiratory and Critical Care Medicine, 181: A5067 (2010)

XIV. J. Tolnai, M.V. Szabari, G. Albu, K. Boda and Z. Hantos: Changes in lung function in a rat model of mild emphysema. European Respiratory Journal, 34 Suppl. 53: 835s (2009)

XV. M.V. Szabari, G. Albu, Z. Hantos, Á. Adamicza and B. Suki: Development of elastase-induced emphysema in mice. European Journal of Medical Research 13: 143 (2008)

XVI. Z. Hantos, G. Albu, M.V. Szabari, Á. Adamicza and B. Suki: Increase in lung compliance and FRC but not residual volume in elastase treated mice: a follow-up study. European Respiratory Journal, 32 Suppl. 52: 533s (2008)

XVII. Z. Hantos, G. Albu, M.V. Szabari and Á. Adamicza: Repeated measurements of functional residual capacity and low-frequency respiratory impedance parameters in mice. American Journal of Respiratory and Critical Care Medicine, 177: A224 (2008)

XVIII. J. Tolnai, Á. Adamicza, M.V. Szabari, T. Z. Jánosi, K. Török, L. Tiszlavicz, B. Suki and Z. Hantos: In vivo vs. in vitro morphometry of alveolar size in normal and emphysematous mice. American Journal of Respiratory and Critical Care Medicine, 175: A527 (2007)

XIX. Z. Hantos, Á. Adamicza, M.V. Szabari and B. Suki: Lung volumes and respiratory mechanics in elastase-treated mice. European Respiratory Journal, 26: Suppl. 49: 365S (2005) 


\section{Table of Contents}

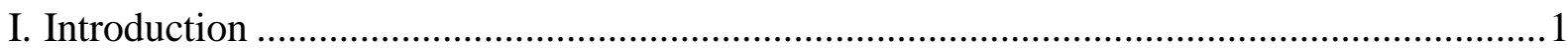

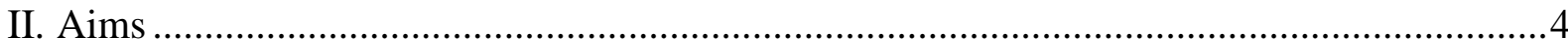

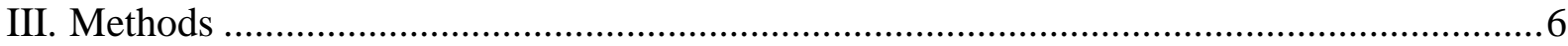

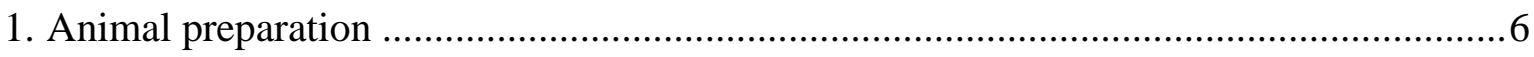

1.1. Relationship between lung volumes and respiratory mechanics (Study I) ...............6

1.2. Functional and morphological assessment of early impairment of the airway

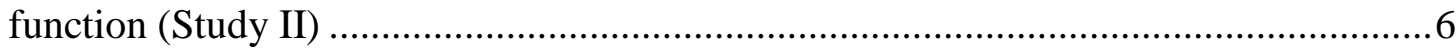

1.3. Long-term changes in lung structure and function in emphysema (Study III) ..........7

1.4. The effects of mechanical forces on lung structure and function (Study IV) ............7

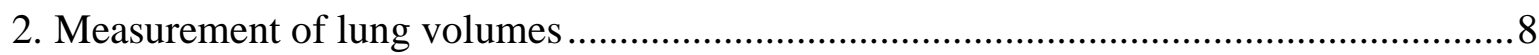

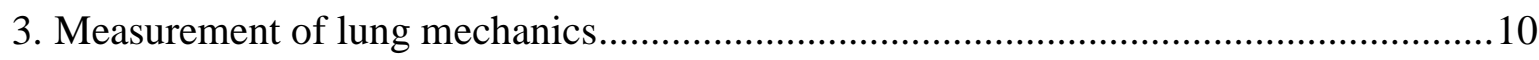

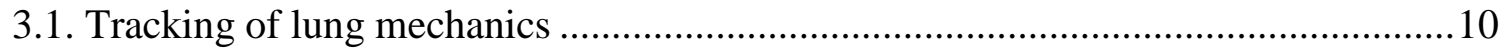

3.2. Lung mechanics measurements with the FlexiVent ............................................. 11

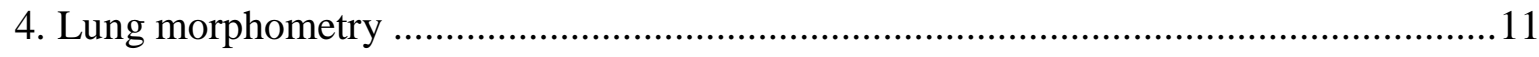

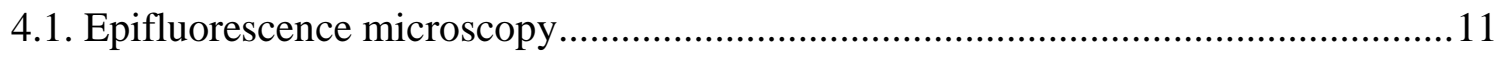

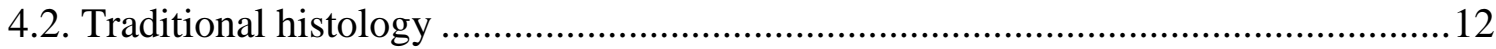

4.3. Orthogonal polarization spectral (OPS) imaging ........................................... 15

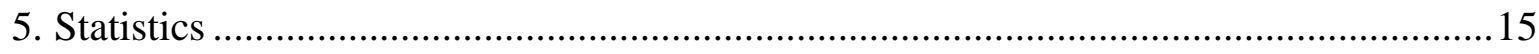

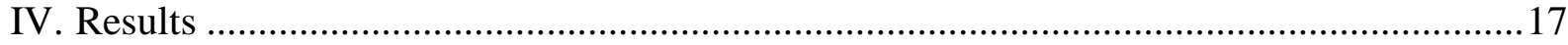

1. Relationship between lung volumes and respiratory mechanics (Study I) ................... 17

2. Functional and morphological assessment of early impairment of the airway

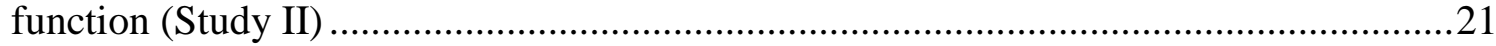

3. Long-term changes in lung structure and function in emphysema (Study III) ..............24

4. The effects of mechanical forces on lung structure and function (Study IV) ...............29

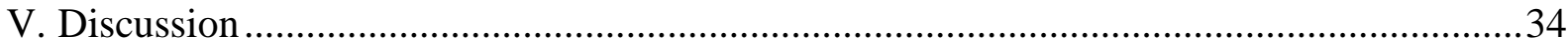

1. Lung volumes and respiratory mechanics in PPE-induced emphysema........................34

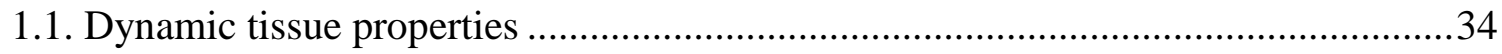

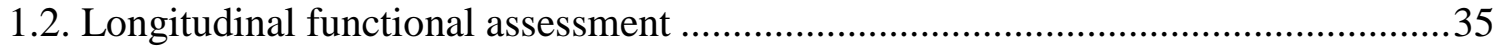

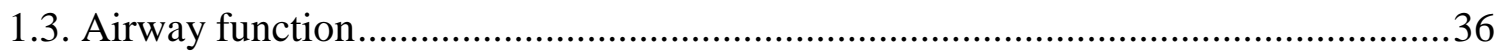


2. Lung morphometry in PPE-induced emphysema ................................................ 36

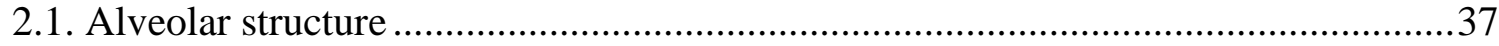

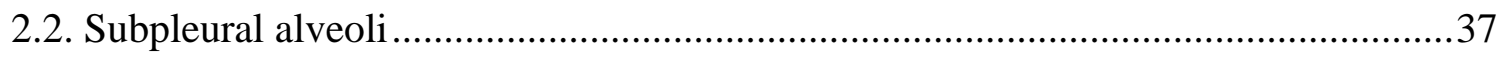

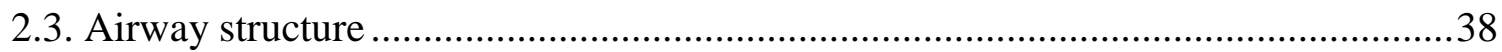

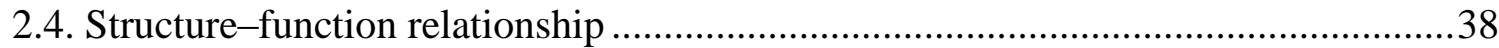

3. Mechanical effects on chemically weakened lung tissue.........................................39

3.1. Lung volumes and respiratory mechanics .....................................................40

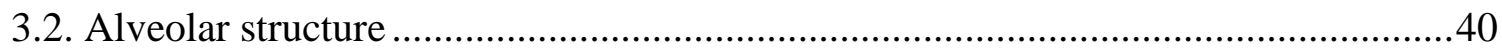

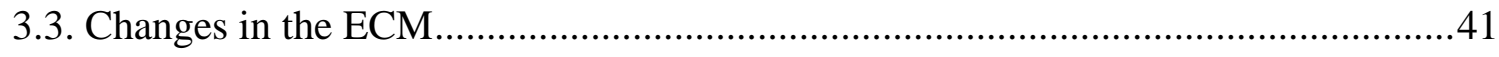

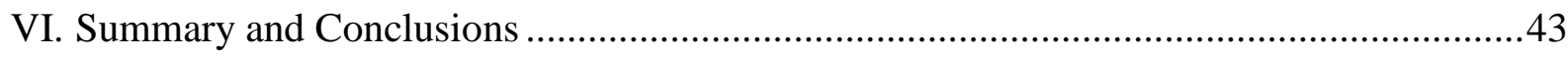

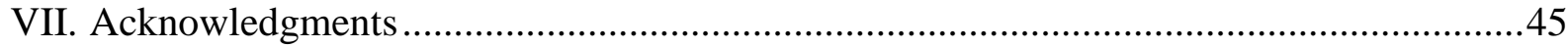

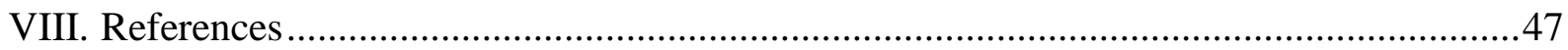




\section{List of figures and tables}

Figure 1: Experimental set-up for the measurement of thoracic gas volume and oscillatory mechanics.

Figure 2: Definition of lung slices for histological evaluation and the areas used for alveolar morphometry in every slice.

Figure 3: Inner and outer boundaries of the airway wall, determined automatically for the calculation of elastin density. 14

Figure 4: Epifluorescence microscopy pictures of agarose-fixed lung slices .17

Figure 5: Probability distribution of equivalent alveolar or terminal airspace diameters in subpopulations of control and porcine pancreatic elastase-treated mice.

Figure 6: Inflation and deflation curves of thoracic gas volume vs. transrespiratory pressure averaged for the control mice and the porcine pancreatic elastase-treated animals.

Figure 7: A: Elastance coefficient $(\mathrm{H})$ vs. transrespiratory pressure $\left(\mathrm{P}_{\mathrm{rs}}\right)$ during slow inflation from a $\mathrm{P}_{\mathrm{rs}}$ of 0 to $20 \mathrm{cmH}_{2} \mathrm{O}$. B: $\mathrm{H}$ vs. thoracic gas volume

Figure 8: A: Newtonian (airway) resistance $\left(\mathrm{R}_{\mathrm{N}}\right)$ vs. transrespiratory pressure $\left(\mathrm{P}_{\mathrm{rs}}\right)$ during slow inflation from a $\mathrm{P}_{\mathrm{rs}}$ of 0 to $20 \mathrm{cmH}_{2} \mathrm{O}$. B: $\mathrm{R}_{\mathrm{N}}$ vs. thoracic gas volume...... 20

Figure 9: Mean \pm SD values of lung volumes in the control and PPE-treated groups.............21

Figure 10: Relative frequencies of the alveolar diameters

Figure 11: Relative frequencies of the bronchial diameters (a), and the density of the septal attachments (b). Relationship between the calculated bronchial diameters and the average wall thickness in the control and porcine pancreatic elastase-treated rats (c).

Figure 12: Effects of time and treatment (porcine pancreatic elastase vs. saline controls) on physiological variables .25

Figure 13: A-D: Representative pictures of the parenchymal structure and distributions of the alveolar diameters. .26

Figure 14: Morphological results obtained from H\&E-stained histological samples .27

Figure 15: Mean values of the components of the extracellular matrix, obtained from stained histological samples. 
Figure 16: Structure-function correlation. Tissue elastance as a function of the mean alveolar diameter from traditional histology in control and porcine pancreatic elastase-treated

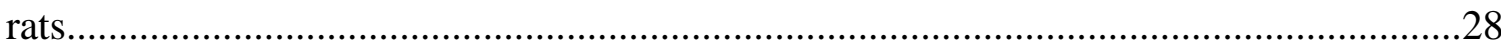

Figure 17: Effects of time and DIs on physiological variables.......................................29

Figure 18: Examples of H\&E-stained histological sections..............................................30

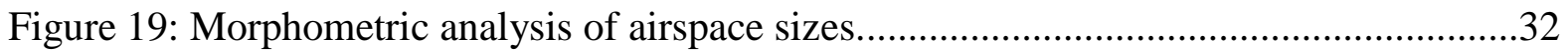

Figure 20: Morphometric analysis of the wall thickness of the airspaces. ...........................32

Figure 21: Representative images of stained histological sections......................................33

Figure 22: Visualization of all alveolar septal end tips, including possible alveolar ruptures

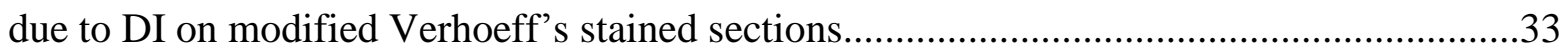

Table 1: Thoracic gas volumes and oscillatory mechanical parameters at transrespiratory pressures of $0 \mathrm{cmH}_{2} \mathrm{O}$ (suffix 0) and $20 \mathrm{cmH}_{2} \mathrm{O}$ (suffix 20) in the control and the porcine

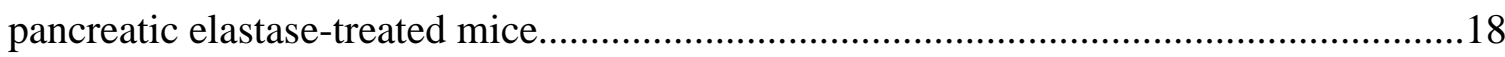

Table 2: Mechanical parameters of the lungs in the control animals and those treated with porcine pancreatic elastase.

Table 3: Mean values of alveolar diameters, binned into groups of small, medium and large 


\section{Glossary of abbreviations}

$\eta \ldots$ tissue hysteresivity

$\mathrm{A}_{\text {alv }}$... alveolar or terminal

airspace cross-sectional area

Ad ... attachment density

AECOPD . . . acute exacerbation

of chronic obstructive pulmonary

disease

C . . respiratory compliance

COPD ... chronic obstructive

pulmonary disease

$\mathrm{D}_{2} \ldots$ area-weighted alveolar

diameter

$\mathrm{D}_{\mathrm{alv}}$... alveolar diameter

$\mathrm{D}_{\mathrm{b}}$... bronchial diameter

DI . . deep inspiration

ECM . . . extracellular matrix

ERV . . . expiratory reserve volume

FEV1 . . forced expiratory

volume in the first second

F . . f fitting error of the model

FRC . . . functional residual

capacity

G . . constant-phase tissue

damping

H . . constant-phase tissue

elastance

$\mathrm{H} \& \mathrm{E}$. . . hematoxylin and eosin

I . . . inertance

IC . . inspiratory capacity
ID ... internal diameter

IU . . . international unit

LFOT . . . low-frequency forced

oscillation technique

Mcc ... mean collagen density

Mec ... mean elastin density

$\mathrm{N}_{\mathrm{S}} \ldots$ number of septal attachments

$\mathrm{N}_{\text {sr }}$. . number of septal ruptures

OPS ... orthogonal polarization

spectral

P ... pressure

$\mathrm{P}_{1} \ldots$ lateral pressure at the outlet of

the tube

$\mathrm{P}_{2} \ldots$ lateral pressure at the inlet of the tube

$\mathrm{Pb}$. . . bronchial perimeter

Pbox ... plethysmograph box pressure

PBS ... phosphate-buffered saline

PEEP . . p positive end-expiratory

pressure

PPE ... porcine pancreatic elastase

$\mathrm{P}_{\mathrm{rs}} \ldots$ transrespiratory pressure

Ptr . . . tracheal pressure

$\mathrm{R}_{\mathrm{N}}$. . Newtonian (airway) resistance

RV ... residual volume

$\mathrm{R}_{\mathrm{wt}}$... resistance of the wave tube

$\mathrm{TGV}$... thoracic gas volume

TLC . . . total lung capacity

$\mathrm{T}_{\mathrm{w}} \ldots$ airway wall thickness 
V ... volume

VEGFR-2 . . vascular endothelial growth factor receptor-2

$\mathrm{V}_{\mathrm{T}} \ldots$ tidal volume

$\mathrm{V}(\mathrm{t}) \ldots$ inflation volume
V'... flow

$\mathrm{Wt}$. . alveolar wall thickness

Zrs ... impedance of the total

respiratory system 


\section{INTRODUCTION}

Chronic obstructive pulmonary disease (COPD) is the third major cause of death worldwide after ischemic heart disease and stroke ${ }^{1}$. COPD is a type of obstructive lung disease characterized by airway narrowing, dyspnea, cough and sputum production. It is an umbrella term for two disorders: chronic bronchitis and emphysema.

Emphysema is a long-term disease, with progressive structural changes in the lung in which the alveolar walls are destroyed. This disorder is characterized clinically by a loss of elastic recoil and significant hyperexpansion of the lungs, as a result of permanent destruction of the parenchymal tissue structure ${ }^{2}$. A variety of mechanisms, including a protease-antiprotease imbalance ${ }^{3}$, inflammation ${ }^{4}$, abnormal extracellular matrix remodeling ${ }^{5}$ and mechanical forces ${ }^{6}$, have been proposed to be involved in its pathogenesis. From the point of view of respiratory mechanics, the decrease in the retraction capacity due to the prenchymal destruction modifies the elastic balance between the chest wall and the lungs, and this leads to an elevation of the end-expiratory lung volume, without the involvement of dynamic hyperinflation resulting from the expiratory flow limitation characteristic of COPD. Additionally, parenchymal destruction weakens the tethering forces transmitted to the airway wall by the alveolar attachments and the rest of the parenchymal structure from the pleural space. While it appears plausible that this change in the elastic forces leads to lower transbronchial pressures and a consequent decrease in the airway lumen, it has remained unclear whether or not the weaker tethering per se can lead to the obstructive conditions in COPD. The limited clinical knowledge available on the early phase of COPD can be explained by the symptomless period of the disease, when there is no airway involvement and hence no decline in lung function: FEV1 (the standard measure of the COPD severity) and the airway conductance are not affected ${ }^{7}$. This early phase of the disease is therefore one of the most challenging aspects in the understanding of the pathomechanisms of COPD, highlighting both the importance of a sensitive and detailed assessment of the respiratory mechanics and the need for appropriate animal model studies on the pathomechanisms.

These aspects are closely linked. While the alterations in lung volumes are a solid landmark of emphysema, and are routinely addressed in the diagnostics of COPD, the 
assessment of the airway function is overwhelmingly based on (and simplified into) forced spirometry ${ }^{2,7}$. The most detailed measurement of respiratory mechanics, the low-frequency forced oscillation technique $(\mathrm{LFOT})^{8}$, permits a separate estimation of the airway and tissue mechanics ${ }^{9}$. However, LFOT measurements assume apneic conditions and hence have been employed in merely a few studies on ventilated COPD patients ${ }^{10,11,12}$. On the other hand, while a few investigations on rodent models of emphysema have used LFOT to characterize the airway and tissue mechanics ${ }^{13,14}$, changes in lung volumes have been assessed with rudimentary methods at most, and the relationships between lung volume and mechanics have basically been left unaddressed.

To gain insight into the pathogenesis and progression of the human disease, various small animal models of emphysema have been developed ${ }^{15-18}$. In the first animal model reported 50 years ago ${ }^{19}$, papain extracted from plants was applied intratracheally to induce emphysema. Nowadays there are a number of ways to induce emphysema: the intratracheal instillation of porcine pancreatic elastase (PPE), human neutrophil elastase ${ }^{15}$, beta-D$x y \operatorname{loside}^{20}$ (an inhibitor of the proteoglycan synthesis), intravenous vascular endothelial growth factor receptor-2 (VEGFR-2) ${ }^{21}$ blockers and gain (knock-in, increased activity of tissue collagenase) or loss of function (knock-out) ${ }^{22}$ mutations. PPE treatment induces not only emphysema with hypoxemia, but also right ventricle hypertrophy and lung function alterations, similarly as the human disease does. As additional group of animal models make use of airway irritants: smoke $^{23}$, cadmium chloride ${ }^{24}$, nitrogen oxide ${ }^{25}$, mineral dust, e.g. silicon dioxide ${ }^{26}$, which can result in an airflow obstruction (of more clinical relevance) and secondary parenchymal changes.

Rodent models of PPE-induced emphysema are commonly used ${ }^{27}$ for the rapid generation of an emphysema-like airspace enlargement that can be studied easily within a month; the investigation period is usually limited to 2-4 weeks. In contrast, the human disease is a slowly progressing pathological condition with long-term effects on the patient, which usually starts around midlife. To promote the understanding of the chronic aspects of human emphysema, follow-up measurements may be made in rodents in order to reveal how changes in the tissue structure impact on the lung function on a long-term basis. Since repeated intubations during the anesthesia of small animals pose technical challenges, most rodent studies have been limited to cross-sectional analyses of the disease progression ${ }^{28-30}$. 
Additionally, while elastolytic, parenchymal destruction has been investigated widely in PPE-induced rodent animal models ${ }^{28,31,32}$, less attention has been paid to the possible link between the decreased tethering forces and the airway involvement, a potential limitation of the PPE-induced emphysema model.

COPD patients are usually characterized by increased lung volumes and expiratory resistance, resulting in dynamic hyperinflation and increased overall lung strain and stretch. From time to time, the acute exacerbation of COPD (AECOPD) can occur, with periods of severe productive cough and shortness of breath; these flare-ups increase the mechanical stress and its destructive effect on the lung. AECOPD worsens the patient's respiratory symptoms, which exceed the normal day-to-day variations and can necessitate to changes in medication $^{2}$. Thus, exacerbations constitute a significant component of the clinical manifestations of $\mathrm{COPD}^{2}$ becoming increasingly more frequent as the disease progresses ${ }^{33}$. However, a detailed understanding of how exacerbation augments the irreversible functional changes is lacking. Since mechanical forces have been shown to be the governing mechanism of tissue destruction in emphysema ${ }^{6,34,35}$, the combination of mechanical and chemical effects may constitute a clinically more relevant model of the human disease. 


\section{AIMS}

The overall goal of this $\mathrm{PhD}$ project was to study the structural and functional changes during the development and the progression of PPE-induced emphysema in rat and mice, using the LFOT for the detailed characterization of lung mechanics, body plethysmography for the measurement of lung volumes, and various visualization techniques to investigate the lung structure. A further aim was also to create a partial model of COPD exacerbation involving only mechanical stress to the lungs. The specific aims of these studies were as follows.

Study I: The purpose of this study was to map the mechanical properties of the airways and respiratory tissues as functions of the lung volume and transrespiratory pressure in mice treated with PPE, the most common animal model of emphysema. To this end, we tracked the resistive and elastic parameters of the respiratory system during slow inspiratoryexpiratory maneuvers.

Study II: The aim of this study was to examine in further detail whether PPEtreatment induces pure parenchymal destruction or whether it also involves airway abnormalities. The functional changes of emphysematous rat lungs were characterized by the LFOT assessment of the airway and tissue mechanics. To evaluate the structural changes underlying the functional alterations, the morphological properties of the parenchyma, including alveolar attachments around small airways, were assessed; additionally, the elastin and collagen in the septal and airway walls were visualized and quantified.

Study III: Since emphysema is a slowly progressing, chronic pathological condition, we studied the structural and functional alterations in a PPE-induced rat model of emphysema in follow-up experiments starting at 3 days after the PPE treatment and lasting for 105 days i.e. much longer than the usual few weeks. Specifically, we set out to assess the extent to which the remodeling-induced changes in alveolar structure and extracellular matrix (ECM) composition determine the lung function. 
Study IV: The goal here was to create an "emphysema exacerbation" model involving a combination of elastolytic and mechanical interventions. We hypothesized that, while viral or bacterial infections are the triggers in the AECOPD, the mechanical forces during the exacerbation phase play a key role in the tissue rupture, leading to irreversible changes in lung structure and function. To avoid the confounding effects of viral and bacterial infections, we tested this hypothesis by superimposing deep inspirations (DIs) during mechanical ventilation on the remodeled parenchyma at different stages of PPE-induced emphysema in mice. 


\section{METHODS}

\section{ANIMAL PREPARATION}

The four study protocols were approved by the Institutional Animal Care and Use Committees of the University of Szeged and Boston University.

\subsection{Relationship between lung volumes and respiratory mechanics (Study I)}

$\mathrm{CBA} / \mathrm{Ca}$ female mice were anesthetized with an intraperitoneal injection of pentobarbital sodium $\left(75 \mathrm{mg} \cdot \mathrm{kg}^{-1}\right)$ and intubated with a 20-mm-long, 0.8-mm inner diameter polyethylene cannula under the control of a cold light source (model FLQ85E, Helmuth Hund, Wetzlar, Germany), according to the technique described by others ${ }^{36,37}$. The elastasetreated animals (group E, N=14) received PPE (Sigma-Aldrich Hungary, Budapest, Hungary) in $50 \mu \mathrm{l}$ of saline in one of two doses: 0.3 international unit (IU) $(\mathrm{N}=10)$ and $0.6 \mathrm{IU}(\mathrm{N}=4)$ via intratracheal instillation. The control animals $(\mathrm{N}=14$, group $C)$ were treated with $50 \mu \mathrm{l}$ of saline only. Three weeks thereafter, the mice were anesthetized with pentobarbital sodium (75 mg. $\mathrm{kg}^{-1}$ ), tracheotomized, and cannulated with a $0.8-\mathrm{mm}$ internal diameter (ID) polyethylene tube. The animals were placed in the supine position in a custom-built 160-ml body plethysmograph and ventilated with a small-animal respirator (Harvard Apparatus, South Natick, MA, USA) at a rate of $160 \mathrm{~min}^{-1}$, a tidal volume $\left(\mathrm{V}_{\mathrm{T}}\right)$ of $0.25 \mathrm{ml}$, and a positive end-expiratory pressure (PEEP) of $2 \mathrm{cmH}_{2} \mathrm{O}$. Supplemental doses of pentobarbital sodium (15 mg. $\left.\mathrm{kg}^{-1}\right)$ were administered as needed, generally at the beginning of the measurements.

1.2. Functional and morphological assessment of early impairment of the airway function (Study II)

Fourteen adult (10-week-old) male Sprague-Dawley rats were included in the experiment. The animals were anesthetized with an intraperitoneal injection of chloral hydrate $\left(350 \mathrm{mg} \cdot \mathrm{kg}^{-1}\right)$. Supplemental doses of anesthetic $\left(50 \mathrm{mg} \cdot \mathrm{kg}^{-1}\right)$ were administered 
during the experiment as needed. The rats were intubated with a polyethylene cannula (14gauge, Braun, Melsungen, Germany). Eight animals were treated with an intratracheal instillation of $50 \mathrm{IU}$ PPE (Affymetrix/USB, Cleveland, OH, USA) in $0.5 \mathrm{ml}$ of saline and 6 rats were treated only with the same amount of saline. The rats were anesthetized again as described before, tracheotomized, and cannulated with a 1.7-mm-ID polyethylene tube 6 weeks after the treatment. The rats were then placed in the supine position in a custom-built 2.8-1 body plethysmograph and mechanically ventilated with a small-animal respirator at a rate of $80 \mathrm{~min}^{-1}$ and $\mathrm{V}_{\mathrm{T}}$ of $8 \mathrm{ml} . \mathrm{kg}^{-1}$. After the measurements, the animals were overdosed with anesthetic and the lungs were removed for histopathological evaluation.

\subsection{Long-term changes in lung structure and function in emphysema (Study III)}

Forty Sprague-Dawley rats were anesthetized with chloral hydrate $\left(350 \mathrm{mg} \cdot \mathrm{kg}^{-1}\right)$ and intubated. They were then placed into a plethysmograph and ventilated with a $V_{T}$ of 7-8 $\mathrm{ml} . \mathrm{kg}^{-1}$ at a rate of $75 . \mathrm{min}^{-1}$ with a small-animal respirator. After the lung function measurements, the rats were treated with an intratracheal instillation ${ }^{38}$ of PPE (Affymetrix/USB, Cleveland, OH, USA) with a dose of $50 \mathrm{IU}$ of PPE in $0.5 \mathrm{ml}$ of saline (PPE-treated group: $\mathrm{T}, \mathrm{N}=21$ ) or with $0.5 \mathrm{ml}$ of saline (control group: $\mathrm{C}, \mathrm{N}=19$ ), and were allowed to recover. The same animals were anesthetized, intubated and measured again at 3 , 10, 21 and 105 days after treatment. The corresponding groups are denoted as T0 and C0 (treated and control on day 0), T3 and C3 (treated and control on day 3), T10 and C10 (treated and control on day 10), T21 and C21 (treated and control on day 21), and T105 and C105 (treated and control on day 105).

\subsection{The effects of mechanical forces on lung structure and function (Study IV)}

Fifty-nine male C57BL/6 mice were slightly anesthetized with isoflurane vapor (3\%) in oxygen $\left(1.51 . \mathrm{min}^{-1}\right)$. In an adequate anesthetic condition, when the observed breath rate was approximately $60 \mathrm{~min}^{-1}$, the animals were suspended by the upper incisors by means of a rubber band on a $60^{\circ}$ inclined platform and treated via oropharyngeal aspiration ${ }^{39}$ with PPE (EC134; Elastin Products Company, Inc., Owensville, MO, USA) (6 IU of PPE/animal 
dissolved in $100 \mu \mathrm{l}$ of phosphate-buffered saline (PBS)). After the treatment, the animals were fed with laboratory rodent chow and water ad libitum. The mice were maintained on a 12-hour light/dark cycle. There was no perianesthetic death associated with the PPE administration. Fifteen animals served as intact controls.

At 2 days, 1 week and 3 weeks after the treament, animals were anesthetized with intraperitoneally administered sodium pentobarbital (initial dose: $75 \mathrm{mg} \cdot \mathrm{kg}^{-1}$, supporting dose: $10-20 \mathrm{mg} \cdot \mathrm{kg}^{-1}$ as necessary). Tracheostomy was performed with a polyethylene tube and the mice were in the supine position into a custom-built body plethysmograph and mechanically ventilated with the FlexiVent (SCIREQ Scientific Respiratory Equipment Inc., Montreal, Canada) $\left(\mathrm{V}_{\mathrm{T}}=8 \mathrm{ml} . \mathrm{kg}^{-1}\right.$, rate $\left.=240 \mathrm{~min}^{-1}\right)$ at a PEEP of $3 \mathrm{cmH}_{2} \mathrm{O}$ for 1 hour with or without deep inspiration (DI). DI is defined as an inflation up to an airway pressure of 35 $\mathrm{cmH}_{2} \mathrm{O} 2$ times per minute. Thus, the following groups were formed with the treatment and the ventilation protocol: Control DI (0 DI) (N=7, 25.681 $\pm 0.899(\mathrm{SD}) \mathrm{g})$, Control no-DI (0 noDI) $(\mathrm{N}=8,24.546 \pm 1.314 \mathrm{~g}), 2$ days treated DI $(2 \mathrm{~d} \mathrm{DI})(\mathrm{N}=8,23.278 \pm 1.032 \mathrm{~g}), 2$ days treated

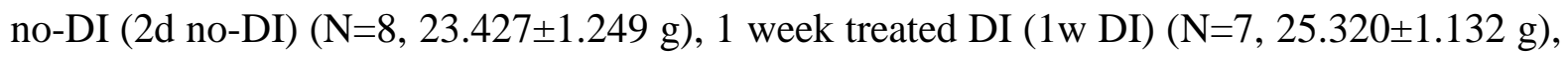
1 week treated no-DI $(1 \mathrm{w}$ no-DI) $(\mathrm{N}=8,25.538 \pm 1.011 \mathrm{~g}), 3$ weeks treated DI (3w DI) $(\mathrm{N}=7$, $27.120 \pm 1.457 \mathrm{~g})$, and 3 weeks treated no-DI (3w no-DI) $(\mathrm{N}=6,27.641 \pm 0.807 \mathrm{~g})$.

\section{MEASUREMENT OF LUNG VOLUMES}

In Study I, the thoracic gas volume (TGV) at end-expiration at zero transrespiratory pressure (TGV0), i.e. at functional residual capacity (FRC), was measured with the plethysmographic technique ${ }^{40}$, modified for the measurement of TGV in anesthetized mice that have a weak or no respiratory effort ${ }^{41}$. Briefly, 2-3 s after the respirator was stopped, the tracheal cannula was occluded and the intercostal muscles were stimulated with two electrodes arranged diagonally between the upper and lower chest regions, with single impulses of 8-12 $\mathrm{V}$ in amplitude and $0.1 \mathrm{~ms}$ in duration (model S44, Grass Instruments, Quincy, MA, USA), repeated 5 or 6 times in a 10-s recording interval. Figure 1 illustrates the setup of the measurement. The plethysmograph pressure (Pbox) and tracheal pressure (Ptr) were measured with miniature pressure transducers (model 8507C-2, Endevco, San Juan 
Capistrano, CA, USA). TGV0 was estimated from the Pbox vs. Ptr relationship on the basis of Boyle's principle, as described previously ${ }^{41}$. Following the measurement of TGV0, the tracheal cannula was connected to a loudspeaker through a $100-\mathrm{cm}, 0.117-\mathrm{cm}$ ID polyethylene tube (a wave tube). After a 5-s pause at end-expiration, Pbox was lowered approximately linearly by connecting the plethysmograph to a vacuum line until $-20 \mathrm{cmH}_{2} \mathrm{O}$ was reached, and Pbox was then allowed to return quasiexponentially to $0 \mathrm{cmH}_{2} \mathrm{O}$ by opening the box to atmosphere through a resistor. The inflation and deflation phases lasted for approximately 20 and $25 \mathrm{~s}$, respectively. $\mathrm{P}_{1}$ and $\mathrm{P}_{2}$, the inlet and outlet lateral pressures of the wave tube were measured with another pair of Endevco transducers. Inflation volume $\mathrm{V}(\mathrm{t})$ was obtained by integration of the flow ( $V^{\prime}$ ) determined as $V^{\prime}=\mathrm{P}_{2} / \mathrm{R}_{\mathrm{wt}}$, where $\mathrm{R}_{\mathrm{wt}}$ is the direct current resistance of the wave tube. TGV as a function of time was obtained as TGV(t) $=\mathrm{TGV0}+\mathrm{V}(\mathrm{t})$. Transrespiratory pressure, $\mathrm{P}_{\mathrm{rs}}$ was calculated as $\mathrm{Ptr}-\mathrm{Pbox}$.

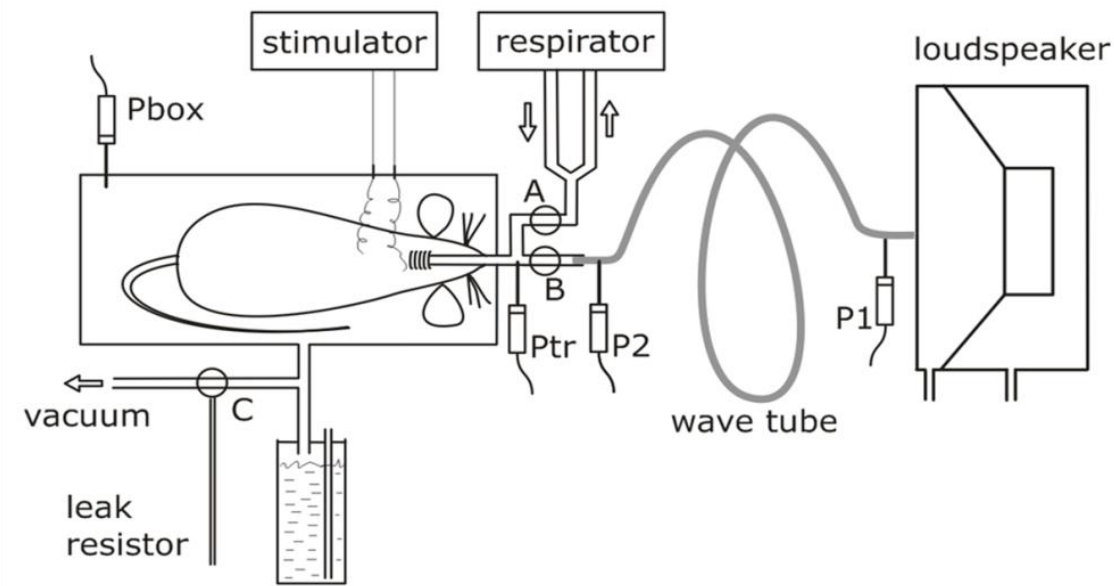

Figure 1: Experimental
set-up for the
measurement of thoracic
gas volume (TGV) and
oscillatory mechanics.
During the measurement
of TGV with respiratory
muscle stimulation,
stoppers A, B and C were closed, and plethysmograph box pressure (Pbox) and tracheal pressure (Ptr) were recorded. The tracheal cannula was then connected via stopper $B$ and a wave tube to a loudspeaker box open to the atmosphere, and inflation was started by opening stopper $C$ to a vacuum source; a water column limited Pbox at -20 or -35 $\mathrm{cmH}_{2} \mathrm{O}$. During the subsequent deflation, the box was connected to the atmosphere via $C$ through a leak resistor. During inflation-deflation, the loudspeaker delivered an oscillatory signal via the wave tube whose inlet $\left(P_{1}\right)$ and outlet lateral pressures $\left(P_{2}\right)$ were recorded.

FRC was measured with a similar arrangement of the plethysmographic technique ${ }^{40}$ in rats in Study II and Study III, where stimulation of the respiratory muscles was not necessary. Briefly, the respirator was stopped at end-expiration and the spontaneous 
breathing efforts against the occluded tracheal cannula were recorded for $6 \mathrm{~s}$. Pbox and Ptr were measured with a Validyne MP-45 $\left( \pm 2 \mathrm{cmH}_{2} \mathrm{O}\right)$ pressure sensor (Validyne, Northridge, CA, USA) and a miniature pressure transducer, respectively. In Study IV, FRC was measured in mice with a body plethysmograph at $0 \mathrm{cmH}_{2} \mathrm{O}$ PEEP before and after the 1-h ventilation. The arrangement was similar to that in Study I, with the exception of muscle stimulation.

In Study II and Study III, the inspiratory capacity (IC) and expiratory reserve volume (ERV), respectively, were defined as the volume changes accomplished by decreasing Pbox to $-35 \mathrm{cmH}_{2} \mathrm{O}$ and increasing it to $20 \mathrm{cmH}_{2} \mathrm{O}$. The IC and ERV maneuvers were shorter than 35 and $15 \mathrm{~s}$, respectively. The volume changes were measured by means of the pressure drop through the wave tube. The total lung capacity (TLC) and residual volume (RV) were calculated as TLC $=\mathrm{FRC}+\mathrm{IC}$ and $\mathrm{RV}=\mathrm{FRC}-\mathrm{ERV}$.

\section{MEASUREMENT OF LUNG MECHANICS}

\subsection{Tracking of lung mechanics}

The tracking estimation of the total respiratory system impedance (Zrs) during slow inflation-deflation maneuvers was performed in the group $C$ and group E mice in Study I. The measurement of Zrs was similar to that described previously ${ }^{42}$, with the modification that a negative body surface pressure was applied ${ }^{43}$ instead of the positive pressure inflation. Briefly, Zrs was measured as the load impedance of the wave tube by using a pseudorandom signal (4-38 Hz). The mean Zrs was computed for the first $5 \mathrm{~s}$ of oscillation before the inflation started (to estimate Zrs at TGV0) and for every successive 0.5-s interval during the maneuver. Each Zrs spectrum was fitted by a model ${ }^{44}$ containing a Newtonian (airway) resistance $\left(\mathrm{R}_{\mathrm{N}}\right)$, an inertance $(\mathrm{I})$, and a constant-phase tissue unit characterized by the coefficients of damping $(\mathrm{G})$ and elastance $(\mathrm{H})$. Hysteresivity $(\eta)$ was calculated as $\eta=\mathrm{G} / \mathrm{H}$; this ratio represents the relationship between dissipated and elastically stored energies in the

tissue $^{45}$. The resistance and the inertance of the tubing including the tracheal cannula were subtracted from $R_{N}$ and $I$, respectively; since the inertance of this tubing was the major component of I, the remaining values were considered physiologically unimportant and are not reported. The slow inflation-deflation maneuvers were repeated 3 times, together with the 
preceding measurements of TGV0, in each animal, to reach a standard volume history and to ensure that the $\mathrm{P}_{\mathrm{rs}}-\mathrm{V}$ loops and the $\mathrm{Zrs}$ spectra as a function of lung volume were reproducible. During the inflation and deflation, the Zrs parameters did not exhibit different volume dependences; hence, for clarity, the tracking results are presented only for inflation. In the rats in Study II and Study III, the same method was used to measure Zrs and calculate the lung mechanics with a pseudorandom signal between $0.5-16 \mathrm{~Hz}$.

\subsection{Lung mechanics measurements with the FlexiVent}

The FlexiVent is a computer-controlled precision piston pump that can intersperse mechanical ventilation with a variety of volume and pressure-controlled maneuvers to obtain accurate, reproducible measurements of respiratory mechanics ${ }^{46}$. The low-frequency respiratory impedance $(2-19 \mathrm{~Hz})$ was measured at $3 \mathrm{cmH}_{2} \mathrm{O}$ PEEP with optimal ventilation waveforms $^{47}$ by measuring the piston volume displacement and cylinder pressure while delivering 2-s oscillatory volume perturbations to the airway opening. Respiratory compliance $(\mathrm{C}=1 / \mathrm{H}), \mathrm{R}_{\mathrm{N}}$ and $\mathrm{G}$ were calculated by fitting the constant-phase model to input impedance ${ }^{9}$. The FlexiVent was used in Study $I V$.

\section{LUNG MORPHOMETRY}

\subsection{Epifluorescence microscopy}

The mice in Study I were euthanized at the end of the measurement with an overdose of anesthetic (pentobarbital sodium), and the heart and the lungs were removed en bloc. The collapsed lungs were then slowly inflated via the tracheal cannula by injecting $1 \mathrm{ml}$ of lowmelt $4 \%$ agarose warmed up to $45^{\circ} \mathrm{C}$. Successful fixation was accomplished in 4 PPE-treated and 5 control mice. Epifluorescence microscopy was performed to investigate the alveolar morphometry in 2 or 3 slices per lung. Following thresholding, the alveolar or terminal airspace cross-sectional areas $\left(\mathrm{A}_{\mathrm{alv}}\right)$ were measured by using image-processing software (INVIVO, Pictron, Budapest, Hungary), and an equivalent alveolar diameter $\left(\mathrm{D}_{\text {alv }}\right)$ was

calculated as $D_{\text {alv }}=\left(4 A_{a l v} / \pi\right)^{1 / 2}$. From the values of $A_{a l v}$, an area-weighted mean equivalent 
diameter $\left(D_{2}\right)$ was computed ${ }^{48}$. The number of $D_{\text {alv }}$ values obtained in the individual animals was not sufficient to allow calculation of a complete diameter distribution. Since, the characteristics of the alveolar structure were very similar in the treated mice on visual inspection we pooled the diameters and constructed the single-diameter distribution for both the control and the treated animals. The $\mathrm{D}_{2}$ is very useful in that it is not sensitive to shape and it can characterize the alveolar structure better than other morphological indices in the case of heterogeneity ${ }^{48}$.

\subsection{Traditional histology}

Formaldehyde fixation and hematoxylin-eosin (H\&E) staining were common methods in Studies II, III and IV.

Study II: After the experiments, the rats were euthanized with an overdose of anesthetic, and the heart and lungs were removed from the chest en bloc. The isolated lungs were then hung in an airtight glass box, and the tracheal cannula was led through the lid of the bottle and attached to a formaldehyde-filled container outside. The lungs were filled with $4 \%$ buffered formaldehyde through the tracheostomy tube from a height of $10 \mathrm{~cm}$ while maintaining a pressure of $-15 \mathrm{cmH}_{2} \mathrm{O}$ around the lungs. The trachea was then ligated at this fixation pressure $\left(25 \mathrm{cmH}_{2} \mathrm{O}\right)$, and the lungs were stored in formaldehyde for 7 days before paraffin embedding. In each lung, 3 transversal sections of $4-\mu \mathrm{m}$ thickness were made at 25 , 50, and 75\% lung height for H\&E staining, and 8, 5, and 4 areas, respectively, of 2,085 x 2,085 $\mu \mathrm{m}$ were chosen in each section for morphometric evaluation (Fig. 2). To avoid and minimize the bias in sampling, the selection of these areas was random, except when an area fell on a major structure such as the heart. The digitized images were then segmented into individual airspaces by using a previously published algorithm ${ }^{49}$ and the area of each individual airspace was measured. Large airways, blood vessels and alveolar ducts were excluded from the analysis manually. $\mathrm{D}_{\text {alv }}$ was then calculated as in Study I (see section 4.1). The whole sections were scanned for the identification of bronchi suitable for further analyses with a circularity $>50 \%$. From the readings of bronchial perimeter $(\mathrm{Pb})$, the diameter of an equivalent circular cross-section $\left(D_{b}\right)$ was computed. The mean airway wall 
thickness $\left(\mathrm{T}_{\mathrm{w}}\right)$ from 3 or 4 measurements and the number of septal attachments $\left(\mathrm{N}_{\mathrm{S}}\right)$ were determined for each airway. Septal attachment density was calculated as $\mathrm{N}_{\mathrm{S}} / \mathrm{Pb}$.

Visualization and quantification of elastin: to visualize the total amount of elastin, the established method of Verhoeff-Van Gieson staining for elastic fibers (adapted from IHCWORD) was used with slight modifications.
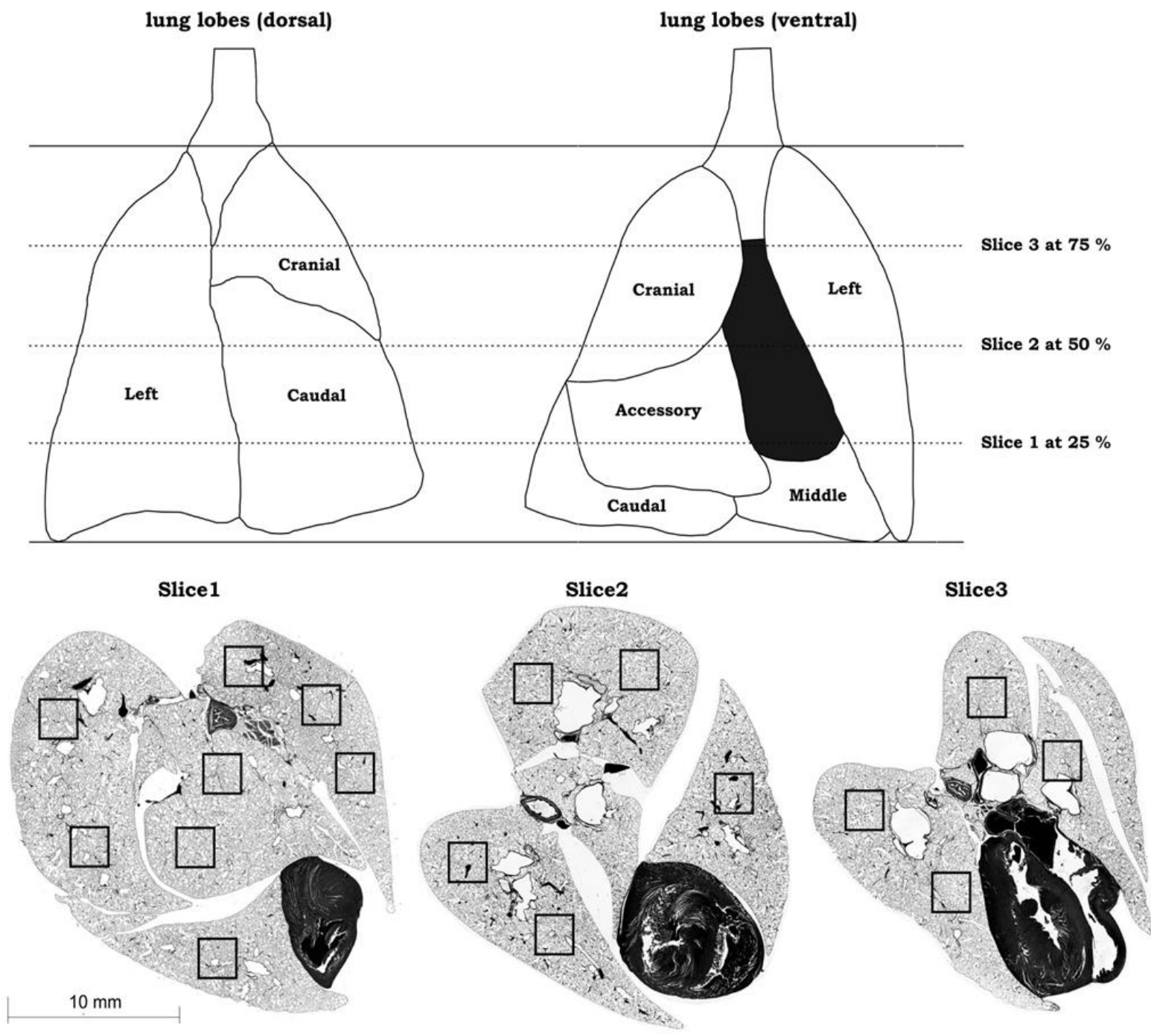

Figure 2: Definition of lung slices for histological evaluation (top) and the areas used for alveolar morphometry in every slice (bottom).

The omission of the counter staining provided only the elastic fibers with a blue color and this was used for quantification. Elastin was analyzed on randomly selected lung 
sections, using custom-made software. A total of 51 and 52 airways were examined quantitatively in the control and PPE groups, respectively. Once an airway had been manually chosen, the software determined the inner boundary of the airway and created an outer boundary by moving along the outward normal to the inner boundary by 8 pixels.

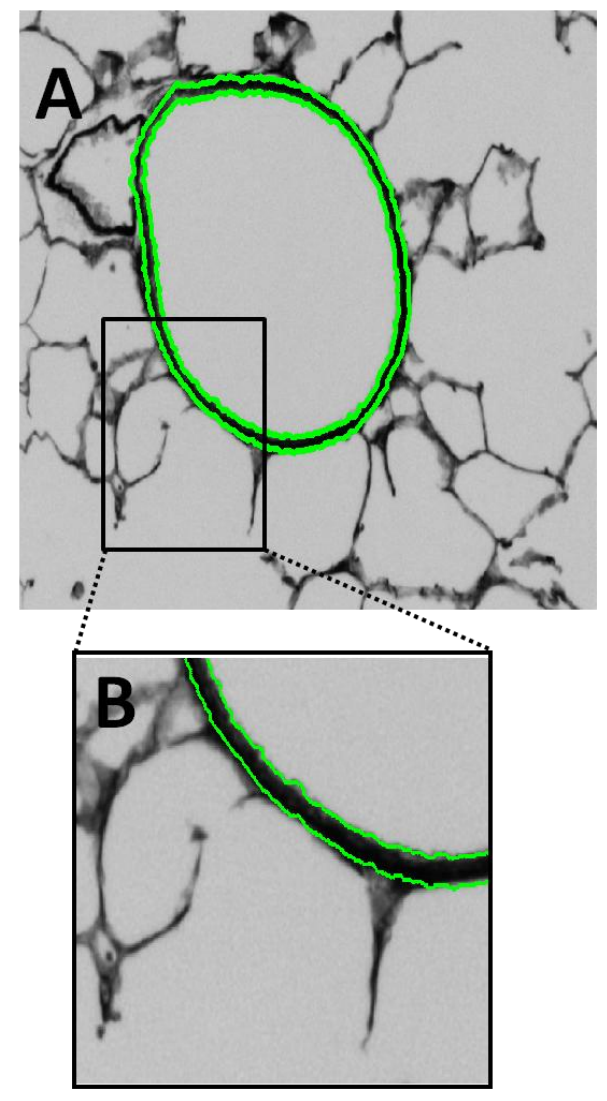

Figure 3: Inner and outer boundaries of the airway wall, determined automatically for the calculation of elastin density.

This procedure automatically defined a band around the airway (Fig. 3). The pixels within the band were then split into 2 colors, white and blue, with blue representing elastin. The mean, the SD and the sum of the grayscale values for the pixels which were identified as blue were determined. The perimeter and area enclosed by the band were also recorded.

Study III: Whole lungs in groups T105 and C105, and subgroups of T3, C3, T21 and C21 ( $\mathrm{n}=4$ or 5 each) were fixed with $4 \%$ buffered formaldehyde at 25 $\mathrm{cmH}_{2} \mathrm{O}$ pressure and processed for imaging ${ }^{50}$. Samples were stained with H\&E, and modified Movat's and Masson's methods were used to visualize elastin and collagen, respectively. $\mathrm{D}_{\mathrm{alv}}, \mathrm{D}_{2}$, the alveolar wall thickness $(\mathrm{Wt})$, and the mean elastin (Mec) and mean collagen (Mcc) densities were calculated with custom-made software based on monochromatic transformation of the images, where the color pixels were equivalent to the collagen or the elastin content.

Study IV: At the end of the protocol, while the animals were under deep anesthesia, the pulmonary circulatation was flushed out through the right ventricule with PBS. After the the mice had been sacrificed, the lungs and heart were resected en bloc and fixed at 20 $\mathrm{cmH}_{2} \mathrm{O}$ transpulmonary pressure with $10 \%$ buffered formalin. Sections were stained with H\&E. Randomly selected regions were imaged and segmented by using custom-made 
software. $\mathrm{D}_{\mathrm{alv}}$ was computed as the diameter of a circle with the same area as the airspace. For each mouse, $\mathrm{D}_{2}$ was calculated from the set of $\mathrm{D}_{\text {alv }}$ values ${ }^{48}$. Since $\mathrm{D}_{2}$ has been shown to be sensitive to heterogeneities and able to detect small changes in structure as compared with $\mathrm{D}_{\text {alv }}$ or the mean linear intercept ${ }^{48}$, we also characterized the airspace structure with this parameter. On the H\&E-stained sections, Wt was measured, and the attachment density (Ad) was determined by dividing the number of septal walls attached to a small airway by the outer perimeter of the airway wall. Collagen and elastin fibers were visualized with modified Masson's trichrome and Verhoeff's methods, respectively ${ }^{51}$. The total number of end tips, as a measure of the number of septal ruptures $\left(\mathrm{N}_{\mathrm{sr}}\right)$ per image per tissue fraction was measured on elastin stained samples for the 21 days DI and 21 days no-DI groups.

\subsection{Orthogonal polarization spectral (OPS) imaging}

On day 105, the lungs and heart were removed en bloc and suspended from the tracheal cannula. The transpulmonary pressure was $25 \mathrm{cmH}_{2} \mathrm{O}$. Ten areas on different lobes were randomly selected, and the lung surface was scanned $\left(\right.$ Cytoscan $^{\mathrm{TM}}$, Cytometrics, Philadelphia, PA, USA). From each video recording, 10-12 non-overlapping frames (650 $\mu \mathrm{m}$ in diameter) were selected. Custom-made software was used to identify the septal borders, and from each enclosed area $\mathrm{D}_{\text {alv }}$ was calculated. Alveoli truncated by the edge of the frame were also included if the edge segment constituted less than $15 \%$ of the total circumference. This imaging modality was employed in Study III.

\section{5. $\quad$ STATISTICS}

Study I: The differences in mechanical parameters between the control and PPEtreated animals were compared by using repeated-measures ANOVA tests. The variability of the alveolar diameters was compared by using $\mathrm{F}$ test.

Study II: The differences in lung volumes and mechanical parameters between the control and PPE-treated rats were compared by using Student's $t$-test. All the results are expressed as means \pm SD. Distributions were compared by means of the Kolmogorov- 
Smirnov test. The dependence of $\mathrm{T}_{\mathrm{w}}$ on $\mathrm{D}_{\mathrm{b}}$ in the two groups was tested by analysis of covariance.

Study III: The effects of PPE, time, Mec and Mcc were analyzed with two-way ANOVA. The body weights were compared with the $t$-test. The distributions of $\mathrm{D}_{\mathrm{alv}}$ were compared with the Kolmogorov-Smirnov test. The structure-function relations were compared by using linear regressions.

Study IV: The effects of DIs and time were analyzed with two-way ANOVA, while the effects of PPE treatment before ventilation were analyzed with one-way ANOVA. Where normality failed, $\log$ transformation was applied. The effects of DIs on $\mathrm{N}_{\mathrm{sr}}$ were compared by means of Mann-Whitney's rank sum test.

$p$ values of less than 0.05 were considered significant. 


\section{RESULTS}

\section{Relationship between lung volumes and respiratory mechanics (Study I)}

Morphometric evaluation of the lung slices (Fig. 4) revealed a significant enlargement of the alveolar airspace sizes in the PPE-treated animals: the equivalent diameter $\mathrm{D}_{\text {alv }}$ increased from $46.5 \pm 13.8 \mu \mathrm{m}$ in the control mice to $70.3 \pm 34.2 \mu \mathrm{m}$ in the treated mice $(\mathrm{p}<0.001)$. Additionally, the variance of the alveolar diameters was also significantly higher in the treated mice $(\mathrm{p}<0.001)$. There was a significant increase in $\mathrm{D}_{2}$, from $55 \mu \mathrm{m}$ to $107 \mu \mathrm{m}$ $(p<0.01)$. In both groups, the distribution of the diameters was significantly different from normal distribution $(\mathrm{p}<0.001)$. The distribution of the diameters was skewed in both groups; however, in the treated mice, the distribution exhibited a significantly longer tail, reaching values above $200 \mu \mathrm{m}$ (Fig. 5).
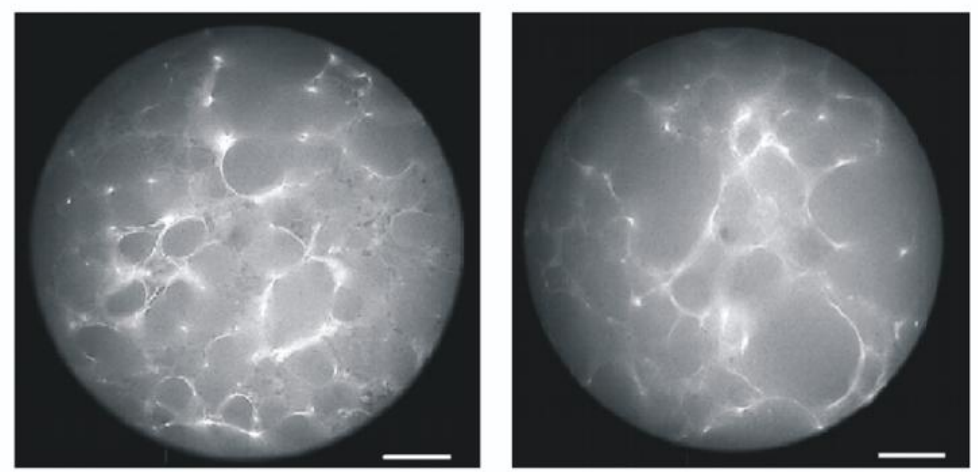

Figure 4: $\quad$ Epifluorescence microscopy pictures of agarosefixed lung slices. Left: control lung, right: PPE-treated lung. Bar: $50 \mu m$.

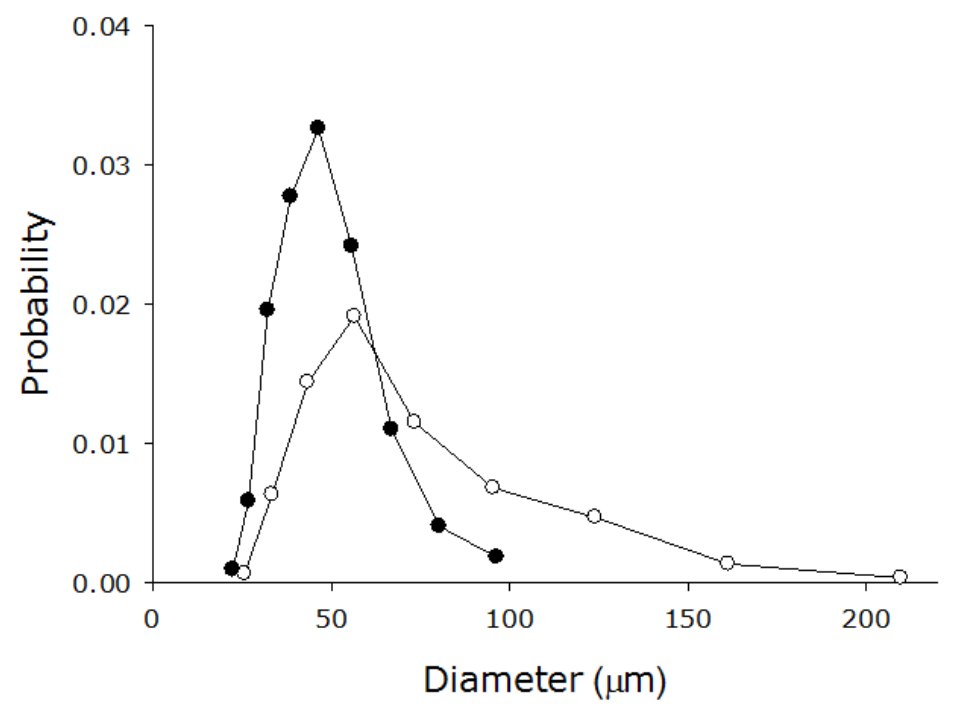

Figure 5: Probability distribution of equivalent alveolar or terminal airspace diameters in subpopulations of control (•) and PPE-treated mice (०). 
PPE treatment resulted in marked and statistically highly significant changes in the lung volumes: relative to the control, $\mathrm{TGV0}$ and $\mathrm{TGV}$ at a $\mathrm{P}_{\mathrm{rs}}$ of $20 \mathrm{cmH}_{2} \mathrm{O}$ (TGV20) increased by $52 \%$ and $45 \%$, respectively (Table 1 ). There was no difference between the group E mice treated with the 0.3 and 0.6 IU doses of PPE in any of the morphometric indices or the mechanical parameters except for $\eta$ at TGV20 $(0.170 \pm 0.007$ vs. $0.157 \pm 0.004$; $\mathrm{p}<0.01)$. Therefore, both the mechanical and morphometric parameters from the two groups were pooled. The average TGV vs. $\mathrm{P}_{\mathrm{rs}}$ curves also reflected the changes due to the PPE treatment (Fig. 6), with the mean values of TGV significantly different $(p<0.001)$ between the groups at all $\mathrm{P}_{\mathrm{rs}}$ levels. The ratios of TGV between the groups at the same $\mathrm{P}_{\mathrm{rs}}$ were fairly constant (between 1.44 and 1.60 for inspiration, and between 1.43 and 1.52 for expiration), suggesting a nearly proportional increase of $\mathrm{TGV}$ at all $\mathrm{P}_{\mathrm{rs}}$ values, i.e. an unchanged shape of the PV loops. The inspiratory volume (TGV20-TGV0) increased by $37 \%$ in the treated animals, which was accompanied by a $27 \%$ decrease in the chord tissue elastance between 0 and $20 \mathrm{cmH}_{2} \mathrm{O}$.

\begin{tabular}{|c|c|c|c|c|c|c|c|c|c|}
\hline group & $\begin{array}{c}\text { weight } \\
(\mathrm{g})\end{array}$ & TGV0 (ml) & $\begin{array}{l}\text { TGV20 } \\
(\mathrm{ml})\end{array}$ & $\begin{array}{c}\mathrm{H} 0 \\
\left(\mathrm{cmH}_{2} \mathrm{O} .\right. \\
\left.. \mathrm{ml}^{-1}\right)\end{array}$ & $\begin{array}{c}\mathrm{H} 20 \\
\left(\mathrm{cmH}_{2} \mathrm{O} .\right. \\
\left.. \mathrm{ml}^{-1}\right)\end{array}$ & $\eta 0$ & $\eta 20$ & $\begin{array}{c}\mathrm{R}_{\mathrm{N}} \mathrm{O} \\
\left(\mathrm{cmH} \mathrm{H}_{2} \mathrm{O} .\right. \\
\left.. \mathrm{s} . \mathrm{ml}^{-1}\right)\end{array}$ & $\begin{array}{c}\mathrm{R}_{\mathrm{N}} 20 \\
\left(\mathrm{cmH}_{2} \mathrm{O} .\right. \\
\left.. \mathrm{s} . \mathrm{ml}^{-1}\right)\end{array}$ \\
\hline$C$ & $29 \pm 2$ & $0.31 \pm 0.06$ & $0.76 \pm 0.11$ & $52 \pm 10$ & $129 \pm 9$ & $0.24 \pm 0.02$ & $0.15 \pm 0.01$ & $0.46 \pm 0.14$ & $0.12 \pm 0.02$ \\
\hline$E$ & $29 \pm 3$ & $0.47 \pm 0.10$ & $1.10 \pm 0.18$ & $22 \pm 7$ & $94 \pm 12$ & $0.38 \pm 0.07$ & $0.17 \pm 0.01$ & $0.45 \pm 0.18$ & $0.11 \pm 0.02$ \\
\hline $\mathrm{P}$ & NS & $<0.001$ & $<0.001$ & $<0.001$ & $<0.001$ & $<0.001$ & $<0.001$ & NS & NS \\
\hline
\end{tabular}

Table 1: Thoracic gas volumes (TGV) and oscillatory mechanical parameters at transrespiratory pressures of $\mathrm{O}_{\mathrm{cmH}_{2} \mathrm{O}}$ (suffix 0) and $2 \mathrm{O}^{2} \mathrm{H}_{2} \mathrm{O}$ (suffix 20) in the control (group $\mathrm{C}, \mathrm{N}=14$ ) and the PPE-treated (group E, N=14) mice. H: tissue elastance coefficient, $\eta$ : hysteresivity, $R_{N}$ : Newtonian (airway) resistance

The mechanical parameters obtained from the small-amplitude forced oscillatory measurements on the PPE-treated mice exhibited similarly marked changes: as compared with the control, the decreases in $\mathrm{H}$ were $57 \%$ and $27 \%$, respectively, at $\mathrm{P}_{\mathrm{rs}}$ values of 0 and $20 \mathrm{cmH}_{2} \mathrm{O}$ (Table 1). The values of $\eta$ were also altered by the PPE treatment, with increases 
more marked at $0 \mathrm{cmH}_{2} \mathrm{O}(55 \%)$ than at $20 \mathrm{cmH}_{2} \mathrm{O}(12 \%)$. By contrast, small and statistically insignificant decreases were observed in $\mathrm{R}_{\mathrm{N}}$ at both $0 \mathrm{cmH}_{2} \mathrm{O}(-2 \%)$ and $20 \mathrm{cmH}_{2} \mathrm{O}(-10 \%)$. Since the pressure protocol in the inflation-deflation maneuver was standardized, the group mean values of these parameters were calculated as functions of both $\mathrm{P}_{\mathrm{rs}}$ and TGV.

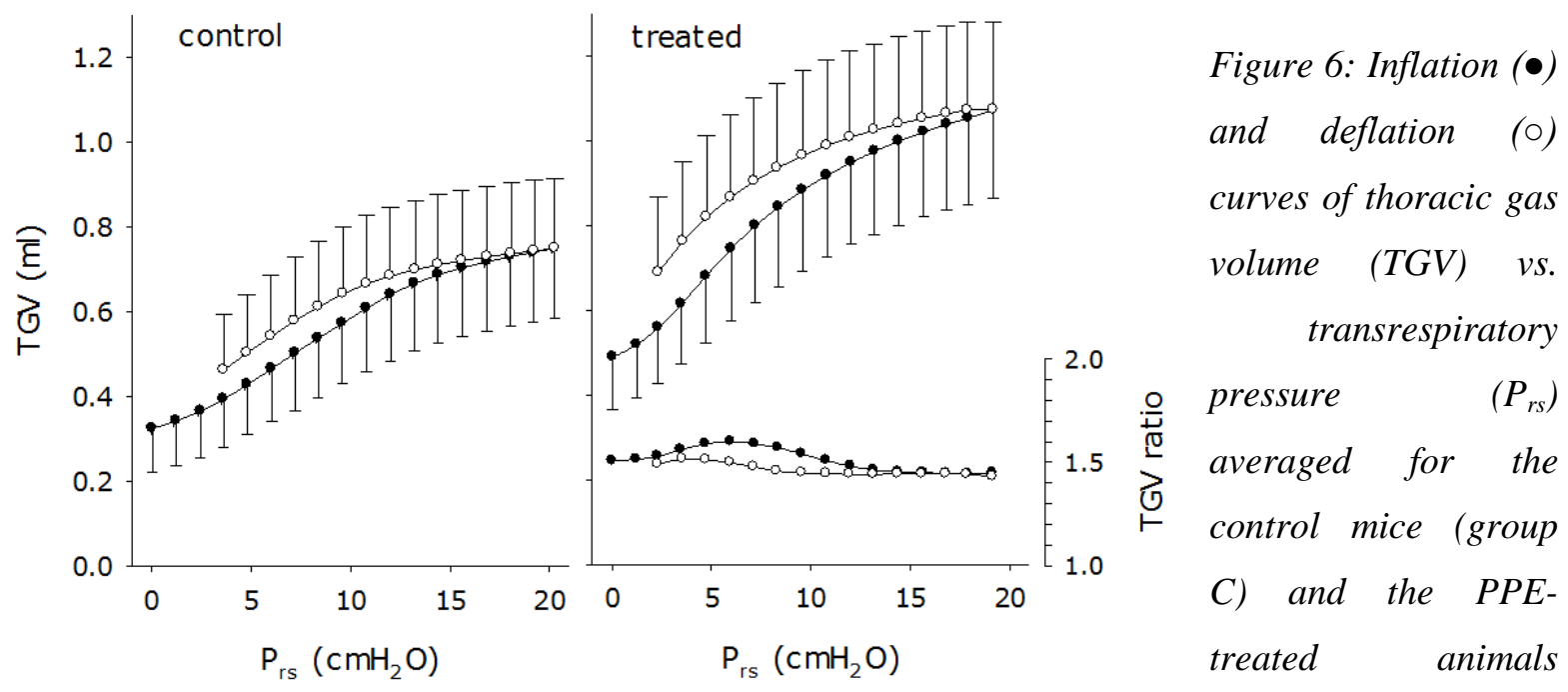

(group E). Bars indicate SD. The ratio of the TGV values of the PPE-treated mice to those in the controls is also plotted as a function of $P_{r s}$ (right panel, bottom).
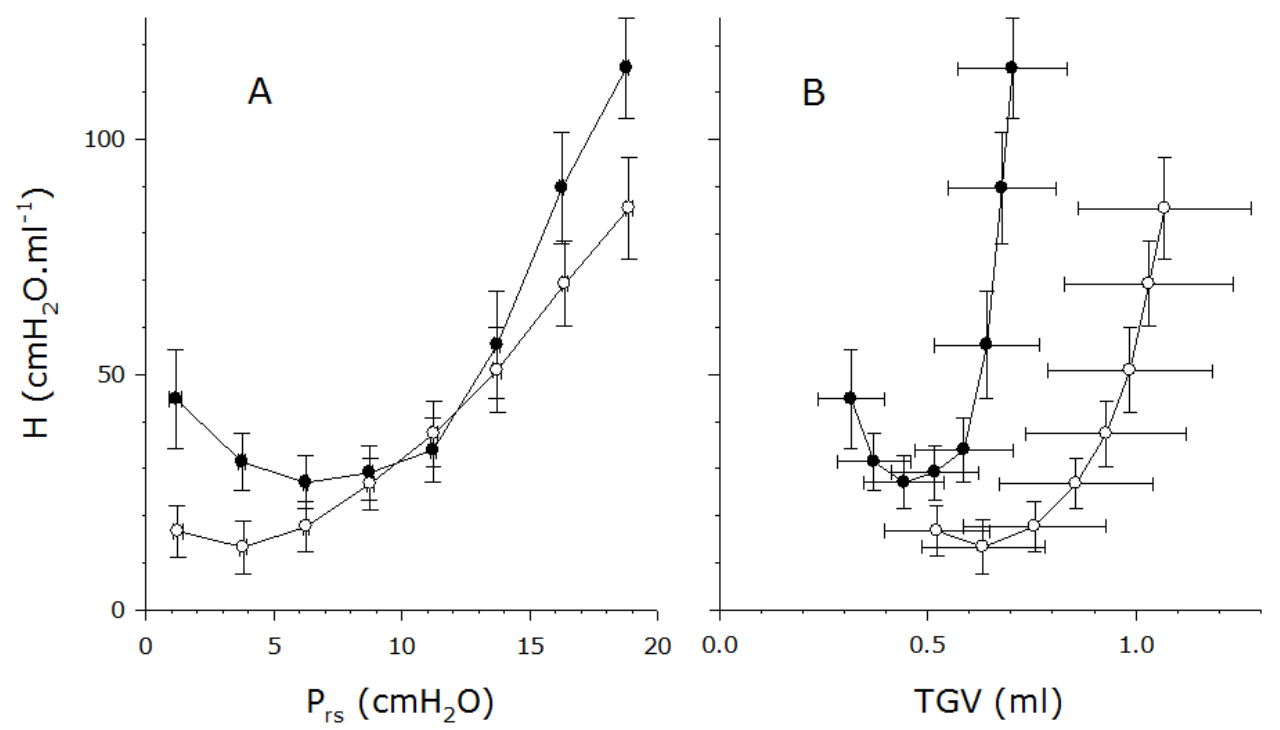

Figure 7: A: Tissue elastance coefficient $(H)$ vs. transrespiratory pressure $\left(P_{r s}\right)$ during slow inflation from a $P_{r s}$ of 0 to $20 \mathrm{cmH}_{2} \mathrm{O}$. The values in each animal were averaged for successive 2.5- $\mathrm{cmH}_{2} \mathrm{O}$ ranges of $P_{r s}$. The mean values of $H$ for the animals in the control (group $C$ ) mice $(\bullet)$ and the PPEtreated (group E) mice (O) are significantly different $(p<0.05)$ at $P_{r s}<8 \mathrm{cmH}_{2} \mathrm{O}$ and $\mathrm{P}_{r s}>14 \mathrm{cmH}_{2} \mathrm{O}$. 
Bars denote SD. B: $H$ vs. thoracic gas volume $(T G V)$. The values of $H$ are significantly different between the two groups at all ranges of $P_{r s}$.

Figures 7A and 7B display the dependences of $\mathrm{H}$ on $\mathrm{P}_{\mathrm{rs}}$ and $\mathrm{TGV}$, respectively. The differences in $\mathrm{H}$ between the group $E$ and group $C$ animals in the low and the high $\mathrm{P}_{\mathrm{rs}}$ range were in accord with the mean values of $\mathrm{H}$ at $0 \mathrm{cmH}_{2} \mathrm{O}$ and $20 \mathrm{cmH}_{2} \mathrm{O}$ (see Table 1), whereas this difference disappeared in the pressure range between 9 and $13 \mathrm{cmH}_{2} \mathrm{O}$ (Fig. 7A). When plotted as a function of TGV (Fig. 7B), the values of $\mathrm{H}$ corresponding to the control and treated animals were completely separated. The mean $\mathrm{H}$ at comparable $\mathrm{TGV}$ was significantly lower in the treated animals, which suggests that the dynamic elastance in the treated mice reached values similar to those in the control animals at about twice as high absolute lung volumes.

The mean $\mathrm{R}_{\mathrm{N}}$ data did not differ between the groups at any value of $\mathrm{P}_{\mathrm{rs}}$ (Fig. 8A). However, the $\mathrm{R}_{\mathrm{N}}$ curves as a function of $\mathrm{TGV}$ were markedly different from those expressed in terms of $\mathrm{P}_{\mathrm{rs}}$ (Fig. 8B). PPE treatment resulted in a rightward shift of the mean $\mathrm{R}_{\mathrm{N}} \mathrm{vs}$. TGV relationship and, consequently, in significantly higher $\mathrm{R}_{\mathrm{N}}$ values at comparable lung volumes (Fig. 8B).
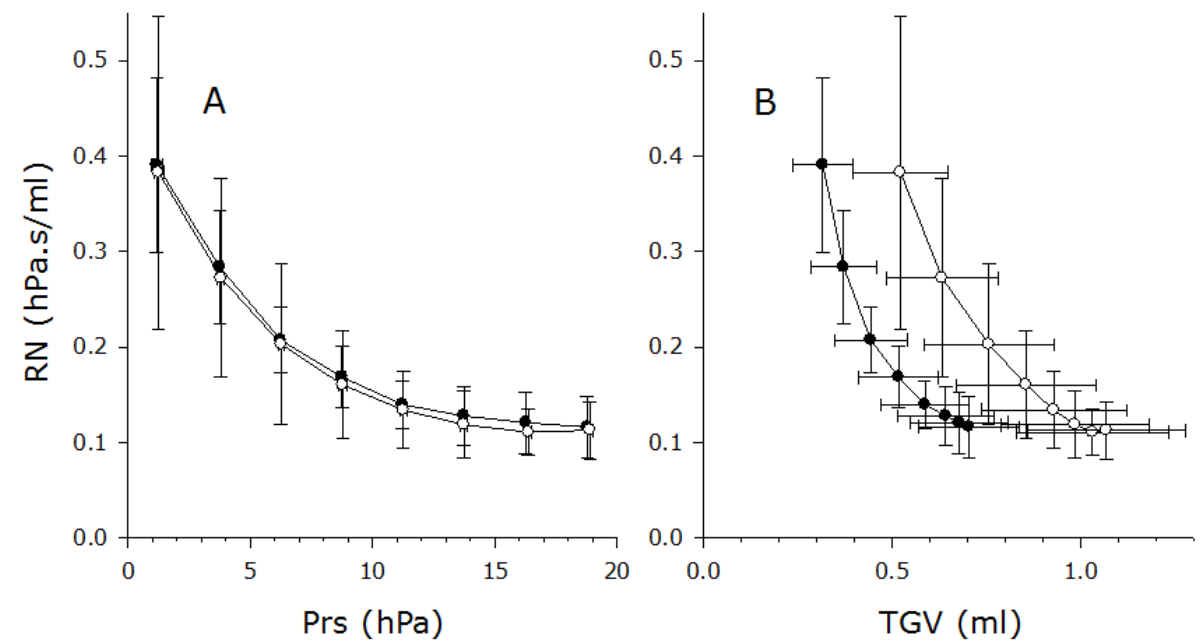

Figure 8A: Newtonian (airway) resistance $\left(R_{N}\right)$ vs. transrespiratory pressure $\left(P_{r s}\right)$ during slow inflation from a $P_{r s}$ of 0 to $20 \mathrm{cmH}_{2} \mathrm{O}$. The values in each animal were averaged for successive 2.5$\mathrm{cmH}_{2} \mathrm{O}$ ranges of $P_{r s}$. No significant difference was found between the mean values of $R_{N}$ for the control (group C) mice (•) and the PPE-treated (group E) mice (O) in any range of $P_{r s}$. Bars denote $S D$. B: $R_{N} v$ s. thoracic gas volume $(T G V)$. The values of $R_{N}$ are significantly different between the two groups for all $T G V$ values.

Margit V. Szabari: PhD Thesis 
2. Functional and morphological assessment of early impairment of the airway function (Study II)

There were no significant differences in body weight between the control (C) and the PPE groups of rats either at the time of treatment $(318 \pm 34$ vs. $314 \pm 25 \mathrm{~g})$ or 6 weeks thereafter $(468 \pm 52$ vs. $471 \pm 58 \mathrm{~g})$.

Lung volumes: FRC and RV were significantly higher in the PPE group as compared with the controls (by $38 \%$ and 53\%, respectively); however, the increase in TLC in the treated rats $(5 \%)$ was not significant (Fig. 9).

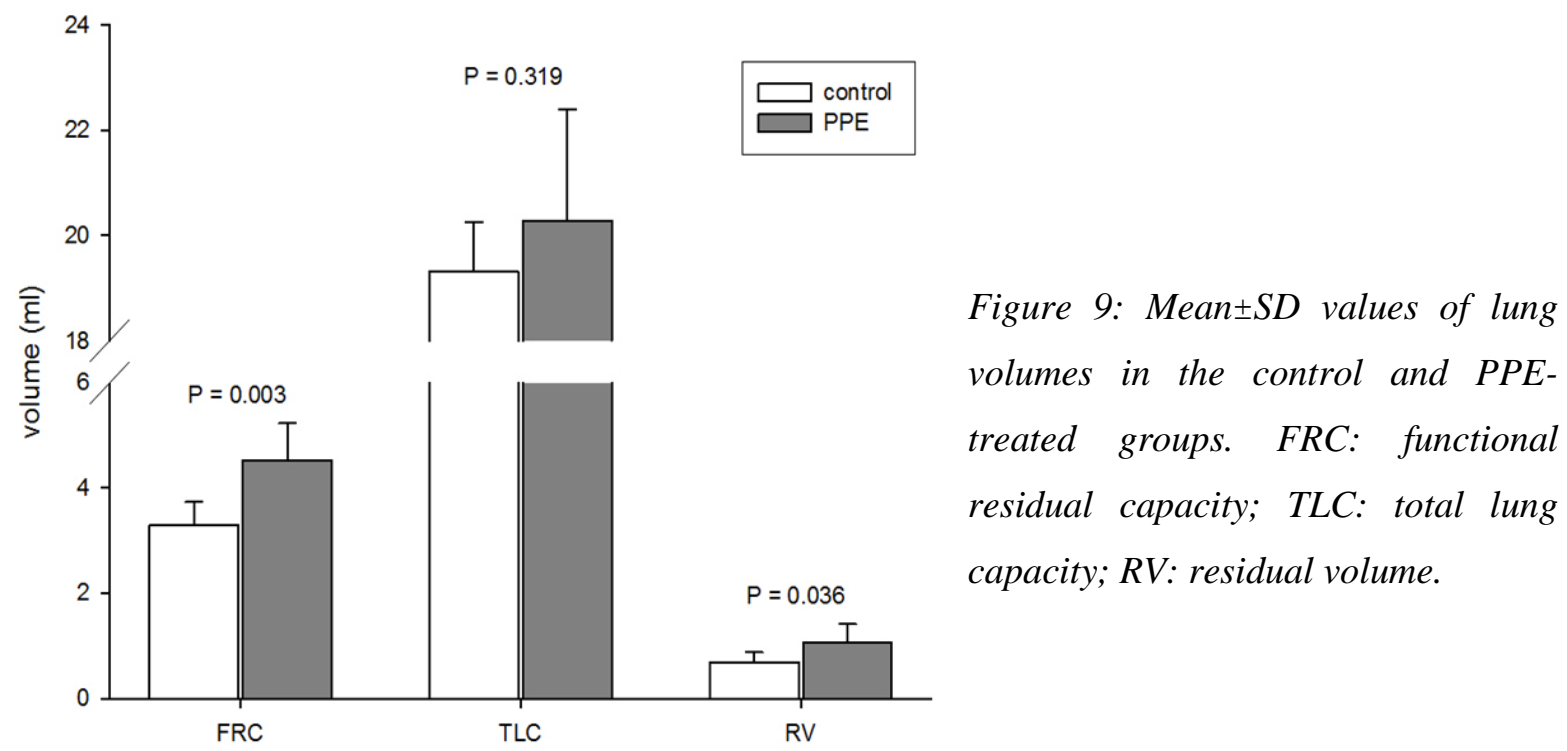

Respiratory mechanics: Table 2 presents the respiratory mechanical parameters estimated from the impedance data. $\mathrm{G}$ and $\mathrm{H}$ were significantly smaller in the PPE-treated rats than in the controls (76\% and 62\%). Because of the larger decrease in $\mathrm{H}$ than in $\mathrm{G}$ in the treated rats, $\eta$ was elevated $(129 \%)$. There was no difference in $R_{N}$ or the error of model fitting between the groups.

Alveolar and bronchial morphometry: Figure 10 compares the size distributions of $\mathrm{D}_{\text {alv }}$ pooled from all regions and animals in either group. The average number of alveoli evaluated in all regions of an animal was 8091. In the PPE group, the distribution was shifted to higher $\mathrm{D}_{\mathrm{alv}}$ values and, according to the Mann-Whitney rank sum test, the median of $\mathrm{D}_{\text {alv }}$ was significantly higher in the treated group $(68.4 \mu \mathrm{m}$ vs. $61.8 \mu \mathrm{m} ; \mathrm{p}<0.001)$. 


\begin{tabular}{|c|c|c|c|c|c|}
\hline & $\begin{array}{c}\mathrm{R}_{\mathrm{N}} \\
\left(\mathrm{cmH}_{2} \mathrm{O} \cdot \mathrm{s} \cdot \mathrm{l}^{-1}\right)\end{array}$ & $\begin{array}{c}\mathrm{G} \\
\left(\mathrm{cmH}_{2} \mathrm{O}^{\left.-1^{-1}\right)}\right.\end{array}$ & $\begin{array}{c}\mathrm{H} \\
\left(\mathrm{cmH}_{2}{\left.\mathrm{O} . \mathrm{I}^{-1}\right)}^{-1}\right.\end{array}$ & $\begin{array}{c}\eta \\
(=\mathrm{G} / \mathrm{H})\end{array}$ & $\mathrm{F} \%$ \\
\hline $\bar{C}$ & $39 \pm 8.5$ & $653 \pm 99$ & $2178 \pm 305$ & $0.30 \pm 0.01$ & $2.40 \pm 0.40$ \\
\hline PPE & $35.5 \pm 8.5$ & $496 \pm 66$ & $1344 \pm 216$ & $0.37 \pm 0.04$ & $2.53 \pm 0.34$ \\
\hline $\mathrm{p}$ & 0.451 & 0.004 & $<0.001$ & 0.002 & 0.512 \\
\hline
\end{tabular}

Table 2. Mechanical parameters of the lungs in the control animals $(C)$ and those treated with porcine pancreatic elastase (PPE). $R_{N}$, Newtonian (airway) resistance; $G$, tissue damping; $H$, tissue elastance; $\eta$, hysteresivity; F\%, average fitting error of the model; $p$ : level of significance for differences between groups.

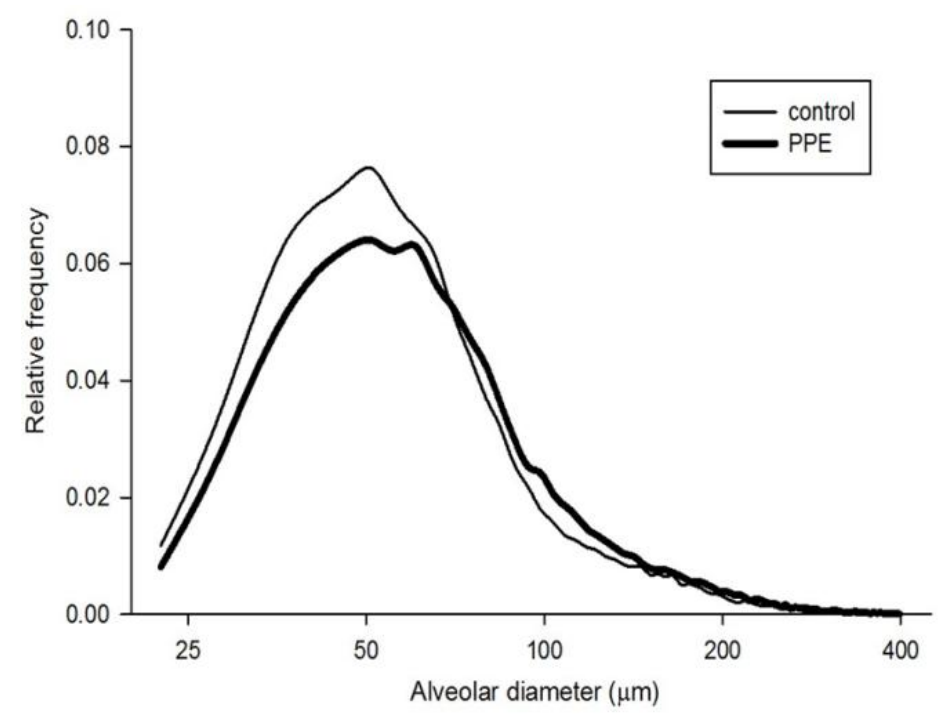

Figure 10: Relative frequencies of the alveolar diameters in the two groups.

The number of bronchial cross-sections analyzed in each rat ranged between 40 and 50. The distributions of $D_{b}$ were not different between the groups (Fig. 11a). The attachment density $\mathrm{N}_{\mathrm{S}} / \mathrm{Pb}$ (Fig. 11b) was mildly, but significantly lower in the PPE group (median 0.0175 vs. $\left.0.0189 \mu \mathrm{m}^{-1} ; \mathrm{p}<0.001\right)$. Regression analysis showed that $\mathrm{T}_{\mathrm{w}}$ did not depend on $\mathrm{D}_{\mathrm{b}}$ in either group (Fig. 11c). However, the mean value of $\mathrm{T}_{\mathrm{w}}$ was higher in the PPE group than in the controls (12.4 vs. $10.8 \mu \mathrm{m} ; \mathrm{p}<0.0001)$. 

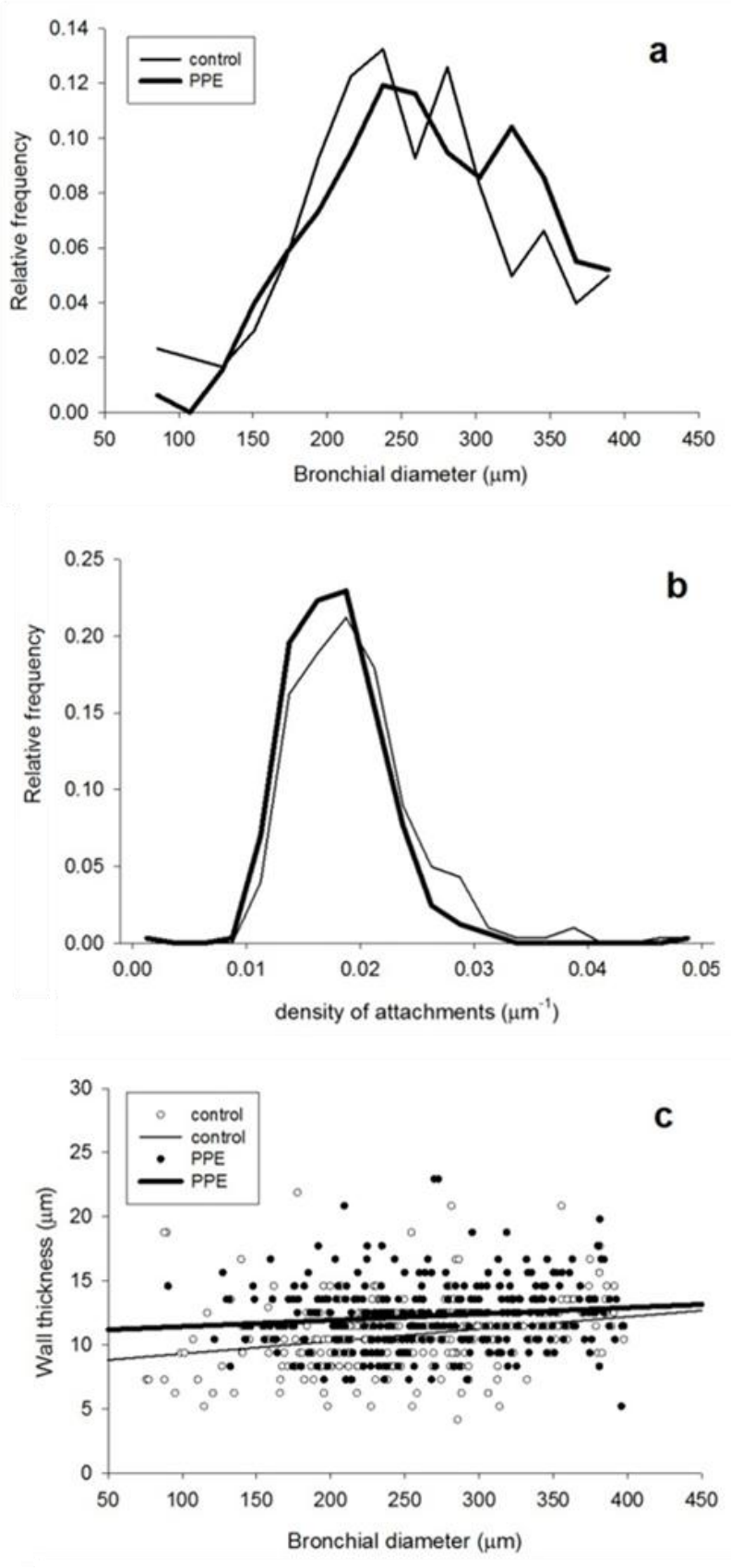

Figure 11. Relative frequencies of the bronchial diameters (a), and density of septal attachments (b). Relationship between the calculated bronchial diameters $\left(D_{b}\right)$ and average airway wall thickness $\left(T_{w}\right)$ in the control and PPE-treated rats; lines illustrate the regressions from the co-variance analysis (c).

Elastin and collagen density in the bronchial wall: Similarly to the bronchial morphometry, there was no difference between the $D_{b}$ of the airways of the control and PPE-treated animals for which the elastin and collagen density was evaluated. The mean and SD of the elastin grayscale representing the average and the spatial variability, respectively of the elastin density within the bronchial wall, were not different in the groups. The sum of all grayscale values representing the total elastin in the 8-pixel band inside the bronchial wall did not differ between the groups either. The inter-airway variance of the elastin density likewise did not differ between the control and treated animals. Interestingly, the collagen density and its intrabronchial SD were increased by $12 \%$ and $17 \%$ in the treated group $(\mathrm{p}<0.05)$. Furthermore, the inter-airway variance of the collagen density was substantially higher $(67 \%, \mathrm{p}<0.01)$ in the treated animals. The densities of elastin and collagen did not correlate with $\mathrm{D}_{\mathrm{b}}$. 


\section{Long-term changes in lung structure and function in emphysema (Study III)}

During the 105 days of the study, the rats gained weight from an average of $244 \pm 17 \mathrm{~g}$ (C0 and T0) to $558 \pm 70 \mathrm{~g}$ (C105 and T105) (Fig. 12A). The weight gain was observed throughout the time course of the study ( $\mathrm{p}<0.001$; two-way ANOVA) uniformly in the $\mathrm{C}$ and $\mathrm{T}$ groups with the exception of the $\mathrm{T} 3$ group, which exhibited a weight loss of $11 \%$ relative to the $\mathrm{C} 3$ animals $(\mathrm{p}=0.022)$.

Lung volumes: FRC, TLC and RV increased with time, and also as a result of growth, but the increase was faster in the treated animals $(\mathrm{p}<0.001)$ : while group $\mathrm{C}$ showed an increase of $75 \%$ in FRC, and $56 \%$ in RV from the beginning to the end of the study, the corresponding changes in group $\mathrm{T}$ were $194 \%$ and $244 \%$, respectively. There were statistically significant differences between the control and treated rats throughout the study (Figs 12B, 12C and 12D): for FRC and RV, a difference already appeared on day 3, whereas there was no difference in TLC until day 21 . The increases in all lung volumes reflected the combined effects of PPE and time, and there was a statistically significant interaction between the treatments and time $(\mathrm{p}<0.001)$ for all lung volumes.

Respiratory mechanics: The treatment had significant $(\mathrm{p}<0.001)$ effects on $\mathrm{H}$ and $\eta$ (Figs $12 \mathrm{~F}$ and $12 \mathrm{H}$, respectively). The interaction between treatment and time was statistically significant ( $p=0.001$ ) for these parameters. There was no difference between $R_{N}$ in the control and the treated animals at any time point (Fig. 12E). Differences between the groups in $\mathrm{H}$ and $\eta$ developed as early as day 3. 

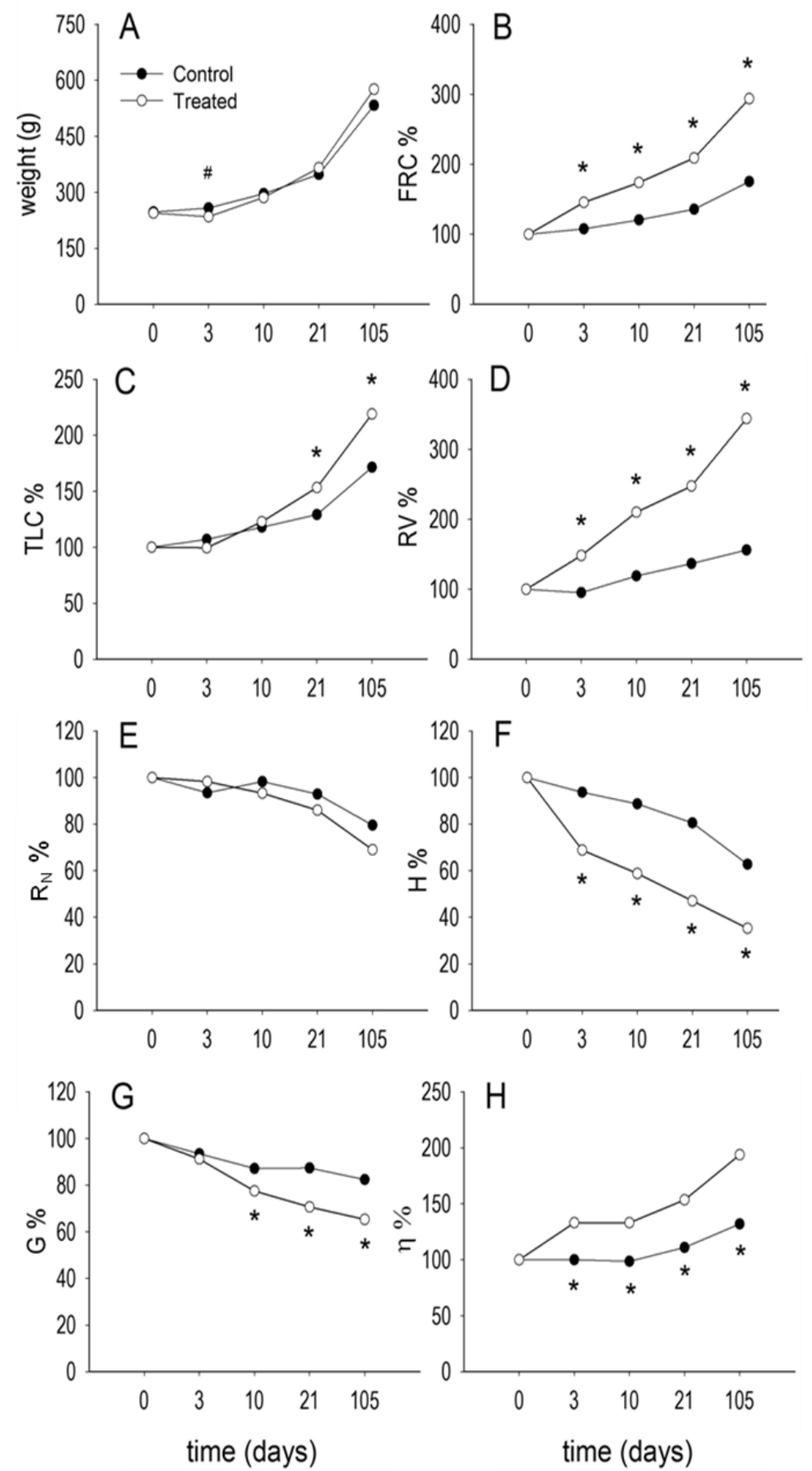

Figure 12: Effects of time and treatment (PPE vs. saline controls) on physiological variables. A: Body weight. B: Percentage change in the functional residual capacity (FRC\%). Statistics on $\log (F R C)$. C: Percentage change in the total lung capacity (TLC\%). D: Percentage change in the residual volume (RV\%). E: Percentage change in the Newtonian (airway) resistance $\left(R_{N} \%\right) . F$ : Percentage change in the tissue elastance (H\%). G: Percentage change of the tissue damping (G\%). H: Percentage change in the hysteresivity ( $\eta \%)$. Statistically significant differences between saline and PPE-treated animal: ${ }^{*} p<0.001,{ }^{\#} p=0.022$.

\section{Morphological}

evaluations: The H\&E-stained samples from the T105 group exhibited large areas of tissue destruction, with enlarged airspaces and septal wall breaks

(Figs $13 \mathrm{~A}$ and 13B), and the distribution of the $\mathrm{D}_{\text {alv }}$ values included diameters larger than $300 \mu \mathrm{m}$ (Fig. 13E). The median $\mathrm{D}_{\text {alv }}$ (Fig. 14A) increased significantly with time $(\mathrm{p}<0.001)$ in both the control (C3 vs. C105) and the treated groups (T3 vs. T105). In the control rats, the median $\mathrm{D}_{\text {alv }}$ increased from $57.8 \mu \mathrm{m}$ to $73.1 \mu \mathrm{m}(126.5 \% ; \mathrm{p}=0.007)$, while in the treated animals the corresponding changes were from $66.7 \mu \mathrm{m}$ to $88.4 \mu \mathrm{m}(132.5 \%$; $\mathrm{p}<0.001)$. The 
difference between the control and the treated animals became statistically significant on day $21(\mathrm{p}=0.027)$, and remained significant up to day $105(\mathrm{p}=0.004)$.
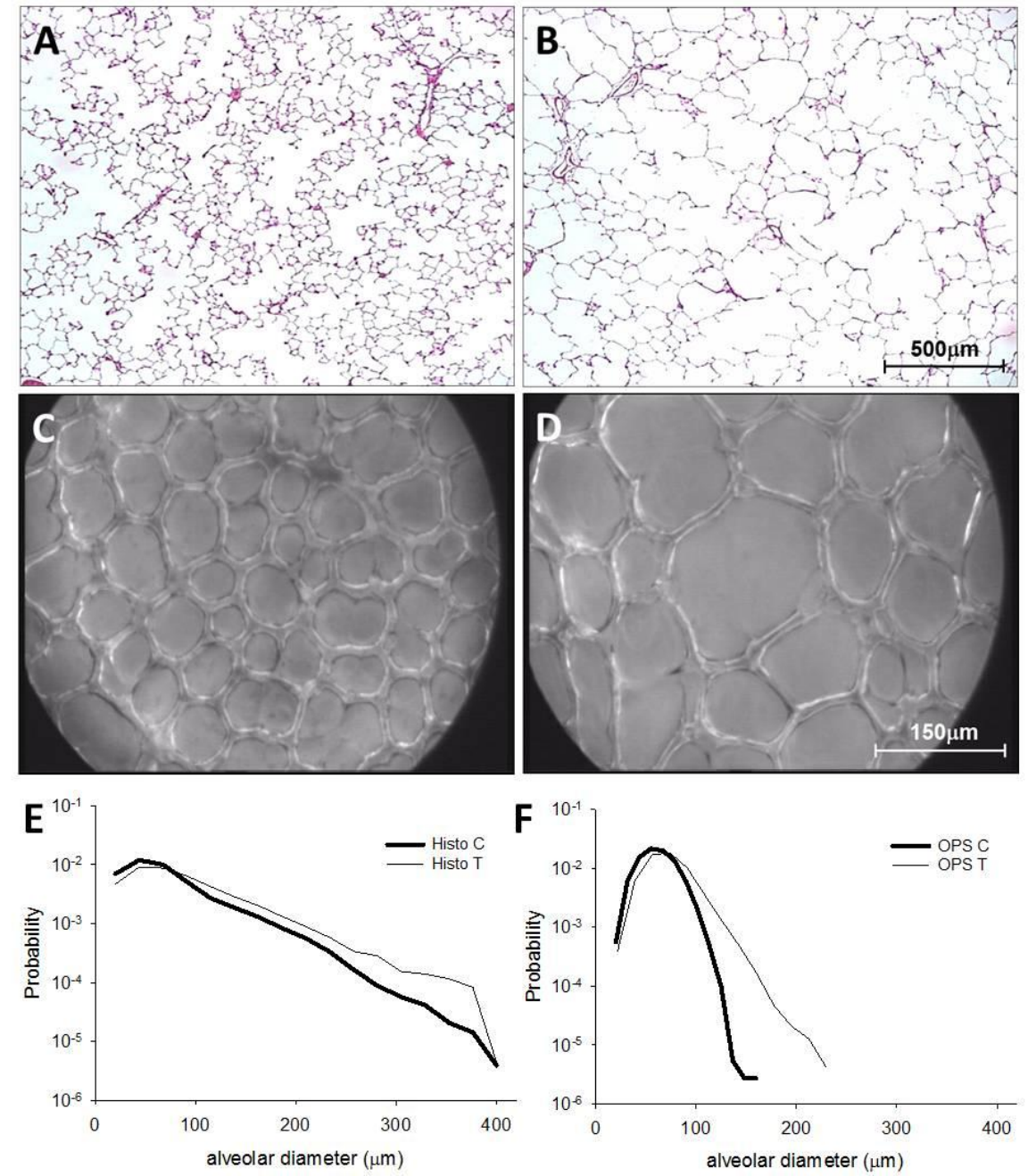

Figure 13: A-D: Representative pictures of the parenchymal structure and distributions of the alveolar diameters.

Hematoxylin-eosin (H\&E) stained samples from the $105 d$ control group (A, number of alveoli: 32,432) and the $105 d$ treated group (B: 28,893); Orthogonal Polarization Spectral (OPS) images from the $105 d$ control group (C:31,504) and the 105 $d$ treated group (D: 13,656) $E-F$ :

Distribution of the alveolar diameters $\left(D_{a l v}\right)$ in the $105 \mathrm{~d}$ animals, obtained from H\&E-stained sections $(E)$ and OPS images $(F)$.

In contrast with $\mathrm{D}_{\mathrm{alv}}, \mathrm{D}_{2}$ already revealed a difference in alveolar size between the two groups by day 3 (Fig. 14B). The highest values of Wt were found on day 3 in both groups (Fig. 14C), which was followed by decreases on day 21 and a reversal on day 105. The treated groups exhibited significantly higher values of Wt than the controls at all time points.

The ex vivo images obtained with the OPS technique revealed enlargements of the subpleural airspaces in the T105 group as compared with those in the C105 animals (cf. Fig. 
13D and 13C), which resulted in a rightward shift of the $\mathrm{D}_{\text {alv }}$ distribution (Fig. 13F), with the median increasing from 66.3 to $78.4 \mu \mathrm{m}$ ( $\mathrm{p}<0.001$, Kolmogorov-Smirnov test).
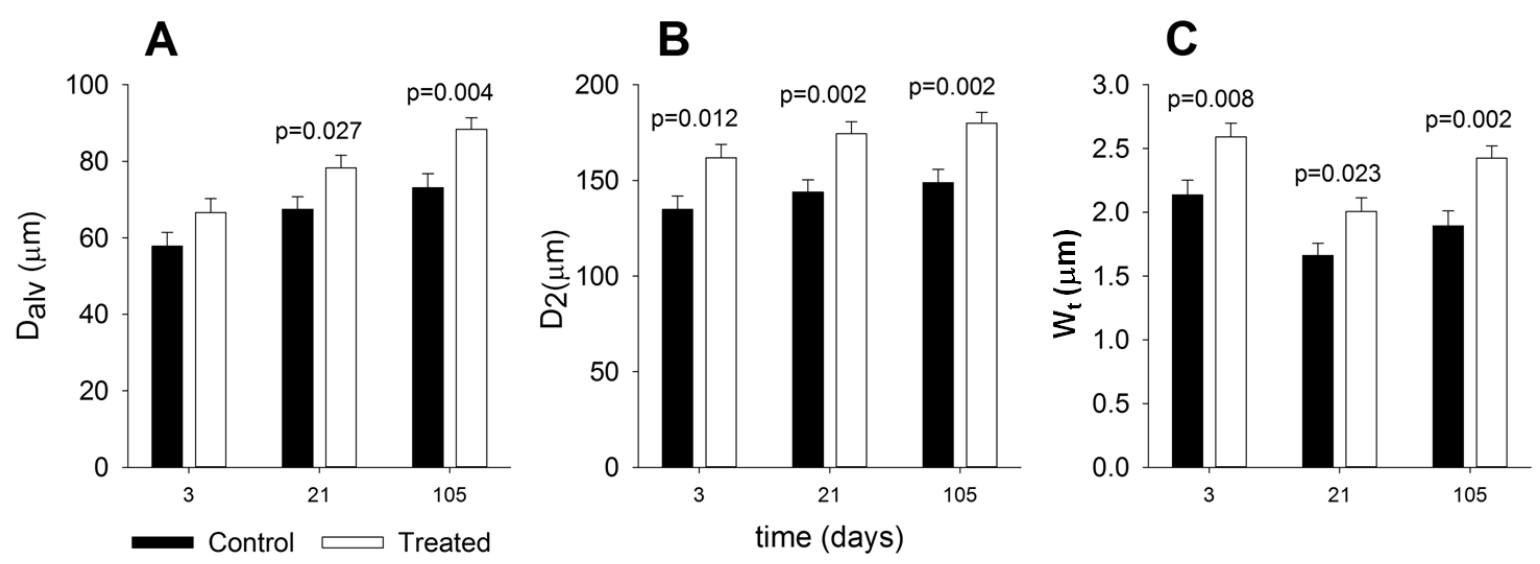

Figure 14: Morphological results obtained from the $H \& E$-stained histological samples. A: The alveolar diameter $\left(D_{a l v}\right)$. B: The area-weighted alveolar diameter $\left(D_{2}\right)$, and $C:$ The wall thickness (Wt) as functions of time after treatment. Median values; bars denote SEM. $p$ values indicate the levels of statistical significance between the control and treated groups.

Examples of elastin and collagen stained samples are presented in Figs 15B, 15C, $15 \mathrm{E}$ and $15 \mathrm{~F}$. These ECM components showed only mild changes. The highest levels of Mec were found on day 3 with no difference between groups C3 and T3, whereas significant differences between the control and treated groups $(\mathrm{p}<0.001)$ were observed on days 21 and 105 (Fig. 15A), with larger values of Mec in the treated groups. Mcc presented a reverse tendency (Fig. 15D); the difference observed between $\mathrm{C}$ and $\mathrm{T}$ on day 3 was sustained on day $21(\mathrm{p}<0.001)$, but vanished by day 105 .

The values of $\mathrm{H}$ are plotted against the corresponding mean values of $\mathrm{D}_{\text {alv }}$ in all animals in Fig. 16. The inverse relationship between $H$ and $D_{a l v}$ reveals a strong structurefunction correlation with both the control and the treated rats following this relationship. 

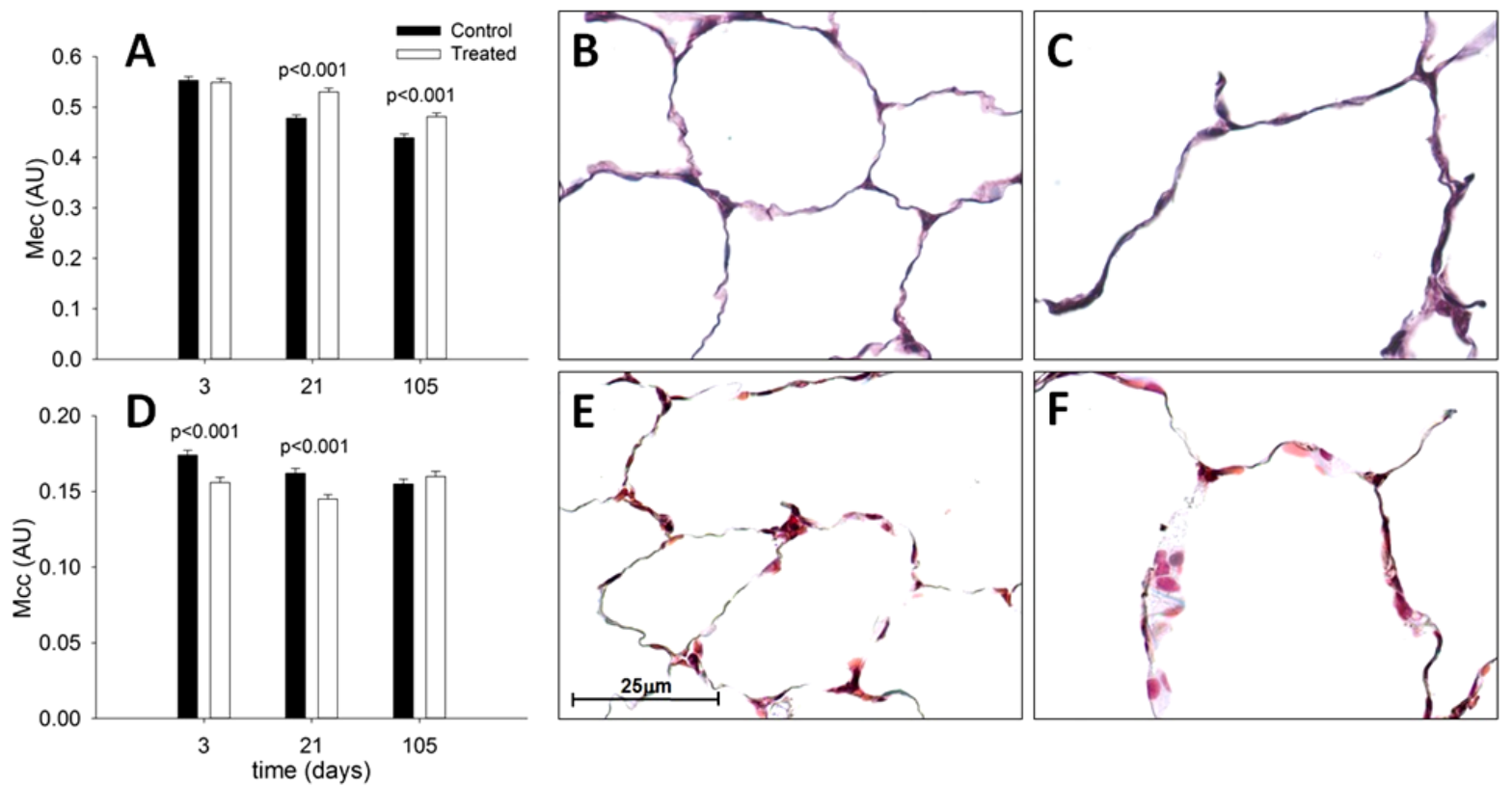

Figure 15: Mean values of the components of the extracellular matrix, obtained from the stained histological samples and representative micrographs (60x magnifications). A: Mean elastin content (Mec). B and C: Micrographs of the modified Movat staining in a day 105 control and treated animal, respectively. D: Mean collagen content (Mcc). E and F: Micrographs of the Masson's trichrome staining, in a day 105 control and treated animal, respectively. Median values; bars denote SEM. $p$ values indicate the levels of statistical significance between the control and treated groups.

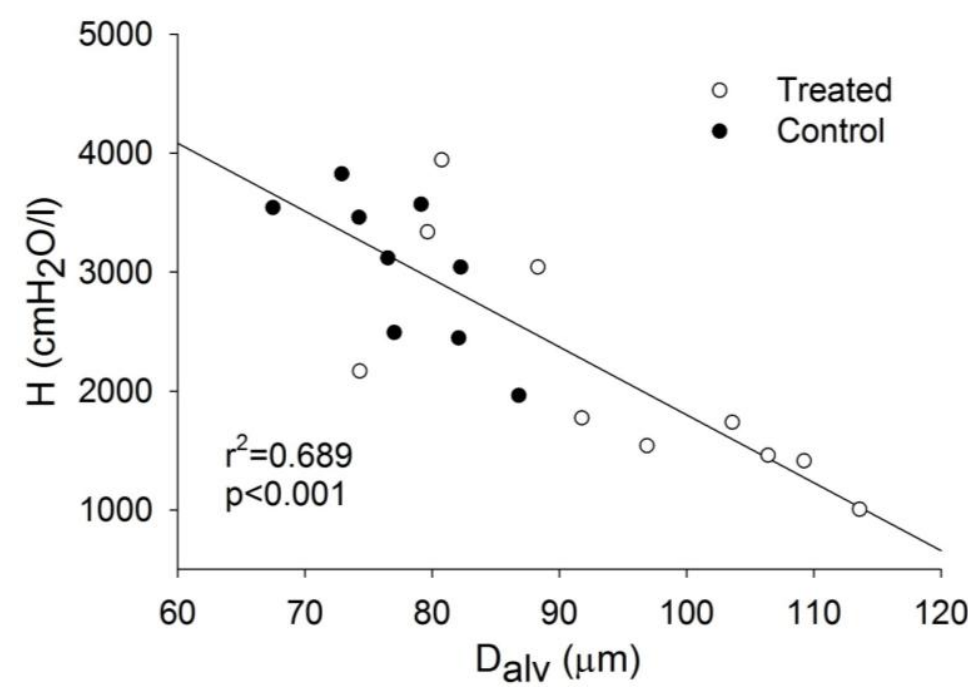

Figure 16: Structure-function correlation. The tissue elastance $(H)$ as a function of the mean alveolar diameter ( $D_{\text {alv }}$ from traditional histology) in control and PPE-treated rats. Pooled data from control and treated rats. 
4. The effects of mechanical forces on lung structure and function (Study IV)

PPE significantly increased FRC before ventilation, with mean values of $0.25 \pm 0.026$ (SD) $\mathrm{ml}$ in the control, Od group, and $0.39 \pm 0.064 \mathrm{ml}$ in the PPE-treated 21d group $(\mathrm{p}<0.001)$ (Fig. 17A). Independently of time, the DIs increased FRC $(\mathrm{p}<0.001)$. Following a 1-h ventilation, FRC was $0.32 \pm 0.05 \mathrm{ml}$ and $0.19 \pm 0.02 \mathrm{ml}$ in the $0 \mathrm{~d}$ DI group and the $0 \mathrm{~d}$ no-DI group, respectively. FRC increased from $0.37 \pm 0.07 \mathrm{ml}$ in the $21 \mathrm{~d}$ no-DI group to $0.45 \pm 0.05$ in the 21d DI group.

PPE also increased $\mathrm{C}$ with time before ventilation $(\mathrm{p}<0.001)$, with values of $0.031 \pm 0.005 \mathrm{ml} / \mathrm{cmH}_{2} \mathrm{O}$ and $0.055 \pm 0.013 \mathrm{ml} / \mathrm{cmH}_{2} \mathrm{O}$ in the $0 \mathrm{~d}$ and $21 \mathrm{~d}$ groups, respectively (Fig. 17B). Similarly to FRC, a strong effect of the DIs was seen on $\mathrm{C}$ at each time point $(\mathrm{p}<0.001)$.
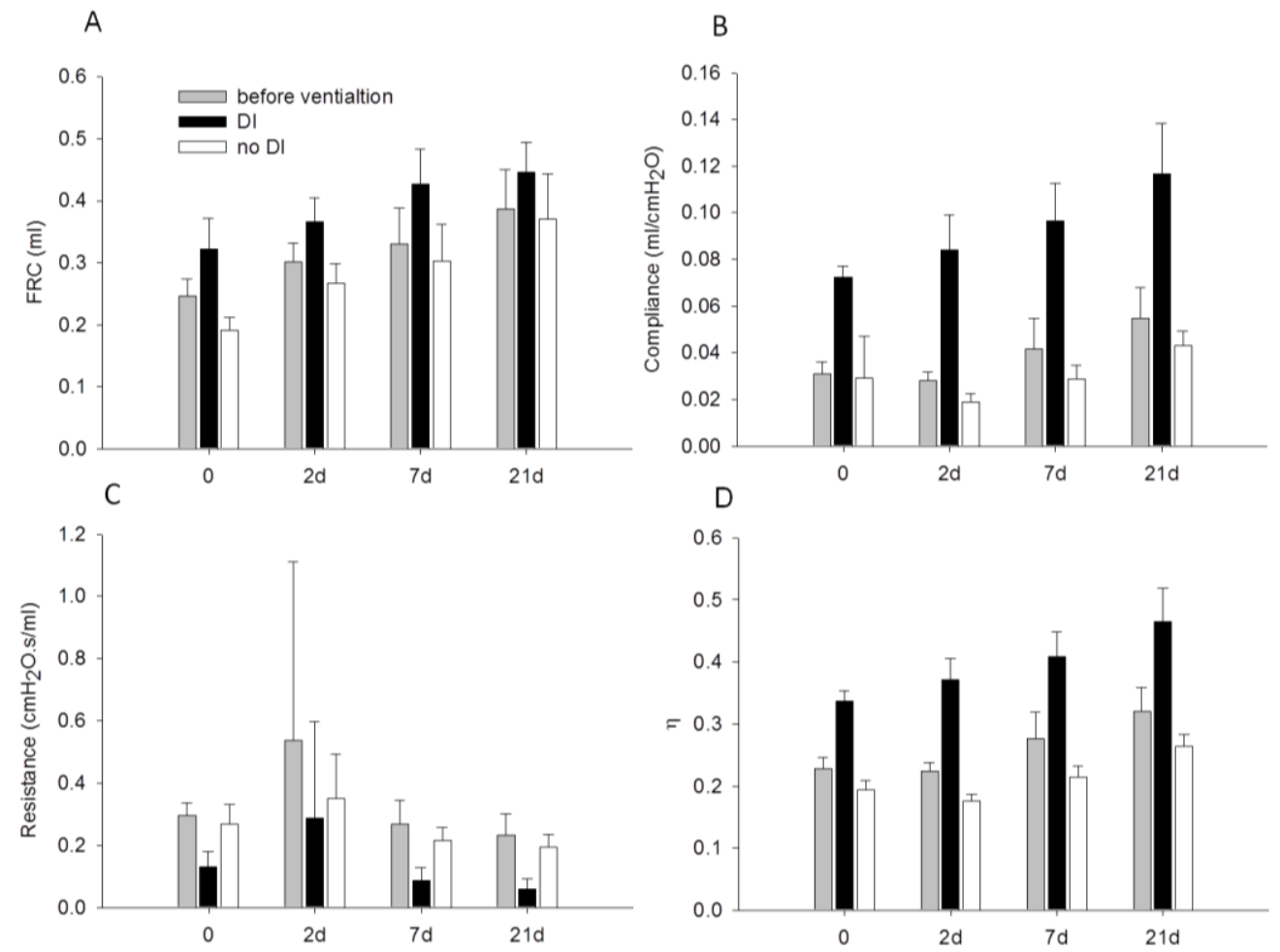

Figure 17: Effects of time and DIs on physiological variables. A: functional residual capacity (FRC). Before ventilation, FRC increased with time (21d vs. Od and $2 d: p<0.05 ; 7 d v s .0: p<0.05 ; 2 d$ vs. 0 : $p<0.05)$ and the DIs had a significant effect on FRC at each time point ( $p<0.001$ ). B: Respiratory compliance $(C)$. Before ventilation, $C$ increased with time $(21 d v s .0 / 2 d, 7 d v s .2 d: p<0.05)$ and the DIs had a significant effect on $C$ at each time point ( $p<0.001)$. C: Newtonian (airway) resistance 
$\left(R_{N}\right)$. Before ventilation, $R_{N}$ showed a decreasing trend with time $(21 d v s .0$ and $2 d: p<0.05)$ and the DIs had a significant effect on $R_{N}(0: p=0.003,2 d: p=0.03,7 d$ and $21 d: p<0.001)$. D: Hysteresivity ( $\eta)$. Before ventilation, $\eta$ showed an increasing trend with time (21d vs. 0) and the DIs had a significant effect at each time point $(p<0.001)$. Bars denote SDs.

$\mathrm{R}_{\mathrm{N}}$ (Fig. 17C) gradually decreased with time, the difference reaching significance at 21d $(p=0.021) . \eta$ (Fig. 17D) significantly differed between the DI and no-DI groups $(\mathrm{p}<0.001)$ and increased with time $(\mathrm{p}<0.05)$, except from $0 \mathrm{~d}$ to $2 \mathrm{~d}$ and from $7 \mathrm{~d}$ to $21 \mathrm{~d}$.

Figure 18 shows typical airspace structures in the control and at each time point following treatment in the DI groups. The PPE treatment increased $\mathrm{D}_{\text {alv }}$ from $29.6 \pm 1.4 \mu \mathrm{m}$ in the $0 \mathrm{~d}$ group to $34.9 \pm 2.9 \mu \mathrm{m}$ at 21 days after treatment $(\mathrm{p}<0.001)$ (Fig. 19A). $\mathrm{D}_{2}$ (Fig. 19B), which is sensitive to changes in both the mean and the heterogeneity of the airspace sizes, revealed much more pronounced differences between the groups in time $(\mathrm{p}<0.001)$.

However, neither of these lumped structural indices indicated a difference between the DI and no-DI groups at any time point.

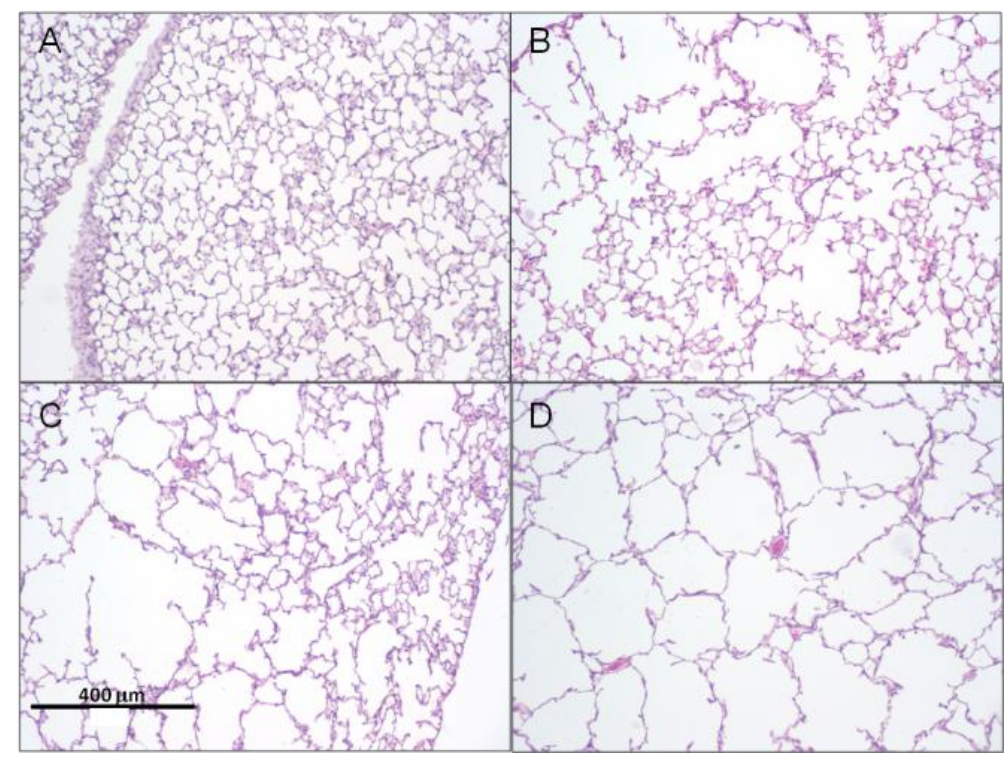

Figure 18: Examples of $H \& E$ stained histological sections. A: Control following 1 -h ventilation with the DIs. B-D: 2, 7 and 21 days after treatment, following 1$h$ ventilation with the DIs.

To explore the possibility that the DIs caused a more subtle structural change in some preferential airspace size, the alveoli were pooled from all animals and grouped into small, medium and large airspaces according to their $\mathrm{D}_{\text {alv }}$ values, and statistics were done within these size categories (Table 3). For the smallest airspaces, significant differences were found between the DI and no-DI groups at $0 \mathrm{~d}$ and $21 \mathrm{~d}(\mathrm{p}<0.001)$ and at $7 \mathrm{~d}(\mathrm{p}=0.003)$. For the medium-sized airspaces, there were differences at $21 \mathrm{~d}(\mathrm{p}=0.007)$ and $0 \mathrm{~d}(\mathrm{p}=0.015)$, whereas Margit V. Szabari: PhD Thesis 
for the largest airspaces, $\mathrm{D}_{\text {alv }}$ was different only at $0 \mathrm{~d}(\mathrm{p}<0.001)$. Even though the percentage differences are small, it is interesting that, in the control animals, the no-DI group had a larger $D_{\text {alv }}$, whereas in the treated animals, the DI groups always had a larger $D_{\text {alv }}$.

\begin{tabular}{|c|c|c|c|c|c|c|}
\hline & \multicolumn{2}{|c|}{ Small } & \multicolumn{2}{c|}{ Medium } & \multicolumn{2}{c|}{ Large } \\
\hline & $\begin{array}{c}\text { DI } \\
(\mu \mathrm{m})\end{array}$ & $\begin{array}{c}\text { no DI } \\
(\mu \mathrm{m})\end{array}$ & $\begin{array}{c}\text { DI } \\
(\mu \mathrm{m})\end{array}$ & $\begin{array}{c}\text { no DI } \\
(\mu \mathrm{m})\end{array}$ & $\begin{array}{c}\text { DI } \\
(\mu \mathrm{m})\end{array}$ & $\begin{array}{c}\text { no DI } \\
(\mu \mathrm{m})\end{array}$ \\
\hline 0 & & $*$ & & & \\
& 17.9 & 18.2 & 41.7 & 41.7 & 92.3 & 98.0 \\
\hline $2 \mathrm{~d}$ & & & & & & \\
\hline $7 \mathrm{~d}$ & 27.4 & 27.4 & 142.3 & 141.6 & 329.1 & 335.1 \\
\hline $21 \mathrm{~d}$ & 28.1 & 27.6 & 147.0 & 147.0 & 339.9 & 353.0 \\
\hline & 27.6 & 27.0 & 154.5 & 149.3 & 342.0 & 360.2 \\
\hline
\end{tabular}

Table 3: Mean values of alveolar diameters binned into groups of small, medium and large. Values of deep inspirations (DIs) are in micrometers $(\mu m)$. The corresponding bins in the untreated control animals (0 days) are: 5-30 $\mu \mathrm{m}, \quad 30-80 \mu \mathrm{m}$, and $80 \mu \mathrm{m}$; and in the treated animals: 5-100 $\mu \mathrm{m}, 100-300 \mu \mathrm{m}$, and $300 \mu \mathrm{m},{ }^{*} p<0.001,{ }^{*} p=0.003$, $* * * p=0.007,{ }^{\#} p=0.015$.

Wt increased by $47 \%$ (Fig. 20), from $2.5 \pm 0.3 \mu \mathrm{m}$ at $0 \mathrm{~d}$ to $3.4 \pm 0.2 \mu \mathrm{m}$ at $21 \mathrm{~d}$ ( $\mathrm{p}<0.001)$. Moreover, at 21d, the DIs induced a 13\% elevation in Wt relative to the no-DI group ( $\mathrm{p}=0.01)$. Interestingly, there appeared to be more cell nuclei in the thicker septal walls following the application of the DIs (Fig. 20B). Figure 21 presents microstructural images of the septal walls with and without DIs.

The increased wall thickness with the DIs was apparent for both staining. Further, the elastin stained images also suggested a slightly more disorganized microstructure within the septal walls. Figure 22 demonstrates the evaluation of the septal wall ruptures on $21 \mathrm{~d}$. Statistical analysis revealed that $\mathrm{N}_{\mathrm{sr}}$ was significantly larger in the DI group than in the no-DI group, with values of $165 \pm 63$ and $134 \pm 68(\mathrm{p}=0.006)$, respectively. The perimeters of the airways in the DI and no-DI groups on 21d for which Ad was evaluated did not differ. However, Ad was $11 \%$ lower in the DI group than in the no-DI group $(\mathrm{p}=0.026)$. 

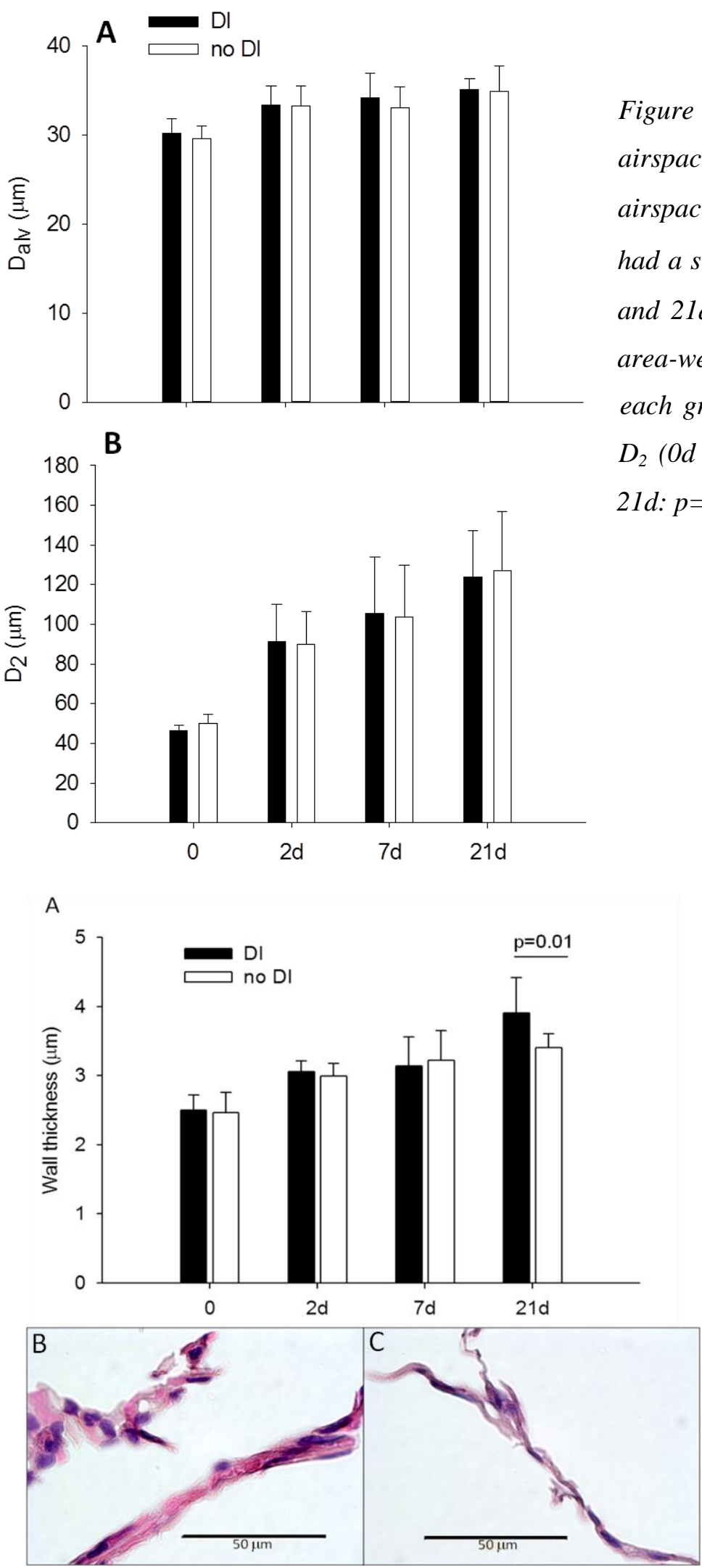

Figure 19: Morphometric analysis of airspace sizes. A: Mean and SD of equivalent airspace diameters, $D_{a l}$, in each group. PPE had a significant effect on $D_{a l v}(0 d v s .2 d, 7 d$ and 21d: $p$ <0.001). B: Mean and SD of the area-weighted mean alveolar diameter, $D_{2}$, in each group. PPE had a significant effect on $D_{2}$ (Od vs. $2 d, 7 d$ and 21d: $p<0.001,2 d$ vs. 21d: $p=0.01$ ).
Figure 20: Morphometric analysis of the wall thickness of the airspaces. A: Mean and SD of wall thickness, Wt, as functions of time and DI. PPE had a significant effect on Wt (Od vs 2d, 7d and 21d, 21d vs $2 d$ and $7 d: p<0.001)$. The DIs had a significant effect on Wt at 21 days (p<0.01). B and C: Microstructural evidence of increased Wt due to DIs 21 days after treatment. $B: H \& E$ staining with Dis. C: $H \& E$ staining with no-DI. 


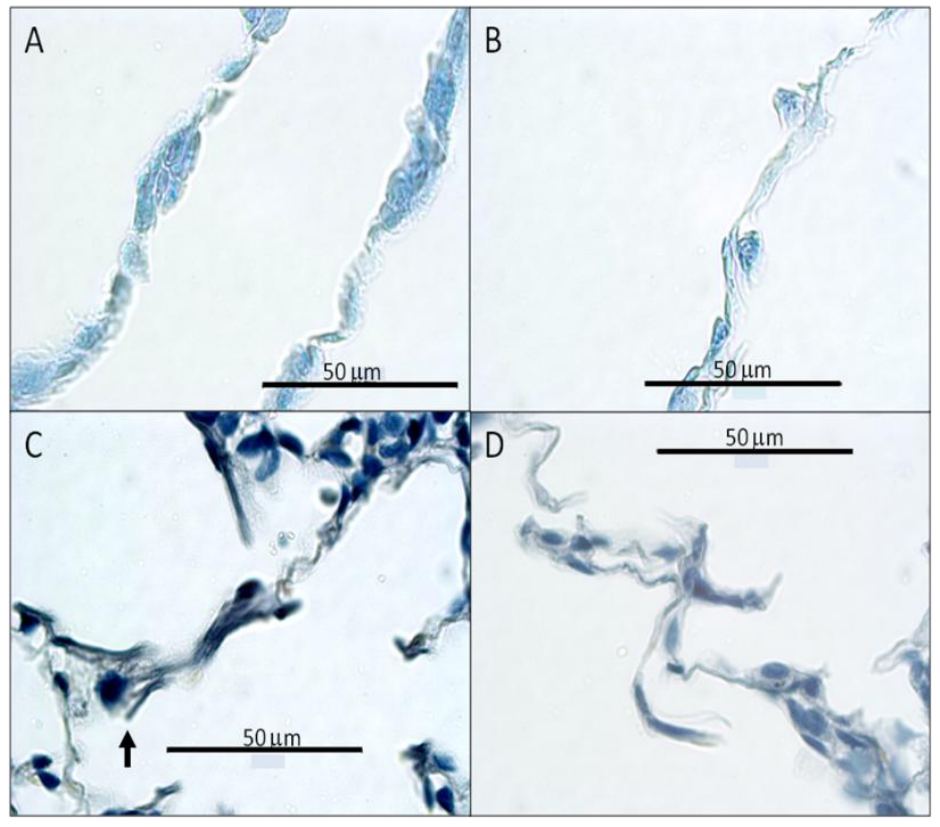

Figure 21: Representative images of stained histological sections. A: Masson's trichrome staining for collagen, 21d DI. B: Masson's trichrome staining for collagen, 21d no-DI. C: Modified Verhoeff's staining showing increased wall thickness with stray elastin (arrow,) which is a potential site of rupture, 21d DI. D: Modified Verhoeff's staining, 21d no-DI.

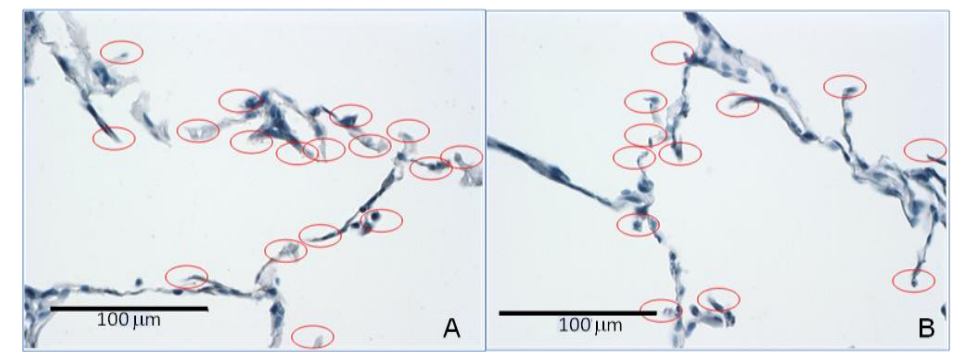

Figure 22: Visualization of all alveolar septal end tips, including possible alveolar ruptures due to DI on modified Verhoeff's stained sections. A: DI; B: no-DI. Red ellipses mark free septal ends. 


\section{DISCUSSION}

In the investigations underlying the current thesis, we studied the early and long-term effects of elastolytic intervention on the pulmonary structure and function in rodents. We observed emphysematous changes in lung function: increased lung volumes (FRC, TLC and $\mathrm{RV}$ ) and altered lung tissue mechanics due to parenchymal destruction with no airway function impairment. Traditional histology, epifluorescence microscopy and OPS imaging confirmed alveolar enlargement, increased alveolar and airway wall thickness, decreased alveolar attachment density around the airways and increased heterogeneity in the PPEtreated lungs. Elastin and collagen contents, visualized with specific staining methods, and confirmed ECM remodeling in the follow-up after the elastolytic insult. We also investigated the effects of acute mechanical stress (DIs) on the structure and mechanics of emphysematous lungs at different stages of the progression of emphysema, thereby creating a partial model of COPD exacerbation.

\section{Lung volumes and respiratory mechanics in PPE-induced emphysema}

In accordance with the other emphysema model studies that we performed, the results of the most comprehensive functional investigation (Study I) indicated that 1) the lung volumes (FRC, RV and TLC) were increased significantly in the PPE-induced animals 21 days after the treatment, similarly as seen in patients with emphysema; 2) the pressurevolume relationship was markedly altered by the elastolysis; 3) the tissue elastance was significantly lower in the emphysematous animals at all lung volumes and $\mathrm{P}_{\mathrm{rs}}$ levels, except in a narrow medium range of $\mathrm{P}_{\mathrm{rs}}$; and 4) the airway resistance $\left(\mathrm{R}_{\mathrm{N}}\right)$ did not differ between the control and the PPE-treated groups at any $\mathrm{P}_{\mathrm{rs}}$ level.

1.1. Dynamic tissue properties. Although $\mathrm{H}$ decreased significantly in the PPE-treated animals at both low and high $\mathrm{P}_{\mathrm{rs}}$ (Table 1), the initial decrease in $\mathrm{H}$ with increasing $\mathrm{P}_{\mathrm{rs}}$ and the reversal toward higher $P_{r s}$ values remained a characteristic feature of the $H$ vs. $P_{r s}$ relationship following the PPE treatment (Fig. 7A). However, the initial decrease was reversed at a lower $\mathrm{P}_{\mathrm{rs}}$ in the PPE-treated mice, in accordance with the results of a study on mice that develop emphysema spontaneously (tight skin mice) ${ }^{13}$. The elevation in $\mathrm{H}$ at high $\mathrm{P}_{\mathrm{rs}}$ is probably due to the stretching of the lung tissues and the recruiting of collagen in the 
lung parenchyma ${ }^{14,52}$, whereas the mechanisms behind the initial decrease in $\mathrm{H}$ may be explained by alveolar recruitment, reorganization of the tissue matrix and the surfactant layer ${ }^{14,42,53}$, or the chest wall mechanics ${ }^{54}$. The biphasic pattern of the $\mathrm{H}$ vs. $\mathrm{P}_{\mathrm{rs}}$ relationship was also seen as a function of TGV and was not altered by the PPE treatment (Fig. 7B); nevertheless, when $\mathrm{H}$ was plotted against TGV, the separation between the two groups became more apparent. It should be noted that the pulmonary and chest wall mechanics were not partitioned in either of the studies included in this thesis. In the mouse studies (Studies I and $I V$ ), the contribution of the chest wall to the elastic and resistive parameters of the total respiratory system can be regarded as negligible ${ }^{55,56}$, whereas the less compliant chest wall in the rat might have attenuated the PPE-induced decreases in $\mathrm{H}$.

Tissue hysteresivity was also affected markedly by the PPE treatment. The 55\% increase in $\eta$ at end-expiration (Study I) is in accord with the findings of several previous studies ${ }^{18,57,58}$. At higher lung volume, the difference between the values of $\eta$ in the two groups, both exhibiting a significant fall from the values obtained at end-expiration, decreased drastically to $12 \%$. The decrease in $\eta$ with increasing lung volume in normal mice has been attributed to the increasing contribution of the lower-hysteresivity collagen to tissue resistance ${ }^{14,59}$. Further, Ito et al. ${ }^{49}$ reported that, following the treatment of mice with PPE, respiratory elastance decreased, despite a nearly $50 \%$ increase in the total collagen content of the lung, implying an abnormal collagen function due to remodeling. Together with the increase in tissue heterogeneity discussed above, the abnormal collagen function might also have contributed to the overall increase in $\eta$ in the treated mice (Table 1).

1.2. Longitudinal functional assessment. The data from our long-term, follow-up animal study (Study III) reflected both the continuous progression of emphysema in the PPEtreated rats and the somatic growth in all animals up to day 105. These changes similarly affected the lung volumes and the tissue mechanics. The lung volume increases in the PPEtreated groups resembles the typical feature of the human disease ${ }^{60}$. Our finding that the differences between the two groups increased further after day 21 of the study (an interval around the standard recommended time for the PPE rodent model ${ }^{15}$ ) indicates the need for longer protocols for the investigation of late-stage emphysema.

The changes in the mechanical properties of the respiratory tissues with time paralleled those in the lung volume. While natural growth leads to a decrease in elastance, 
PPE induced an accelerated decrease in H. Interestingly, the difference in G between the control and the treated group did not develop as quickly and to such an extent as that in $\mathrm{H}$ (cf. Figs $12 \mathrm{~F}$ and $12 \mathrm{G}$ ); as a result of this (and as discussed above), $\eta$ increased abruptly in the treated group (Fig. 12H). This may indicate either an immediate alteration in parenchymal viscoelasticity (as a consequence of the elastolytic treatment) or an increase in lung heterogeneity.

1.3. Airway function. Uniformly in our mice and rat emphysema studies (Studies I-IIIII), LFOT did not reveal any difference in $\mathrm{R}_{\mathrm{N}}$ between the control and treated groups. The lack of difference in $R_{N}$ indicates that the airway function is not affected by the loss of parenchymal tethering forces, as expected from the fall in elastance ${ }^{28,61-64}$, and some observations on human emphysema also indicate that an airspace enlargement and an airflow limitation do not necessarily combine ${ }^{65-67}$. In this context, the changes following PPE treatment may characterize an initial or mild degree of emphysema, where the loss of alveolar attachments (which must have accompanied the marked increase in both alveolar size and lung volumes) is compensated by new elastic equilibria within the lung parenchyma and between the lung and chest wall, so that the patency of the airways is retained. There were mild gradual decreases in $\mathrm{R}_{\mathrm{N}}$, which were similar in the control and the PPE-treated groups, and can be attributed to body (and lung) growth with age. Whereas $R_{N}$ for the emphysematous animals was higher at the same absolute lung volume, a fact also established in clinical cases of emphysema and $\mathrm{COPD}^{68}$, it is important to point out that there was no difference in $\mathrm{R}_{\mathrm{N}}$ between the control and treated animals at the actual operating lung volumes.

\section{Lung morphometry in PPE-induced emphysema}

The results of histology from Studies I-III revealed that 1) the measures of alveolar size were significantly higher and the distribution of the alveolar diameters was shifted toward higher values in the PPE group; 2) the alveolar attachment density was lower, and the alveolar and bronchial wall thicknesses were higher in emphysematous animals; 3) the collagen content per unit wall thickness of the bronchial wall was higher and more 
heterogeneous in the treated than in the control animals; and 4) the elastin component of the ECM increased, while the collagen component decreased in PPE-induced emphysema.

2.1. Alveolar structure. The increases in $\mathrm{D}_{\mathrm{alv}}$ and $\mathrm{D}_{2}$ in the treated animals are consistent with the morphological features of emphysema, i.e. the destructured wall of the airspaces and the enlarged alveoli, with $\mathrm{D}_{2}$ being more sensitive to the morphological changes in this pathological condition as it also incorporates the heterogeneity of the structure $^{48,69}$. The wall thickness of the alveoli in the histological images was higher in the PPE-treated animals due to tissue remodeling. Previous studies also indicated an elevated alveolar septal wall thickness in PPE-treated mice, although there was no significant difference between the control and the PPE-treated animals ${ }^{18,70}$. However, in those studies the intervals of the investigation, the treatment dose and method and the strain all differed. In Sprague-Dawley rats, the same results were found ${ }^{71}$, where the mean thickness was 2.1 and $2.9 \mu \mathrm{m}$ in the control and the emphysematous animals, respectively, 38 days after the PPE treatment. Increased septal wall thickness was likewise observed in human emphysema within moderate lesions ${ }^{5}$, though, the wall thickness was twice that in the healthy controls $(5.2 \mu \mathrm{m}$ vs. $2.2 \mu \mathrm{m})$, indicating that the elastolytic rodent model may mimic the early stage of emphysema.

2.2. Subpleural alveoli. The OPS technique was designed to image the human microcirculation $^{72}$, using reflected light from the surface of a solid organ such as the brain, $\operatorname{skin}^{73}$, liver, pancreas ${ }^{74}$ and conjunctiva or cornea ${ }^{75}$. Although this imaging technique can be used in vivo, we chose the ex vivo condition so as to avoid the confounding effects of the beating heart, which allowed us to investigate the subpleural alveoli in their unaltered, physiological condition. The distribution of the subpleural alveoli exhibited a slight shift in the treated group due to septal wall ruptures, which lead to enlarged airspaces. Thus, this technique is capable of detecting structural differences between the normal and the emphysematous lung. The distribution of the alveoli from the traditional histological samples revealed a similar scenario, but the histogram demonstrated a longer tail, which may indicate that the subpleural alveoli are smaller in the OPS images in both the control and the PPEtreated animals than in the histological samples, where the entire plane of the section was investigated. This difference may be explained by the cohesive effect of the pleura, which can mitigate any increase in alveolar size in both groups. Similar results were found 
regarding the size of the subpleural alveoli in mice by Mitzner et al. ${ }^{76}$. With traditional histology they observed significantly smaller mean airspace chord lengths close to the pleura than in the interior parts of the lung. While we acknowledge the possible size differences between the subpleural and interior alveolar populations, we argue that the OPS images display an intact structure free from irregular airspaces (such as ductal structures resulting in a long tail in the size distributions toward large values in the histological samples). Indeed, the OPS alveolar size distribution in the control rats is remarkably normal, while it becomes asymmetrical in the treated animals (Fig. 13F).

2.3. Airway structure. In Study II we quantified the parenchymal tethering by measuring the number of attachments per unit airway wall perimeter, and found that the treatment reduced the average attachment density by $7 \%$. This is similar to the finding of Collie et al. ${ }^{77}$ who reported a decreased number of attachments around the bronchi of sheep after PPE treatment. It might be argued that, if the wall is more compliant in the treated lungs, the decreased attachment density is simply a result of the larger airway diameters at the same fixation pressure in the treated animals. However, there was no difference in diameter between the two populations of airways included in our analysis, which suggests that the reduction in attachment density was probably due to the loss of parenchymal tethering. The elastin density of the walls measured from the histological images was similar in the two groups. It should be pointed out that the elastin density was measured in a band of fixed width around the bronchi. Since the wall thickness in the treated animals was larger by $15 \%$, it is likely that the total elastin content was also higher in the bronchial walls of the treated rats, implying cellular remodeling of the airway walls. However, collagen also contributes to stiffness, especially at higher transmural pressures. The increased collagen density of the wall and the elevated intra-wall heterogeneity suggest disordered remodeling following PPE treatment. Furthermore, the increased wall thickness would also result in a higher volumetric elastance of the airway wall ${ }^{78}$. Thus, these considerations imply a real decrease in tethering forces as well as stiffening of the airway walls as a consequence of the PPE treatment.

2.4. Structure-function relationship. An important finding of our follow-up rat emphysema study (Study III) is a strong structure-function relation that links the lung elasticity (parameter $H$ ) to the mean alveolar diameter $\left(D_{\text {alv }}\right)$. The mechanism behind this 
relation is probably involves rupture of the septal walls. There are two consequences of a septal wall rupture: 1) a coalescence of two neighboring alveoli and increase of the alveolar diameters; and 2) a decrease in the number of walls carrying the load in the parenchyma, which in turn decreases the lung stiffness. Moreover, a single rupture transmits the tension in the wall to its neighbors, which increases the likelihood of a subsequent rupture. A sufficient number of ruptures results in a macroscopically measurable decrease in H. Thus, through a common mechanism, the rupture of the septal walls ${ }^{79,80}$, the alveolar structure and the parenchymal stiffness become intimately linked. Since the airspace diameter steadily increases (Fig. 14A), while both the elastin and the collagen content decrease (Fig. 15A and 15D), it seems plausible that the amount of load-bearing ECM constituents determines the failure of the septal walls and indirectly the alveolar airspace diameters. However, the ECM constituents also decrease in the control group during the natural growth of the animal. One possibility is that the cross-link density and distribution are different in the remodeled elastin and collagen fibers, which makes them vulnerable to failure. Mechanical failure in turn exposes fragments which are chemoattractant to macrophages in the $\operatorname{lung}^{38}$ and a vicious circle may result: tissue inflammation leads to mechanical failure, which maintains inflammation and ultimately a steady progression of the disease. However, with due caution because of the small sample size, we can state that the intra-group relationships reflect tendencies similar to those for the pooled data (Fig. 16). Further investigations are needed to establish whether there is a general size-compliance relationship or whether different trajectories exist for healthy and emphysematous lungs.

\section{Mechanical effects on chemically weakened lung tissue}

The acute increases in mild mechanical forces achieved by the frequent DIs in Study $I V$ resulted in 1) large changes in the functional mechanical properties of the respiratory system, such as FRC and compliance, and 2) noticeable structural alterations in the parenchyma and airways, seen on day 21 after treatment. The latter suggests that, when the ECM of the lung is sufficiently weakened, mechanical forces are able to induce irreversible changes in the lung structure. 
3.1. Lung volumes and respiratory mechanics. FRC, $\mathrm{C}$ and $\eta$ increased with time (Fig. 17) as a result of the development of emphysema after PPE treatment, as in previous studies $^{74,81}$. The DIs significantly increased FRC and $\mathrm{C}$ in the control and treated mice. To interpret these results, we first note that anesthetized mice in the supine position easily derecruit large regions of the lung ${ }^{82}$. A single DI recruits some regions, which tend to collapse again with time. Further DI-activated mechanisms that may contribute to the elevation in $\mathrm{C}$ in this experimental setting are the ruptures of fibers in the septal wall and the large stretches triggering surfactant release ${ }^{83}$. Thus, the changes in $C$ in the control mice are due to recruitment and surfactant secretion, whereas the contribution to the increase in $\mathrm{C}$ in the treated lung made by the mechanical failure. In order to identify the contributing mechanisms and establish whether the DIs caused any irreversible change during the 1-h of ventilation, a detailed analysis of the lung structure is required.

3.2. Alveolar structure. The progression of emphysema was accompanied by increases in $\mathrm{D}_{\text {alv }}$ and $\mathrm{D}_{2}$ (Fig. 19). In a more refined analysis, we pooled $\mathrm{D}_{\text {alv }}$ from all animals and grouped them into small, medium and large size categories (Table 3). Significant differences were detected between the no-DI and DI groups: although the absolute differences were small, the significance levels were strong, due to the large number $(>10,000)$ of airspaces.

In the control animals, the DIs decreased the sizes of the airspaces in all 3 airspace size categories. This may be related to the finding by Namati et al. ${ }^{84}$ that the alveoli became smaller at end-inspiration, due to recruitment in the lung. They suggested that at higher inflation pressures (similar to those in our DI protocol), secondary (daughter) alveoli pop open and inflate via the primary (mother) alveoli through the pores of Kohn. In contrast, in our treated animals, the DIs generated larger $D_{\text {alv }}$ in the two smallest size categories, suggesting that at the same fixation pressure the DIs definitely increased the airspace diameters. These results imply that the septal walls of some small and medium-sized airspaces became softer or the septal walls actually ruptured during ventilation with the DIs. The microstructural changes caused by the DIs were most pronounced on day 21. Indeed, while the septal wall thickness Wt steadily increased with time (Fig. 20), the DIs caused a significant increase only on day 21 . The increased thickness, which is a characteristic feature of severe AECOPD ${ }^{82}$, was apparent on all three types of staining (Figs. 20 and 21). The H\&E 
staining demonstrated more cell nuclei (Fig. 20B), a sign of inflammation similar to that in the airways of COPD patients after exacerbation ${ }^{85}$. The elastin staining additionally suggests a disorganized fiber network in the wall, with possible microruptures (Fig. 21C). These findings are consistent with the sudden deterioration of lung structure that accompanies AECOPD. We note that the increase in $\mathrm{Wt}$ is associated with an increase in $\mathrm{C}$ in the DI group (Fig. 17B), most probably as a consequence of capillary rupture, leakage and edema ${ }^{86}$.

3.3. Changes in the ECM. On day 21, analysis revealed that $\mathrm{N}_{\mathrm{sr}}$ was larger in the DI group than in the no-DI group. Similar to $\mathrm{N}_{\mathrm{sr}}$, Ad around the airways increased due to the DIs. In the control animals, we did not see any evidence of ruptures, and hence the increase in FRC was caused by pure recruitment. Additionally, on day 21, the DI-induced increases in $\mathrm{N}_{\text {sr }}$ and Ad resulted in larger $\mathrm{D}_{\text {alv }}$ (Table 3) and a proportion of the increases in FRC and C must therefore have resulted from ruptures. These results prove that our model reproduces some features of AECOPD, with irreversible changes in structure and function. Moreover, we found wall thickening, fiber and septal wall rupture only on day 21; a threshold in ECM remodeling may therefore exist below which acute increases in mechanical forces do not seem to induce irreversible changes.

As the ECM becomes weaker, it is possible that DI-induced microruptures also occur at earlier time points. For example, $\mathrm{D}_{\text {alv }}$ was increased for the smallest size category (Table 3) on day 7. Such subtle changes in structure may not cause noticeable changes in function. However, when ECM structures rupture, fragments of molecules will be exposed. Elastin ${ }^{15}$ and proteoglycan ${ }^{87}$ fragments are chemoattractant and potentiate further inflammation, which is also characteristic of $\mathrm{AECOPD}^{2}$ and may contribute to the increased susceptibility of patients to infection-induced inflammation. If a sufficient number of elements of the wall fail, the entire wall ruptures, which can influence the distribution of low attenuation areas on CT images ${ }^{88}$ and become clinically observable. Since the parenchyma is always under tensile stress, when an alveolar wall will rupture, the stress the wall carried just before failure is redistributed among the neighboring walls. Consequently, some neighbors will experience increased stress, which unfolds new binding sites for enzymes such as elastase and increases the unbinding and cleaving rate ${ }^{89}$. These mechanisms result in a higher probability of the wall failure. Thus, a single rupture can lead to a cascade of ruptures and serve as a positive feedback to potentiate further breakdown ${ }^{6}$. This mechanism might help explain why previous 
AECOPDs increase the probability of future AECOPDs, leading to the emergence of the “frequent-exacerbation" phenotype ${ }^{90}$. 


\section{SUMMARY AND CONCLUSIONS}

1. We have demonstrated in three animal studies (Studies I-III) that PPE-induced destruction of the lung parenchyma is accompanied by elevated respiratory compliance and lung volumes, and hence modeling the changes in human emphysema; however, the decrease in the tethering forces, together with the observed subtle remodeling of the bronchial wall, does not result in increased airway resistance. This model may correspond to an early symptomless phase of COPD and suggests that, in addition to the altered elastic equilibrium between the lungs and the chest wall, the involvement of other factors is necessary for the development of an airway obstruction.

2. We followed the progression of emphysema induced by a single dose of PPE in a long-term study (Study III). During the 105-day follow-up, there were steady increases in lung volumes and pulmonary compliance, without any impairment in the airway function, further raising the necessity of additional pathomechanisms that target the bronchi. This study is the first to employ OPS imaging to visualize the subpleural alveoli ex vivo, and its results complement those of conventional morphometry by avoiding the usual artifacts of the latter. At the level of the ECM, we observed that elastin remodeling was delayed as compared with collagen remodeling. Overall, a strong structure-function relationship has been identified between alveolar size and lung compliance, which is apparently driven by septal wall ruptures.

3. We have demonstrated that exacerbation-like irreversible changes in structure and function can be induced by acute increases in mechanical forces in the absence of bacterial or viral infections, as long as the lung ECM is sufficiently weak (Study IV). Thus, it is possible that, the increases in mechanical stresses on the emphysematous tissue associated with cough and hyperinflation are also important contributors to the irreversible changes in AECOPD in humans. While we acknowledge that infection is a likely cause of the generation of mechanical stresses and is ultimately needed for impairment of the airway function, our study also suggests that the clinical treatment 
of AECOPD should minimize mechanical stresses, for instance by e.g. attenuating coughing or carefully choosing mechanical ventilation parameters if the patient needs to be ventilated. 


\section{ACKNOWLEDGMENTS}

First and foremost, I would like to acknowledge the support of my supervisor, Professor Zoltán Hantos. I am grateful to him for all the training and for his invaluable help and time in most of the experimental work, the data analysis and the preparation of the thesis. I greatly appreciate his guidance and his support over the last 12 years!! (Yes, time flies, for sure.)

My most grateful thanks and appreciation are also due to my honorary supervisors at Boston University, Professor Béla Suki and Erzsébet Bartolák-Suki, who supported me so strongly during recent years. I also greatly appreciate their continuous guidance and invaluable advice, and all the opportunities they have afforded me.

I would like to express my thanks to my colleagues and friends, József Tolnai and Harikrishnan Parameswaran, for their support and help. I am likewise very grateful to Ágnes Adamicza and Gabriella Varga, who introduced me to small-animal surgery, for their continuous guidance and support.

I further wish to express my thanks to all of the staff and colleagues from the Department of Physics and Medical Informatics and the Institute for Surgical Research at the University of Szeged, who made my work fun and easier through their help.

I additionally wish to express my gratitude to my current PI, Guido Musch and to my colleagues in the laboratory at Massachusetts General Hospital/Harvard Medical School in Boston, for their care and emotional support during the last 3 years and while I was writing my thesis. My Friends! Thank you so much for all of your help and kindness!

I would particularly like to thank Professor Tilo Winkler for his mentorship and continuous guidance in the last 3 years. I truly appreciate all of our conversations, his encouragement and his advice about science and LIFE.

And last, I would like to express my greatest thanks to my Family, for their continuous support and unconditional love during my adventurous periods. 
The work presented in this thesis was supported by Hungarian Scientific Research (OTKA) Grants 66700, 105403, T42971, T37810 and HURO/0901/137/2.2.2, National Health and Medical Research Council of Australia Grant 139024, National Science Foundation Grant BES-0402530, National Heart, Lung, and Blood Institute Grants HL059215, HL-090757 and HL-098976, and the Rosztóczy Foundation. 


\section{REFERENCES}

1. http://www.who.int/mediacentre/factsheets/fs310/en/.

2. http://www.goldcopd.org/uploads/users/files/GOLD_Report_2011_Feb21.pdf. Global Initiative for Chronic Obstructive Lung Disease Global Strategy for the Diagnosis, Management, and Prevention of Chronic Obstructive Pulmonary Disease.

3. Janoff, A. Elastase in tissue injury. Annual review of medicine 36, 207-216 (1985).

4. Hogg, J.C. Pathophysiology of airflow limitation in chronic obstructive pulmonary disease. Lancet 364, 709-721 (2004).

5. Vlahovic, G., Russell, M.L., Mercer, R.R. \& Crapo, J.D. Cellular and connective tissue changes in alveolar septal walls in emphysema. American journal of respiratory and critical care medicine 160, 2086-2092 (1999).

6. Suki, B., Lutchen, K.R. \& Ingenito, E.P. On the progressive nature of emphysema: roles of proteases, inflammation, and mechanical forces. American journal of respiratory and critical care medicine 168, 516-521 (2003).

7. Brusasco, V. \& Martinez, F. Chronic obstructive pulmonary disease. Comprehensive Physiology 4, 1-31 (2014).

8. Bates, J.H., Irvin, C.G., Farre, R. \& Hantos, Z. Oscillation mechanics of the respiratory system. Comprehensive Physiology 1, 1233-1272 (2011).

9. Hantos, Z., Adamicza, A., Govaerts, E. \& Daroczy, B. Mechanical impedances of lungs and chest wall in the cat. Journal of applied physiology 73, 427-433 (1992).

10. Farre, R., Ferrer, M., Rotger, M., Torres, A. \& Navajas, D. Respiratory mechanics in ventilated COPD patients: forced oscillation versus occlusion techniques. The European respiratory journal 12, 170-176 (1998).

11. Kaczka, D.W., Ingenito, E.P., Body, S.C., Duffy, S.E., Mentzer, S.J., DeCamp, M.M. \& Lutchen, K.R. Inspiratory lung impedance in COPD: effects of PEEP and immediate impact of lung volume reduction surgery. Journal of applied physiology 90, 1833-1841 (2001).

12. Lorx, A., Szabo, B., Hercsuth, M., Penzes, I. \& Hantos, Z. Low-frequency assessment of airway and tissue mechanics in ventilated COPD patients. Journal of applied physiology 107, 1884-1892 (2009).

13. Ito, S., Bartolak-Suki, E., Shipley, J.M., Parameswaran, H., Majumdar, A. \& Suki, B. Early emphysema in the tight skin and pallid mice: roles of microfibril-associated glycoproteins, collagen, and mechanical forces. American journal of respiratory cell and molecular biology 34, 688-694 (2006).

14. Sly, P.D., Collins, R.A., Thamrin, C., Turner, D.J. \& Hantos, Z. Volume dependence of airway and tissue impedances in mice. Journal of applied physiology 94, 14601466 (2003).

15. Snider, G.L., Lucey, E.C. \& Stone, P.J. Animal models of emphysema. The American review of respiratory disease 133, 149-169 (1986).

16. Mahadeva, R. \& Shapiro, S.D. Chronic obstructive pulmonary disease * 3: Experimental animal models of pulmonary emphysema. Thorax 57, 908-914 (2002).

17. D'Armiento, J., Dalal, S.S., Okada, Y., Berg, R.A. \& Chada, K. Collagenase expression in the lungs of transgenic mice causes pulmonary emphysema. Cell 71, 955-961 (1992). 
18. Ito, S., Ingenito, E.P., Arold, S.P., Parameswaran, H., Tgavalekos, N.T., Lutchen, K.R. \& Suki, B. Tissue heterogeneity in the mouse lung: effects of elastase treatment. Journal of applied physiology 97, 204-212 (2004).

19. Gross, P., Pfitzer, E.A., Tolker, E., Babyak, M.A. \& Kaschak, M. Experimental Emphysema: Its Production with Papain in Normal and Silicotic Rats. Archives of environmental health 11, 50-58 (1965).

20. van Kuppevelt, T.H., van de Lest, C.H., Versteeg, E.M., Dekhuijzen, P.N. \& Veerkamp, J.H. Induction of emphysematous lesions in rat lung by beta-D-xyloside, an inhibitor of proteoglycan synthesis. American journal of respiratory cell and molecular biology 16, 75-84 (1997).

21. Kasahara, Y., Tuder, R.M., Taraseviciene-Stewart, L., Le Cras, T.D., Abman, S., Hirth, P.K., Waltenberger, J. \& Voelkel, N.F. Inhibition of VEGF receptors causes lung cell apoptosis and emphysema. The Journal of clinical investigation 106, 13111319 (2000).

22. Shapiro, S.D. Mighty mice: transgenic technology "knocks out" questions of matrix metalloproteinase function. Matrix biology : journal of the International Society for Matrix Biology 15, 527-533 (1997).

23. Wright, J.L. \& Churg, A. Cigarette smoke causes physiologic and morphologic changes of emphysema in the guinea pig. The American review of respiratory disease 142, 1422-1428 (1990).

24. Snider, G.L., Lucey, E.C., Faris, B., Jung-Legg, Y., Stone, P.J. \& Franzblau, C. Cadmium-chloride-induced air-space enlargement with interstitial pulmonary fibrosis is not associated with destruction of lung elastin. Implications for the pathogenesis of human emphysema. The American review of respiratory disease 137, 918-923 (1988).

25. Chitano, P., Hosselet, J.J., Mapp, C.E. \& Fabbri, L.M. Effect of oxidant air pollutants on the respiratory system: insights from experimental animal research. The European respiratory journal 8, 1357-1371 (1995).

26. Wright, J.L., Harrison, N., Wiggs, B. \& Churg, A. Quartz but not iron oxide causes air-flow obstruction, emphysema, and small airways lesions in the rat. The American review of respiratory disease 138, 129-135 (1988).

27. Stevenson, C.S. \& Birrell, M.A. Moving towards a new generation of animal models for asthma and COPD with improved clinical relevance. Pharmacology \& therapeutics 130, 93-105 (2011).

28. Bellofiore, S., Eidelman, D.H., Macklem, P.T. \& Martin, J.G. Effects of elastaseinduced emphysema on airway responsiveness to methacholine in rats. Journal of applied physiology 66, 606-612 (1989).

29. Artaechevarria, X., Blanco, D., de Biurrun, G., Ceresa, M., Perez-Martin, D., Bastarrika, G., de Torres, J.P., Zulueta, J.J., Montuenga, L.M., Ortiz-de-Solorzano, C. \& Munoz-Barrutia, A. Evaluation of micro-CT for emphysema assessment in mice: comparison with non-radiological techniques. European radiology 21, 954-962 (2011).

30. Emami, K., Cadman, R.V., Woodburn, J.M., Fischer, M.C., Kadlecek, S.J., Zhu, J., Pickup, S., Guyer, R.A., Law, M., Vahdat, V., Friscia, M.E., Ishii, M., Yu, J., Gefter, W.B., Shrager, J.B. \& Rizi, R.R. Early changes of lung function and structure in an 
elastase model of emphysema--a hyperpolarized 3He MRI study. Journal of applied physiology 104, 773-786 (2008).

31. Tasaka, S., Inoue, K., Miyamoto, K., Nakano, Y., Kamata, H., Shinoda, H., Hasegawa, N., Miyasho, T., Satoh, M., Takano, H. \& Ishizaka, A. Role of interleukin-6 in elastase-induced lung inflammatory changes in mice. Experimental lung research 36, 362-372 (2010).

32. Lourenco, J.D., Neves, L.P., Olivo, C.R., Duran, A., Almeida, F.M., Arantes, P.M., Prado, C.M., Leick, E.A., Tanaka, A.S., Martins, M.A., Sasaki, S.D. \& Lopes, F.D. A treatment with a protease inhibitor recombinant from the cattle tick (Rhipicephalus Boophilus microplus) ameliorates emphysema in mice. PloS one 9, e98216 (2014).

33. Anzueto, A. Impact of exacerbations on COPD. European respiratory review : an official journal of the European Respiratory Society 19, 113-118 (2010).

34. Kononov, S., Brewer, K., Sakai, H., Cavalcante, F.S., Sabayanagam, C.R., Ingenito, E.P. \& Suki, B. Roles of mechanical forces and collagen failure in the development of elastase-induced emphysema. American journal of respiratory and critical care medicine 164, 1920-1926 (2001).

35. Mishima, M., Hirai, T., Itoh, H., Nakano, Y., Sakai, H., Muro, S., Nishimura, K., Oku, Y., Chin, K., Ohi, M., Nakamura, T., Bates, J.H., Alencar, A.M. \& Suki, B. Complexity of terminal airspace geometry assessed by lung computed tomography in normal subjects and patients with chronic obstructive pulmonary disease.

Proceedings of the National Academy of Sciences of the United States of America 96, 8829-8834 (1999).

36. Brown, R.H., Walters, D.M., Greenberg, R.S. \& Mitzner, W. A method of endotracheal intubation and pulmonary functional assessment for repeated studies in mice. Journal of applied physiology 87, 2362-2365 (1999).

37. Glaab, T., Mitzner, W., Braun, A., Ernst, H., Korolewitz, R., Hohlfeld, J.M., Krug, N. \& Hoymann, H.G. Repetitive measurements of pulmonary mechanics to inhaled cholinergic challenge in spontaneously breathing mice. Journal of applied physiology 97, 1104-1111 (2004).

38. Houghton, A.M., Quintero, P.A., Perkins, D.L., Kobayashi, D.K., Kelley, D.G., Marconcini, L.A., Mecham, R.P., Senior, R.M. \& Shapiro, S.D. Elastin fragments drive disease progression in a murine model of emphysema. The Journal of clinical investigation 116, 753-759 (2006).

39. Lakatos, H.F., Burgess, H.A., Thatcher, T.H., Redonnet, M.R., Hernady, E., Williams, J.P. \& Sime, P.J. Oropharyngeal aspiration of a silica suspension produces a superior model of silicosis in the mouse when compared to intratracheal instillation. Experimental lung research 32, 181-199 (2006).

40. Dubois, A.B., Botelho, S.Y., Bedell, G.N., Marshall, R. \& Comroe, J.H., Jr. A rapid plethysmographic method for measuring thoracic gas volume: a comparison with a nitrogen washout method for measuring functional residual capacity in normal subjects. The Journal of clinical investigation 35, 322-326 (1956).

41. Janosi, T.Z., Adamicza, A., Zosky, G.R., Asztalos, T., Sly, P.D. \& Hantos, Z. Plethysmographic estimation of thoracic gas volume in apneic mice. Journal of applied physiology 101, 454-459 (2006). 
42. Hantos, Z., Collins, R.A., Turner, D.J., Janosi, T.Z. \& Sly, P.D. Tracking of airway and tissue mechanics during TLC maneuvers in mice. Journal of applied physiology 95, 1695-1705 (2003).

43. Bozanich, E.M., Janosi, T.Z., Collins, R.A., Thamrin, C., Turner, D.J., Hantos, Z. \& Sly, P.D. Methacholine responsiveness in mice from 2 to $8 \mathrm{wk}$ of age. Journal of applied physiology 103, 542-546 (2007).

44. Hantos, Z., Daroczy, B., Suki, B., Nagy, S. \& Fredberg, J.J. Input impedance and peripheral inhomogeneity of dog lungs. Journal of applied physiology 72, 168-178 (1992).

45. Fredberg, J.J. \& Stamenovic, D. On the imperfect elasticity of lung tissue. Journal of applied physiology 67, 2408-2419 (1989).

46. http://www.scireq.com/products/flexivent.

47. Lutchen, K.R., Yang, K., Kaczka, D.W. \& Suki, B. Optimal ventilation waveforms for estimating low-frequency respiratory impedance. Journal of applied physiology 75, 478-488 (1993).

48. Parameswaran, H., Majumdar, A., Ito, S., Alencar, A.M. \& Suki, B. Quantitative characterization of airspace enlargement in emphysema. Journal of applied physiology 100, 186-193 (2006).

49. Ito, S., Ingenito, E.P., Brewer, K.K., Black, L.D., Parameswaran, H., Lutchen, K.R. \& Suki, B. Mechanics, nonlinearity, and failure strength of lung tissue in a mouse model of emphysema: possible role of collagen remodeling. Journal of applied physiology 98, 503-511 (2005).

50. Tolnai, J., Szabari, M.V., Albu, G., Maar, B.A., Parameswaran, H., Bartolak-Suki, E., Suki, B. \& Hantos, Z. Functional and morphological assessment of early impairment of airway function in a rat model of emphysema. Journal of applied physiology 112, 1932-1939 (2012).

51. Hamakawa, H., Bartolak-Suki, E., Parameswaran, H., Majumdar, A., Lutchen, K.R. $\&$ Suki, B. Structure-function relations in an elastase-induced mouse model of emphysema. American journal of respiratory cell and molecular biology 45, 517-524 (2011).

52. Donaldson, G.C., Seemungal, T.A., Bhowmik, A. \& Wedzicha, J.A. Relationship between exacerbation frequency and lung function decline in chronic obstructive pulmonary disease. Thorax 57, 847-852 (2002).

53. Finlay, G.A., O'Donnell, M.D., O'Connor, C.M., Hayes, J.P. \& FitzGerald, M.X. Elastin and collagen remodeling in emphysema. A scanning electron microscopy study. The American journal of pathology 149, 1405-1415 (1996).

54. Hirai, T., McKeown, K.A., Gomes, R.F. \& Bates, J.H. Effects of lung volume on lung and chest wall mechanics in rats. Journal of applied physiology 86, 16-21 (1999).

55. Tankersley, C.G., Rabold, R. \& Mitzner, W. Differential lung mechanics are genetically determined in inbred murine strains. Journal of applied physiology $\mathbf{8 6}$, 1764-1769 (1999).

56. Mitzner, W., Brown, R. \& Lee, W. In vivo measurement of lung volumes in mice. Physiological genomics 4, 215-221 (2001).

57. Brewer, K.K., Sakai, H., Alencar, A.M., Majumdar, A., Arold, S.P., Lutchen, K.R., Ingenito, E.P. \& Suki, B. Lung and alveolar wall elastic and hysteretic behavior in 
rats: effects of in vivo elastase treatment. Journal of applied physiology 95, 19261936 (2003).

58. Lundblad, L.K., Thompson-Figueroa, J., Leclair, T., Sullivan, M.J., Poynter, M.E., Irvin, C.G. \& Bates, J.H. Tumor necrosis factor-alpha overexpression in lung disease: a single cause behind a complex phenotype. American journal of respiratory and critical care medicine 171, 1363-1370 (2005).

59. Faffe, D.S., D'Alessandro, E.S., Xisto, D.G., Antunes, M.A., Romero, P.V., Negri, E.M., Rodrigues, N.R., Capelozzi, V.L., Zin, W.A. \& Rocco, P.R. Mouse strain dependence of lung tissue mechanics: role of specific extracellular matrix composition. Respiratory physiology \& neurobiology 152, 186-196 (2006).

60. Cooper, C.B. Assessment of pulmonary function in COPD. Seminars in respiratory and critical care medicine 26, 246-252 (2005).

61. Barnas, G.M., Delaney, P.A., Gheorghiu, I., Mandava, S., Russell, R.G., Kahn, R. \& Mackenzie, C.F. Respiratory impedances and acinar gas transfer in a canine model for emphysema. Journal of applied physiology 83, 179-188 (1997).

62. Boyd, R.L., Fisher, M.J. \& Jaeger, M.J. Non-invasive lung function tests in rats with progressive papain-induced emphysema. Respiration physiology 40, 181-190 (1980).

63. Brusselle, G.G., Bracke, K.R., Maes, T., D'Hulst A, I., Moerloose, K.B., Joos, G.F. \& Pauwels, R.A. Murine models of COPD. Pulmonary pharmacology \& therapeutics 19, 155-165 (2006).

64. Martin, E.L., Truscott, E.A., Bailey, T.C., Leco, K.J., McCaig, L.A., Lewis, J.F. \& Veldhuizen, R.A. Lung mechanics in the TIMP3 null mouse and its response to mechanical ventilation. Experimental lung research 33, 99-113 (2007).

65. Clark, K.D., Wardrobe-Wong, N., Elliott, J.J., Gill, P.T., Tait, N.P. \& Snashall, P.D. Patterns of lung disease in a "normal" smoking population: are emphysema and airflow obstruction found together? Chest 120, 743-747 (2001).

66. Petty, T.L., Silvers, G.W. \& Stanford, R.E. Mild emphysema is associated with reduced elastic recoil and increased lung size but not with air-flow limitation. The American review of respiratory disease 136, 867-871 (1987).

67. Vulterini, S., Bianco, M.R., Pellicciotti, L. \& Sidoti, A.M. Lung mechanics in subjects showing increased residual volume without bronchial obstruction. Thorax 35, 461-466 (1980).

68. Zamel, N., Hogg, J. \& Gelb, A. Mechanisms of maximal expiratory flow limitation in clinically unsuspected emphysema and obstruction of the peripheral airways. The American review of respiratory disease 113, 337-345 (1976).

69. Jacob, R.E., Carson, J.P., Gideon, K.M., Amidan, B.G., Smith, C.L. \& Lee, K.M. Comparison of two quantitative methods of discerning airspace enlargement in smoke-exposed mice. PloS one 4, e6670 (2009).

70. Imai, H., Kimura, A., Iguchi, S., Hori, Y., Masuda, S. \& Fujiwara, H. Noninvasive detection of pulmonary tissue destruction in a mouse model of emphysema using hyperpolarized 129Xe MRS under spontaneous respiration. Magnetic resonance in medicine: official journal of the Society of Magnetic Resonance in Medicine / Society of Magnetic Resonance in Medicine 64, 929-938 (2010).

71. Seifart, C., Muyal, J.P., Plagens, A., Yildirim, A.O., Kohse, K., Grau, V., Sandu, S., Reinke, C., Tschernig, T., Vogelmeier, C. \& Fehrenbach, H. All-trans retinoic acid 
results in irregular repair of septa and fails to inhibit proinflammatory macrophages. The European respiratory journal 38, 425-439 (2011).

72. Groner, G.F. Medical dictation: a new generation. Journal of AHIMA / American Health Information Management Association 70, 20-21 (1999).

73. Harris, A., Sinitsina, I., Messmer, K.,. Qunatitative analysis of orthogonal polarization spectral images: validation in the hamster dorsal skinfold chamber. in Orthogonal Polarization Spectral Imaging (ed. Messmer, K.) 21-31 (Karger, Basel, 2000).

74. Langer, S., von Dobschuetz, E., Harris, A., Krombach, F., Messmer, K., . Validation of the orthogonal polarization spectral imaging technique on solid organs. in Orthogonal Polarization Spectral Imaging (ed. Messmer, K.) 36-42 (Karger, Basel, 2000).

75. Laemmel, E.R.T., Sinitsina, I., Boczkowski, J., . Using orthogonal polarization spectral imaging for the experimental study of microcirculation: comparisons with intravital microscopy. in Orhogonal polarization spectral imaging. (ed. Messmer, K.) 50-60 ( Karger, Basel, 2000).

76. Mitzner, W., Fallica, J. \& Bishai, J. Anisotropic nature of mouse lung parenchyma. Annals of biomedical engineering 36, 2111-2120 (2008).

77. Collie, D.D., McLean, N., Sallenave, J.M., Baker, A., Blundell, R., Milne, E., Rhind, S. \& Woodall, C. Local lung responses following endobronchial elastase and lipopolysaccharide instillation in sheep. International journal of chronic obstructive pulmonary disease 1, 189-199 (2006).

78. Suki, B., Habib, R.H. \& Jackson, A.C. Wave propagation, input impedance, and wall mechanics of the calf trachea from 16 to $1,600 \mathrm{~Hz}$. Journal of applied physiology 75, 2755-2766 (1993).

79. Parameswaran, H., Majumdar, A. \& Suki, B. Linking microscopic spatial patterns of tissue destruction in emphysema to macroscopic decline in stiffness using a 3D computational model. PLoS computational biology 7, e1001125 (2011).

80. Suki, B., Jesudason, R., Sato, S., Parameswaran, H., Araujo, A.D., Majumdar, A., Allen, P.G. \& Bartolak-Suki, E. Mechanical failure, stress redistribution, elastase activity and binding site availability on elastin during the progression of emphysema. Pulmonary pharmacology \& therapeutics 25, 268-275 (2012).

81. Mouded, M., Egea, E.E., Brown, M.J., Hanlon, S.M., Houghton, A.M., Tsai, L.W., Ingenito, E.P. \& Shapiro, S.D. Epithelial cell apoptosis causes acute lung injury masquerading as emphysema. American journal of respiratory cell and molecular biology 41, 407-414 (2009).

82. Allen, G.B., Suratt, B.T., Rinaldi, L., Petty, J.M. \& Bates, J.H. Choosing the frequency of deep inflation in mice: balancing recruitment against ventilator-induced lung injury. American journal of physiology. Lung cellular and molecular physiology 291, L710-717 (2006).

83. Wirtz, H.R. \& Dobbs, L.G. Calcium mobilization and exocytosis after one mechanical stretch of lung epithelial cells. Science 250, 1266-1269 (1990).

84. Namati, E., Thiesse, J., de Ryk, J. \& McLennan, G. Alveolar dynamics during respiration: are the pores of Kohn a pathway to recruitment? American journal of respiratory cell and molecular biology 38, 572-578 (2008). 
85. Qiu, Y., Zhu, J., Bandi, V., Atmar, R.L., Hattotuwa, K., Guntupalli, K.K. \& Jeffery, P.K. Biopsy neutrophilia, neutrophil chemokine and receptor gene expression in severe exacerbations of chronic obstructive pulmonary disease. American journal of respiratory and critical care medicine 168, 968-975 (2003).

86. West, J.B. Invited review: pulmonary capillary stress failure. Journal of applied physiology 89, 2483-2489; discussion 2497 (2000).

87. Cantor, J.O. \& Nadkarni, P.P. Hyaluronan: the Jekyll and Hyde molecule. Inflammation \& allergy drug targets 5, 257-260 (2006).

88. Tanabe, N., Muro, S., Hirai, T., Oguma, T., Terada, K., Marumo, S., Kinose, D., Ogawa, E., Hoshino, Y.\& Mishima, M. Impact of exacerbations on emphysema progression in chronic obstructive pulmonary disease. American journal of respiratory and critical care medicine 183, 1653-1659 (2011).

89. Jesudason, R., Sato, S., Parameswaran, H., Araujo, A.D., Majumdar, A., Allen, P.G., Bartolak-Suki, E. \& Suki, B. Mechanical forces regulate elastase activity and binding site availability in lung elastin. Biophysical journal 99, 3076-3083 (2010).

90. Hurst, J.R., Vestbo, J., Anzueto, A., Locantore, N., Mullerova, H., Tal-Singer, R., Miller, B., Lomas, D.A., Agusti, A., Macnee, W., Calverley, P., Rennard, S., Wouters, E.F., Wedzicha, J.A. \& Evaluation of, C.L.t.I.P.S.E.I. Susceptibility to exacerbation in chronic obstructive pulmonary disease. The New England journal of medicine 363, 1128-1138 (2010). 
I. Z. Hantos, Á. Adamicza, T. Jánosi, M.V. Szabari, J. Tolnai and B. Suki: Lung volumes and respiratory mechanics in elastase-induced emphysema in mice. Journal of Applied Physiology, 105: 1864-1872 (2008) 
Z. Hantos, Á. Adamicza, T. Z. Jánosi, M. V. Szabari, J. Tolnai and B. Suki

J Appl Physiol 105:1864-1872, 2008. First published Oct 9, 2008; doi:10.1152/japplphysiol.90924.2008

You might find this additional information useful...

This article cites 49 articles, 31 of which you can access free at:

http://jap.physiology.org/cgi/content/full/105/6/1864\#BIBL

This article has been cited by 1 other HighWire hosted article:

Noninvasive and Invasive Pulmonary Function in Mouse Models of Obstructive and

Restrictive Respiratory Diseases

J. A. J. Vanoirbeek, M. Rinaldi, V. De Vooght, S. Haenen, S. Bobic, G. Gayan-Ramirez, P. H.

M. Hoet, E. Verbeken, M. Decramer, B. Nemery and W. Janssens

Am. J. Respir. Cell Mol. Biol., January 1, 2010; 42 (1): 96-104.

[Abstract] [Full Text] [PDF]

Updated information and services including high-resolution figures, can be found at:

http://jap.physiology.org/cgi/content/full/105/6/1864

Additional material and information about Journal of Applied Physiology can be found at: http://www.the-aps.org/publications/jappl

This information is current as of June 4, 2010 .

Journal of Applied Physiology publishes original papers that deal with diverse areas of research in applied physiology, especially those papers emphasizing adaptive and integrative mechanisms. It is published 12 times a year (monthly) by the American

Physiological Society, 9650 Rockville Pike, Bethesda MD 20814-3991. Copyright (C) 2005 by the American Physiological Society.

ISSN: 8750-7587, ESSN: 1522-1601. Visit our website at http://www.the-aps.org/. 


\title{
Lung volumes and respiratory mechanics in elastase-induced emphysema in mice
}

\author{
Z. Hantos, ${ }^{1,4}$ Á. Adamicza, ${ }^{2}$ T. Z. Jánosi, ${ }^{1}$ M. V. Szabari, ${ }^{1}$ J. Tolnai, ${ }^{1}$ and B. Suki ${ }^{3}$ \\ ${ }^{1}$ Department of Medical Informatics and Engineering, ${ }^{2}$ Institute of Surgical Research, University of Szeged, Szeged, Hungary; \\ ${ }^{3}$ Department of Biomedical Engineering, Boston University, Boston, Massachussetts; and ${ }^{4}$ Telethon Institute for Child Health \\ Research and Centre for Child Health Research, University of Western Australia, Perth, Australia
}

Submitted 17 July 2008; accepted in final form 6 October 2008

\begin{abstract}
Hantos Z, Adamicza Á, Jánosi TZ, Szabari MV, Tolnai J, Suki B. Lung volumes and respiratory mechanics in elastase-induced emphysema in mice. J Appl Physiol 105: 1864-1872, 2008. First published October 9, 2008; doi:10.1152/japplphysiol.90924.2008.-Absolute lung volumes such as functional residual capacity, residual volume (RV), and total lung capacity (TLC) are used to characterize emphysema in patients, whereas in animal models of emphysema, the mechanical parameters are invariably obtained as a function of transrespiratory pressure (Prs). The aim of the present study was to establish a link between the mechanical parameters including tissue elastance $(\mathrm{H})$ and airway resistance (Raw), and thoracic gas volume (TGV) in addition to Prs in a mouse model of emphysema. Using low-frequency forced oscillations during slow deep inflation, we tracked $\mathrm{H}$ and Raw as functions of TGV and Prs in normal mice and mice treated with porcine pancreatic elastase. The presence of emphysema was confirmed by morphometric analysis of histological slices. The treatment resulted in an increase in TGV by 51 and $44 \%$ and a decrease in $\mathrm{H}$ by 57 and $27 \%$, respectively, at 0 and $20 \mathrm{cmH}_{2} \mathrm{O}$ of Prs. The Raw did not differ between the groups at any value of Prs, but it was significantly higher in the treated mice at comparable TGV values. In further groups of mice, tracheal sounds were recorded during inflations from RV to TLC. All lung volumes but RV were significantly elevated in the treated mice, whereas the numbers and size distributions of inspiratory crackles were not different, suggesting that the airways were not affected by the elastase treatment. These findings emphasize the importance of absolute lung volumes and indicate that tissue destruction was not associated with airway dysfunction in this mouse model of emphysema.
\end{abstract}

elastance; airway resistance; pressure-volume curve; airway reopening; crackle sound

EMPHYSEMA IS CLINICALLY CHARACTERIZED by loss of elastic recoil and significant hyperexpansion of the lungs due to a permanent destruction of the parenchymal tissue structure (35). Although a variety of mechanisms including protease-antiprotease imbalance (27), inflammation (23), abnormal extracellular matrix remodeling (46), and mechanical forces (44) have been proposed to be involved in its pathogenesis, the progressive nature of emphysema is still poorly understood (3).

The assessment and evaluation of emphysema raise several questions related to both the functional and structural aspects of the disease. Specifically, the physiological characterization of emphysema requires the measurement of pulmonary or respiratory mechanics $(18,39)$. In clinical studies, absolute lung volumes such as residual volume (RV), functional residual capacity, or total lung capacity (TLC), as well as their ratios

Address for reprint requests and other correspondence: Z. Hantos, Dept. of Medical Informatics, Univ. of Szeged, Korányi fasor 9, H-6720 Szeged, Hungary (e-mail: hantos@dmi.u-szeged.hu). are used to characterize the emphysematous changes $(14,47$, 49). To gain insight into the pathogenesis and progression of the human disease, various small animal models of emphysema have been developed $(11,25,32,41,45)$. However, in animal experiments, the mechanical parameters are most often represented in terms of their dependence on transpulmonary $\left(\mathrm{P}_{\mathrm{L}}\right)$ or transrespiratory pressure (Prs) or positive end-expiratory pressure (PEEP) (25). This is particularly true for the mouse, the most preferred experimental animal because of the availability of genetic manipulations (12), in which the assessment of changes in absolute lung volume is technically demanding due to the small lung size and is therefore rarely reported. Thus it remains unclear how the physiological findings including the mechanical properties of the lung expressed in terms of $\mathrm{P}_{\mathrm{L}}$ or Prs in the various mouse models of emphysema are related to the clinically observable pathophysiological changes in lung volumes and the associated alterations in respiratory resistance and elastance in patients.

The purpose of this study was to establish a link between the mechanical properties of the respiratory system and absolute lung volumes in mice treated with porcine pancreatic elastase (PPE). To this end, we used a previously developed technique to track the elastic and resistive parameters of the respiratory system during slow inspiratory-expiratory maneuvers (19) while recording the changes in lung volume. Our findings suggest that presentation of parameters in terms of absolute lung volumes differ substantially from that in terms of transrespiratory pressures.

\section{METHODS}

Animal preparation. Female CBA/Ca mice were anesthetized with an intraperitoneal injection of pentobarbital sodium $(75 \mathrm{mg} / \mathrm{kg})$ and intubated with a 20 -mm-long, 0.8-mm inner diameter polyethylene cannula under the guidance of a cold light source (model FLQ85E, Helmuth Hund, Wetzlar, Germany), according to the technique described in detail by others $(8,17)$. The elastase-treated animals received PPE (Sigma-Aldrich Hungary, Budapest, Hungary) in $50 \mu \mathrm{l}$ of saline in one of two doses: $0.3 \mathrm{IU}(n=15)$ and $0.6 \mathrm{IU}(n=4)$ via intratracheal instillation. The control animals $(n=19)$ received $50 \mu \mathrm{l}$ of saline only. Three weeks thereafter, the mice were anesthetized with an intraperitoneal injection of pentobarbital sodium $(75 \mathrm{mg} / \mathrm{kg})$, tracheotomized, and cannulated with a $0.8-\mathrm{mm}$ inner diameter polyethylene tube. The animals were placed in a custom-built $160-\mathrm{ml}$ body plethysmograph in the supine position and ventilated transmurally with a small-animal respirator (Harvard Apparatus, South Natick, MA) at a rate of $160 \mathrm{~min}^{-1}$, tidal volume of $0.25 \mathrm{ml}$, and a positive

The costs of publication of this article were defrayed in part by the payment of page charges. The article must therefore be hereby marked "advertisement" in accordance with 18 U.S.C. Section 1734 solely to indicate this fact. 
end-expiratory pressure of $2 \mathrm{cmH}_{2} \mathrm{O}$. Supplemental doses of pentobarbital sodium $(15 \mathrm{mg} / \mathrm{kg})$ were administered as needed, generally at the beginning of the measurements. The study protocol was approved by the Institutional Animal Care and Use Committees of the University of Szeged and Boston University.

Measurement of lung volumes. Thoracic gas volume (TGV) at end expiration at zero transrespiratory pressure (TGV0) was measured with the plethysmographic technique (13), modified recently for the measurement of thoracic gas volume in anesthetized mice that have weak or no respiratory effort (28). Briefly, 2-3 s after the respirator was stopped, the tracheal cannula was occluded and the intercostal muscles were stimulated via a pair of electrodes arranged diagonally between the upper and lower chest regions, with single impulses of $8-12 \mathrm{~V}$ in amplitude and $0.1 \mathrm{~ms}$ in duration (model S44, Grass Instruments, Quincy, MA), repeated five to six times in a 10-s recording interval. Figure 1 shows the measurement setup. Plethysmograph pressure $\left(\mathrm{P}_{\text {box }}\right)$ and tracheal pressure $(\mathrm{Ptr})$ were measured with miniature pressure transducers (model 8507C-2, Endevco, San Juan Capistrano, CA). TGV0 was estimated from the $\mathrm{P}_{\text {box }}$ vs. Ptr relationship on the basis of Boyle's principle, as described previously in detail (28). Following the measurement of TGV0, in 14 control animals (group C1) and 14 elastase-treated mice (group E1) the tracheal cannula was connected to a loudspeaker via a $100-\mathrm{cm}$, $0.117-\mathrm{cm}$ inner diameter polyethylene tube (a wave tube; see below). After a 5-s pause at end expiration, $\mathrm{P}_{\mathrm{box}}$ was lowered approximately linearly by connecting the plethysmograph to a vacuum line until -20 $\mathrm{cmH}_{2} \mathrm{O}$ was reached, and then $\mathrm{P}_{\text {box }}$ was allowed to return quasiexponentially to $0 \mathrm{cmH}_{2} \mathrm{O}$ by opening the box to atmosphere through a resistor. The inflation and deflation phases lasted for $\sim 20$ and $\sim 25$ $\mathrm{s}$, respectively. Inlet and outlet lateral pressures of the wave tube $\left(\mathrm{P}_{1}\right.$

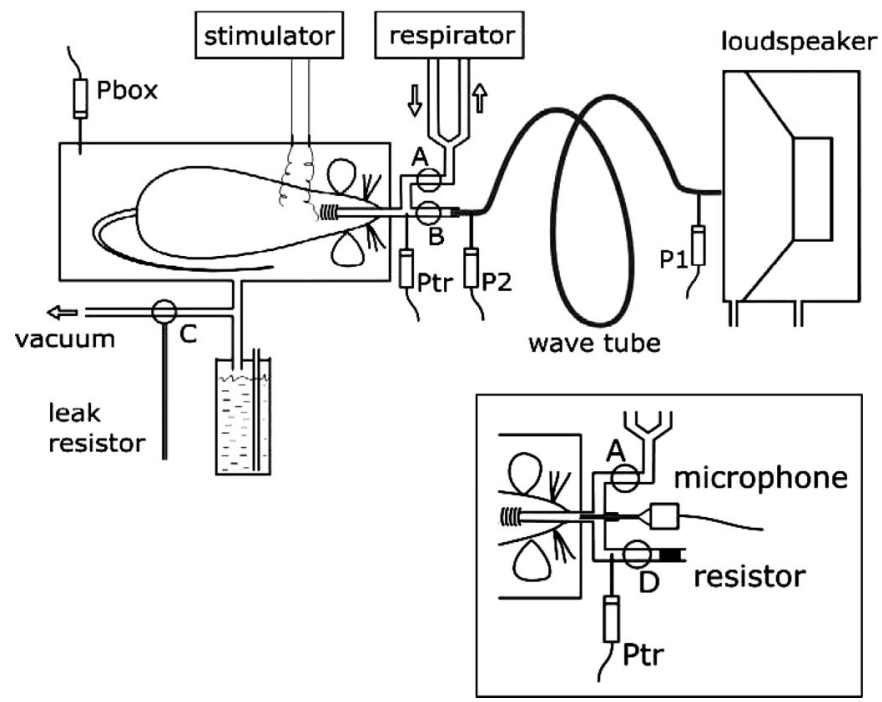

Fig. 1. Schematic arrangement for the measurement of thoracic gas volume (TGV) and oscillatory mechanics. During the measurement of TGV with respiratory muscle stimulation, stoppers $A, B$, and $C$ were closed, and plethysmograph box pressure (Pbox) and tracheal pressure (Ptr) were recorded. The tracheal cannula was then connected via stopper $B$ and a wave tube to a loudspeaker box open to atmosphere, and inflation was started by opening stopper $C$ to a vacuum source; a water column limited $\mathrm{P}_{\text {box }}$ at -20 or -35 $\mathrm{cmH}_{2} \mathrm{O}$. During the subsequent deflation, the box was connected to atmosphere via stopper $C$ through a leak resistor. During inflation-deflation, the loudspeaker delivered an oscillatory signal via the wave tube whose inlet $\left(\mathrm{P}_{1}\right)$ and outlet lateral pressures $\left(\mathrm{P}_{2}\right)$ were recorded. Inset: modified arrangement for the recording of tracheal sounds during reinflation from residual volume $\left(\mathrm{P}_{\text {box }}=\right.$ $\left.20 \mathrm{cmH}_{2} \mathrm{O}\right)$ to total lung capacity $\left(\mathrm{P}_{\text {box }}=-35 \mathrm{cmH}_{2} \mathrm{O}\right)$ in the group $C 2$ and group E2 mice. With stopper A closed and stopper $B$ open, tracheal flow was measured as the pressure drop (Ptr) across a capillary bundle resistor while the microphone recorded the sound. and $\mathrm{P}_{2}$, respectively) were measured by another pair of Endevco transducers. Inflation volume $\mathrm{V}(t)$ was obtained by integration of flow $\left(\mathrm{V}^{\prime}\right)$ determined as $\mathrm{V}^{\prime}=\mathrm{P}_{2} / \mathrm{R}_{\mathrm{wt}}$, where $\mathrm{R}_{\mathrm{wt}}$ is the direct current resistance of the wave tube. TGV as a function of time was obtained as $\operatorname{TGV}(t)=\mathrm{TGV} 0+\mathrm{V}(t)$. Transrespiratory pressure (Prs) was calculated as $\mathrm{Ptr}-\mathrm{P}_{\text {box }}$.

In five control mice (group C2) and five mice treated with $0.3 \mathrm{IU}$ elastase (group E2), the measurement of TGV0 was followed by deflation to $\mathrm{RV}$, accomplished by elevating $\mathrm{P}_{\text {box }}$ to $20 \mathrm{cmH}_{2} \mathrm{O}$; subsequently, $\mathrm{P}_{\text {box }}$ was lowered to $-35 \mathrm{cmH}_{2} \mathrm{O}$ through the vacuum line in $\sim 30$ s to obtain an estimate of TLC. The box was then opened to atmosphere via a resistor to allow for a passive deflation. During this deflation-inflation-deflation maneuver, $\mathrm{V}^{\prime}$ was measured with a capillary bundle (resistance $=180 \mathrm{cmH}_{2} \mathrm{O} \cdot \mathrm{s} \cdot 1^{-1}$ ) and the Ptr transducer (Fig. 1, inset). Expiratory reserve volume (ERV) was determined by integration, and RV was obtained as TGV0 - ERV.

Measurement of respiratory impedance. The tracking estimation of the impedance of the total respiratory system $\left(\mathrm{Z}_{\mathrm{rs}}\right)$ during slow inflation-deflation maneuvers was performed in the group $C l$ and group E1 mice. The measurement of $\mathrm{Z}_{\mathrm{rs}}$ was similar to that described previously in detail (19), with the modification that a negative body surface pressure was applied (6) instead of the positive pressure inflation. Briefly, $\mathrm{Z}_{\mathrm{rs}}$ was measured as the load impedance of the wave tube by using a pseudorandom signal between 4 and $38 \mathrm{~Hz}$. Mean $\mathrm{Z}_{\mathrm{rs}}$ was computed for the first $5 \mathrm{~s}$ of oscillation before the inflation started (to estimate $Z_{\mathrm{rs}}$ at $\mathrm{TGV0}$ ) and for every successive 0.5 -s interval during the maneuver. Each $\mathrm{Z}_{\mathrm{rs}}$ spectrum was fitted by a model (20) containing a Newtonian resistance ascribed to the airways (Raw), an inertance (I), and a constant-phase tissue unit characterized by the coefficients of damping $(G)$ and elastance $(H)$. Hysteresivity $(\eta)$, the ratio of the dissipated and elastically stored energies in the tissue (16), was calculated as $\eta=\mathrm{G} / \mathrm{H}$. The resistance and the inertance of the tubing including the tracheal cannula were subtracted from Raw and I, respectively; since the inertance of this tubing was the major component of I, the remaining values are considered physiologically unimportant and are not reported.

The slow inflation-deflation maneuvers, together with the preceding measurements of TGV0, were repeated three times in each animal to establish a standard volume history and to ascertain that the Prs-V loops and the $Z_{\mathrm{rs}}$ spectra as a function of lung volume were reproducible. The $\mathrm{Z}_{\mathrm{rs}}$ parameters did not exhibit different volume dependences during inflation and deflation; hence, for clarity, the tracking results are presented only for inflation.

Crackle sound recordings. For the measurements in the $C 2$ and $E 2$ groups, the setup was modified so that a microphone ending in a 15-mm-long, 0.7-mm outer diameter metal tube was connected to the tracheal tube adaptor of the plethysmograph (Fig. 1, inset). Tracheal sound was recorded at a sampling rate of $44 \mathrm{kHz}$ and a 16-bit resolution and preprocessed with a GoldWave sound editor (version 5.12, GoldWave, St. John's NFLD, Canada). High-pass filtering at 2 $\mathrm{kHz}$ was used to eliminate the cardiac noise. Subsequently, a short 0.5 -ms time window was set up and moved along the sound recording. An individual crackle event was identified if the sound energy in a window increased above a threshold that was chosen to eliminate most of the background noise. The crackle energy was represented by its cumulative distribution defined as the sum of energy up to a given inflation pressure normalized by the total energy, whereas the crackle amplitudes were characterized with their probability density distribution. The details of sound recording and processing are described in Ref. 37.

Lung morphometry. At the end of the measurements, the mice were killed with an overdose of pentobarbital sodium, and the heart and the lungs were removed en bloc. The collapsed lungs were then slowly inflated via the tracheal cannula by injecting $1 \mathrm{ml}$ of low melt agarose warmed to $45^{\circ} \mathrm{C}$ at a concentration of $4 \%$. Successful fixation was accomplished in four elastase-treated and five control mice. Epifluorescence microscopy was employed to study alveolar morphometry in 
two to three slices in each lung. Following thresholding, the alveolar or terminal airspace cross-sectional areas $(A)$ were measured using image-processing software (INVIVO, Pictron, Budapest, Hungary), and an equivalent alveolar diameter $(D)$ was calculated as $D=$ $(4 A / \pi)^{1 / 2}$. From the values of $A$, an area-weighted mean equivalent diameter $\left(D_{2}\right)$ was also calculated. The number of $D$ values obtained in individual animals was not sufficient to compute a complete diameter distribution. Since, by visual inspection, the characteristics of the alveolar structure were similar in the treated animals, we pooled the diameters and constructed single-diameter distribution for both the control and treated mice. The equivalent diameter is useful in that it is not sensitive to shape and it can better characterize the alveolar structure than other morphological indexes in the presence of structural heterogeneity (34).

Statistical analysis. The differences in mechanical parameters between the control and elastase-treated animals were compared using repeated-measures ANOVA tests. The variability of alveolar diameters was compared using $F$ test.

\section{RESULTS}

Morphometric evaluation of the lung slices (Fig. 2) revealed a significant enlargement of the alveolar airspace sizes in the elastase-treated animals: the equivalent diameter $D$ increased from $46.5 \pm 13.8 \mu \mathrm{m}$ in the control mice to $70.3 \pm 34.2 \mu \mathrm{m}$ in the treated mice $(P<0.001)$. Additionally, the variance of the alveolar diameters was also statistically significantly higher in the treated mice $(P<0.001)$. There was a significant increase in the mean area-weighted diameter $D_{2}$ from 55 to 107 $\mu \mathrm{m}(P<0.01)$. In both groups, the distribution of the diameters was significantly different from a normal distribution $(P<0.001)$. The distribution of diameters was skewed in both groups; however, in the treated mice, the distribution exhibited a significantly longer tail reaching values above $200 \mu \mathrm{m}$ (Fig. 3).

Elastase treatment resulted in marked and statistically highly significant changes in lung volumes: compared with control, TGV0 and TGV at Prs of $20 \mathrm{cmH}_{2} \mathrm{O}$ (TGV20) increased by 52 and $45 \%$, respectively (Table 1). There was no difference between the group E1 mice treated with the 0.3 and 0.6 IU doses of elastase in any of the morphometric indexes or mechanical parameters except $\eta$ at TGV20 (0.170 \pm 0.007 vs. $0.157 \pm 0.004 ; P<0.01)$. Therefore, both the mechanical and morphometric parameters from the two groups were pooled. The average TGV vs. Prs curves also reflected the changes due to the elastase treatment (Fig. 4), with the mean values of TGV significantly different $(P<0.001)$ between the groups at all Prs levels. The ratios of TGV between the groups at the same
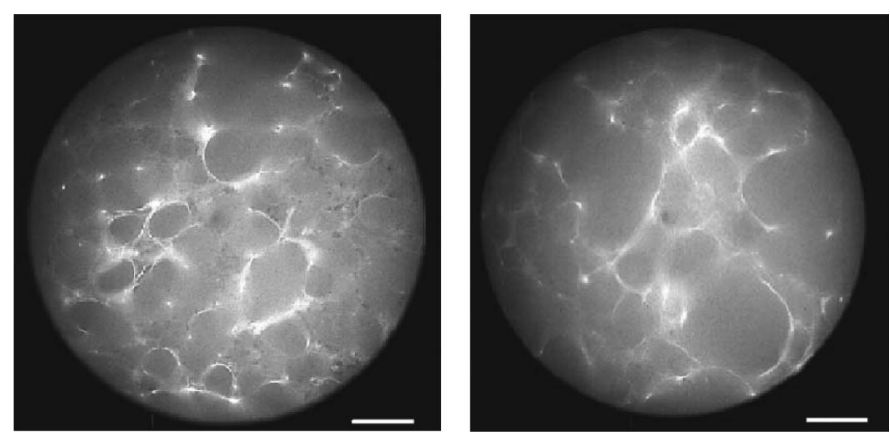

Fig. 2. Epifluorescence microscopy pictures of agarose-fixed lung slices. Left: control lung. Right: elastase-treated lung. Bar $=50 \mu \mathrm{m}$.

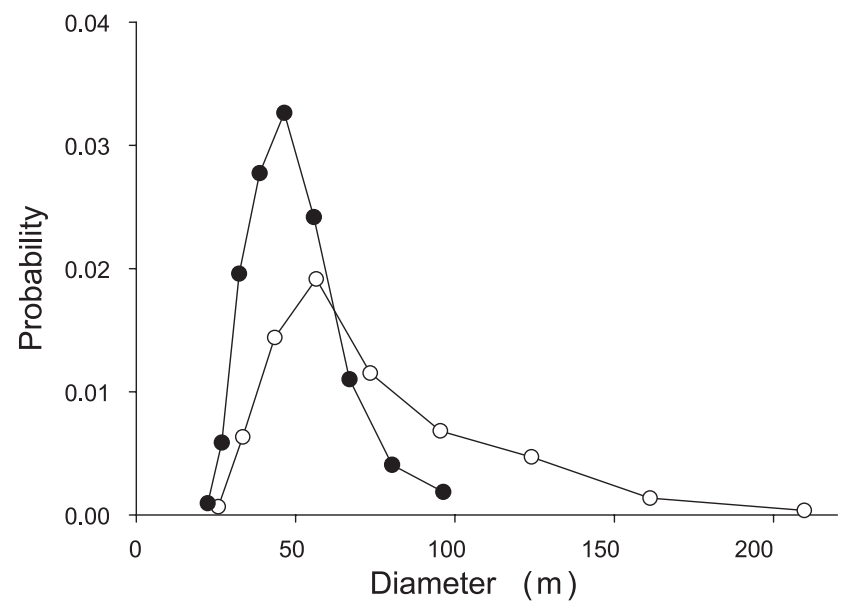

Fig. 3. Probability distribution of equivalent alveolar or terminal airspace diameters in subpopulations of control $(\bullet)$ and elastase-treated mice $(O)$.

Prs were fairly constant (between 1.44 and 1.60 for inspiration and between 1.43 and 1.52 for expiration), suggesting a nearly proportional increase of $\mathrm{TGV}$ at all Prs, i.e., an unchanged shape of the PV loops. Inspiratory volume (TGV20 - TGV0) increased by $37 \%$ in the treated animals, which was also accompanied by a $27 \%$ decrease in chord elastance between 0 and $20 \mathrm{cmH}_{2} \mathrm{O}$.

The mechanical parameters obtained from the small-amplitude forced oscillatory measurements of the elastase-treated mice exhibited similarly marked changes: compared with control, the decreases in $\mathrm{H}$ were 57 and $27 \%$, respectively, at Prs values of 0 and $20 \mathrm{cmH}_{2} \mathrm{O}$ (Table 1). The values of $\eta$ were also altered by the elastase treatment, with increases more marked at 0 $\mathrm{cmH}_{2} \mathrm{O}(55 \%)$ than at $20 \mathrm{cmH}_{2} \mathrm{O}(12 \%)$. By contrast, small and statistically insignificant decreases were observed in Raw at both $0 \mathrm{cmH}_{2} \mathrm{O}(-2 \%)$ and $20 \mathrm{cmH}_{2} \mathrm{O}(-10 \%)$. Since in the inflation-deflation maneuver the pressure protocol was standardized, the group mean values of these parameters were calculated as functions of both Prs and TGV.

Figure 5, $A$ and $B$, display the dependences of $\mathrm{H}$ on Prs and TGV, respectively. The differences in $\mathrm{H}$ between group El and group $C 1$ animals in the low and high Prs range were in accord with the mean values of $\mathrm{H}$ at 0 and $20 \mathrm{cmH}_{2} \mathrm{O}$ (see Table 1), whereas this difference disappeared in the pressure range between 9 and $13 \mathrm{cmH}_{2} \mathrm{O}$ (Fig. 5A). When plotted as a function of TGV (Fig. $5 B$ ), the values of $\mathrm{H}$ corresponding to the control and treated animals were completely separated. The mean $\mathrm{H}$ at comparable TGV was significantly lower in the treated animals, which suggests that the dynamic elastance in the treated mice reached values similar to those of the control animals at about twice as high absolute lung volumes.

The mean Raw data did not differ between the groups at any value of Prs (Fig. 6A). However, the Raw curves as a function of TGV were remarkably different from those expressed in terms of Prs (Fig. 6B). Elastase treatment resulted in a rightward shift of the mean Raw vs. TGV relationship and, consequently, in statistically significantly higher Raw values at comparable lung volumes (Fig. 6B).

The vital capacity (VC) maneuvers performed in the group $C 2$ and group E2 animals also revealed marked differences in all lung volumes but RV; a typical example is shown in Fig. $7 A$. The increase in TGV0 in the treated mice 
Table 1. Thoracic gas volumes and oscillatory mechanical parameters

\begin{tabular}{|c|c|c|c|c|c|c|c|c|c|}
\hline Group & Weight, $\mathrm{g}$ & TGV0, ml & TGV20, ml & $\mathrm{HO}, \mathrm{cmH}_{2} \mathrm{O} / \mathrm{ml}$ & $\mathrm{H} 20, \mathrm{cmH}_{2} \mathrm{O} / \mathrm{ml}$ & $\eta 0$ & $\eta 20$ & Raw0, $\mathrm{cmH}_{2} \mathrm{O} \cdot \mathrm{s} \cdot \mathrm{ml}^{-1}$ & Raw $20, \mathrm{cmH}_{2} \mathrm{O} \cdot \mathrm{s} \cdot \mathrm{ml}^{-1}$ \\
\hline E1 & $29 \pm 3$ & $0.47 \pm 0.10$ & $1.10 \pm 0.18$ & $22 \pm 7$ & $94 \pm 12$ & $0.38 \pm 0.07$ & $0.17 \pm 0.01$ & $0.45 \pm 0.18$ & $0.11 \pm 0.02$ \\
\hline$P$ value & NS & $<0.001$ & $<0.001$ & $<0.001$ & $<0.001$ & $<0.001$ & $<0.001$ & NS & NS \\
\hline
\end{tabular}

Values are means $\pm \mathrm{SD}$. Thoracic gas volumes $(\mathrm{TGV})$ and oscillatory mechanical parameters are at transrespiratory pressures of $0 \mathrm{cmH}_{2} \mathrm{O}(\mathrm{suffix} 0)$ and 20 $\mathrm{cmH}_{2} \mathrm{O}$ (suffix 20) in the control (group $\mathrm{Cl} ; n=14$ ) and the elastase-treated (group E1; $n=14$ ) mice. $\mathrm{H}$, elastance coefficient; $\eta$, hysteresivity; Raw, airway resistance; NS, statistically not significant.

(51\%) was the same as that in the group E1 mice, and similar elevations (41 and 52\%) were observed in TLC and $\mathrm{VC}$, respectively (Table 2). Interestingly, the pressure at the bottom knee of the TGV-Prs curve decreased on average by 5.5 $\mathrm{cmH}_{2} \mathrm{O}$ in the treated animals $(P<0.001)$. The number of crackles detected during inflation from RV to TLC was $\sim 150$ and did not differ between the group $C 2$ and group $E 2$ mice (Table 2). The cumulative distributions of crackle energy in the $C 2$ and E2 groups are compared in Fig. $7 B$ as a function of Prs. In group $C 2$, the cumulative energy rises steeply from 0 to above $95 \%$ within a narrow range of Prs values between 2.5 and $\sim 5 \mathrm{cmH}_{2} \mathrm{O}$. In contrast, the cumulative energy in the E2 group rises almost immediately at the start of inflation but reaches $95 \%$ only by a Prs of $\sim 9 \mathrm{cmH}_{2} \mathrm{O}$. Despite the grossly different rates of crackle energy release during inflation, the probability distribution (П) of crackle amplitudes was very similar in the two groups (Fig. 8). Since both distributions followed a linear decrease on a log-log graph, $\Pi$ can be described by a power law as $\Pi \sim \mathrm{s}^{-\alpha}$, where $\mathrm{s}$ is the crackle amplitude and $\alpha$ is the exponent of the distribution. Furthermore, $\alpha$ had identical values, close to 2 with a small standard deviation, in the two groups of mice (Fig. 8).

\section{DISCUSSION}

The primary purpose of this study was to characterize the mechanical properties of the respiratory system in a mouse model of emphysema in terms of Prs and TGV. To achieve this goal, we used a standard elastase treatment protocol and confirmed the presence of emphysema in the treated mice using morphometric analysis of the alveolar structure at a fixed time point, $3 \mathrm{wk}$ following treatment. We also employed a plethys- mographic method to determine TGV in mice (28) in combination with a forced oscillation technique that is able to separately estimate the airway and tissue mechanical parameters during slow lung inflation and deflation (19). The main findings of the study are that 1 ) both the mean and variance of alveolar diameters significantly increased in the treated mice, which resulted in increases in TGV similar to those seen in FRC and TLC in patients with emphysema; 2) dynamic elastance of the lung as a function of Prs was significantly lower in the treated mice except in a narrow range of Prs corresponding to lung volumes approximately halfway between FRC and TLC; 3) when expressed in terms of absolute lung volume, dynamic elastance was markedly lower in the treated mice; and 4) airway resistance (Raw) was significantly higher in the treated group at comparable lung volumes, but the differences disappeared when Raw was plotted as a function of Prs. Furthermore, measurements made in two additional groups of mice revealed that 5) the elastase treatment did not lead to any increase in RV, and the statistics of crackle properties that are related to airway reopening do not substantiate any change in bronchial patency.

Methodological issues. Several methodological issues warrant discussion. First, the elastase treatment produces a quick injury-like pathophysiology including the deterioration of lung function and airspace enlargement, whereas human emphysema is usually associated with cigarette smoking with its full development often taking more than 5 years. In this respect, the elastase-induced emphysema does not model the human disease. On the other hand, rodents respond to cigarette smoke in a highly variable manner, and the pathophysiologal changes at best mimic mild COPD (48). For the specific purpose of

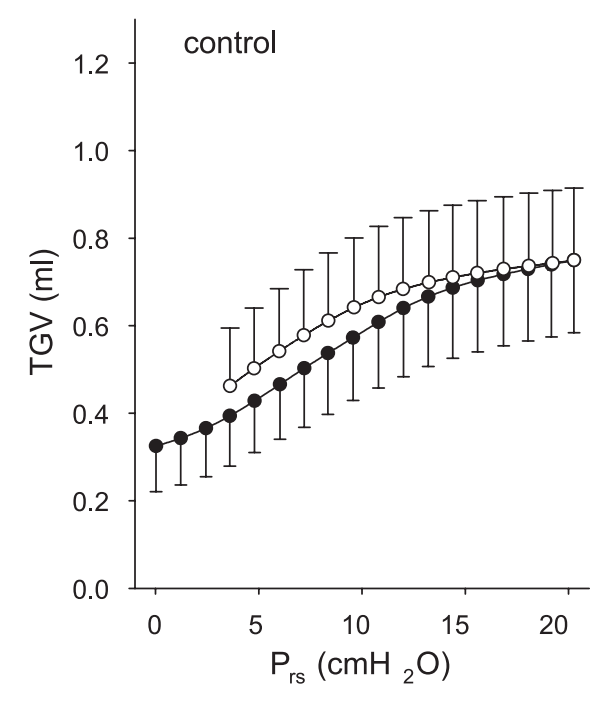

Fig. 4. Inflation (•) and deflation $(\bigcirc)$ curves of thoracic gas volume (TGV) vs. transrespiratory pressure (Prs) averaged for the control mice (group C1) and the elastase-treated animals (group E1). Bars indicate standard deviation. The ratio of TGV values of the elastase-treated mice to those in the controls, as a function of Prs, is also plotted (right and bottom). 
Fig. 5. A: elastance coefficient (H) vs. transrespiratory pressure (Prs) during slow inflation from Prs of $0-20 \mathrm{cmH}_{2} \mathrm{O}$. The values in each animal were averaged for successive 2.5$\mathrm{cmH}_{2} \mathrm{O}$ ranges of Prs. The mean values of $\mathrm{H}$ for the animals in the control (group C1) mice (•) and the elastase-treated (group E1) mice (O) are statistically significantly different $(P<0.05)$ at Prs of $<8 \mathrm{cmH}_{2} \mathrm{O}$ and Prs of $>14 \mathrm{cmH}_{2} \mathrm{O}$. Bars denote standard deviation. $B$ : $\mathrm{H}$ vs. thoracic gas volume (TGV). The values of $\mathrm{H}$ are statistically significantly different between the two groups at all ranges of $\operatorname{Prs}(P<0.05)$.
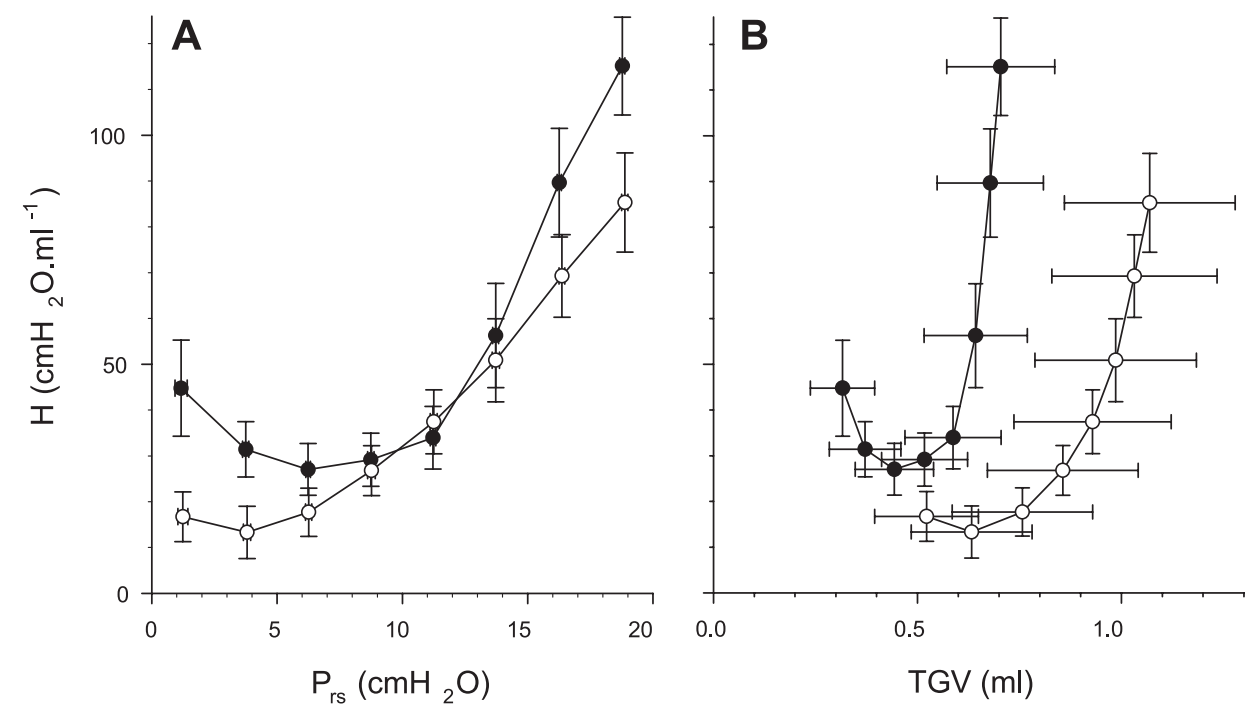

comparing lung physiology as expressed in terms of absolute lung volume or transrespiratory pressure, the widely used elastase treatment targeting the tissue compartment is appropriate. Second, it has been reported that there exists a second "knee" in the pressure-volume curve of mice beyond 20 $\mathrm{cmH}_{2} \mathrm{O}$ (42). To avoid the rapid changes in mechanical properties of such a second knee, the tracking maneuvers were limited to a maximum inflation pressure of $20 \mathrm{cmH}_{2} \mathrm{O}$. We note, however, that the inflation curves initiated from RV (groups $C 2$ and E2) followed a single sigmoidal and were reproducible, and hence we defined TLC as the value of TGV reached at Prs $=35 \mathrm{cmH}_{2} \mathrm{O}$, while acknowledging the problems of the definition of TLC in mice (42). Another issue is related to the measurement of the quasi-static and dynamic properties of the total respiratory system. The contribution of the chest wall to the total respiratory elastance is small in mice, which implies a negligible impact on the pressure-volume curve (30) and a $<10 \%$ share in the dynamic elastance $\mathrm{H}(25$, 40). Therefore, any change in $\mathrm{H}$ following elastase treatment must be proportional to alterations in lung tissue properties. We should also note that, although the parameter Raw estimated from the model fitting to the $\mathrm{Z}_{\mathrm{rs}}$ data represents not only airway resistance but all frequency-independent (Newtonian) viscous losses in the respiratory system, the contribution of the chest wall to the Newtonian resistance was shown to be negligible at any lung volume in mice (40).

Parenchymal structural changes. It has recently been shown that the trapped gas volume in excised lungs from a variety of animal models of emphysema correlated with morphometric evaluation of the alveolar structure (29). In the present study, the larger absolute gas volumes in the treated animals were also associated with a significant increase in the equivalent diameters (D) of the airspaces. It is interesting to note that, in response to elastase treatment, the mean D increased by $51 \%$, which is close to the $45 \%$ increase in TGV20. Furthermore, the equivalent diameters were not normally distributed (Fig. 3), and the treatment resulted in a significant stretch of the tail of the diameter distribution from $\sim 100$ to $200 \mu \mathrm{m}$. As a consequence, the standard deviation of the equivalent diameters nearly tripled, whereas the mean area-weighted diameter $\mathrm{D}_{2}$ doubled following treatment. Since both the variance and $\mathrm{D}_{2}$ are sensitive to heterogeneities (34), these results imply that the elastase treatment significantly increased the structural hetero-
Fig. 6. A: airway resistance (Raw) vs. transrespiratory pressure (Prs) during slow inflation from Prs of $0-20 \mathrm{cmH}_{2} \mathrm{O}$. The values in each animal were averaged for successive 2.5$\mathrm{cmH}_{2} \mathrm{O}$ ranges of Prs. No statistically significant difference was found between the mean values of Raw for the control (group C1) mice $(\bullet)$ and the elastase-treated (group E1) mice (O) in any range of Prs. Bars denote standard deviation. $B$ : raw vs. thoracic gas volume (TGV). The values of Raw are statistically significantly different between the two groups for all TGV $(P<0.05)$.
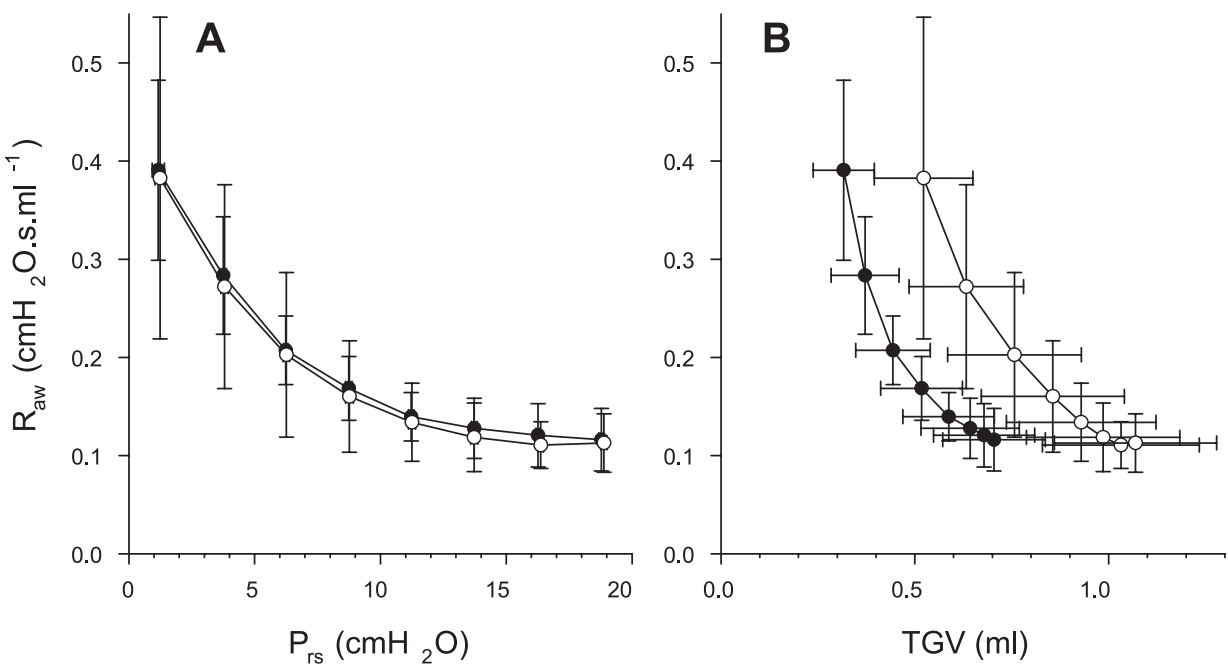

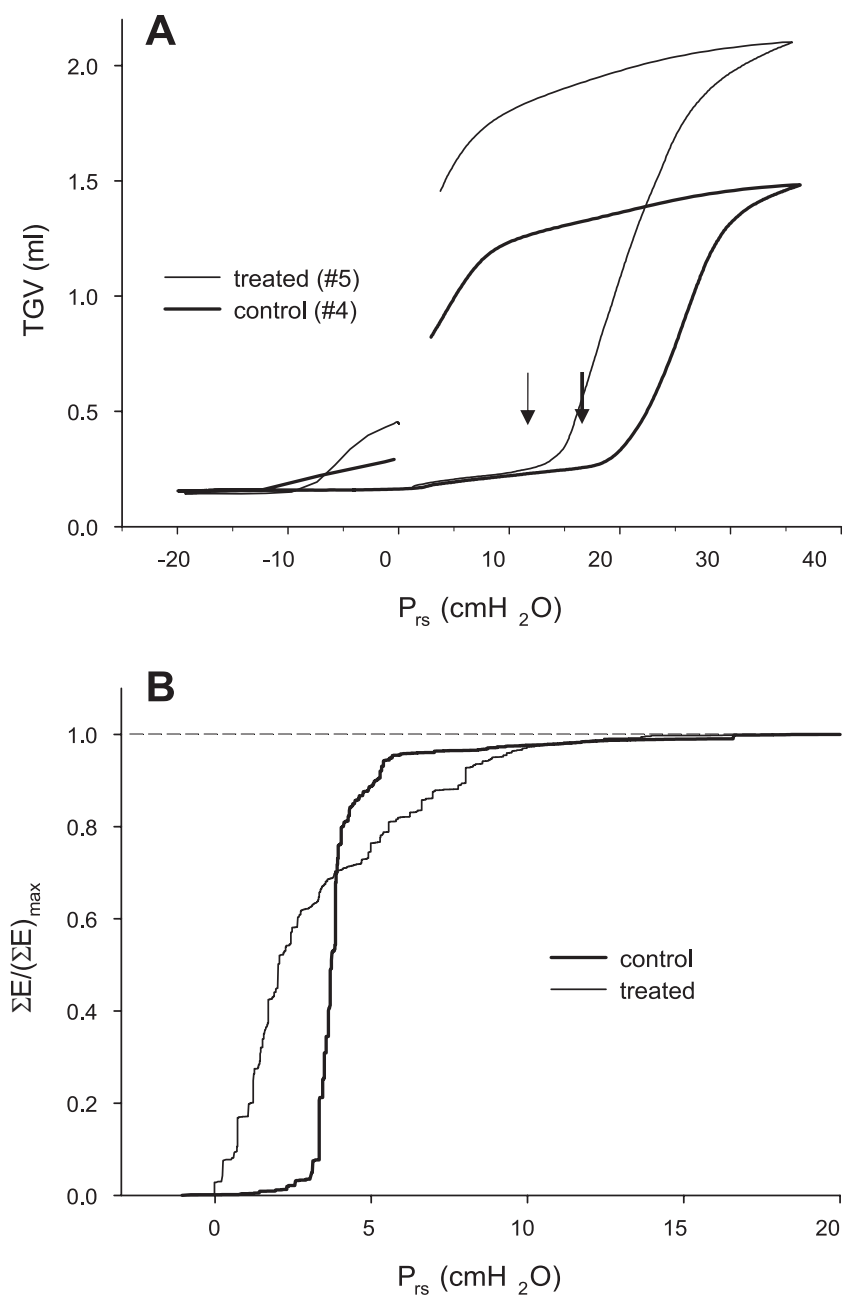

Fig. 7. A: thoracic gas volume (TGV) vs. transrespiratory pressure (Prs) curves recorded during vital capacity maneuvers in a control (group C2) and an elastase-treated (group E2) mouse. Arrows indicate the bottom knees of the inflation curve. $B$ : cumulated crackle sound energy $\Sigma E$ normalized by its maximum value $(\Sigma E)_{\max }$ in the control and the treated mice. Pooled data are in both groups.

geneity of the parenchyma. The increased heterogeneity is also supported by the fact that the coefficient of variation of diameters increased from $30 \%$ in control to $49 \%$ in the treated mice.

The increase in heterogeneity is consistent with the possibility that the enzymatically weakened alveolar walls rupture under the influence of mechanical forces (44). The presence of elastase in the interstitium not only leads to digestion of the elastin of the connective tissue, but it also triggers complex cellular repair processes (46). Such repair is likely abnormal

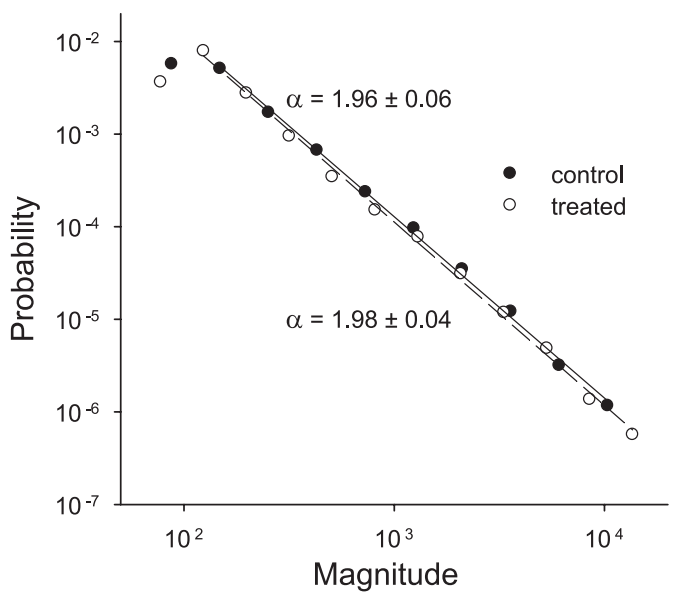

Fig. 8. Log-log plots of the probability distributions of crackle amplitude (in arbitrary units) recorded during inflations from residual volume to total lung capacity in the control (group C2) and the elastase-treated (group E2) mice. Pooled data are from three to five inflation maneuvers in each mouse. The regression lines cover the data range included in the regression.

(46), and the corresponding extracellular assembly of collagen results in mechanically weak collagen fibers in the alveolar walls. At points of stress concentration, the weak collagen and the alveolar wall break. Following rupture, the stress is redistributed in the neighborhood, and, consequently, the nearby intact regions start to experience new stress concentration (39). This ongoing process necessarily leads to an increase in structural heterogeneity as well as a progressive decrease in lung recoil. The latter in turn results in a larger TGV at the same Prs in the treated mice (Fig. 4).

Dynamic tissue properties. Although $\mathrm{H}$ decreased significantly in the treated mice both at low and high Prs (Table 1), the initial decrease in $\mathrm{H}$ with increasing Prs and the reversal toward higher Prs values remained a characteristic feature of the $\mathrm{H}$ vs. Prs relationship following the elastase treatment (Fig. $5 A$ ). However, the initial decrease reverses at a lower Prs in the elastase-treated mice, and this is in accordance with the results of a study on mice spontaneously developing emphysema (tight skin mice) and their controls, in which lung elastance was measured as a function of PEEP (24). The elevation in $\mathrm{H}$ at high Prs is likely due to the stretching of the respiratory tissues and recruiting collagen in the lung parenchyma $(19,40)$, whereas the mechanisms behind the initial decrease in $\mathrm{H}$ are less clear: they may include alveolar recruitment, reorganization of the tissue matrix and the surfactant layer $(19,25,40)$, or chest wall mechanics (22). Whatever the mechanism, the biphasic pattern of the $\mathrm{H}$ vs. Prs is also seen as a function of TGV and is not altered by the elastase treatment (Fig. $5 B$ );

Table 2. End-expiratory thoracic gas volume, residual volume, vital capacity, and total lung capacity

\begin{tabular}{|c|c|c|c|c|c|c|c|}
\hline$E 2$ & $33 \pm 2$ & $0.49 \pm 0.08$ & $0.15 \pm 0.03$ & $1.95 \pm 0.18$ & $2.10 \pm 0.19$ & $15.9 \pm 1.3$ & $166 \pm 72$ \\
\hline
\end{tabular}

Values are means \pm SD. End-expiratory thoracic gas volume (TGV0), residual volume (RV), vital capacity (VC), total lung capacity (TLC) corresponding to the transrespiratory pressure of $35 \mathrm{cmH}_{2} \mathrm{O}$, pressure at the bottom knee of the thoracic gas volume vs. transrespiratory pressure curve ( $\left.\mathrm{P}_{\mathrm{knee}}\right)$, and the number of crackles during an inflation maneuver $\left(\mathrm{N}_{\mathrm{cr}} / \mathrm{infl}\right)$ in the control ( group $\left.C 2 ; n=5\right)$ and the elastase-treated mice $($ group E2;n $=5$ ). 
nevertheless, when $\mathrm{H}$ is plotted against TGV, the separation between the two groups becomes more apparent.

Tissue hysteresivity was also markedly affected by the elastase treatment. The $55 \%$ increase in $\eta$ at end-expiration is in accord with several previous studies $(7,25,31)$. Brewer et al. (7) argued that the increased $\eta$ is a result of remodeling of the alveolar walls. At higher lung volume, the difference between the values of $\eta$ of the two groups, both exhibiting a significant fall from the values obtained at end-expiration, was drastically reduced to $12 \%$. The decrease in $\eta$ with increasing lung volume has been attributed to the increasing contribution of collagen to tissue resistance $(15,40)$. Additionally, Ito et al. (26) reported that, following elastase treatment of mice, respiratory elastance decreased despite a nearly $50 \%$ increase in the total collagen content of the lung, implying an abnormality in collagen function. Together with the increase in tissue heterogeneity discussed above, the abnormal collagen function might also have contributed to the overall increase in $\eta$ in the treated mice (Table 1).

Airway resistance and structure. Several studies using animal models of emphysema have pointed out that the tissue destruction manifested in elevations in TGV and decreases in elastance are not associated with increased airway or pulmonary resistance $(2,4,5,9,33)$, and some observations on human emphysema also indicate that airspace enlargement and airflow limitation do not necessarily combine $(10,38,47)$. In this context, the changes following elastase treatment observed in the present study may characterize an initial or mild degree of emphysema where the loss of alveolar attachments, which must have accompanied the marked increase in both alveolar size and lung volumes, is compensated by new elastic equilibria within the lung parenchyma itself as well as between the lung and chest wall so that the patency of the airways is retained. Therefore, we paid particular attention to the possible alterations in airway function and established that the average Raw vs. Prs relationships of the control and treated groups were remarkably similar (Fig. 6A). Another indicator of the intact airway function was the lack of any increase in airway collapsibility during forced expiration to $\mathrm{RV}$, the only lung volume that, quite unexpectedly, did not change in this emphysema model. Furthermore, the size distribution of crackle amplitudes was identical in the $C 2$ and $E 2$ groups (Fig. 8). Since the power law nature of the crackle amplitude distribution is dominated by the attenuation factors at bifurcations (and not by the opening pressures), which in turn are determined by airway cross-sectional areas (1), we conclude that once the airways opened, the diameters along various pathways must have been similar in the two groups as a function of Prs. Finally, there was no difference in airway closure during the $\mathrm{RV}$ maneuver between the control and treated animals according to the analysis of reinflation crackles, which has been shown to be a sensitive indicator of airway collapse at varying levels of transpulmonary pressure and bronchoconstrictor dose (37). On the other hand, it should be pointed out that, at the same absolute lung volume, the Raw of the emphysematous mice were higher, a fact also established in clinical cases of emphysema and COPD (49). This is a consequence of the fact that, at the same lung volume, transpulmonary pressure in the treated mice is much less, and this, due to the loss of elastic tethering, leads to a higher Raw (Fig. 6A). These findings, together with the different pressure- and volume-dependent be- havior of dynamic elastance highlight the importance of measuring TGV and comparing the mechanical parameters at similar absolute lung volumes.

Quasi-static pressure-volume curves. The structural changes due to the elastase treatment are reflected in the increases in lung volumes at all Prs values (Fig. 4). The elevations in the end-expiratory and end-inspiratory volumes in the treated mice amounted to $\sim 50$ and $\sim 40 \%$, respectively, reflecting an upward stretching in the TGV vs. Prs diagrams with a negligible change in the shape of the TGV vs. Prs loops (Fig. 4). A remarkable finding is the increase in the expiratory reserve volume in the group E2 mice, which corresponds to little or no change in RV. Since RV is most sensitive to small airway collapse, these results imply that the small airways, whose closure determines RV, were not influenced by elastase treatment. Interestingly, the lower knee of the pressure-volume curve (Fig. $7 A$ and Table 2) moved to a lower pressure, and the cumulative crackle energy started increasing at a much lower Prs in the treated mice (Fig. 7B). Both of these findings suggest that a significant fraction of the airways had a lower critical opening pressure in the treated animals. How is it then possible that, whereas RV and Raw at the same Prs are the same in the control and treated mice, the lower knee and the crackle energies are different between the two groups?

The lower knee of the inflation curve is associated with massive airway opening leading to alveolar recruitment (43), although the crackles that were detectable in our experiments may come from larger airways than those that determine RV (21). Thus, although the site of airway closure and the trapped air behind the small airways that determine RV are similar in the two groups, the relative locations of the knee in Fig. $7 \mathrm{~A}$ imply that some of these airways are easier to open up in the emphysematous group. In contrast, since a weakened parenchymal tethering, which characterizes the $E 2$ group, reduces the probability of reopening airways (36), one might expect that the opening pressures would actually be higher in the E2 group. In fact, by examining the cumulative distributions in Fig. $7 B$, both of these statements are true. Indeed, on the one hand, the difference in cumulative crackle energy does imply that some airways must be more difficult to open in the $E 2$ group since $95 \%$ of the total energy is reached only at Prs of 9 $\mathrm{cmH}_{2} \mathrm{O}$ compared with $\mathrm{Prs}$ of $\sim 5 \mathrm{cmH}_{2} \mathrm{O}$ in the $C 2$ group. On the other hand, there are crackles that are triggered at a much lower Prs in the E2 than in the $C 2$ group, indicating that some airways open very easily in the former. Although the reduced tethering in the $E 2$ group explains why some airways are more difficult to open in the $E 2$ group, we are unsure about the exact mechanism responsible for the reduction in airway opening pressures following treatment. Assuming that surface tension is not altered by the elastase treatment, we can speculate as follows. Computer simulations mimicking the breakdown of lung parenchyma have shown that, when the breakdown is governed by mechanical forces, a significant heterogeneity develops in the network (44). This leads to a wide distribution of mechanical forces around the damaged area, including elastic elements that carry significantly smaller as well as larger forces than before the breakdown (24). The higher forces would then generate locally an increased tethering and hence a reduced opening pressure. Nevertheless, the above uncertainties indicate that further 
investigations involving time course studies with a longer time period after the elastase treatment are warranted to further characterize the relevance of this murine model of emphysema to the human disease.

\section{GRANTS}

Supported by Hungarian Scientific Research Fund Grants T42971, T37810, and 67700, National Health and Medical Research Council of Australia no. 139024, National Science Foundation Grant BES-0402530, and National Heart, Lung, and Blood Institute Grant HL-059215.

\section{REFERENCES}

1. Alencar AM, Hantos Z, Petak F, Tolnai J, Asztalos T, Zapperi S, Andrade JS Jr, Buldyrev SV, Stanley HE, Suki B. Scaling behavior in crackle sound during lung inflation. Phys Rev E Stat Phys Plasmas Fluids Relat Interdiscip Topics 60: 4659-4663, 1999.

2. Barnas GM, Delaney PA, Gheorghiu I, Mandava S, Russell RG, Kahn R, Mackenzie CF. Respiratory impedances and acinar gas transfer in a canine model for emphysema. J Appl Physiol 83: 179-188, 1997.

3. Barnes PJ, Stockley RA. COPD: current therapeutic interventions and future approaches. Eur Respir J 25: 1084-1106, 2005.

4. Bellofiore S, Eidelman DH, Macklem PT, Martin JG. Effects of elastase-induced emphysema on airway responsiveness to methacholine in rats. J Appl Physiol 66: 606-612, 1989.

5. Boyd RL, Fisher MJ, Jaeger MJ. Non-invasive lung function tests in rats with progressive papain-induced emphysema. Respir Physiol 40: 181190, 1980.

6. Bozanich EM, Janosi T, Collins RA, Thamrin C, Turner DJ, Hantos Z, Sly PD. Methacholine responsiveness in mice from 2 to 8 weeks of age. J Appl Physiol 103: 542-546, 2007.

7. Brewer KK, Sakai H, Alencar AM, Majumdar A, Arold SP, Lutchen KR, Ingenito EP, Suki B. Lung and alveolar wall elastic and hysteretic behavior in rats: effects of in vivo elastase treatment. J Appl Physiol 95: 1926-1936, 2003.

8. Brown RH, Walters DM, Greenberg RS, Mitzner W. A method of endotracheal intubation and pulmonary functional assessment for repeated studies in mice. $J$ Appl Physiol 87: 2362-2365, 1999.

9. Brusselle GG, Bracke KR, Maes T, D'Hulst AI, Moerloose KB, Joos GF, Pauwels RA. Murine models of COPD. Pulm Pharmacol Ther 19: 155-165, 2006.

10. Clark KD, Wardrobe-Wong N, Elliott JJ, Gill PT, Tait NP, Snashall PD. Patterns of lung disease in a "normal" smoking population: are emphysema and airflow obstruction found together? Chest 120: 743-747, 2001.

11. D'Armiento J, Dalal SS, Okada Y, Berg RA, Chada K. Collagenase expression in the lungs of transgenic mice causes pulmonary emphysema. Cell 71: 955-961, 1992.

12. Drazen JM, Takebayashi T, Long NC, De Sanctis GT, Shore SA. Animal models of asthma and chronic bronchitis. Clin Exp Allergy 29, Suppl 2: 37-47, 1999.

13. DuBois AB, Botelho SY, Bedell GN, Marshall R, Comroe JH Jr. A rapid plethysmographic method for measuring thoracic gas volume: a comparison with a nitrogen washout method for measuring functional residual capacity in normal subjects. J Clin Invest 35: 322-326, 1956.

14. Dykstra BJ, Scanlon PD, Kester MM, Beck KC, Enright PL. Lung volumes in 4,774 patients with obstructive lung disease. Chest 115: $68-74,1999$.

15. Faffe DS, D'Alessandro ES, Xisto DG, Antunes MA, Romero PV, Negri EM, Rodrigues NR, Capelozzi VL, Zin WA, Rocco PR. Mouse strain dependence of lung tissue mechanics: role of specific extracellular matrix composition. Respir Physiol Neurobiol 152: 186-196, 2006.

16. Fredberg JJ, Stamenovic D. On the imperfect elasticity of lung tissue. J Appl Physiol 67: 2408-2419, 1989.

17. Glaab T, Mitzner W, Braun A, Ernst H, Korolewitz R, Hohlfeld JM, Krug N, Hoymann HG. Repetitive measurements of pulmonary mechanics to inhaled cholinergic challenge in spontaneously breathing mice. J Appl Physiol 97: 1104-1111, 2004.

18. Govaerts E, Demedts M, Van de Woestijne KP. Total respiratory impedance and early emphysema. Eur Respir J 6: 1181-1185, 1993.

19. Hantos Z, Collins RA, Turner DJ, Janosi TZ, Sly PD. Tracking of airway and tissue mechanics during TLC maneuvers in mice. $J$ Appl Physiol 95: 1695-1705, 2003.
20. Hantos Z, Daroczy B, Suki B, Nagy S, Fredberg JJ. Input impedance and peripheral inhomogeneity of dog lungs. J Appl Physiol 72: 168-178, 1992.

21. Hantos Z, Tolnai J, Asztalos T, Petak F, Adamicza A, Alencar AM, Majumdar A, Suki B. Acoustic evidence of airway opening during recruitment in excised dog lungs. J Appl Physiol 97: 592-598, 2004.

22. Hirai T, McKeown KA, Gomes RF, Bates JH. Effects of lung volume on lung and chest wall mechanics in rats. J Appl Physiol 86: 16-21, 1999.

23. Hogg JC. Pathophysiology of airflow limitation in chronic obstructive pulmonary disease. Lancet 364: 709-721, 2004.

24. Ito S, Bartolak-Suki E, Shipley JM, Parameswaran H, Majumdar A, Suki B. Early emphysema in the tight skin and pallid mice: roles of microfibril-associated glycoproteins, collagen, and mechanical forces. Am J Respir Cell Mol Biol 34: 688-694, 2006.

25. Ito S, Ingenito EP, Arold SP, Parameswaran H, Tgavalekos NT, Lutchen KR, Suki B. Tissue heterogeneity in the mouse lung: effects of elastase treatment. J Appl Physiol 97: 204-212, 2004.

26. Ito S, Ingenito EP, Brewer KK, Black LD, Parameswaran H, Lutchen KR, Suki B. Mechanics, nonlinearity, and failure strength of lung tissue in a mouse model of emphysema: possible role of collagen remodeling. J Appl Physiol 98: 503-511, 2005.

27. Janoff A. Elastase in tissue injury. Апnи Rev Med 36: 207-216, 1985.

28. Jánosi TZ, Adamicza Á, Zosky GR, Asztalos T, Sly PD, Hantos Z. Plethysmographic estimation of thoracic gas volume in apneic mice. J Appl Physiol 101: 454-459, 2006.

29. Jansson AH, Smailagic A, Andersson AM, Zackrisson C, Fehniger TE, Stevens TR, Wang X. Evaluation of excised lung gas volume measurements in animals with genetic or induced emphysema. Respir Physiol Neurobiol 150: 240-250, 2006.

30. Lai YL, Chou H. Respiratory mechanics and maximal expiratory flow in the anesthetized mouse. J Appl Physiol 88: 939-943, 2000.

31. Lundblad LK, Thompson-Figueroa J, Leclair T, Sullivan MJ, Poynter ME, Irvin CG, Bates JH. Tumor necrosis factor-alpha overexpression in lung disease: a single cause behind a complex phenotype. Am J Respir Crit Care Med 171: 1363-1370, 2005.

32. Mahadeva R, Shapiro SD. Chronic obstructive pulmonary disease * 3: experimental animal models of pulmonary emphysema. Thorax 57: $908-$ 914, 2002.

33. Martin EL, Truscott EA, Bailey TC, Leco KJ, McCaig LA, Lewis JF, Veldhuizen RA. Lung mechanics in the TIMP3 null mouse and its response to mechanical ventilation. Exp Lung Res 33: 99-113, 2007.

34. Parameswaran H, Majumdar A, Ito S, Alencar AM, Suki B. Quantitative characterization of airspace enlargement in emphysema. J Appl Physiol 100: 186-193, 2006.

35. Pauwels RA, Buist AS, Calverley PM, Jenkins CR, Hurd SS. Global strategy for the diagnosis, management, and prevention of chronic obstructive pulmonary disease. NHLBI/WHO Global Initiative for Chronic Obstructive Lung Disease (GOLD) Workshop summary. Am J Respir Crit Care Med 163: 1256-1276, 2001.

36. Perun ML, Gaver DP, 3rd. Interaction between airway lining fluid forces and parenchymal tethering during pulmonary airway reopening. $J$ Appl Physiol 79: 1717-1728, 1995.

37. Petak F, Habre W, Babik B, Tolnai J, Hantos Z. Crackle-sound recording to monitor airway closure and recruitment in ventilated pigs. Eur Respir J 27: 808-816, 2006.

38. Petty TL, Silvers GW, Stanford RE. Mild emphysema is associated with reduced elastic recoil and increased lung size but not with air-flow limitation. Am Rev Respir Dis 136: 867-871, 1987.

39. Rabe KF, Hurd S, Anzueto A, Barnes PJ, Buist SA, Calverley P, Fukuchi Y, Jenkins C, Rodriguez-Roisin R, van Weel C, Zielinski J. Global strategy for the diagnosis, management, and prevention of chronic obstructive pulmonary disease: GOLD executive summary. Am J Respir Crit Care Med 176: 532-555, 2007.

40. Sly PD, Collins RA, Thamrin C, Turner DJ, Hantos Z. Volume dependence of airway and tissue impedances in mice. J Appl Physiol 94: 1460-1466, 2003.

41. Snider GL, Lucey EC, Stone PJ. Animal models of emphysema. Am Rev Respir Dis 133: 149-169, 1986.

42. Soutiere SE, Mitzner W. On defining total lung capacity in the mouse. J Appl Physiol 96: 1658-1664, 2004.

43. Suki B, Andrade JS Jr, Coughlin MF, Stamenovic D, Stanley HE, Sujeer M, Zapperi S. Mathematical modeling of the first inflation of degassed lungs. Ann Biomed Eng 26: 608-617, 1998. 
44. Suki B, Lutchen KR, Ingenito EP. On the progressive nature of emphysema: roles of proteases, inflammation, and mechanical forces. Am J Respir Crit Care Med 168: 516-521, 2003.

45. Tuder RM, McGrath S, Neptune E. The pathobiological mechanisms of emphysema models: what do they have in common? Pulm Pharmacol Ther 16: 67-78, 2003.

46. Vlahovic G, Russell ML, Mercer RR, Crapo JD. Cellular and connective tissue changes in alveolar septal walls in emphysema. Am J Respir Crit Care Med 160: 2086-2092, 1999.
47. Vulterini S, Bianco MR, Pellicciotti L, Sidoti AM. Lung mechanics in subjects showing increased residual volume without bronchial obstruction. Thorax 35: 461-466, 1980.

48. Wright JL, Cosio M, Churg A. Animal models of chronic obstructive pulmonary disease. Am J Physiol Lung Cell Mol Physiol 295: L1-L15, 2008.

49. Zamel N, Hogg J, Gelb A. Mechanisms of maximal expiratory flow limitation in clinically unsuspected emphysema and obstruction of the peripheral airways. Am Rev Respir Dis 113: 337-345, 1976.

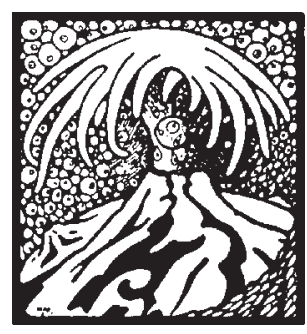


II. J. Tolnai, M.V. Szabari, G. Albu, B.A. Maár, H. Parameswaran, E. Bartolák-Suki, B. Suki and Z. Hantos: Functional and morphological assessment of early impairment of airway function in a rat model of emphysema. Journal of Applied Physiology, 112: 1932-1939 (2012) 


\title{
Functional and morphological assessment of early
} impairment of airway function in a rat model of emphysema

\author{
J. Tolnai, M. V. Szabari, G. Albu, B. A. Maár, H. Parameswaran, E. Bartolák-Suki, B.
} Suki and Z. Hantos

J Appl Physiol 112:1932-1939, 2012. First published 22 March 2012;

doi: 10.1152/japplphysiol.00587.2011

You might find this additional info useful...

This article cites 29 articles, 19 of which you can access for free at:

http://jap.physiology.org/content/112/11/1932.full\#ref-list-1

Updated information and services including high resolution figures, can be found at: http://jap.physiology.org/content/112/11/1932.full

Additional material and information about Journal of Applied Physiology can be found at: http://www.the-aps.org/publications/jappl

This information is current as of December 10, 2012. 


\title{
Functional and morphological assessment of early impairment of airway function in a rat model of emphysema
}

\author{
J. Tolnai, ${ }^{1,3}$ M. V. Szabari, ${ }^{1,2}$ G. Albu, ${ }^{1}$ B. A. Maár, ${ }^{1}$ H. Parameswaran, ${ }^{4}$ E. Bartolák-Suki, ${ }^{4}$ B. Suki, ${ }^{4}$ \\ and Z. Hantos ${ }^{1,2}$ \\ ${ }^{1}$ Department of Medical Physics and Informatics, ${ }^{2}$ Institute for Surgical Research, and ${ }^{3}$ Department of Pathology, University \\ of Szeged, Szeged, Hungary; and ${ }^{4}$ Department of Biomedical Engineering, Boston University, Boston, Massachusetts
}

Submitted 9 May 2011; accepted in final form 17 March 2012

Tolnai J, Szabari MV, Albu G, Maár BA, Parameswaran H, Bartolák-Suki E, Suki B, Hantos Z. Functional and morphological assessment of early impairment of airway function in a rat model of emphysema. J Appl Physiol 112: 1932-1939, 2012. First published March 22, 2012; doi:10.1152/japplphysiol.00587.2011.-The aim of this study was to evaluate airway structure-function relations in elastase-induced emphysema in rats. Sprague-Dawley rats were treated intratracheally with $50 \mathrm{IU}$ porcine pancreatic elastase (PPE, $n=8$ ) or saline (controls, $n=6$ ). Six weeks later, lung volumes [functional residual capacity (FRC), residual volume (RV), and total lung capacity (TLC)] and low-frequency impedance parameters (Newtonian resistance, $\mathrm{R}_{\mathrm{N}}$; tissue damping; tissue elastance, $\mathrm{H}$ ) were measured, and tracheal sounds were recorded during slow inflation to TLC following in vivo degassing. The lungs were fixed and stained for standard morphometry, elastin, and collagen. In the PPE group, FRC and RV were higher [4.53 $\pm 0.7(\mathrm{SD})$ vs. $3.28 \pm 0.45 \mathrm{ml} ; P=$ 0.003 and $1.06 \pm 0.35$ vs. $0.69 \pm 0.18 \mathrm{ml} ; P=0.036$, respectively], and $\mathrm{H}$ was smaller in the PPE-treated rats than in the controls $\left(1,344 \pm 216\right.$ vs. $\left.2,178 \pm 305 \mathrm{cmH}_{2} \mathrm{O} / 1 ; P<0.001\right)$, whereas there was no difference in $\mathrm{R}_{\mathrm{N}}$. The average number of crackles per inflation was similar in the two groups; however, the crackle size distributions were different and the lower knee of the pressure-volume curves was higher in the PPE group. Microscopic images revealed different alveolar size distributions but similar bronchial diameters in the two groups. The treatment caused a slight but significant decrease in the numbers of alveolar attachments, no difference in elastin and slightly increased mean level and heterogeneity of collagen in the bronchial walls. These results suggest that tissue destruction did not affect the conventionally assessed airway resistance in this emphysema model, whereas the alterations in the recruitment dynamics can be an early manifestation of impaired airway function.

respiratory mechanics; elastase; crackles; lung volumes; morphometry

EMPHYSEMA IS THOUGHT TO BE a disease of the parenchymal structure deep in the periphery of the lung (27). However, emphysema and chronic bronchitis, the two main components of chronic obstructive pulmonary disease (COPD), can also occur together (26). Animal models are commonly used to study the pathogenesis of COPD (29). While parenchymal destruction in emphysema is often investigated in animal models such as elastase treatment of rodents, less attention is paid to the possibility of airway involvement. One of the reasons is that in most studies, little or no change in airway function such as airway resistance (Raw) is observed. Indeed, Raw has been reported to be similar in normal and emphysematous mice $(10,13)$; baseline pulmonary resistance in Brown-

Address for reprint requests and other correspondence: Z. Hantos, Dept. of Medical Physics and Informatics, Univ. of Szeged, 9 Korányi fasor, H-6720 Szeged, Hungary (e-mail: hantos.zoltan@med.u-szeged.hu).
Norway rats returned to the control level after 3 wk of elastase treatment (2). This raises the question of the relevance of the elastase-treated rodent as a model of the human disease.

More recently, we reported measurements of Raw and tissue elastance $(\mathrm{H})$ as a function of both thoracic gas volume (TGV) and transrespiratory pressure (Ptr) in normal and elastasetreated mice (10). Interestingly, the results showed that Raw was different between the groups only when it was plotted as a function of TGV and this difference was attributed to the reduced elastic tethering in the treated mice. Indeed, several earlier studies reported a reduction in the number of alveolar attachments around small airways $(2,5,7,29)$. On the other hand, the mRNA levels of the two structurally most important components of the extracellular matrix, elastin and collagen, were upregulated in the airway wall within $6 \mathrm{~h}$ after elastase treatment of hamsters (17). If these events are manifested in remodeling, they likely alter airway wall stiffness and hence the balance between wall elasticity and tethering, which in turn could lead to a change in airway diameter and Raw.

The present study was undertaken to examine whether elastase treatment of rodents, the most common animal model of emphysema, induces pure parenchymal destruction or if it also involves airway abnormalities. To this end, rats were treated with porcine pancreatic elastase (PPE) and the functional changes were characterized by detailed assessment of airway and tissue mechanics using the forced oscillation technique. The pressure-volume (P-V) curve and crackle sound were also measured during inflation from the in vivo degassed state, which provide separate and additional information on parenchymal and airway mechanics. To evaluate the structural changes underlying the functional alterations, the morphological properties of the parenchyma including alveolar attachments around small airways were assessed and elastin as well as collagen in the septal and airway walls was visualized and quantified. Our results suggest that the PPE-induced severe alveolar destruction is accompanied by subtle remodeling of the airway wall with a potential change in airway function.

\section{METHODS}

Animal preparation. The study protocol was approved by the Institutional Animal Care and Use Committees of the University of Szeged and Boston University. The studies were performed in 14 male adult (10 wk old) Sprague-Dawley rats. The animals were anesthetized with a single intraperitoneal injection of chloral hydrate (350 $\mathrm{mg} / \mathrm{kg}$ ). Supplemental doses of anesthesia $(50 \mathrm{mg} / \mathrm{kg}$ ) were administered during the measurement as needed.

Rats were intubated with a polyethylene cannula (14-gauge, Braun, Melsungen, Germany) under illumination with a cold light source (model FLQ85E, Helmuth Hund, Wetzlar, Germany) as described in detail previously by Brown et al. (4). Eight animals were treated with 
intratracheal instillation of $50 \mathrm{IU}$ porcine pancreatic elastase (PPE, Affymetrix/USB, Cleveland, $\mathrm{OH}$ ) in $0.5 \mathrm{ml}$ saline, and six rats were given only saline.

Six weeks after the treatment, rats were reanesthetized as described before, tracheotomized, and cannulated with a 1.7$\mathrm{mm}$-ID polyethylene tube. The rats were placed in the supine position in a custom-built 2.8-liter body plethysmograph and mechanically ventilated with a small-animal respirator (Harvard Apparatus, South Natick, MA) at a rate of $80 \mathrm{~min}^{-1}$ and tidal volume of $8 \mathrm{ml} / \mathrm{kg}$. Following the measurements, the animals were killed with an overdose of anesthetics and the lungs were removed for histopathological evaluation.

There were no significant differences in body weight between the control (C) and the PPE groups either at the time of treatment (318 \pm 34 vs. $314 \pm 25 \mathrm{~g})$ or 6 wk thereafter $(468 \pm 52$ vs. $471 \pm 58 \mathrm{~g})$.

Measurement of lung volumes. Functional residual capacity (FRC) was measured with the body plethysmographic technique (6). Briefly, the respirator was stopped at end expiration and the breathing efforts against the occluded tracheal cannula were recorded for $6 \mathrm{~s}$. Box pressure $\left(\mathrm{P}_{\text {box }}\right)$ and tracheal pressure $\left(\mathrm{P}_{\text {tr }}\right)$ were measured with a Validyne MP-45 $\left( \pm 2 \mathrm{cmH}_{2} \mathrm{O}\right)$ pressure sensor (Validyne, Northridge, CA) and a miniature pressure transducer (model 8507C-2, Endevco, San Juan Capistrano, CA), respectively. FRC was estimated from the $\mathrm{P}_{\mathrm{box}}$ and $\mathrm{P}_{\mathrm{tr}}$ relationship on the basis of Boyle's principle and the thermal characteristics of the plethysmograph (15).
Inspiratory capacity (IC) and expiratory reserve volume (ERV), respectively, were defined as the volume changes accomplished by decreasing $\mathrm{P}_{\text {box }}$ to $-35 \mathrm{cmH}_{2} \mathrm{O}$ and increasing it to $20 \mathrm{cmH}_{2} \mathrm{O}$. The IC and ERV maneuvers were shorter than 35 and $15 \mathrm{~s}$, respectively. The volume changes were measured by means of the pressure drop through the wave tube (see below). Total lung capacity (TLC) and residual volume $(\mathrm{RV})$ were calculated as TLC $=$ FRC + IC and $\mathrm{RV}=\mathrm{FRC}-\mathrm{ERV}$.

Measurement of respiratory impedance. Low-frequency impedance of the total respiratory system $\left(\mathrm{Z}_{\mathrm{rs}}\right)$ was measured with the wave tube pseudorandom forced oscillation method $(12,28)$ between 0.5 and $16 \mathrm{~Hz}$ at FRC. $\mathrm{Z}_{\mathrm{rs}}$ was determined as the load impedance of a $100-\mathrm{cm}$ tube (ID $=2 \mathrm{~mm}$ ) during 6-s interruptions of mechanical ventilation.

Newtonian resistance $\left(\mathrm{R}_{\mathrm{N}}\right)$, tissue elastance $(\mathrm{H})$, tissue damping $(\mathrm{G})$, and inertance (I) were estimated by fitting the constant-phase model (11) to the average $Z_{\mathrm{rs}}$ data obtained from 5-6 successive recordings. Hysteresivity $(\eta)$, which is the ratio of the dissipative and elastic parameters of the tissue impedance (14) was calculated as $\eta=$ $\mathrm{G} / \mathrm{H}$. Contribution of the resistance and the inertance of the tubing including the tracheal cannula to $\mathrm{R}_{\mathrm{N}}$ and $\mathrm{I}$ were subtracted. The remaining values of I are considered physiologically unimportant in small animals and are not reported.

Crackle sound recordings. Intratracheal sounds were recorded during slow ( $\sim 20$-s) inflations from the degassed state of the lungs to
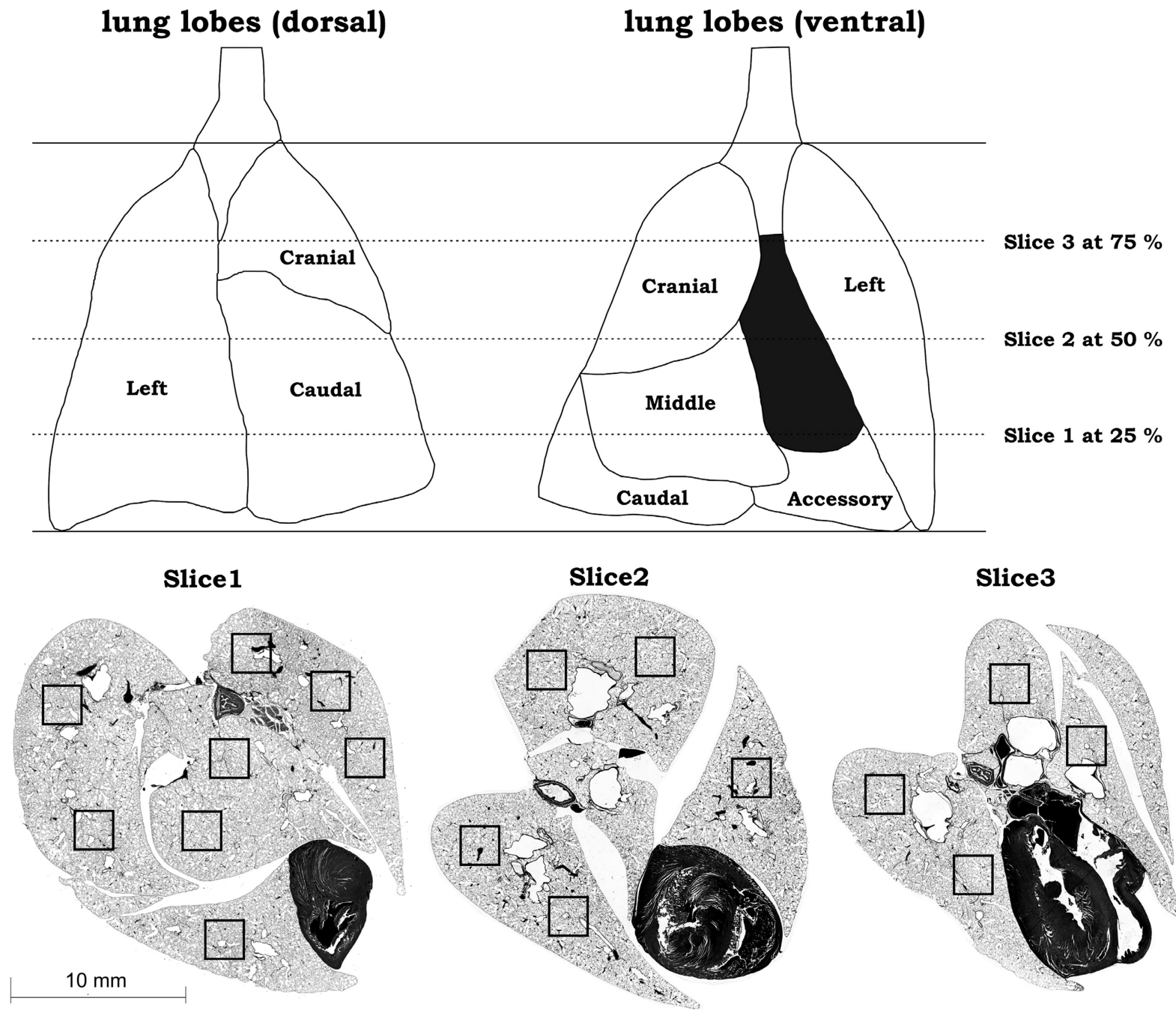

Fig. 1. Definition of lung slices for histological evaluation (top) and illustration of the areas in every slice used for alveolar and airway morphometry (bottom). 


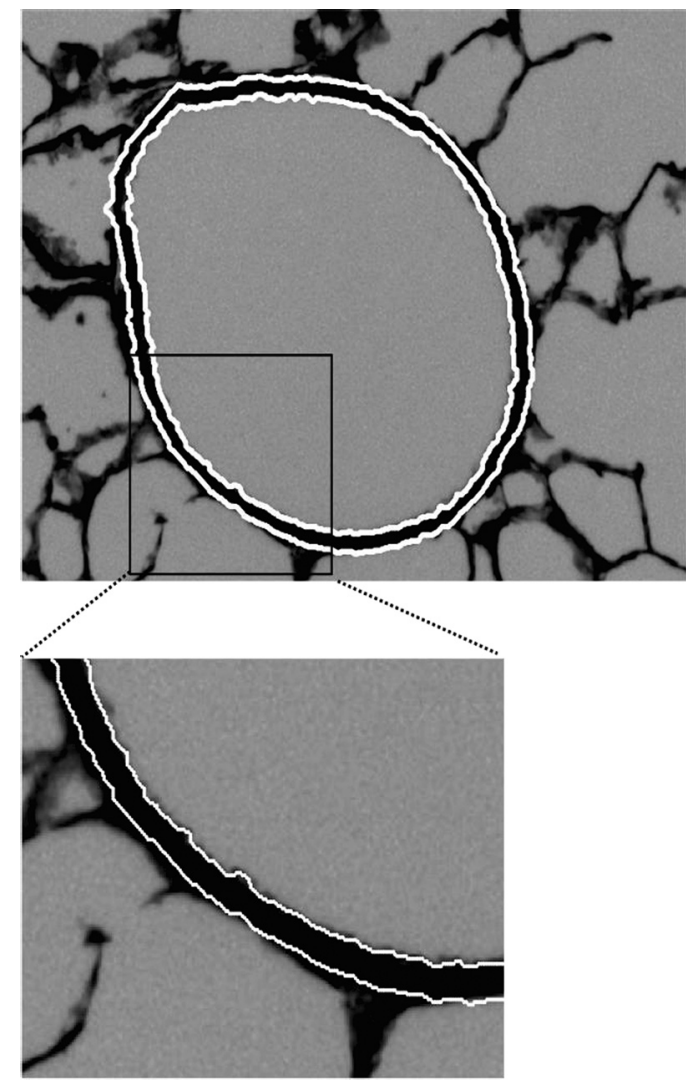

Fig. 2. Inner and outer boundary of the airway wall determined automatically for the calculation of elastin density.

TLC, similarly as described previously in mice (10). In short, degassing was accomplished with a 10-min ventilation with $100 \% \mathrm{O}_{2}$ and subsequent ERV maneuver followed by tracheal occlusion for $10 \mathrm{~s}$; the degassing-reinflation maneuver was repeated 2 more times in each animal. A 15-mm metal tube (0.7-mm OD) attached to the microphone was positioned in the tracheal cannula. Sound was recorded at a sampling rate of $44 \mathrm{kHz}$ with 16-bit resolution and was high-pass filtered at $2 \mathrm{kHz}$ to eliminate the cardiac noise. Individual crackle events were identified in 0.33 -ms time windows, if the sound energy in a window was higher than a threshold and increased with a given step compared with the previous window, as described previously in detail (22).

Morphometry. After the measurements, rats were euthanized with an overdose of anesthetics, and the heart and lungs were removed from the chest en bloc. The isolated lungs were then hung in an airtight glass box, and the tracheal cannula was led through the lid of the bottle and attached to a formaldehyde-filled container outside. Lungs were filled with $4 \%$ buffered formaldehyde via the tracheostomy tube from a height of $10 \mathrm{~cm}$ while maintaining a pressure of $-15 \mathrm{cmH}_{2} \mathrm{O}$ around the lungs. The trachea was then ligated at this fixation pressure $\left(25 \mathrm{cmH}_{2} \mathrm{O}\right)$, and the lungs were stored in formaldehyde for 7 days before embedding in paraffin. In each lung, three transversal sections of $4-\mu \mathrm{m}$ thickness were made at 25,50 , and $75 \%$ lung height for hematoxylin and eosin (H\&E) staining, and eight, five, and four areas, respectively, of 2,085 $\times 2,085 \mu \mathrm{m}$, were chosen in each section for morphometric assessment (Fig. 1). To minimize the bias in sampling, the selection of these areas was random except when an area fell on a major structure such as the heart. The digitized images were then segmented into individual airspaces using a previously published algorithm (20) and the area of each individual airspace was measured. Large airways, blood vessels, and alveolar ducts were manually excluded from the analysis. The equivalent diameter $\left(D_{\text {alv }}\right)$ of an airspace with area $A$ was then calculated as $\mathrm{D}_{\mathrm{alv}}=2 \sqrt{A / \pi}$. The whole sections were scanned for identification of bronchi suitable for further analyses with a circularity $>50 \%$. From the readings of bronchial perimeter $\left(\mathrm{P}_{\mathrm{b}}\right)$ the diameter of an equivalent circular cross-section $\left(D_{b}\right)$ was calculated. Mean wall thickness $\left(T_{w}\right)$ from 3-4 measurements at random locations along the perimeter and the number of septal attachments $\left(\mathrm{N}_{\mathrm{s}}\right)$ were manually determined for each airway. Septal attachment density was calculated as $\mathrm{N}_{\mathrm{s}} / \mathrm{P}_{\mathrm{b}}$.

Visualization and quantification of elastin and collagen. To visualize the elastin content in the airway wall, the established method of Verhoeff-Van Gieson staining for elastic fibers (adapted from IHC World; http://www.ihcworld.com/_protocols/special_stains/vvg.htm) was used with slight modifications. The omission of the counter Van Gieson staining provided blue color only of elastic fibers and was used for quantification. To visualize collagen, the Mason's trichrome was used. Quantitative analysis of elastin and collagen density was made on randomly selected lung sections using custom-made software. A total of 51 and 52 airways for elastin and 51 and 57 airways for collagen were examined quantitatively in the control and PPE groups, respectively. Once an airway was manually chosen, the algorithm determined the inner boundary of the airway and created an outer boundary by moving along the outward normal to the inner boundary by $9 \mu \mathrm{m}$. This procedure automatically defined a band inside the airway wall (Fig. 2). The thickness of $9 \mu \mathrm{m}$ was chosen so that the band was always inside the bronchial wall. The pixels within the band were then split into two colors, white and blue, with blue representing elastin or collagen. The mean and SD of the grayscale values for the pixels that were identified as blue were determined.

Statistical analysis. The differences in lung volumes and mechanical parameters between the control and elastase-treated rats were compared by using Student's $t$-test. All the results are expressed as means $\pm \mathrm{SD}$. Distributions were compared using the KolmogorovSmirnov test. Dependencies of $\mathrm{T}_{\mathrm{w}}$ on $\mathrm{D}_{\mathrm{b}}$ in the two groups were tested with the analysis of covariance. A $P$ value of less than 0.05 was considered significant.

\section{RESULTS}

Lung volumes. FRC and RV were statistically significantly higher in the PPE group compared with the controls (by 38\% and $53 \%$, respectively); however, the increase in TLC in the treated rats $(5 \%)$ was statistically not significant (Fig. 3).

Respiratory mechanics. Table 1 summarizes the respiratory mechanical parameters estimated from the impedance data. G

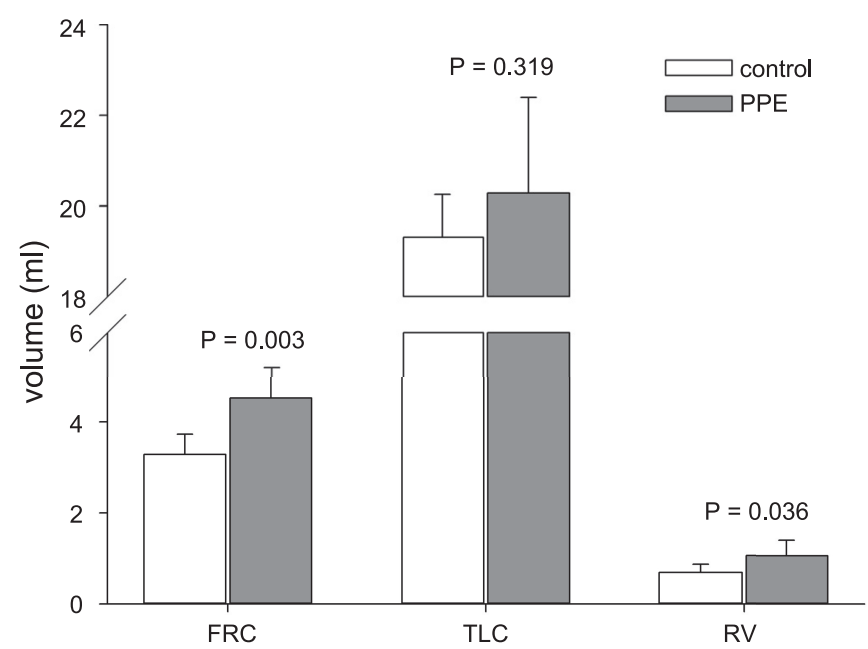

Fig. 3. Mean $\pm \mathrm{SD}$ values of lung volumes in the control and porcine pancreatic elastase (PPE)-treated groups. FRC, functional residual capacity; TLC, total lung capacity; RV, residual volume. 
Table 1. Mechanical parameters of the lungs in the control animals and those treated with porcine pancreatic elastase

\begin{tabular}{lcccc}
\hline \hline & $\mathrm{R}_{\mathrm{N}}, \mathrm{cmH} \mathrm{H}_{2} \mathrm{O} \cdot \mathrm{s} / \mathrm{l}$ & $\mathrm{G}, \mathrm{cmH}_{2} \mathrm{O} / \mathrm{l}$ & $\mathrm{H}, \mathrm{cmH}_{2} \mathrm{O} / 1$ & $\eta(=\mathrm{G} / \mathrm{H})$ \\
\hline $\mathrm{C}$ & $39 \pm 8.5$ & $653 \pm 99$ & $2,178 \pm 305$ & $0.30 \pm 0.01$ \\
$\mathrm{PPE}$ & $35.5 \pm 8.5$ & $496 \pm 66$ & $1,344 \pm 216$ & $0.37 \pm 0.04$ \\
$P$ & 0.451 & 0.004 & $<0.001$ & 0.002 \\
\hline
\end{tabular}

Values are means \pm SD. C, control animals; PPE, animals treated with porcine pancreatic elastase; $\mathrm{R}_{\mathrm{N}}$, Newtonian resistance; G, tissue damping; H, tissue elastance; $\eta$, hysteresivity; $\mathrm{F} \%$, average fitting error of the model; $P$, level of significance for differences between groups.

and $\mathrm{H}$, respectively, were statistically significantly smaller in the PPE-treated rats than in the controls (76 and 62\%). Because of the larger differences in $\mathrm{H}$, tissue hysteresivity $(\eta=\mathrm{G} / \mathrm{H})$ was elevated $(129 \%)$ in the treated rats. There was no difference in $R_{N}$ and the error of model fitting between the groups.

Crackles. The lower knee of the inflation P-V curves from the degassed state (as defined by the intercept of the lines fit to the P-V curve between 5 and 15 , and the maximum slope projected to the $\mathrm{P}$ axis) was shifted to higher pressures (19.3 \pm 1.0 vs. $\left.17.8 \pm 1.2 \mathrm{cmH}_{2} \mathrm{O} ; P=0.021\right)$ and the asymptotic volume level (TLC) was slightly larger in the PPE group than in the control rats (Fig. 4). The crackle numbers (N) per inflation were not different between the two groups $(1,152 \pm$ 593 vs. $1,203 \pm 538 ; P=0.778)$; however, their distributions expressed as relative frequencies $\left(\mathrm{N} / \mathrm{N}_{\text {total }}\right)$ were statistically significantly different $(P<0.001)$. In the control rats, $\mathrm{N}$ peaked at lower pressures $\left(\sim 10 \mathrm{cmH}_{2} \mathrm{O}\right)$ than in the PPE group $\left(\sim 17 \mathrm{cmH}_{2} \mathrm{O}\right)$, and exhibited another maximum at $\sim 25-30$ $\mathrm{cmH}_{2} \mathrm{O}$ (Fig. 5A). This latter fact suggests a bimodal distribution of the sounds of reopening, which is also expressed by the $\log \left(\mathrm{N} / \mathrm{N}_{\text {total }}\right)$ vs. volume $(\mathrm{V})$ graphs exhibiting a second peak at $\sim 19-23 \mathrm{ml}$ in the control group (Fig. 5B).

Alveolar and bronchial morphometry. Figure 6 compares the size distributions of $\mathrm{D}_{\text {alv }}$ pooled from all regions and animals in either group. The average number of alveoli evaluated in all regions of an animal was 8,091. In the PPE group, the distribution was shifted to higher $D_{\text {alv }}$ values and, according to the Mann-Whitney rank sum test, the median of $\mathrm{D}_{\text {alv }}$ was significantly higher in the treated group $(68.4$ vs. $61.8 \mu \mathrm{m} ; P<$ $0.001)$.

The number of bronchial cross-sections analyzed in each rat ranged between 40 and 50 . The distributions of $D_{b}$ were not

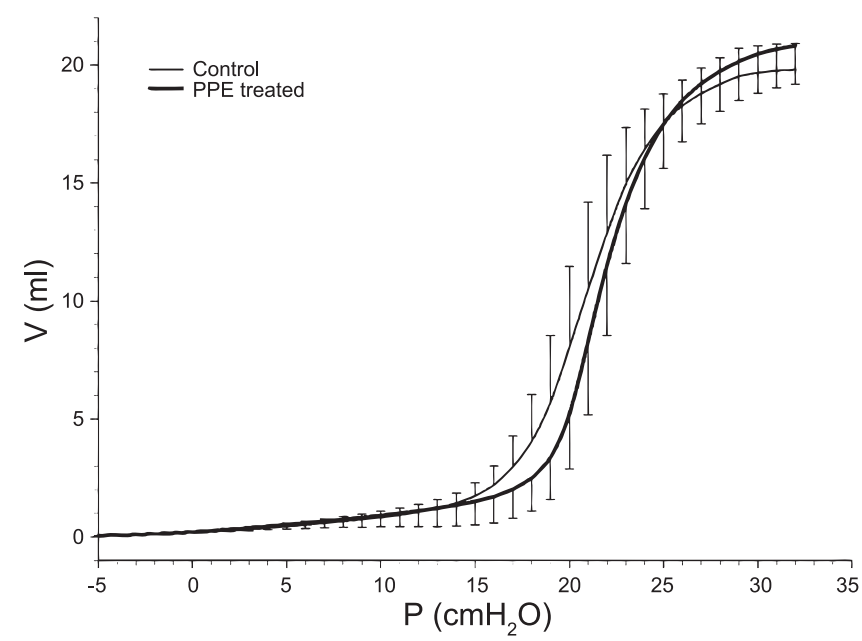

Fig. 4. Comparison of the inflation pressure-volume (PV) curves of control (thin line) and PPE (thick line) groups from degassed state (means \pm SD). different between the groups (Fig. 7A). The attachment density $\mathrm{N}_{\mathrm{s}} / \mathrm{P}_{\mathrm{b}}$ (Fig. $7 B$ ) was mildly but statistically significantly lower in the PPE group (median 0.0175 vs. $0.0189 \mu \mathrm{m}^{-1} ; P<$ 0.001 ). Regression analysis showed that $\mathrm{T}_{\mathrm{w}}$ did not depend on $D_{b}$ in either group (Fig. 7C). However, the mean value of $T_{w}$ was higher in the PPE group compared with the controls (12.4 vs. $10.8 \mu \mathrm{m} ; P<0.0001)$.

Elastin and collagen density in the bronchial wall. Similarly to the bronchial morphometry, there was no difference between the $D_{b}$ of the airways of control and PPE-treated animals for which elastin and collagen densities were evaluated. The mean and SD of elastin grayscale representing the average and the spatial variability of elastin density within the bronchial wall, respectively, were not different in the groups. The sum of all grayscale values, which represents the total elastin in the $9-\mu \mathrm{m}$ band inside the bronchial wall, was also not different between the groups. The density of elastin and collagen did not correlate with $\mathrm{D}_{\mathrm{b}}$. The interairway variance of the elastin density was also not different between control and treated animals. Interestingly, the collagen density as well as its intrabronchial SD were increased by 12 and $17 \%$ in the treated group $(P<0.05)$. Furthermore, the interairway variance of collagen density was substantially higher $(67 \%, P<0.01)$ in the treated animals. Figure 8 illustrates the difference in collagen wall structure between the control and treated animals.

\section{DISCUSSION}

In this rat model of emphysema, we aimed at investigating the alveolar and bronchial structural changes underlying the alterations in lung volume and mechanics, and the acoustic manifestations of airway function. The combination of structural and functional measurements revealed that 1) the PPE treatment caused significant increases in FRC and RV, whereas no change in TLC was observed; 2) the tissue mechanical parameters were significantly lower in the treated group, whereas there was no detectable alteration in the total airway resistance as measured at FRC; 3) while the number of crackles per inflation was similar, the distributions of crackles as a function of transpulmonary pressure or lung volume were statistically significantly different between the PPE-treated and control groups, and the lower knee of the inflation $\mathrm{P}-\mathrm{V}$ curve moved to higher $\mathrm{P}$ in the treated rats; 4) the distribution of alveolar diameters was shifted toward higher values in the PPE group with a slightly higher median alveolar diameter; 5) bronchial morphometry revealed that compared with controls, alveolar attachment density was 7\% lower and wall thickness was $15 \%$ higher in emphysematous animals; and 6) while no difference was found in the elastin content per unit wall 

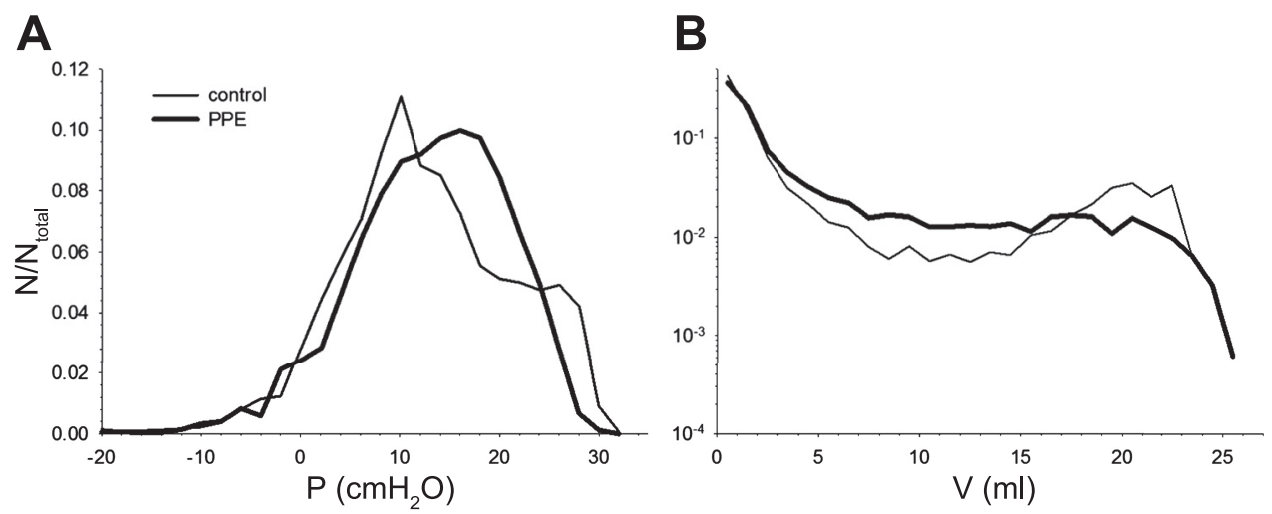

Fig. 5. Relative frequencies $\left(\mathrm{N} / \mathrm{N}_{\text {total }}\right)$ of crackles in the control and PPE group as a function of pressure $(\mathrm{P})$ on a lin-lin scale $(A)$ and volume $(\mathrm{V})$ on a lin-log scale $(B)$.

thickness of the bronchial wall, collagen content was higher and more heterogeneous in the treated animals.

Changes in lung volumes and parenchymal mechanics. The increases in lung volumes observed in the current study are in accord with the effects of elastase treatment in rats, with regard to FRC $(2,8,16,18,23,30)$ and $\operatorname{RV}(18,30)$. However, we observed no change in TLC whereas previous studies found significant increases in $\operatorname{TLC}(8,16,18,23,30)$. Often the changes in TLC are more variable than those in RV and FRC and depend on the definition of TLC, the dose of elastase, and the time period after treatment. For example, Yokoyama et al. (30) reported no change in TLC until $7 \mathrm{wk}$ after treatment, in agreement with our results. Our finding that $\mathrm{H}$ as measured at FRC decreased following treatment is also in line with the reported elevations in compliance $(8,16,18,23,30)$. Total respiratory resistance has been found to decrease, probably via the smaller contribution of the tissue resistance, due to the elastolytic processes (8). We also observed a decrease in G, although to a lesser extent compared with that in $\mathrm{H}$; this resulted in an elevation in $\eta$ similarly to the effect of elastase treatment in mice $(3,10,14)$, most likely reflecting the structural alterations in the parenchymal composition. Although the parenchymal changes may have been masked by the contributions of the chest wall impedance to $\mathrm{G}$ and $\mathrm{H}$ in both groups of rats, it is still unclear why the decrease in dynamic elasticity at FRC is not accompanied by a fall in quasi-static elastance at high transrespiratory pressures resulting in an elevation of lung volume.

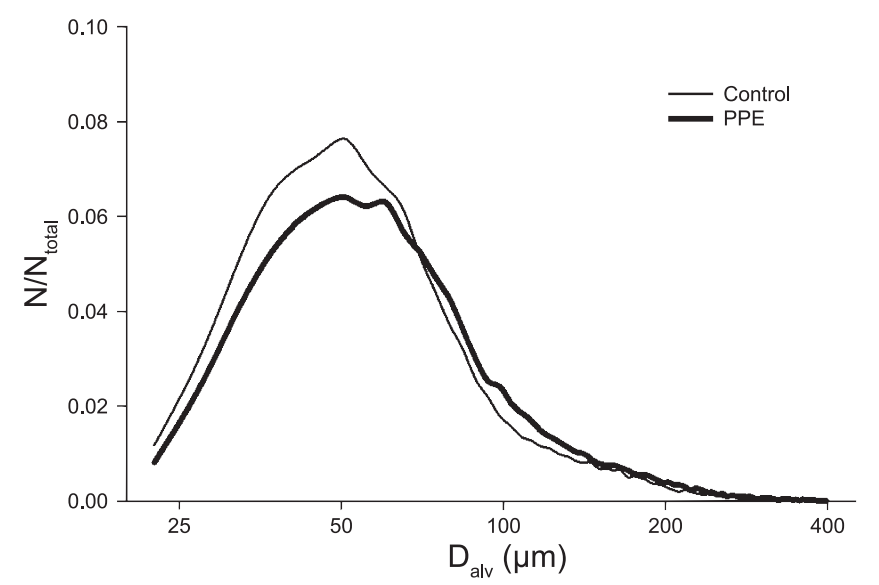

Fig. 6. Relative frequencies of the alveolar diameters $\left(D_{\text {alv }}\right)$ in the control and the elastase-treated (PPE) groups.
Airway resistance, crackles, and morphometry. The shift in the inflation P-V curve was consistent with a delayed recruitment process also indicated by the crackle intensity. The mechanisms behind the bimodal crackle distribution in the control rats are unclear. Nevertheless, it is tempting to speculate that the altered shape of the crackle distribution in the PPE-treated animals is directly related to the high airway-toairway variability of the remodeled collagen density and hence of bronchial wall stiffness (see below).

The $R_{N}$ parameter was not different between the two groups suggesting that the overall resistance of the bronchial tree was not affected by the elastase treatment, with the provision that the contribution of the Newtonian resistance of the chest wall to $R_{N}$ was similar in both groups. However, the knee of the P-V curve is shifted to the right in the treated animals by about $9 \%$, which was statistically significant. Since the lower knee of the P-V curve signifies airway openings (24), this shift implies that the critical opening pressure at which massive airway opening allows the alveoli to start filling up was higher in the treated lungs. The critical opening pressure is influenced by many factors, including surface tension and viscosity of the air-liquid interface (9), airway wall stiffness, and parenchymal tethering (21). While surface tension appears to be normal in elastase-induced emphysema (19), little is known about how liquid film viscosity or airway wall stiffness might change with treatment.

In this study, we quantified the strength of parenchymal tethering by measuring the number of attachments per unit airway wall perimeter and found that the treatment reduced the average attachment density by $7 \%$. This is similar to the findings of Collie et al. (5) who reported a decreased number of attachments and an increased average distance between attachments around the bronchi of sheep following elastase treatment. One might argue that if the wall is more compliant in the treated lungs, the decreased attachment density is simply a result of the larger airway diameters at the same fixation pressure in the treated animals. However, there was no difference in diameter between the two populations of airways included in our analysis, suggesting that the reduction in attachment density was likely due to loss of parenchymal walls around airways. The elastin density of the walls measured from the histologic images was similar in the two groups. We should point out that the elastin density was measured in a band of fixed width around the bronchi. Since the wall thickness in the treated animals was larger by $15 \%$, it is likely that the total elastin content was also larger in the bronchial walls of the 


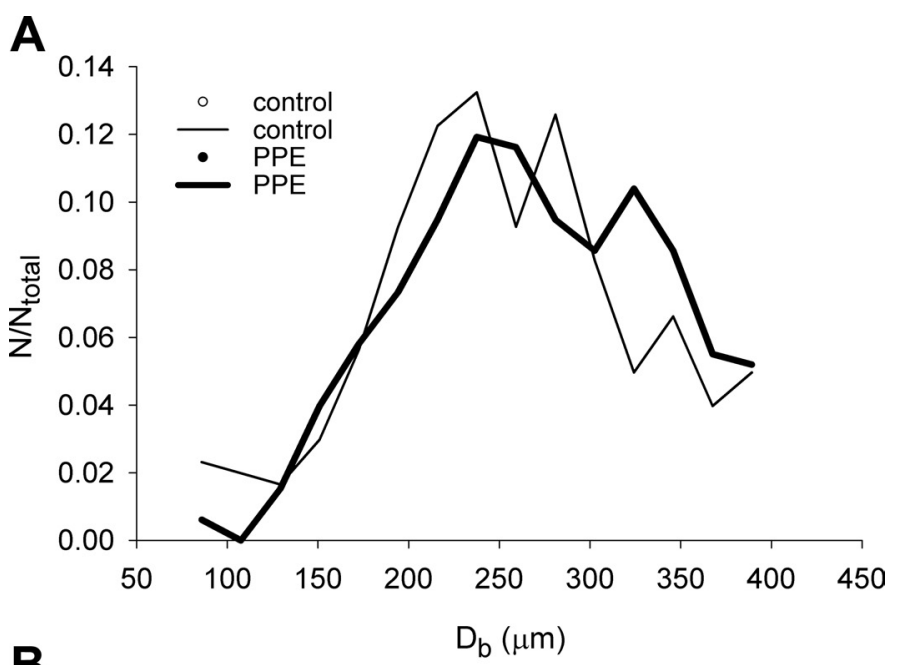

B
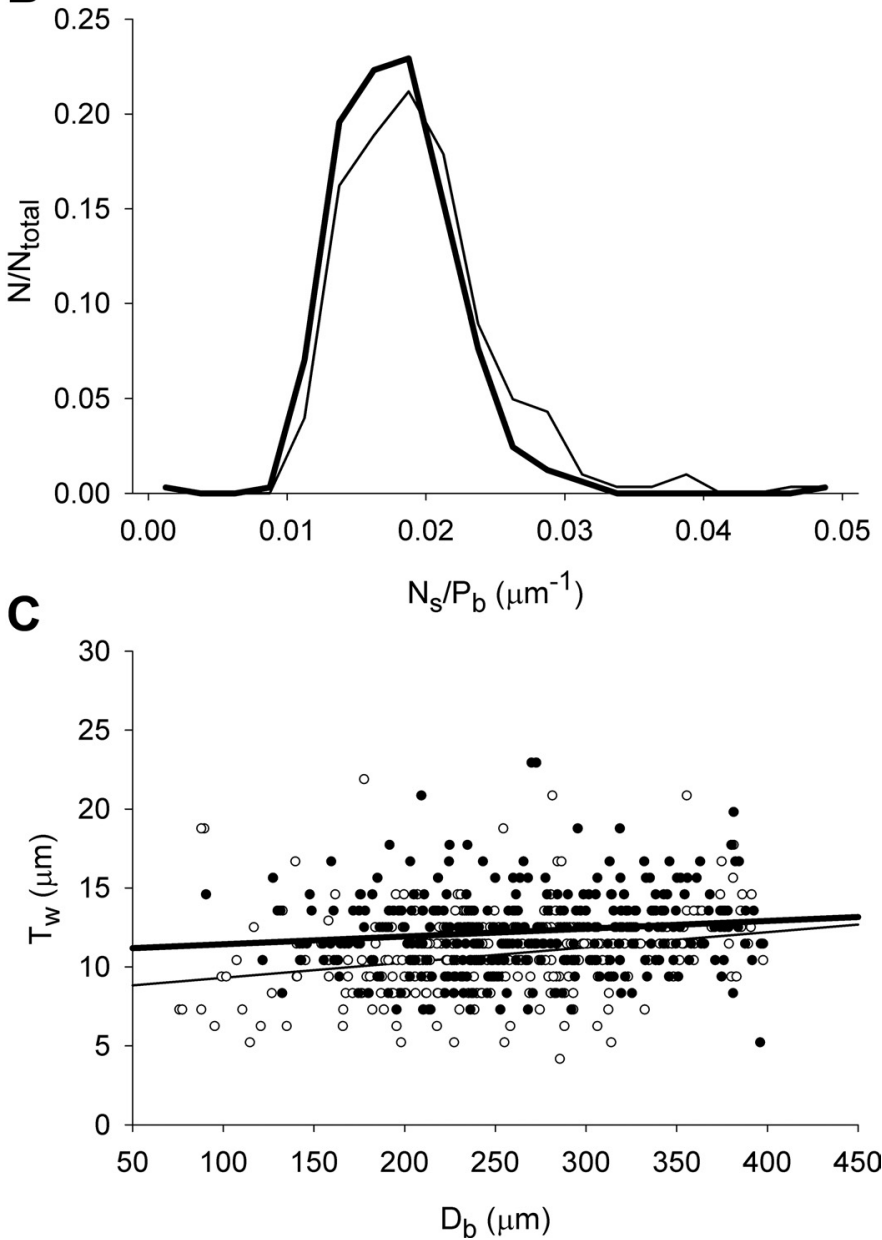

Fig. 7. Relative frequencies of the bronchial diameters, $\mathrm{D}_{\mathrm{b}}(A)$, and density of septal attachments, $\mathrm{N}_{\mathrm{s}} / \mathrm{P}_{\mathrm{b}}(B)$. C : relationship between the calculated bronchial diameters $\left(\mathrm{D}_{\mathrm{b}}\right)$ and average wall thickness $\left(\mathrm{T}_{\mathrm{w}}\right)$ in the control and PPE-treated rats; lines illustrate the regressions from the co-variance analysis.

treated rats, implying cellular remodeling of the airway walls. However, collagen also contributes to stiffness especially at higher transmural pressures. The increased collagen density of the wall and the elevated intrawall heterogeneity suggest a disordered cellular remodeling following PPE treatment. It is thus likely that the incremental Young's modulus of the airway walls was also elevated in the treated animals especially at high lung volume where collagen is expected to contribute to stiffness more than elastin. Furthermore, the increased wall thickness would also result in a higher volumetric elastance of the airway wall (25). Thus these considerations imply a real decrease in tethering forces as well as a likely stiffening of the airway walls as a consequence of the PPE treatment.

Examining the results from the crackle sounds, we also found major differences in the distribution of the number of crackles as a function of airway pressure or lung volume (Fig. 5). The amplitude distribution of the crackle sounds followed a power law (not shown) in agreement with previous studies in normal dog lungs (1) and in elastase-treated mice (10). The exponent $\alpha$ of the power law distribution has been shown to reflect the average bifurcation geometry of the airway tree (1). Specifically, it was shown that $\alpha=\ln (2 / \mathrm{b}) / \ln (\mathrm{b})$, where $\mathrm{b}=2 \mathrm{~A}_{1} /$ $\left(A_{0}+A_{1}+A_{2}\right)$ and $A_{0}$ is the cross-sectional area of the parent airway, $A_{1}$ is the cross-sectional area of the daughter branch where the crackles comes from, and $A_{2}$ is the cross sectional area of the other daughter branch. Assuming that on average, the bifurcation geometry is symmetric (i.e., $A_{1}=A_{2}$ ) and knowing $\alpha$ and hence $b$ from experiments, the average diameter ratio $\mathrm{d}_{1} / \mathrm{d}_{0}$ at bifurcations can be estimated. The values of $\mathrm{b}$ in the control and treated rats were 0.573 and 0.512 , respectively, resulting in corresponding diameter ratios of 0.757 and 0.712. Although the assumption of symmetric bifurcations seems unwarranted, based on the theory published earlier (1), it is possible to show that similar results can also be derived using asymmetric bifurcations (unpublished data). This analysis then suggests that on average, airway diameters decrease faster along the airway tree in the treated animals than in the control animals, which seems to contradict the fact that $R_{N}$ was not different between the two groups. However, whereas $R_{N}$ characterizes air flow resistance around FRC, the distribution of crackle amplitudes mostly reflects diameters at much higher lung volumes than FRC. Furthermore, the reduced diameter ratio obtained from crackles is also in accord with both a stiffer wall due to increased collagen content and wall thickness, and a reduced parenchymal tethering as a result of the lower attachment density and septal stiffness. We thus conclude that the reduced diameter ratio inferred from crackles and the shift of the knee of the P-V curve imply an important deterioration in airway patency under conditions such as airway reopening and high lung volumes that the FOT-based $R_{N}$ measured around FRC does not detect.

Conclusions. In this study, we have shown that elastase treatment of the rat lung that is often used to generate airspace enlargement as a model of human emphysema also leads to altered airway mechanics, which manifests in enhanced collapsibility and increased difficulty to reopen the airways. These results cannot be observed by evaluating lung and airway mechanics around FRC. Our results also imply that this loss of function is partly due to reduced alveolar tethering and partly due to increased stiffness of the remodeled bronchial wall. Since such deterioration in airway function also occurs in human COPD, the implications are important both in mechanical ventilation where airway collapse and the hindered ability to reopen the airways can lead to flow limitation and trapped gas, and in exercise where the reduced airway diameter ratios at higher lung volumes may limit the exercise capacity of patients. 
A

Fig. 8. Representative high-magnification images of similar size airway walls stained for collagen in a normal $(A)$ and a PPE-treated $(B)$ lung. Selected areas are magnified in the upper right corners. Note the different patterns of collagen structure between the airways in the mucosal layer (arrows) represented by the blue color.

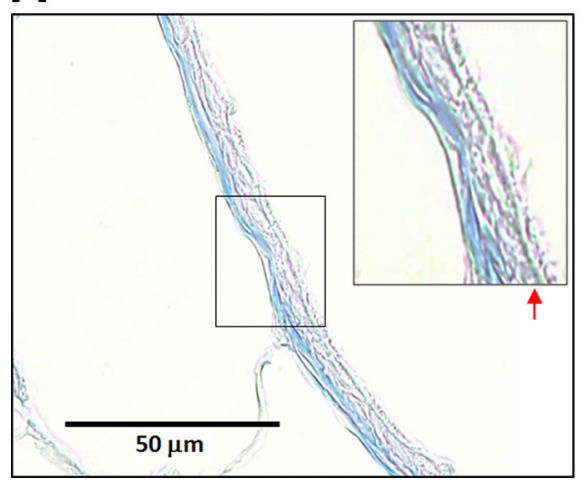

B

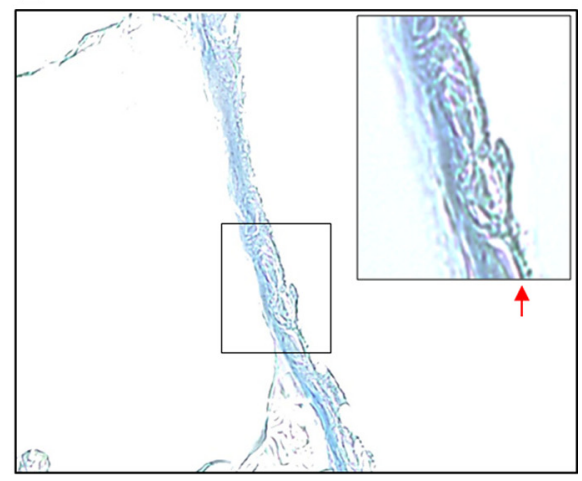

\section{ACKNOWLEDGMENTS}

We thank Dr. L. Tiszlavicz for valuable advice on the histological preparations.

\section{GRANTS}

This study was supported by Hungarian Scientific Research Fund Grant (OTKA) 67700, National Institutes of Health Grant HL-090757, and HURO/ 0901/137/2.2.2. M. V. Szabari was supported by the Rosztoczy Foundation.

\section{DISCLOSURES}

No conflicts of interest, financial or otherwise, are declared by the author(s).

\section{AUTHOR CONTRIBUTIONS}

Author contributions: J.T., M.V.S., B.S., and Z.H. conception and design of research; J.T., M.V.S., G.A., B.A.M., and Z.H. performed experiments; J.T., G.A., B.A.M., H.P., E.B.-S., B.S., and Z.H. analyzed data; J.T., M.V.S., G.A., H.P., E.B.-S., B.S., and Z.H. interpreted results of experiments; J.T., B.A.M., H.P., and E.B.-S. prepared figures; J.T., M.V.S., B.S., and Z.H. drafted manuscript; J.T., M.V.S., G.A., B.A.M., H.P., E.B.-S., B.S., and Z.H. approved final version of manuscript; E.B.-S., B.S., and Z.H. edited and revised manuscript.

\section{REFERENCES}

1. Alencar AM, Hantos Z, Petak F, Tolnai J, Asztalos T, Zapperi S, Andrade JS Jr, Buldyrev SV, Stanley HE, Suki B. Scaling behavior in crackle sound during lung inflation. Phys Rev E Stat Phys Plasmas Fluids Relat Interdiscip Topics 60: 4659-4663, 1999.

2. Bellofiore S, Eidelman DH, Macklem PT, Martin JG. Effects of elastase-induced emphysema on airway responsiveness to methacholine in rats. J Appl Physiol 66: 606-612, 1989.

3. Brewer KK, Sakai H, Alencar AM, Majumdar A, Arold SP, Lutchen KR, Ingenito EP, Suki B. Lung and alveolar wall elastic and hysteretic behavior in rats: effects of in vivo elastase treatment. J Appl Physiol 95: 1926-1936, 2003.

4. Brown RH, Walters DM, Greenberg RS, Mitzner W. A method of endotracheal intubation and pulmonary functional assessment for repeated studies in mice. J Appl Physiol 87: 2362-2365, 1999.

5. Collie DD, McLean N, Sallenave JM, Baker A, Blundell R, Milne E, Rhind S, Woodall C. Local lung responses following endobronchial elastase and lipopolysaccharide instillation in sheep. Int J Chron Obstruct Pulmon Dis 1: 189-199, 2006.

6. DuBois AB, Botelho SY, Bedell GN, Marshall R, Comroe JH Jr. A rapid plethysmographic method for measuring thoracic gas volume: a comparison with a nitrogen washout method for measuring functional residual capacity in normal subjects. J Clin Invest 35: 322-326, 1956.

7. Eidelman DH, Bellofiore S, Chiche D, Cosio MG, Martin JG. Behavior of morphometric indices in pancreatic elastase-induced emphysema in rats. Lung 168: 159-169, 1990.

8. Emami K, Chia E, Kadlecek S, Macduffie-Woodburn JP, Zhu J, Pickup S, Blum A, Ishii M, Rizi RR. Regional correlation of emphysematous changes in lung function and structure: a comparison between pulmonary function testing and hyperpolarized MRI metrics. J Appl Physiol 110: 225-235, 2011.
9. Gaver DP 3rd, Samsel RW, Solway J. Effects of surface tension and viscosity on airway reopening. $J$ Appl Physiol 69: 74-85, 1990.

10. Hantos Z, Adamicza A, Janosi TZ, Szabari MV, Tolnai J, Suki B. Lung volumes and respiratory mechanics in elastase-induced emphysema in mice. J Appl Physiol 105: 1864-1872, 2008.

11. Hantos Z, Daroczy B, Suki B, Nagy S, Fredberg JJ. Input impedance and peripheral inhomogeneity of dog lungs. J Appl Physiol 72: 168-178, 1992.

12. Hantos Z, Petak F, Adamicza A, Asztalos T, Tolnai J, Fredberg JJ. Mechanical impedance of the lung periphery. J Appl Physiol 83: 15951601, 1997.

13. Ito S, Ingenito EP, Arold SP, Parameswaran H, Tgavalekos NT, Lutchen KR, Suki B. Tissue heterogeneity in the mouse lung: effects of elastase treatment. J Appl Physiol 97: 204-212, 2004.

14. Ito S, Ingenito EP, Brewer KK, Black LD, Parameswaran H, Lutchen KR, Suki B. Mechanics, nonlinearity, and failure strength of lung tissue in a mouse model of emphysema: possible role of collagen remodeling. $J$ Appl Physiol 98: 503-511, 2005.

15. Janosi TZ, Adamicza A, Zosky GR, Asztalos T, Sly PD, Hantos Z. Plethysmographic estimation of thoracic gas volume in apneic mice. $J$ Appl Physiol 101: 454-459, 2006.

16. Kuraki T, Ishibashi M, Takayama M, Shiraishi M, Yoshida M. A novel oral neutrophil elastase inhibitor (ONO-6818) inhibits human neutrophil elastase-induced emphysema in rats. Am J Respir Crit Care Med 166: 496-500, 2002.

17. Lucey EC, Goldstein RH, Stone PJ, Snider GL. Remodeling of alveolar walls after elastase treatment of hamsters. Results of elastin and collagen mRNA in situ hybridization. Am J Respir Crit Care Med 158: 555-564, 1998.

18. Mansoor JK, Hyde DM, Schelegie ES. Pulmonary vagal reflexes and breathing pattern are not altered in elastase-induced emphysema in rats. Exp Lung Res 23: 441-457, 1997.

19. Mouded M, Egea EE, Brown MJ, Hanlon SM, Houghton AM, Tsai LW, Ingenito EP, Shapiro SD. Epithelial cell apoptosis causes acute lung injury masquerading as emphysema. Am J Respir Cell Mol Biol 41: 407-414, 2009.

20. Parameswaran H, Majumdar A, Ito S, Alencar AM, Suki B. Quantitative characterization of airspace enlargement in emphysema. $J$ Appl Physiol 100: 186-193, 2006.

21. Perun ML, Gaver DP 3rd. Interaction between airway lining fluid forces and parenchymal tethering during pulmonary airway reopening. $J$ Appl Physiol 79: 1717-1728, 1995.

22. Petak F, Habre W, Babik B, Tolnai J, Hantos Z. Crackle-sound recording to monitor airway closure and recruitment in ventilated pigs. Eur Respir J 27: 808-816, 2006.

23. Schmiedl A, Lempa T, Hoymann HG, Rittinghausen S, Popa D, Tschernig T, Fehrenbach H, Pabst R, Hoeper MM, Hohlfeld JM. Elastase-induced lung emphysema in rats is not reduced by hematopoietic growth factors when applied preventionally. Virchows Arch 452: 675-688, 2008.

24. Suki B, Andrade JS Jr, Coughlin MF, Stamenovic D, Stanley HE, Sujeer M, Zapperi S. Mathematical modeling of the first inflation of degassed lungs. Ann Biomed Eng 26: 608-617, 1998.

25. Suki B, Habib RH, Jackson AC. Wave propagation, input impedance, and wall mechanics of the calf trachea from 16 to 1,600 Hz. J Appl Physiol 75: 2755-2766, 1993. 
26. Thurlbeck WM. Aspects of chronic airflow obstruction. Chest 72: $341-$ 349, 1977.

27. Thurlbeck WM. Pathophysiology of chronic obstructive pulmonary disease. Clin Chest Med 11: 389-403, 1990.

28. Van de Woestijne KP, Franken H, Cauberghs M, Landser FJ, Clement J. A modification of the forced oscillation technique. In: $28 \mathrm{th}$
Int Cong of Physiol Sci Budapest, Hungary: Akademiai Kiado 1981, p. 655-660.

29. Wright JL, Cosio M, Churg A. Animal models of chronic obstructive pulmonary disease. Am J Physiol Lung Cell Mol Physiol 295: L1-L15, 2008.

30. Yokoyama E, Nambu Z, Uchiyama I, Kyono H. An emphysema model in rats treated intratracheally with elastase. Environ Res 42: 340-352, 1987.

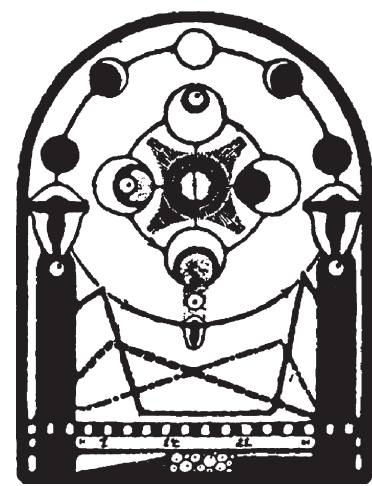


III. M.V. Szabari, J. Tolnai, B.A. Maár, H. Parameswaran, E. Bartolák-Suki, B. Suki and Z. Hantos: Lung structure and function relation in elastase-treated rats: a longterm follow up study. Respiratory Physiology \& Neurobiology, 215: 13-19 (2015) 


\title{
Lung structure and function in elastase-treated rats: A follow-up study
}

\author{
M.V. Szabari ${ }^{\mathrm{a}, \mathrm{b}}$, J. Tolnai ${ }^{\mathrm{a}, \mathrm{d}}$, B.A. Maár ${ }^{\mathrm{a}, \mathrm{c}}$, H. Parameswaran $^{\mathrm{b}}$, E. Bartolák-Suki ${ }^{\mathrm{b}}$, B. Suki ${ }^{\mathrm{b}}$, \\ Z. Hantos ${ }^{\mathrm{a}, \mathrm{c}, *}$ \\ a Department of Medical Physics and Informatics, University of Szeged, Szeged, Hungary \\ ${ }^{\mathrm{b}}$ Department of Biomedical Engineering, Boston University, Boston, MA, United States \\ ${ }^{\mathrm{c}}$ Institute for Surgical Research, University of Szeged, Szeged, Hungary \\ ${ }^{d}$ Department of Pathology, University of Szeged, Szeged, Hungary
}

\section{A R T I C L E I N F O}

Article history:

Accepted 9 April 2015

Available online 18 April 2015

\section{Keywords:}

Emphysema

Extracellular matrix

Plethysmography

Lung mechanics

Orthogonal polarization spectral imaging

\begin{abstract}
A B S T R A C T
Structural and functional longitudinal alterations of the lungs were followed in an emphysema model. Rats were treated with porcine pancreatic elastase (PPE, $n=21$ ) or saline (controls, C, $n=19$ ). Before the treatment and 3, 10, 21 and 105 days thereafter, absolute lung volumes (FRC, TLC and RV) and tissue mechanical parameters (elastance: $H$; damping: $G$ ) were determined. At 3, 21 and 105 days the lungs were fixed in subgroups of rats. From histological samples the equivalent diameter of airspaces $\left(D_{\text {alv }}\right)$, elastin (Mec) and collagen densities were assessed. In the PPE group, FRC and RV were higher from 3 days after treatment compared to controls $(p<0.001)$, while TLC exhibited a delayed increase. $H$ and $G$ decreased in the PPE group throughout the study $(p<0.001)$. Higher $\operatorname{Mec}(p<0.001)$ and late-phase inflammation were observed at 105 days. We conclude that during the progression of emphysema, septal failures increase $D_{\text {alv }}$ which decreases $H$; this reveals a strong structure-function relationship.
\end{abstract}

(c) 2015 Elsevier B.V. All rights reserved.

\section{Introduction}

Small animal models have extensively been used to study pathological mechanisms underlying the development of chronic obstructive pulmonary disease (COPD) due to their rapid reproduction cycle, low cost housing and genetic manipulations. A number of studies applied elastolytic treatments in animals to evoke emphysema-like alterations in the lung parenchyma (Snider et al., 1986). Porcine pancreatic elastase (PPE)-induced rodent models of emphysema are commonly used (Stevenson and Birrell, 2011) to quickly generate emphysema-like airspace enlargement that can be studied easily within a month, thus the time course of the investigation period is usually 2-4 weeks. However, the human disease is a slowly progressing chronic pathological condition with longterm effects on the patient, which usually starts around midlife. To advance the understanding the chronic aspects of human emphysema, long-term measurements are also needed in rodents to reveal how changes in tissue structure and composition impact on lung function. Such structure-function relations are best obtained in long-term, follow-up studies. Since repeated intubations during anesthesia of small animals pose technical challenges, most rodent

\footnotetext{
* Corresponding author at: Department of Medical Physics and Informatics, University of Szeged, 9 Korányi fasor, H-6720 Szeged, Hungary. Tel.: +36 62545 077; fax: +36 62544566

E-mail address: hantos.zoltan@med.u-szeged.hu (Z. Hantos).
}

studies have been limited to cross-sectional analysis of disease progression (Artaechevarria et al., 2011; Bellofiore et al., 1989; Emami et al., 2008).

The primary aim of this study was to assess the extent to which the changes in alveolar structure and extracellular matrix (ECM) composition, induced by administration of a single dose of PPE determine lung function in follow-up experiments for time scales well beyond the usual several weeks most previous studies report. To this end, we treated rats with PPE and followed the changes in lung function for a period of 105 days. Additionally, at several time points, lung structure was also assessed by standard histology and collagen and elastin distribution from specific staining. Furthermore, we also visualized subpleural airspaces at 105 days after treatment using Orthogonal Polarization Spectral (OPS) imaging, in order to assess the airspace enlargement in its native form without introducing tissue fixation. Our results suggest a progressive and continuous deterioration of lung volumes and mechanics even at 105 days after a single dose of PPE treatment and the existence of strong structure-function relations that result from septal wall failures during the progression of emphysema.

\section{Materials and methods}

The study was approved by the Institutional Committee of Animal Welfare, University of Szeged, and conducted in conformity with the NIH guidelines. 
Table 1

Experimental group design.

\begin{tabular}{|c|c|c|c|c|c|}
\hline $\begin{array}{l}\text { Respiratory } \\
\text { function }\end{array}$ & $\begin{array}{l}\mathrm{C} 0(n=19) \\
\mathrm{TO}(n=21)\end{array}$ & $\begin{array}{l}\text { C3 }(n=19) \\
\text { T3 }(n=21)\end{array}$ & $\begin{array}{l}\mathrm{C} 10(n=15) \\
\mathrm{T} 10(n=16)\end{array}$ & $\begin{array}{l}\text { C21 }(n=15) \\
\text { T21 }(n=16)\end{array}$ & $\begin{array}{l}\text { C105 }(n=9,1 \text { died }) \\
\text { T105 }(n=12)\end{array}$ \\
\hline Histology & $\begin{array}{l}\mathrm{N} / \mathrm{A} \\
\mathrm{N} / \mathrm{A}\end{array}$ & $\begin{array}{l}\mathrm{C} 3(n=4) \\
\mathrm{T} 3(n=5)\end{array}$ & $\begin{array}{l}\mathrm{N} / \mathrm{A} \\
\mathrm{N} / \mathrm{A}\end{array}$ & $\begin{array}{l}\mathrm{C} 21(n=5) \\
\mathrm{T} 21(n=4)\end{array}$ & $\begin{array}{l}\mathrm{C} 105(n=4) \\
\mathrm{T} 105(n=6)\end{array}$ \\
\hline OPS & $\begin{array}{l}\text { N/A } \\
\text { N/A }\end{array}$ & $\begin{array}{l}\text { N/A } \\
\text { N/A }\end{array}$ & $\begin{array}{l}\text { N/A } \\
\text { N/A }\end{array}$ & $\begin{array}{l}\text { N/A } \\
\text { N/A }\end{array}$ & $\begin{array}{l}\text { C105 }(n=5) \\
\text { T105 }(n=5)\end{array}$ \\
\hline
\end{tabular}

See text for the definitions of groups $\mathrm{C}$ and T. OPS: orthogonal polarization spectral imaging.

\subsection{Experimental groups}

Forty Sprague-Dawley rats were anesthetized with chloral hydrate $(350 \mathrm{mg} / \mathrm{kg}$ ) and intubated. Rats were placed in a plethysmograph and ventilated with a tidal volume of $8 \mathrm{ml} / \mathrm{kg}$ and a rate of 75/min using a small-animal respirator (Harvard Apparatus, South Natick, MA). After the lung function measurements were made, the rats were treated with intratracheal instillation (Houghton et al., 2006) of porcine pancreatic elastase (PPE, Affymetrix/USB, Cleveland, Ohio) with a dose of $50 \mathrm{IU}$ PPE in $0.5 \mathrm{ml}$ saline (Hantos et al., 2008) (PPE-treated group: T, $n=21$ ) or $0.5 \mathrm{ml}$ saline (control group: C, $n=19$ ), and were allowed to recover. The same animals were anesthetized, intubated and measured again at 3,10, 21 and 105 days after treatment. The corresponding groups are denoted as T0 and $\mathrm{CO}$ (treated and control at day 0 ), T3 and C3 (treated and control at day 3), T10 and C10 (treated and control at day 10), T21 and C21 (treated and control at day 21), and T105 and C105 (treated and control at day 105); see Table 1.

\subsection{Respiratory function}

Functional residual capacity (FRC), inspiratory capacity (IC), expiratory reserve volume (ERV), total lung capacity (TLC) and residual volume (RV) were determined with body plethysmography (DuBois et al., 1956) as described previously (Jánosi et al., 2006; Tolnai et al., 2012). Respiratory impedance was measured at FRC with forced oscillation technique between 0.5 and $16 \mathrm{~Hz}$. Airway resistance (Raw), $H, G$ and hysteresivity $(\eta=G / H)$ were calculated by fitting the constant-phase model to impedance spectra (Hantos et al., 1992).

\subsection{Orthogonal polarization spectral imaging}

The OPS imaging equipment (Cytoscan ${ }^{\mathrm{TM}}$, Cytometrics, PA) was employed to visualize the subpleural alveolar structure. This technique was developed for microcirculation studies, with a wavelength of $548 \mathrm{~nm}$ at which both oxy-and deoxy-hemoglobin absorb equally (Groner et al., 1999). The resolution was $1 \mu \mathrm{m} /$ pixel and the depth of focus was adjusted in the range $0-200 \mu \mathrm{m}$. On day 105 , lungs and heart were removed en bloc and suspended from the tracheal cannula at a transpulmonary pressure of $25 \mathrm{cmH}_{2} \mathrm{O}$. The lung surface was scanned at 10 randomly selected areas on different lobes. From each video recording, 10-12 non-overlapping frames (650 $\mu \mathrm{m}$ in diameter) were collected. Custom-made software was used to identify the septal borders, and from each enclosed area the alveolar diameters $\left(D_{\text {alv }}\right)$ were calculated. Alveoli truncated by the edge of the frame were also included if the edge segment constituted less than $15 \%$ of the total circumference.

\subsection{Histology}

Whole lungs in groups T105 and C105, and subgroups of T3, C3, T21 and C21 ( $n=5$ each) were fixed with $4 \%$ buffered formaldehyde at $25 \mathrm{cmH}_{2} \mathrm{O}$ pressure and processed for imaging (Tolnai et al., 2012). Samples were stained with hematoxylin-eosin (H\&E), and modified Movat's and Masson's methods were used for visualizing elastin and collagen, respectively. Histological evaluation of inflammatory cells was assessed from the H\&E images. $D_{\text {alv }}$, the area weighted mean diameter $\left(D_{2}\right)$ (Parameswaran et al., 2006), the alveolar septal wall thickness $\left(T_{\mathrm{w}}\right)$, mean elastin $(\mathrm{Mec})$ and mean collagen (Mcc) densities were calculated using custom-made software based on monochromatic transformation of the images, where the color intensity represented collagen or elastin content.

\subsection{Statistical analysis}

The effect of PPE and time, the Mec and Mcc were analyzed with two-way ANOVA. Body weights were compared with $t$-test. The distributions of $D_{\text {alv }}$ were compared with Kolmogorov-Smirnov test. The structure-function relations were compared by using linear regressions. A $p$ value $<0.05$ was considered as significant difference.

\section{Results}

During the 105 days of the study, the animals gained weight from an average of $244 \pm 17 \mathrm{~g}$ (C0 and T0) to $558 \pm 70 \mathrm{~g}$ (C105 and T105) (Fig. 1A). Weight gain was observed during the whole time course of the study ( $p<0.001$; two-way ANOVA) uniformly in the $C$ and $\mathrm{T}$ groups except for the $\mathrm{T} 3$ group, which exhibited a weight loss of $11 \%$ compared to the C 3 animals $(p=0.022)$.

\subsection{Lung volumes}

FRC, TLC and RV increased with time, also as a result of growth, but the increase was faster in the T group $(p<0.001)$ : while group $C$ showed an increase of $75 \%$ in FRC, and 56\% in RV from the beginning to the end of the study, the corresponding changes in group $T$ were $194 \%$ and $244 \%$, respectively. There were statistically significant differences between the control and treated rats throughout the study (Fig. 1B-D): for FRC and RV a difference appeared already on day 3, whereas there was no difference in TLC until day 21. Increases in all lung volumes reflect the combined effect of PPE and time, and there was a statistically significant interaction between treatments and time $(p<0.001)$ for all lung volumes.

\subsection{Respiratory mechanics}

The treatment had significant $(p<0.001)$ effects on $H$ and $\eta$ (Fig. $1 \mathrm{~F}$ and $\mathrm{H}$, respectively). The interaction between treatment and time was statistically significant $(p=0.001)$ for these parameters. There was no difference between Raw in the control and the treated animals at any time point (Fig. 1E). Differences in $H$ and $\eta$ between the groups developed as early as day 3 .

\subsection{Morphological evaluations}

The H\&E stained samples from the T105 group exhibited large areas of tissue destruction with enlarged airspaces and septal 

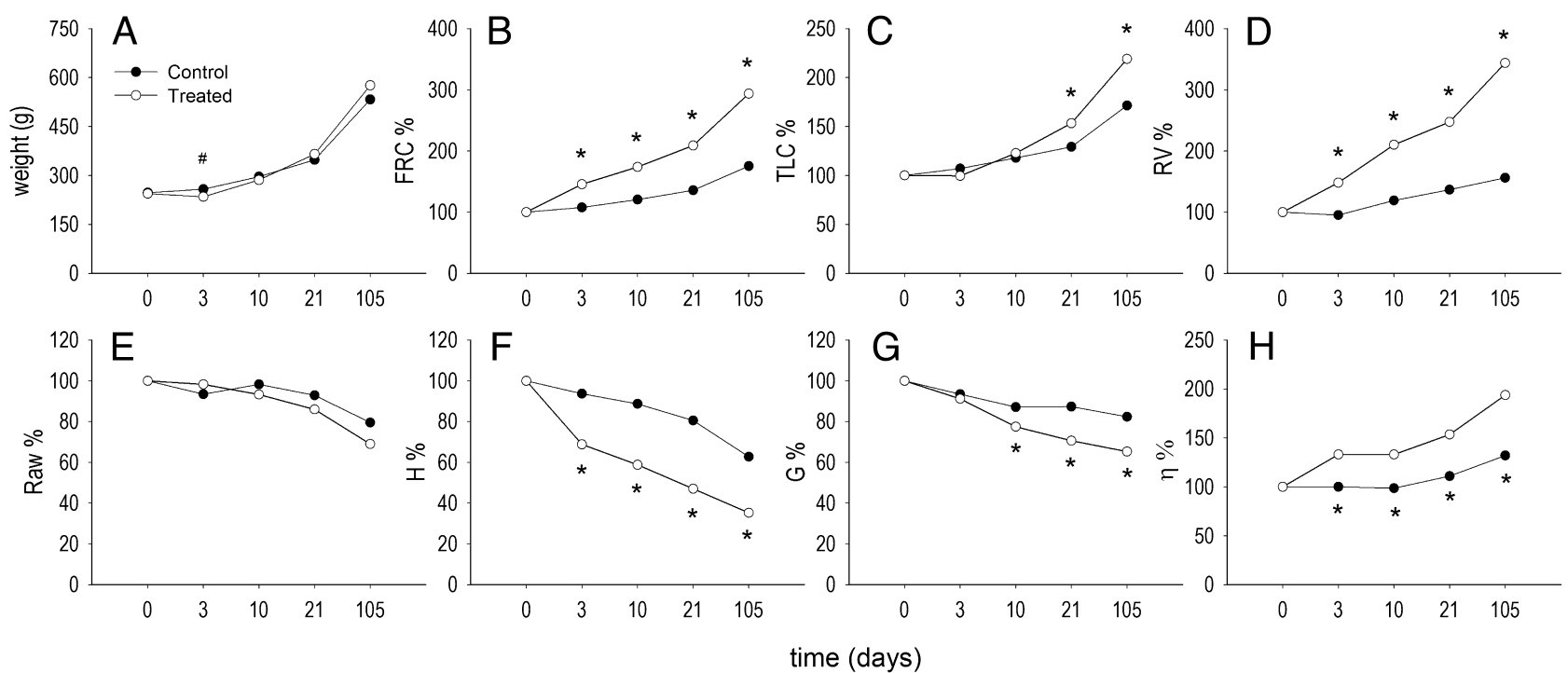

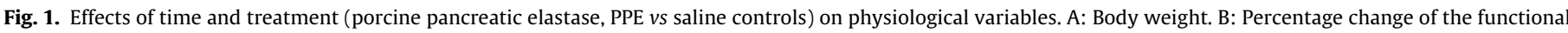

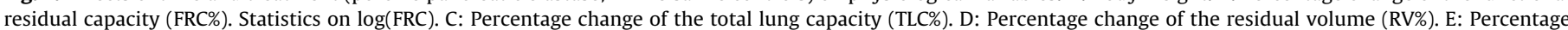

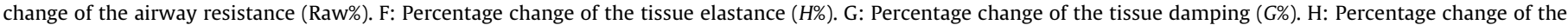
hysteresivity $(\eta \%)$. Statistically significant difference between saline and PPE treated animals $\left({ }^{*} p<0.001, \# p=0.022\right)$.

Table 2

Estimation of inflammatory cells on hematoxylin-eosin stained sections.

\begin{tabular}{lllll}
\hline & & Macrophages & Neutrophils & Lymphocytes \\
\hline \multirow{2}{*}{$3 \mathrm{~d}$} & $\mathrm{~T}$ & +++++++++ & +++++++ & \\
& $\mathrm{C}$ & +++ & ++ & \\
\multirow{2}{*}{$21 \mathrm{~d}$} & $\mathrm{~T}$ & +++ & ++++ & ++ \\
& $\mathrm{C}$ & + & + & \\
$105 \mathrm{~d}$ & $\mathrm{~T}$ & ++++++ & ++ & ++++ \\
& $\mathrm{C}$ & + & & \\
\hline
\end{tabular}

Control (C) and elastase-treated rats (T) at 3, 21 and 105 days after treatment.

wall breaks (Fig. 2A and B), and the distribution of the $D_{\text {alv }}$ values included diameters larger than $300 \mu \mathrm{m}$ (Fig. 2E). The median $D_{\text {alv }}$ (Fig. $\left.3 \mathrm{~A}\right)$ increased significantly with time $(p<0.001)$ both in the control (C3 vs C105) and the treated groups (T3 vs T105). In the control rats, median $D_{\text {alv }}$ increased from $57.8 \mu \mathrm{m}$ to $73.1 \mu \mathrm{m}$ (126.5\%; $p=0.007)$, while in the treated animals the corresponding changes were from 66.7 to $88.4 \mu \mathrm{m}$ (132.5\%; $p<0.001)$. The difference between the control and the treated animals became statistically significant on day $21(p=0.027)$, and remained significant till day $105(p=0.004)$. In contrast to $D_{\mathrm{alv}}, D_{2}$ revealed a difference in alveolar size between the 2 groups already by day 3 (Fig. $3 \mathrm{~B}$ ). The highest values of $T_{\mathrm{w}}$ were found on day 3 in both groups (Fig. $3 \mathrm{C}$ ), which was followed by decreases on day 21 and a reversal on day 105 . The treated groups had significantly higher values of $T_{\mathrm{w}}$ than the controls at all time points.

The ex vivo images obtained with the OPS technique demonstrated enlargements of subpleural airspaces in the T105 group compared to those in the C105 animals ( $c f$. Fig. 2D and C), which resulted in a rightward shift of the $D_{\text {alv }}$ distribution (Fig. 2F) with the median increasing from 66.3 to $78.4 \mu \mathrm{m}(p<0.001$, Kolmogorov-Smirnov test). Note that the OPS $D_{\text {alv }}$ distributions do not extend to the high values that correspond to ductal structures included in the histology distributions.

The evaluation of inflammatory cells showed important changes in time and with treatment (Table 2). There was a two-phase macrophage response to elastase treatment with the first increase occurring on day 3 and the second on day 105 . Neutrophils and lymphocytes exhibited a one-phase invasion but with an early onset (day 3 ) for neutrophils and a late onset (day 105) for lymphocytes.
Examples of elastin and collagen stained samples are presented in Fig. 4B, C, E and F. These ECM components showed only mild changes. The highest levels of Mec were found at day 3 with no difference between groups $\mathrm{C} 3$ and $\mathrm{T} 3$, whereas significant differences between control and treated groups $(p<0.001)$ were observed on days 21 and 105 (Fig. 4A) with larger values of Mec in the treated groups. Mcc presented a reverse tendency (Fig. 4D); the differences between $C$ and $\mathrm{T}$ developed at day 3 that was sustained at day 21 $(p<0.001)$ but vanished by day 105 .

The values of $H$ are plotted against the corresponding mean values of $D_{\text {alv }}$ in all animals in Fig. 5. The inverse relationship between $H$ and $D_{\text {alv }}$ reveals a strong structure-function correlation with both the control and treated rats following this relationship.

\section{Discussion}

This follow-up study was designed to track the elastase-induced alterations in lung structure, ECM composition and function in rats within but also beyond the few weeks intervals usually covered by previous investigations (Schmiedl et al., 2008; Vecchiola et al., 2011). Repeated measurements of respiratory mechanics and lung volumes were made in the same animals at 3, 21 and 105 days after the elastase treatment. Lung morphometry and evaluation of inflammatory cells and the major load bearing ECM components were accomplished at the end of the follow-up study and also in subgroups of rats at 3 and 21 days. Additionally, alveolar structural information on the intact lungs was obtained by ex vivo imaging from the subpleural alveoli at the end of the study.

\subsection{Lung volumes and mechanics}

The longitudinal functional data reflected both the continuous progression of emphysema in the PPE-treated rats and the somatic growth in all animals until day 105 . These changes similarly affect lung volumes and tissue mechanics. Apart from these patterns of change in TLC, the elevation of lung volumes in the PPE treated groups resembles the typical feature of the human disease (Cooper, 2005). Our finding that the differences between the two groups increased further after the 21st day of the study (an interval around the standard recommended time of the PPE rodent model (Snider 

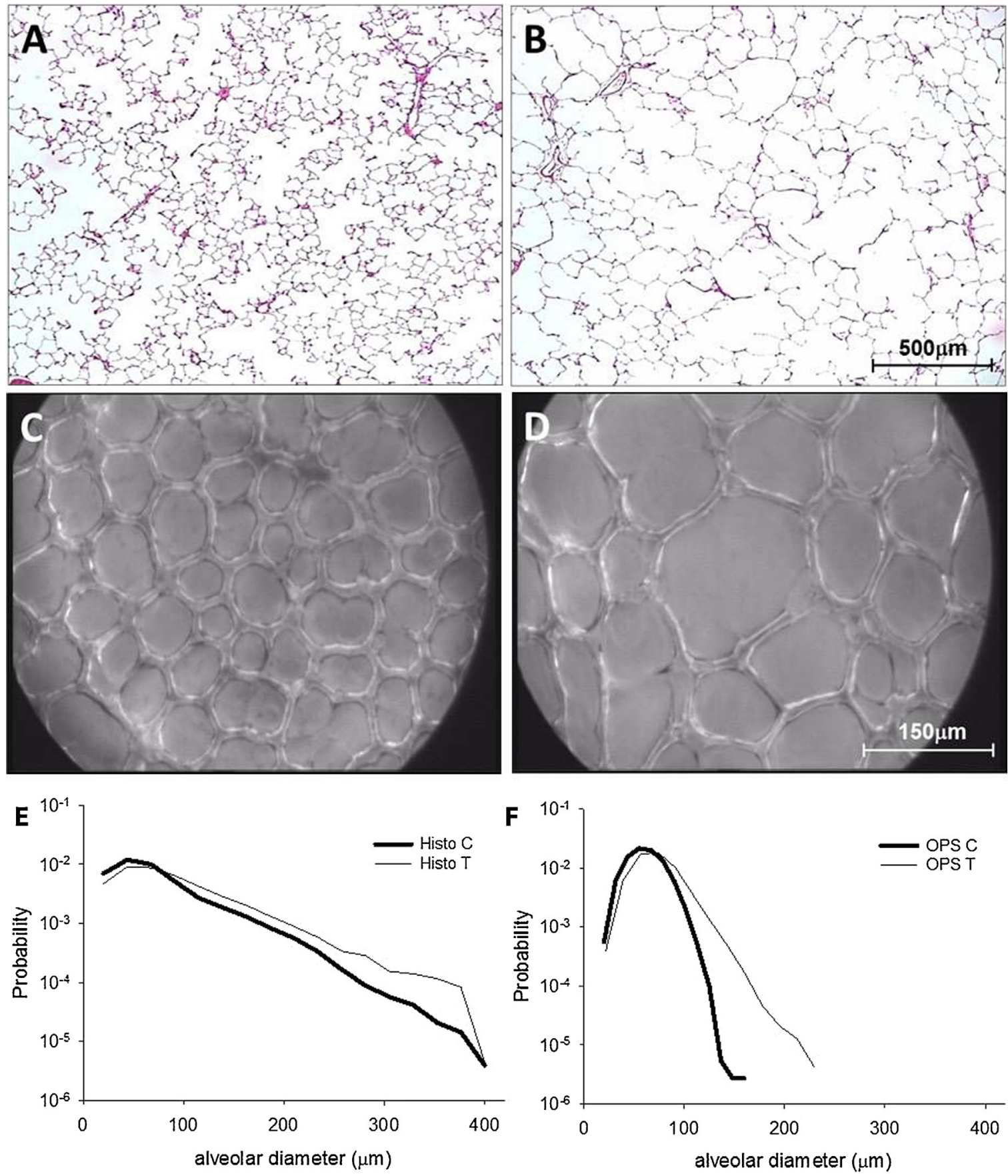

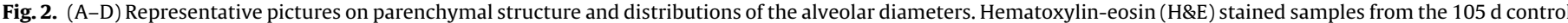

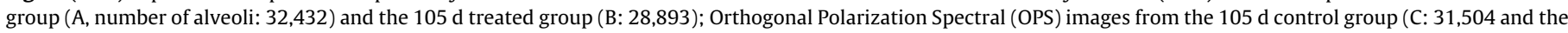
$105 \mathrm{~d}$ treated group (D: 13,656). (E and F) Distribution of the alveolar diameters $\left(D_{\text {alv }}\right)$ in the $105 \mathrm{~d}$ animals obtained from H\&E stained sections (E) and OPS images (F).

et al., 1986)) indicates the need for longer protocols for the investigation of late stage emphysema.

The changes in the mechanical properties of the respiratory tissues paralleled those in lung volumes. While natural growth leads to a decrease in volumetric elastance, PPE induced an accelerated decrease in $H$. Interestingly, the difference in $G$ between groups $C$ and $\mathrm{T}$ did not develop as fast and as much as that in $H$ ( $c f$. Fig. $1 \mathrm{~F}$ and $G$ ); as a result of this, $\eta$ increased abruptly in group T (Fig. $1 \mathrm{H}$ ). This may indicate either an immediate alteration in parenchymal viscoelasticity (as a consequence of the elastolytic intervention) or an increase in lung heterogeneity. The lack of difference in Raw between groups $\mathrm{C}$ and $\mathrm{T}$ at any time point of the study is in accordance with the results of previous studies, where the airway function did not appear to be affected by the loss of parenchymal tethering forces as expected from the fall in elastance (Hantos et al., 2008; Vecchiola et al., 2011). There were mild gradual decreases in Raw, which were similar in groups $\mathrm{C}$ and $\mathrm{T}$, and can be attributed to body (and lung) growth with age.

\subsection{Lung structure}

The OPS technique was designed to image human microcirculation (Groner et al., 1999) using reflected light from the surface of a solid organ such as brain, skin (Harris et al., 2000), liver, 
A

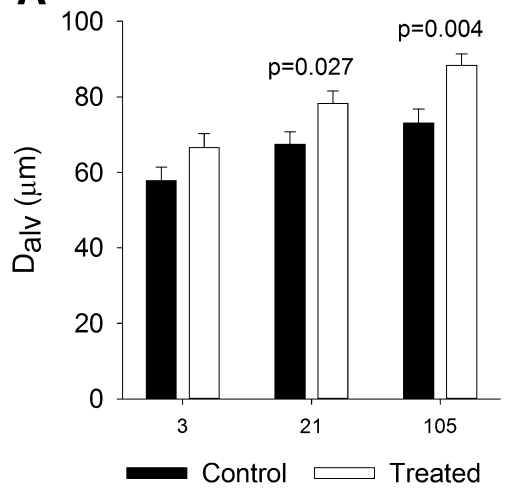

B

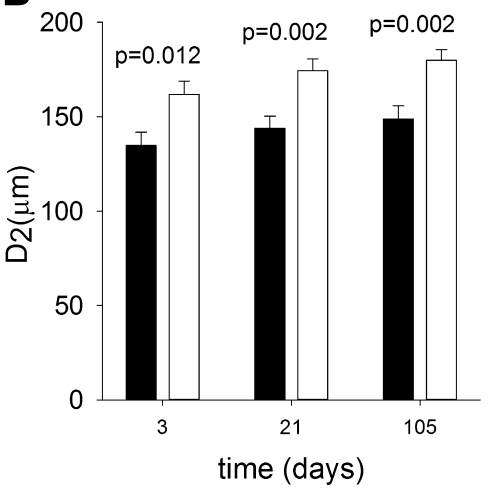

C

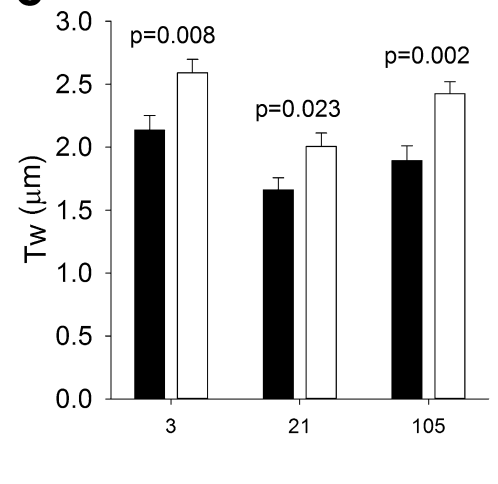

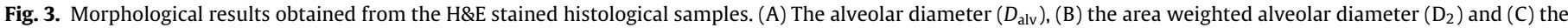

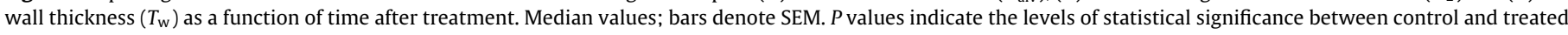
groups.

pancreas (Langer et al., 2000) and conjunctiva or cornea (Laemmel et al., 2000). Although this imaging technique can be used in vivo, we choose the ex vivo condition to avoid the confounding effects of the beating heart, which allowed us to investigate the subpleural alveoli in their unaltered, physiological condition. Despite the fact that the OPS technique is optimized for the visualization of hemoglobin, the present imaging results demonstrate that the blood cells remaining after the exsanguination of lungs provide sufficient contrast in the septal planes perpendicular to the pleural surface. The distribution of the subpleural alveoli showed a slight shift in the treated group due to septal wall ruptures, which lead to enlarged airspaces. Thus, this technique is capable of detecting structural differences between the normal and the emphysematous lung. The distribution of the alveoli from the traditional histological samples indicated a similar scenario, but the histogram revealed a longer tail, which means that the subpleural alveoli are smaller in the OPS images both in the control and PPE-treated animals than in the histological samples where the entire plane of the section was investigated. In addition to the fact that the large ductal structures are not included in the OPS images this difference may be explained by the cohesive effect of the pleura, which can mitigate any increase in alveolar size in both groups. Similar results were found regarding the size of subpleural alveoli in mice by Mitzner et al. (2008). They investigated agarose fixed lung samples with traditional histology and found significantly smaller mean airspace chord lengths close to the pleura than in the interior parts of the lung. We confirm these findings and show here that OPS- and histology-based airspace sizes seen in this study are physiological in nature and the two methods are complementary.

The increases in the median $D_{\text {alv }}$ and $D_{2}$ in the treated animals are consistent with the morphological features of emphysema, i.e. the destructed wall of the airspaces and the enlarged alveoli, with the $D_{2}$ being more sensitive to the morphological changes in this pathological condition because it also incorporates heterogeneity
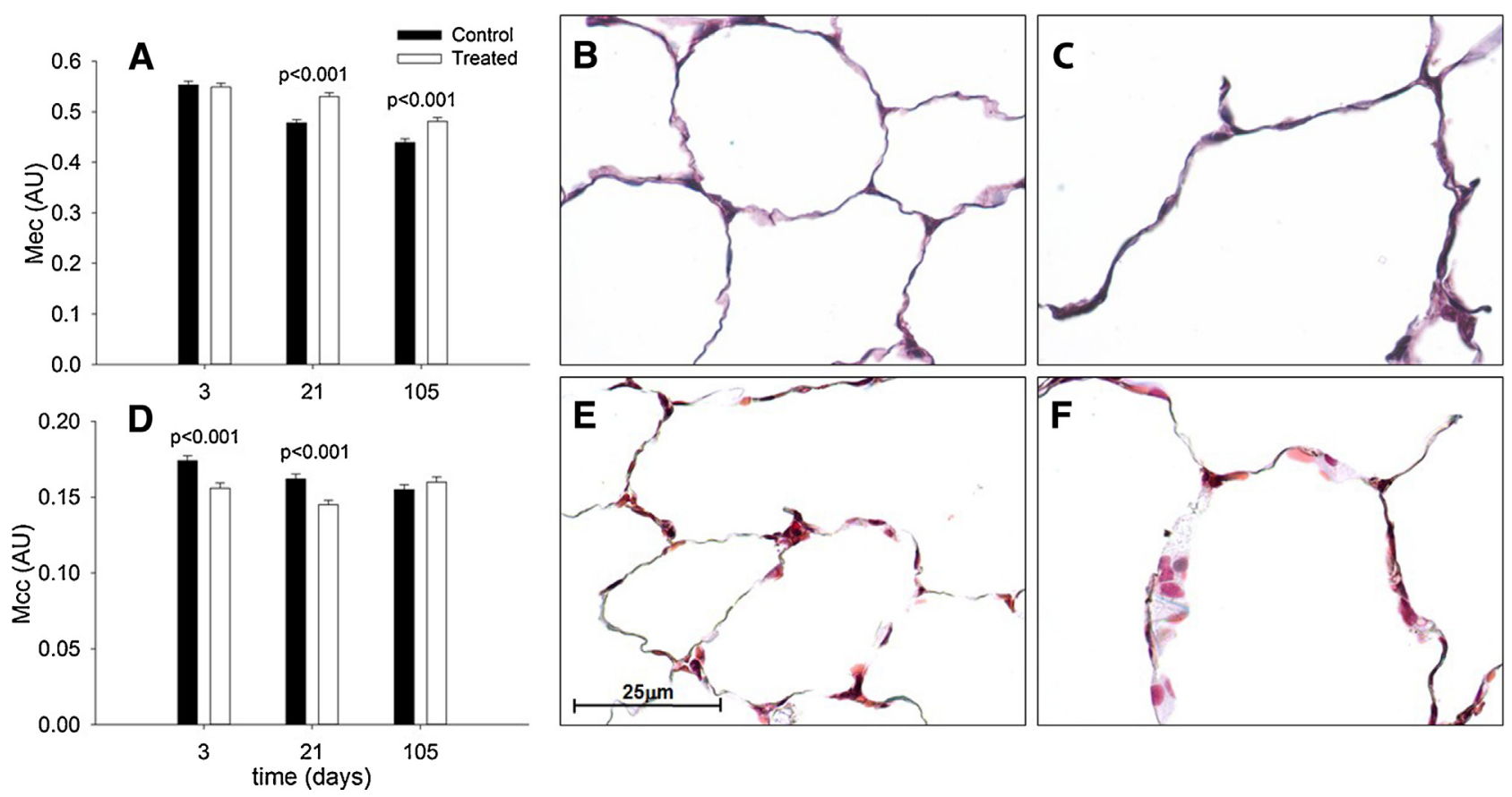

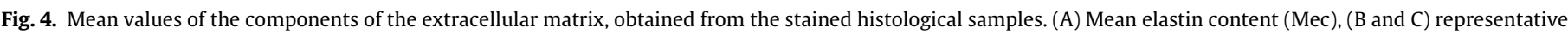

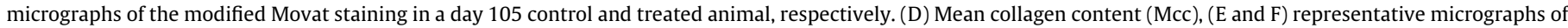

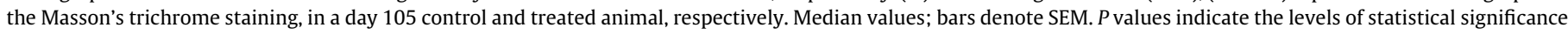
between control and treated groups. Histological pictures with $60 \times$ magnification. 


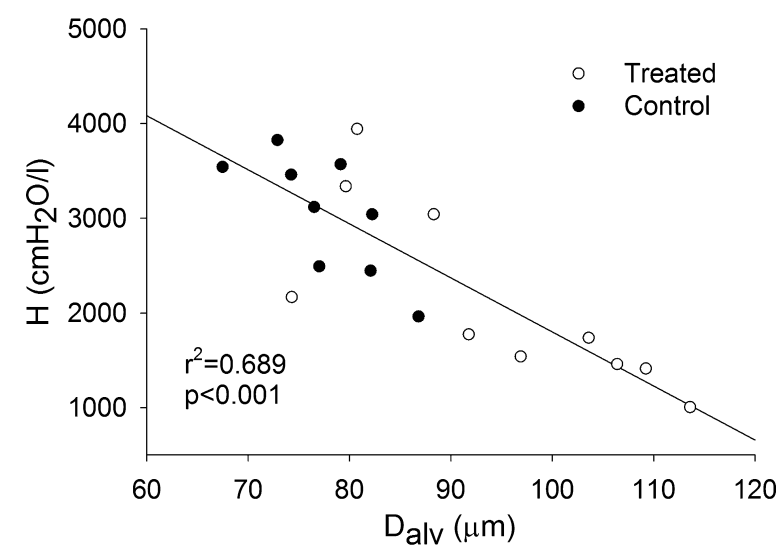

Fig. 5. Structure-function correlation. The tissue elastance $(H)$ as a function of the mean alveolar diameter $\left(D_{\text {alv }}\right)$ in control and elastase-treated rats. Pooled data from control and treated rats.

of structure (Jacob et al., 2009; Parameswaran et al., 2006). The wall thickness of the alveoli on the histological images was higher in the PPE treated animals due to tissue remodeling. Previous studies also found an elevated alveolar septal wall thickness in elastase-treated mice, although there was not a significant difference between the saline-treated control and the PPE-treated animals (Imai et al., 2010; Ito et al., 2004). However, note that in those studies the intervals of the investigation, the treatment dose and method as well as the strain were different. In Sprague-Dawley rats the same results were found (Seifart et al., 2011), where the mean thickness was 2.1 and $2.9 \mu \mathrm{m}$ in the control and the emphysematous animals, respectively, 38 days after the PPE treatment. Increased septal wall thickness was also observed in human emphysema within moderate lesions (Vlahovic et al., 1999); however, the wall thickness was two times higher than in healthy controls $(5.2 \mu \mathrm{m} v s 2.2 \mu \mathrm{m})$ indicating a limitation of the PPE-induced rat model of emphysema.

\subsection{Alterations in lung inflammation}

The evaluation of the inflammatory cells from the histological samples at day 3 showed the expected picture of lung injury (increased number of macrophages and neutrophils, Table 1.) due to the PPE treatment, coinciding with the observed macroscopic appearance of hemorrhaged lungs. The massive invasion of macrophages and neutrophils is attenuated by day 21 in the emphysematous animals, although a second macrophage phase was detectable at day 105 . These cells play important roles in the progression of emphysema because they are capable of releasing matrix metalloproteinases (MMPs) that break down both elastin and collagen. Moreover, macrophages are dominant cells in the airways and air spaces of emphysematous patients (Foronjy and D'Armiento, 2001), so that it is likely that these cells contribute to the progression of the PPE-induced emphysema.

\subsection{Changes in the ECM}

Changes in ECM composition are hallmark features of COPD. Many studies (Finlay et al., 1996; Karlinsky et al., 1983) have investigated the remodeling of elastin and collagen, because these two load-bearing components play crucial roles in the maintenance of the lung elasticity and structure. In our experiments, an increase in elastin content in the treated group was observed from the 21st day and lasted until the endpoint of the 105-day protocol. Similar results were found in hamsters 21 days after treatment with PPE, which was characterized as the elastin remodeling overshoot (Karlinsky et al., 1983). Finlay et al. (Finlay et al., 1996) reported that the sheets of elastin had moth-eaten appearance in rats and humans under scanning electron microscope. Interestingly, changes in collagen content were opposite and faster in the present work, and differences were found between the control and the emphysema groups at 3 and 21 days after the treatment. It is likely that the collagen content decreased as a result of the PPE treatment at the beginning of the study. Note that elastase is a serine protease which cleaves elastin at multiple sites (Houghton et al., 2006) as well as proteoglycans (Mok et al., 1992). However, it is more likely that the inflammatory cells secrete different MMPs (Lanone et al., 2002) including collagenases, which directly degrade the collagen in the ECM (D'Armiento et al., 2013). In response to the initial injury, the degraded collagen and elastin fibers start to be remodeled in the tissue. Indeed, a former rat study showed similar results: thickened collagen fibers under scanning electron microscope (Finlay et al., 1996). In patients, elevated elastin and collagen content was found by Vlahovic et al. (Vlahovic et al., 1999) in moderate emphysematous lesions in contrast to our results, suggesting additional limitations of the PPE-induced emphysema in rats.

An important finding of this study is a strong structure-function relation that links lung elasticity (parameter $H$ ) to mean alveolar diameter. The mechanism behind this relation is likely rupture of the septal walls. There are two consequences of a septal wall rupture. First, it leads to a coalescence of two neighboring alveoli and hence locally the alveolar diameters increase. Second, the rupture decreases the number of walls carrying the load in the parenchyma, which in turn decreases lung stiffness. Furthermore, a single rupture transmits the tension in the wall to its neighbors, which increases the likelihood of a subsequent rupture. Sufficient number of ruptures results in macroscopically measurable decrease in $H$. Thus, through a common mechanism, rupture of septal walls (Parameswaran et al., 2011; Suki et al., 2012), alveolar structure and parenchymal stiffness become intimately linked. Since airspace diameter steadily increases (Fig. 3A) while elastin content decreases and collagen content increases (Fig. 4A and 4D), it seems plausible that the amount of load bearing ECM constituents determine the failure of the septal walls and indirectly alveolar airspace diameters. However, the ECM constituents also decrease in the control group during natural growth of the animal. One possibility is that the cross-link density and distribution are different in the remodeled elastin and collagen fibers that make them vulnerable to failure. Indeed, the difference in the inflammatory cells between the control and treated groups (Table 2) may explain the presence of an aberrant remodeling (Vlahovic et al., 1999) resulting in weak fibers and failure (Kononov et al., 2001). Mechanical failure in turn exposes fragments which are chemoattractant to macrophages in the lung (Houghton et al., 2006) and a vicious circle may form: tissue inflammation leads to mechanical failure which maintains inflammation and ultimately a steady progression of the disease.

\section{Summary}

In conclusion, we have demonstrated that the progression of emphysema induced by a single dose of PPE did not reach a plateau in lung volumes and pulmonary mechanics by the end of this 105-day follow-up study. It is likely that the second phase of macrophage invasion plays an important role in the continued progression of emphysema. The ex vivo (OPS) imaging of subpleural alveoli in the intact lung structure confirmed the results of the conventional morphometry and revealed the elastaseinduced enlargement and destruction of the peripheral airspaces. At the level of the ECM we observed that elastin remodeling was delayed compared to the collagen remodeling. Overall, a strong structure-function relation has been identified that is driven by septal wall ruptures. Thus, such relations obtained from long-term follow-up studies may be used to predict the amount of structural 
deterioration of the parenchyma from non-invasive measurement of lung function.

\section{Acknowledgements}

This study was supported by Hungarian Scientific Research Fund (OTKA) grants 66700 and 105403, and NIH grant HL090757; M. V. Szabari received support from the Rosztóczy Foundation.

\section{References}

Artaechevarria, X., Blanco, D., de Biurrun, G., Ceresa, M., Perez-Martin, D., Bastarrika, G., de Torres, J.P., Zulueta, J.J., Montuenga, L.M., Ortiz-de-Solorzano, C., MunozBarrutia, A., 2011. Evaluation of micro-CT for emphysema assessment in mice: comparison with non-radiological techniques. Eur. Radiol. 21, 954-962.

Bellofiore, S., Eidelman, D.H., Macklem, P.T., Martin, J.G., 1989. Effects of elastaseinduced emphysema on airway responsiveness to methacholine in rats. J. Appl. Physiol. (1985) 66, 606-612.

Cooper, C.B., 2005. Assessment of pulmonary function in COPD. Semin. Respir. Crit. Care Med. 26, 246-252.

D’Armiento, J.M., Goldklang, M.P., Hardigan, A.A., Geraghty, P., Roth, M.D., Connett, J.E., Wise, R.A., Sciurba, F.C., Scharf, S.M., Thankachen, J., Islam, M., Ghio, A.J., Foronjy, R.F., 2013. Increased matrix metalloproteinase (MMPs) levels do not predict disease severity or progression in emphysema. PLoS ONE 8, e56352.

DuBois, A.B., Botelho, S.Y., Bedell, G.N., Marshall, R., Comroe Jr., J.H., 1956. A rapid plethysmographic method for measuring thoracic gas volume: a comparison with a nitrogen washout method for measuring functional residual capacity in normal subjects. J. Clin. Invest. 35, 322-326.

Emami, K., Cadman, R.V., Woodburn, J.M., Fischer, M.C., Kadlecek, S.J., Zhu, J., Pickup, S., Guyer, R.A., Law, M., Vahdat, V., Friscia, M.E., Ishii, M., Yu, J., Gefter, W.B., Shrager, J.B., Rizi, R.R., 2008. Early changes of lung function and structure in an elastase model of emphysema - a hyperpolarized 3He MRI study. J. Appl. Physiol. (1985) 104, 773-786

Finlay, G.A., O’Donnell, M.D., O’Connor, C.M., Hayes, J.P., FitzGerald, M.X., 1996 Elastin and collagen remodeling in emphysema. A scanning electron microscopy study. Am. J. Pathol. 149, 1405-1415

Foronjy, R., D’Armiento, J., 2001. The role of collagenase in emphysema. Respir. Res. 2, 348-352.

Groner, W., Winkelman, J.W., Harris, A.G., Ince, C., Bouma, G.J., Messmer, K., Nadeau, R.G., 1999. Orthogonal polarization spectral imaging: a new method for study of the microcirculation. Nat. Med. 5, 1209-1212.

Hantos, Z., Adamicza, A., Jánosi, T.Z., Szabari, M.V., Tolnai, J., Suki, B., 2008. Lung volumes and respiratory mechanics in elastase-induced emphysema in mice. J. Appl. Physiol. (1985) 105, 1864-1872.

Hantos, Z., Daróczy, B., Suki, B., Nagy, S., Fredberg, J.J., 1992. Input impedance and peripheral inhomogeneity of dog lungs. J. Appl. Physiol. (1985) 72, 168-178.

Harris, A., Sinitsina, I., Messmer, K., 2000. Quantitative Analysis of Orthogonal Polarization Spectral Images: Validation in the Hamster Dorsal Skinfold Chamber Orthogonal Polarization Spectral Imaging. Karger, Basel, pp. 21-31.

Houghton, A.M., Quintero, P.A., Perkins, D.L., Kobayashi, D.K., Kelley, D.G., Marconcini, L.A., Mecham, R.P., Senior, R.M., Shapiro, S.D., 2006. Elastin fragments drive disease progression in a murine model of emphysema. J. Clin. Invest. 116 753-759.

Imai, H., Kimura, A., Iguchi, S., Hori, Y., Masuda, S., Fujiwara, H., 2010. Noninvasive detection of pulmonary tissue destruction in a mouse model of emphysema using hyperpolarized ${ }^{129}$ Xe MRS under spontaneous respiration. Magn. Reson. Med. 64, 929-938.

Ito, S., Ingenito, E.P., Arold, S.P., Parameswaran, H., Tgavalekos, N.T., Lutchen, K.R., Suki, B., 2004. Tissue heterogeneity in the mouse lung: effects of elastase treatment. J. Appl. Physiol. (1985) 97, 204-212.
Jacob, R.E., Carson, J.P., Gideon, K.M., Amidan, B.G., Smith, C.L., Lee, K.M., 2009. Comparison of two quantitative methods of discerning airspace enlargement in smoke-exposed mice. PLoS ONE 4, e6670.

Jánosi, T.Z., Adamicza, A., Zosky, G.R., Asztalos, T., Sly, P.D., Hantos, Z., 2006. Plethysmographic estimation of thoracic gas volume in apneic mice. J. Appl. Physiol. (1985) 101, 454-459.

Karlinsky, J., Fredette, J., Davidovits, G., Catanese, A., Snider, R., Faris, B., Snider, G.L., Franzblau, C., 1983. The balance of lung connective tissue elements in elastaseinduced emphysema. J. Lab. Clin. Med. 102, 151-162.

Kononov, S., Brewer, K., Sakai, H., Cavalcante, F.S., Sabayanagam, C.R., Ingenito, E.P., Suki, B., 2001. Roles of mechanical forces and collagen failure in the development of elastase-induced emphysema. Am. J. Respir. Crit. Care Med. 164, 1920-1926.

Laemmel, E.R.T., Sinitsina, I., Boczkowski, J., 2000. Using orthogonal polarization spectral imaging for the experimental study of microcirculation: comparisons with intravital microscopy. In: Messmer, K. (Ed.), Orthogonal Polarization Spectral Imaging. Karger, Basel, pp. 50-60.

Langer, S., von Dobschuetz, E., Harris, A., Krombach, F., Messmer, K., 2000. Validation of the orthogonal polarization spectral imaging technique on solid organs. In: Messmer, K. (Ed.), Orthogonal Polarization Spectral Imaging. Karger, Basel, pp. 36-42.

Lanone, S., Zheng, T., Zhu, Z., Liu, W., Lee, C.G., Ma, B., Chen, Q., Homer, RJ. Wang, J., Rabach, L.A., Rabach, M.E., Shipley, J.M., Shapiro, S.D., Senior, R.M. Elias, J.A., 2002. Overlapping and enzyme-specific contributions of matrix metalloproteinases-9 and -12 in IL-13-induced inflammation and remodeling. J. Clin. Invest. 110, 463-474.

Mitzner, W., Fallica, J., Bishai, J., 2008. Anisotropic nature of mouse lung parenchyma. Ann. Biomed. Eng. 36, 2111-2120.

Mok, M.T., Ilic, M.Z., Handley, C.J., Robinson, H.C., 1992. Cleavage of proteoglycan aggregate by leucocyte elastase. Arch. Biochem. Biophys. 292, 442-447.

Parameswaran, H., Majumdar, A., Ito, S., Alencar, A.M., Suki, B., 2006. Quantitative characterization of airspace enlargement in emphysema. J. Appl. Physiol. (1985) 100, 186-193.

Parameswaran, H., Majumdar, A., Suki, B., 2011. Linking microscopic spatial patterns of tissue destruction in emphysema to macroscopic decline in stiffness using a 3D computational model. PLoS Comput. Biol. 7, e1001125.

Schmiedl, A., Lempa, T., Hoymann, H.G., Rittinghausen, S., Popa, D., Tschernig, T., Fehrenbach, H., Pabst, R., Hoeper, M.M., Hohlfeld, J.M., 2008. Elastase-induced lung emphysema in rats is not reduced by hematopoietic growth factors when applied preventionally. Virchows Arch. 452, 675-688.

Seifart, C., Muyal, J.P., Plagens, A., Yildirim, A.O., Kohse, K., Grau, V., Sandu, S. Reinke, C., Tschernig, T., Vogelmeier, C., Fehrenbach, H., 2011. All-trans retinoic acid results in irregular repair of septa and fails to inhibit proinflammatory macrophages. Eur. Respir. J. 38, 425-439.

Snider, G.L., Lucey, E.C., Stone, P.J., 1986. Animal models of emphysema. Am. Rev. Respir. Dis. 133, 149-169.

Stevenson, C.S., Birrell, M.A., 2011. Moving towards a new generation of animal models for asthma and COPD with improved clinical relevance. Pharmacol. Ther. 130, 93-105.

Suki, B., Jesudason, R., Sato, S., Parameswaran, H., Araujo, A.D., Majumdar, A., Allen, P.G., Bartolák-Suki, E., 2012. Mechanical failure, stress redistribution, elastase activity and binding site availability on elastin during the progression of emphysema. Pulm. Pharmacol. Ther. 25, 268-275.

Tolnai, J., Szabari, M.V., Albu, G., Maár, B.A., Parameswaran, H., Bartolák-Suki, E., Suki, B., Hantos, Z., 2012. Functional and morphological assessment of early impairment of airway function in a rat model of emphysema. J. Appl. Physiol. (1985) $112,1932-1939$.

Vecchiola, A., de la Llera, J.F., Ramirez, R., Olmos, P., Herrera, C.I., Borzone, G., 2011. Differences in acute lung response to elastase instillation in two rodent species may determine differences in severity of emphysema development. Am. J. Physiol. Regul. Integr. Comp. Physiol. 301, R148-R158.

Vlahovic, G., Russell, M.L., Mercer, R.R., Crapo, J.D., 1999. Cellular and connective tissue changes in alveolar septal walls in emphysema. Am. J. Respir. Crit. Care Med. 160, 2086-2092. 
IV. M.V. Szabari, H. Parameswaran, S. Sato, Z. Hantos, E. Bartolák-Suki and B. Suki: Acute mechanical forces cause deterioration in lung structure and function in elastase-induced emphysema. American Journal of Physiology. Lung Cellular and Molecular Physiology, 303: L567-L574 (2012) 


\section{Acute mechanical forces cause deterioration in lung structure and function in elastase-induced emphysema}

M. V. Szabari, H. Parameswaran, S. Sato, Z. Hantos, E. Bartolák-Suki and B. Suki Am J Physiol Lung Cell Mol Physiol 303:L567-L574, 2012. First published 3 August 2012; doi: 10.1152/ajplung.00217.2012

You might find this additional info useful...

This article cites 42 articles, 31 of which you can access for free at:

http://ajplung.physiology.org/content/303/7/L567.full\#ref-list-1

Updated information and services including high resolution figures, can be found at: http://ajplung.physiology.org/content/303/7/L567.full

Additional material and information about American Journal of Physiology - Lung Cellular and Molecular Physiology can be found at:

http://www.the-aps.org/publications/ajplung

This information is current as of December 10, 2012. 


\title{
CALL FOR PAPERS | Bioengineering the Lung: Molecules, Materials, Matrix,
}

\author{
Morphology, and Mechanics
}

\section{Acute mechanical forces cause deterioration in lung structure and function}

\section{in elastase-induced emphysema}

\author{
M. V. Szabari, ${ }^{1,2}$ H. Parameswaran, ${ }^{1}$ S. Sato, ${ }^{1}$ Z. Hantos, ${ }^{2}$ E. Bartolák-Suki, ${ }^{1}$ and B. Suki ${ }^{1}$ \\ ${ }^{1}$ Boston University, Boston, Massachusetts, ${ }^{2}$ University of Szeged, Szeged, Hungary
}

Submitted 9 July 2012; accepted in final form 31 July 2012

Szabari MV, Parameswaran H, Sato S, Hantos Z, Bartolák-

Suki E, Suki B. Acute mechanical forces cause deterioration in lung structure and function in elastase-induced emphysema. Am J Physiol Lung Cell Mol Physiol 303: L567-L574, 2012. First published August 1, 2012; doi:10.1152/ajplung.00217.2012.-The relation between the progression of chronic obstructive pulmonary disease (COPD) and exacerbations is unclear. Currently, no animal model of acute exacerbation of COPD (AECOPD) exists. The objectives of this study were to evaluate the effects of mechanical forces induced by deep inspirations (DIs) on short-term deterioration of lung structure and function to mimic AECOPD. At 2, 7, or 21 days after treatment with elastase, mice were ventilated with or without DIs $\left(35 \mathrm{cmH}_{2} \mathrm{O}\right.$ airway pressure for $3 \mathrm{~s}, 2$ times/min) for $1 \mathrm{~h}$. Functional residual capacity (FRC) was measured with body plethysmography, and respiratory compliance, resistance, and hysteresivity were obtained via forced oscillations. From hematoxylin and eosin-stained sections, equivalent airspace diameters (D), alveolar wall thickness $\left(\mathrm{W}_{\mathrm{t}}\right)$, number of septal ruptures $\left(\mathrm{N}_{\mathrm{sr}}\right)$, and attachment density $\left(\mathrm{A}_{\mathrm{d}}\right)$ around airways were determined. FRC, compliance, and hysteresivity statistically significantly increased with time, and both increased due to DIs. Interestingly, DIs also had an effect on FRC, compliance, resistance, and hysteresivity in control mice. The development of emphysema statistically significantly increased $\mathrm{D}$ and $\mathrm{W}_{\mathrm{t}}$ in time, and the DIs caused subtle differences in D. At 21 days, the application of DIs changed the distribution of $\mathrm{D}$, increased $\mathrm{W}_{t}$ and $\mathrm{N}_{\mathrm{sr}}$, and decreased $\mathrm{A}_{\mathrm{d}}$. These results suggest that once a critical remodeling of the parenchyma has been reached, acute mechanical forces lead to irreversible changes in structure and function, mimicking COPD exacerbations. Thus, the acute application of DIs in mice with emphysema may serve as a useful model of AECOPD.

AECOPD; mechanical stress; exacerbation; irreversibility

CHRONIC OBSTRUCTIVE PULMONARY disease (COPD), including chronic bronchitis and emphysema, is a slowly developing and progressive disease with episodes of acute exacerbation (AECOPD). According to the latest Global Initiative for Chronic Obstructive Lung Disease (GOLD) Summary (8a), AECOPD is an acute event characterized by a worsening of the patient's respiratory symptoms that is beyond normal day-to-day variations and leads to a change in medication. Most AECOPD is triggered by bacterial (36) or viral (35) infections, by pollutants (33), or by cold temperature (4). Moreover, severe exacerbation-related hospitalization is associated with an increased risk

Address for reprint requests and other correspondence: B. Suki, Dept. of Biomedical Engineering, Boston Univ., 44 Cummington St., Boston, MA, 02215 (e-mail: bsuki@bu.edu). of mortality, even after discharge (8), with a heavy health care burden worldwide.

While the frequency of AECOPD was shown to correlate with lung function decline $(5,34)$, irreversible structural changes behind the functional decline following AECOPD have been identified only recently. Tanabe et al. (38) reported that changes in the distribution of low-attenuation areas on computerized tomography images of COPD patients were consistent with the coalescence of neighboring low-attenuation areas due to alveolar wall destruction. Since tissue destruction is the primary mechanism that drives airspace enlargement, AECOPD should also contribute to the progression of COPD. However, a detailed understanding of how exacerbation results in irreversible functional changes is lacking. Consequently, there is an urgent need for novel animal models of AECOPD.

To our knowledge, the only study that proposed an animal model of AECOPD was by Wang et al. (40). To mimic AECOPD, the authors combined elastase-induced emphysema with viral infection. Unfortunately, they did not compare the structural or functional changes in their model with those due only to elastase. Hence, it remains unclear to what extent the viral infection exaggerated tissue destruction. Nevertheless, they did report that the animals had respiratory distress with coughing similar to human AECOPD. One should note that the main symptoms of AECOPD are always accompanied by increased mechanical stresses in the lung. Indeed, dyspnoe is characterized by hyperinflation (29), cough is preceded by a deep inspiration and followed by forced expiratory efforts with compressive and expulsive phases (22), and sputum production leads to cough. Since mechanical forces have been shown to be the governing mechanism of tissue destruction in emphysema $(19,26,37)$, we hypothesized that while viral or bacterial infections are the triggers, mechanical forces during the exacerbation phase play a key role in tissue rupture leading to irreversible changes in lung structure and function. To avoid the confounding effects of viral and bacterial infections, we tested this hypothesis by superimposing deep inspirations (DIs) during mechanical ventilation on the remodeled parenchyma at different stages of emphysema. If this hypothesis is supported by data, then our experiments will also provide a novel model of AECOPD.

\section{MATERIALS AND METHODS}

Animal treatment and experimental groups. The protocol was approved by the Animal Care and Use Committee of Boston University. Fifty-nine male C57BL/6 mice were slightly anesthetized with 
isofluorane vapor $(3 \%)$ in oxygen $(1.5 \mathrm{l} / \mathrm{min})$. The animals were then suspended by the upper incisors using a rubber band on a 60-degree inclined platform and treated with porcine pancreatic elastase (PPE; Elastin Products, Owensville, MO) (6 IU) via aspiration (20). After treatment, the animals were allowed to recover and maintained on a 12:12-h light-dark cycle. There were no deaths associated with the PPE treatment. Additionally, 15 animals were intact controls.

At 2, 7, or 21 days after the treatment, animals were anaesthetized with intraperitoneally administered pentobarbital sodium (initial dose: $75 \mathrm{mg} / \mathrm{kg}$, supporting dose: $10-20 \mathrm{mg} / \mathrm{kg}$ as needed) and received tracheostomy. The mice were then placed into a custom-built body plethysmograph and mechanically ventilated with FlexiVent (SCIREQ Scientific Respiratory Equipment, Montreal, Canada) (ventilation $=8 \mathrm{ml} / \mathrm{kg}, 240 \mathrm{br} / \mathrm{min}$ ) at $3 \mathrm{cmH}_{2} \mathrm{O}$ positive end expiratory pressure (PEEP) for $1 \mathrm{~h}$ with or without DIs defined as an inflation up to $35 \mathrm{cmH}_{2} \mathrm{O}$ airway pressure for $3 \mathrm{~s}$ delivered two times per minute. The mice were distributed randomly into the following experimental groups: control ( 0 days DI) $[n=7$; weight: $25.7 \pm 0.9 \mathrm{~g}$ (SD)], control $(0$ days no-DI) $(n=8 ; 24.5 \pm 1.3 \mathrm{~g}), 2$ days treated DI $(n=$ $8 ; 23.3 \pm 1.0 \mathrm{~g}), 2$ days treated no-DI $(n=8 ; 23.4 \pm 1.2 \mathrm{~g}), 1 \mathrm{wk}$ treated DI $(n=7 ; 25.3 \pm 1.1 \mathrm{~g}), 1$ wk treated no-DI $(n=8 ; 25.5$ $\mathrm{g} \pm 1.0 \mathrm{~g}), 3 \mathrm{wk}$ treated DI $(n=7 ; 27.1 \pm 1.5 \mathrm{~g}), 3 \mathrm{wk}$ treated no-DI $(n=6 ; 27.6 \pm 0.8 \mathrm{~g})$.

At the end of the ventilation protocol, the pulmonary circulation was flushed through the right ventricle with PBS. After sacrificing the mice, the lungs and heart were resected en block and fixed at 20 $\mathrm{cmH}_{2} \mathrm{O}$ transpulmonary pressure with $10 \%$ buffered formalin.

Physiological measurements. Functional residual capacity (FRC) was measured with a body plethysmograph (7) at $0 \mathrm{cmH}_{2} \mathrm{O}$ PEEP before and after the 1-h ventilation (17). At end expiration, the FlexiVent was stopped, and the tracheal cannula was occluded. During spontaneous breathing efforts for about $6 \mathrm{~s}$, box pressure and tracheal pressure were measured with a Validyne MP-45 $\left( \pm 2 \mathrm{cmH}_{2} \mathrm{O}\right)$ pressure sensor (Validyne, Northridge, CA) and a miniature pressure transducer (model 8507C-2; Endevco, San Juan Capistrano, CA), respectively. FRC was calculated from the box pressure, and tracheal pressure values were corrected with the thermal characteristics of the plethysmograph (17).

Low-frequency respiratory input impedance $(2-19 \mathrm{~Hz})$ was measured at $3 \mathrm{cmH}_{2} \mathrm{O}$ PEEP at the beginning and at the end of the 1-h ventilation with or without DI, using the optimal ventilation waveform (24). Respiratory compliance, Newtonian resistance (which is a surrogate of airway resistance), and hysteresivity were calculated by fitting the constant phase model to the impedance (12).

Histology. Sections were stained with hematoxylin and eosin. Randomly selected regions were imaged and segmented using custom-made software. The equivalent diameter of alveolar airspaces (D) was computed as the diameter of a circle with the same area as the airspace. For each mouse, the area-weighted average diameter $\left(D_{2}\right)$ was calculated from the set of $\mathrm{D}$ values (31). Since $\mathrm{D}_{2}$ has been shown
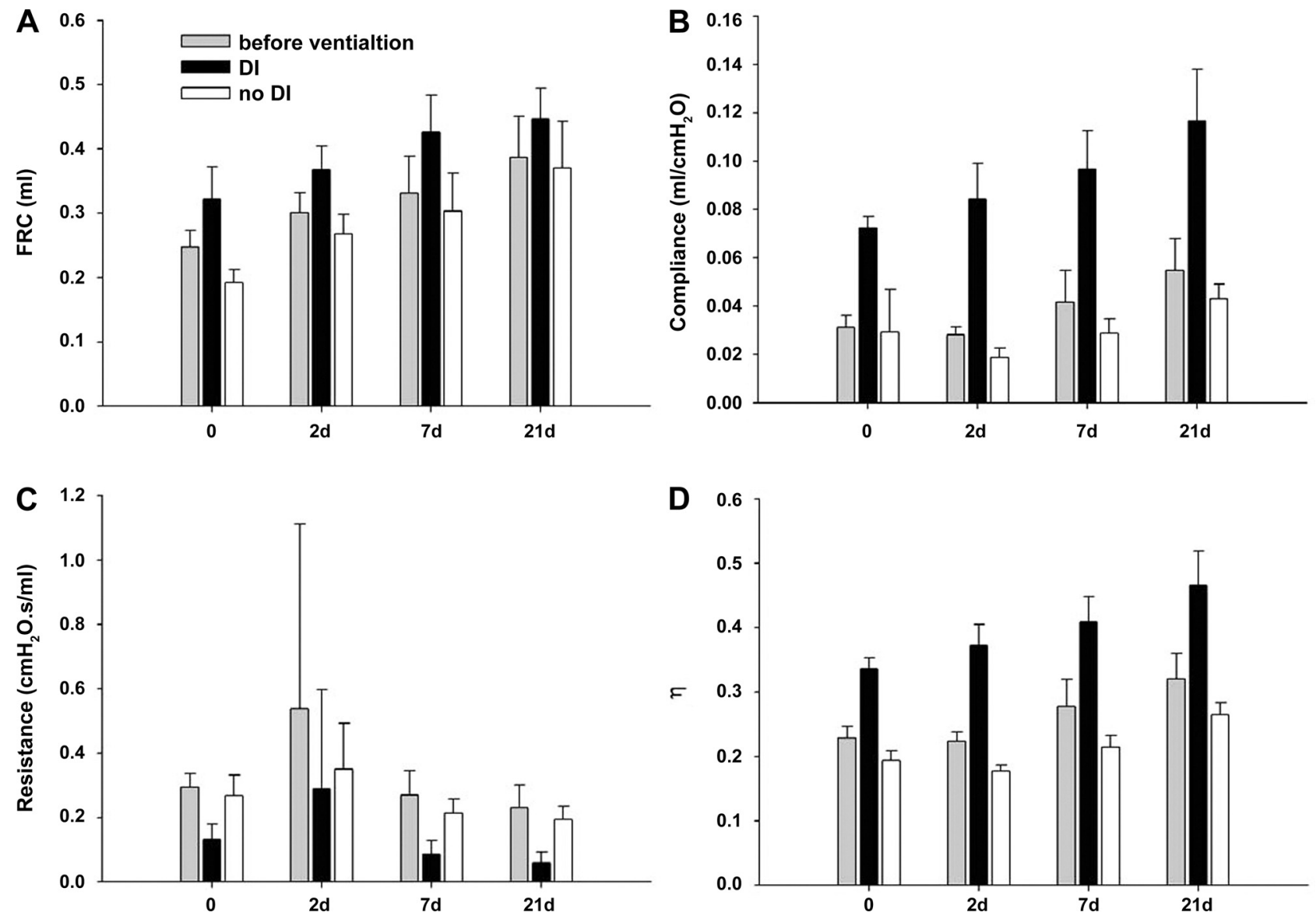

Fig. 1. Effects of time and deep inspirations (DIs) on physiological variables. A: functional residual capacity (FRC). Before ventilation, FRC increased with time (21 vs. 0 and 2 days: $P<0.05 ; 7$ vs. 0 days: $P<0.05 ; 2$ vs. 0 days: $P<0.05)$ and DIs had a significant effect on FRC at each time point $(P<0.001)$. $B$ : respiratory compliance. Before the ventilation, compliance increased with time $(21$ vs. 0 and 2 days, 7 vs. 2 days: $P<0.05)$, and DIs had a significant effect on compliance at each time point $(P<0.001)$. $C$ : respiratory resistance. Before ventilation, resistance showed a decreasing trend with time $(21$ vs. 0 and 2 days: $P<0.05)$, and DIs had a significant effect on resistance ( 0 days: $P=0.003,2$ days: $P=0.03,7$ and 21 days: $P<0.001) . D$ : hysteresivity $(\eta)$. Before the ventilation, hysteresivity showed an increasing trend with time (21 vs. 0 days) and DIs had a significant effect at each time point $(P<0.001)$. Bars denote SDs. 
to be sensitive to heterogeneities and able to detect small changes in structure compared with D or mean linear intercept (31), we also characterized the airspace structure with this parameter. On the hematoxylin and eosin-stained sections, the alveolar septal wall thickness $\left(\mathrm{W}_{\mathrm{t}}\right)$ was measured, and attachment density $\left(\mathrm{A}_{\mathrm{d}}\right)$ was determined by dividing the number of septal walls attached to a small airway with the outer perimeter of the airway wall. Collagen and elastin fibers were visualized with modified Masson's trichrome and Verhoeff's methods, respectively (10). The total number of end tips as a measure of septal ruptures $\left(\mathrm{N}_{\mathrm{sr}}\right)$ per image per tissue fraction was measured for the 21 days DI and 21 days no-DI groups on elastin stained samples.

Statistical analysis. The effects of DIs and time were analyzed with two-way ANOVA, while the effects of PPE treatment before ventilation were analyzed with one-way ANOVA. Where normality failed, $\log$ transformation was applied. The effect of DIs on $\mathrm{N}_{\mathrm{sr}}$ was compared with Mann-Whitney's rank sum test. A $P$ value $<0.05$ was considered statistically significant.

\section{RESULTS}

PPE significantly increased FRC before ventilation, with mean values of $0.25 \pm 0.026 \mathrm{ml}(\mathrm{SD})$ in the control mice $(0$ days), and $0.39 \pm 0.064 \mathrm{ml}$ in the PPE-treated 21 days groups $(P<0.001)$ (Fig. 1A). Independent of time, DIs increased FRC $(P<0.001)$. Following 1 -h ventilation, FRC was $0.32 \pm 0.05$ $\mathrm{ml}$ and $0.19 \pm 0.02 \mathrm{ml}$ in the 0 days DI group and 0 days no-DI group, respectively. In the 21 days groups, FRC increased from $0.37 \pm 0.07 \mathrm{ml}$ in the no-DI group to $0.45 \pm 0.05$ in the DI group.

PPE also increased compliance with time before ventilation $(P<0.001)$ with values of $0.031 \pm 0.005 \mathrm{ml} / \mathrm{cmH}_{2} \mathrm{O}$ and
$0.055 \pm 0.013 \mathrm{ml} / \mathrm{cmH}_{2} \mathrm{O}$ in the 0 days and 21 days groups, respectively (Fig. $1 B$ ). Similar to FRC, a strong effect of DIs can be seen on compliance at each time point $(P<0.001)$.

The parameter resistance (Fig. $1 C$ ) decreased gradually with time reaching significance at 21 days $(P=0.021)$. The hysteresivity (Fig. 1D) showed significant differences between the DI and no-DI groups $(P<0.001)$ and increased with time $(P<0.05)$, except from 0 days to 2 days and from 7 days to 21 days.

Figure 2 shows typical airspace structures in control and at each time point following treatment in the DI groups. The PPE treatment increased the mean airspace diameter (D) from $29.6 \pm 1.4 \mu \mathrm{m}$ in the control group to $34.9 \pm 2.9 \mu \mathrm{m}$ at 21 days after treatment $(P<0.001)$ (Fig. 3A). The $\mathrm{D}_{2}$ (Fig. $\left.3 B\right)$, which is sensitive to changes in both the mean and the heterogeneity of airspace sizes, showed much more prominent differences between the groups in time $(P<0.001)$. However, neither of these lumped structural indexes showed a difference between the DI and the no-DI groups at any time point.

To explore the possibility that the DIs caused a more subtle structural change in some preferential airspace size, the alveoli were pooled from all animals and grouped into small, medium, and large airspaces according to their D values, and statistics were done within these size categories (Table 1). For the smallest airspaces, significant differences were found between the DI and no-DI groups at 0 days and 21 days $(P<0.001)$ as well as at 7 days $(P=0.003)$. For the medium-sized airspaces, there were differences at 21

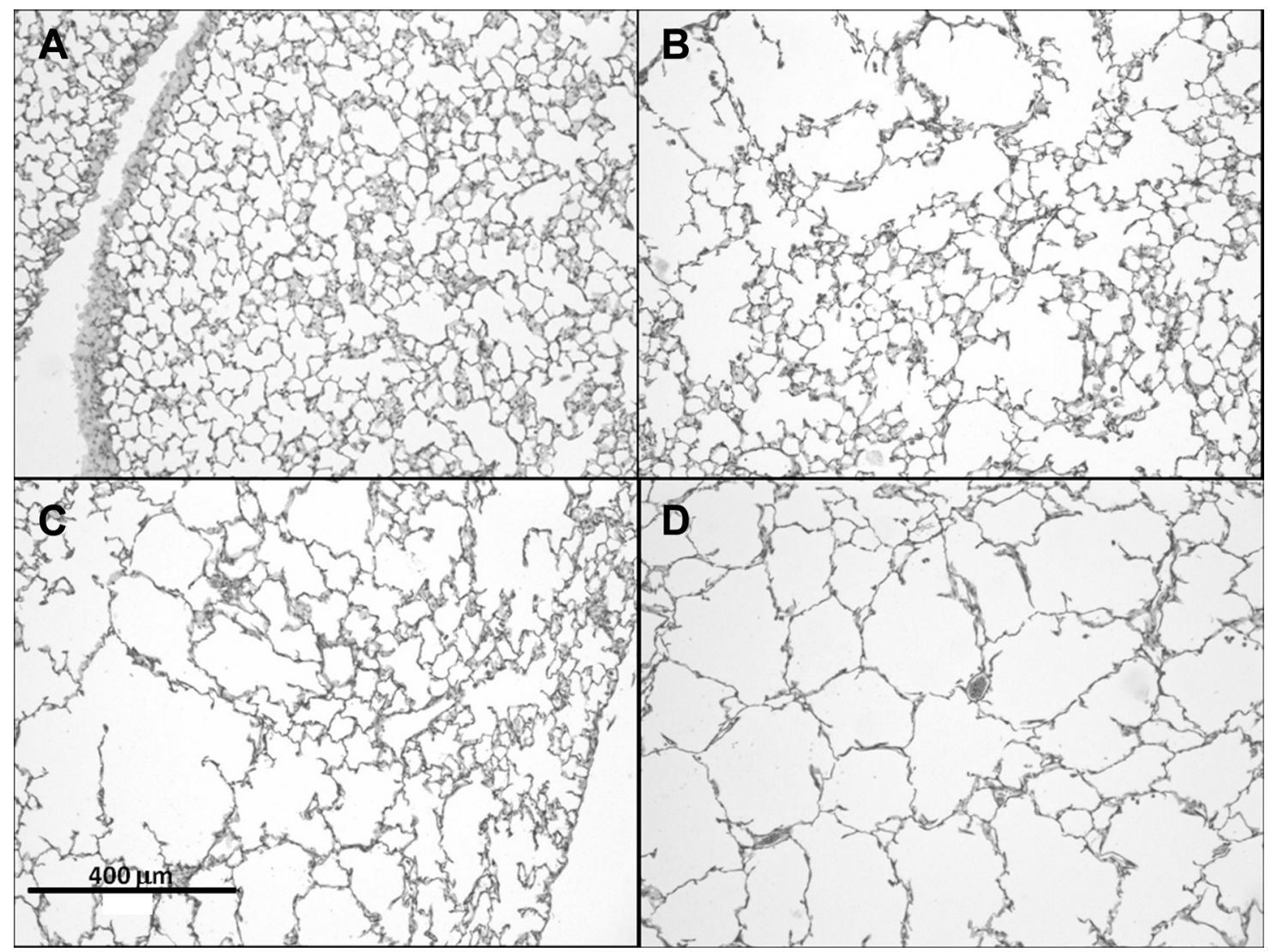

Fig. 2. Examples of hematoxylin and eosin-stained histological sections. A: control following 1-h ventilation with DIs; $B-D: 2,7$, and 21 days, respectively, after treatment following 1-h ventilation with DIs. 

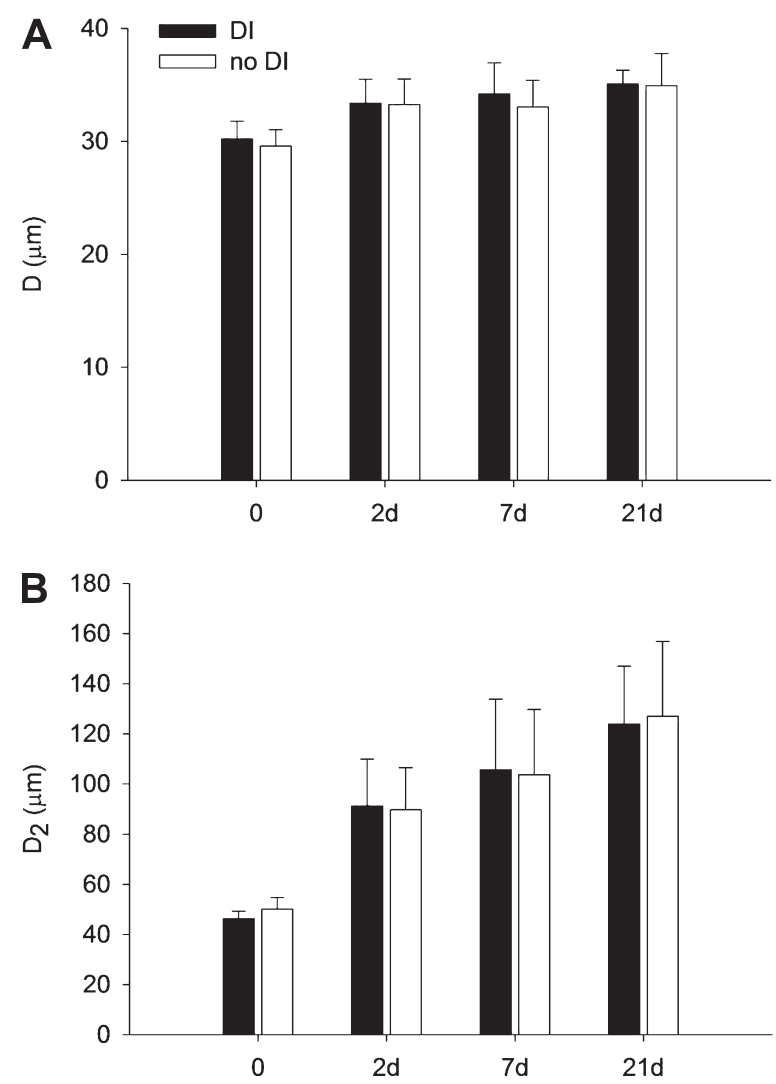

Fig. 3. Morphometric analysis of airspace sizes. $A$ : mean and SD of equivalent airspace diameters (D), in each group. Porcine pancreatic elastase (PPE) had a significant effect on D $(0$ vs. 2,7 , and 21 days: $P<0.001) . B$ : mean and SD of the area-weighted mean alveolar diameter $\left(\mathrm{D}_{2}\right)$ in each group. PPE had a significant effect on $\mathrm{D}_{2}(0$ vs. 2,7 , and 21 days: $P<0.001,2$ vs. 21 days: $P=0.01)$.

days $(P=0.007)$ and 0 days $(P=0.015)$, whereas for the largest airspaces, D was different only at 0 days $(P<$ 0.001). Even though the percent differences are small, it is interesting to note that, in the control animals, the no-DI group had a larger D, but in the treated animals, the DI groups always had a larger D.

The septal $\mathrm{W}_{\mathrm{t}}$ increased by $47 \%$ (Fig. 4) from $2.5 \pm 0.3$ $\mu \mathrm{m}$ at 0 days to $3.4 \pm 0.2 \mu \mathrm{m}$ at 21 days $(P<0.001)$. Moreover, at 21 days, the DIs induced a $13 \%$ elevation in $\mathrm{W}_{\mathrm{t}}$ compared with the no-DI group $(P=0.01)$. Interestingly, there appears to be more cell nuclei in the thicker septal walls following the application of DIs (Fig. 4B). Figure 5 shows microstructural images of the septal walls with and without DIs. The increased $\mathrm{W}_{\mathrm{t}}$ with DIs is apparent on both stainings. Furthermore, the elastin-stained images also suggest a slightly more disorganized microstructure within the septal walls. Figure 6 demonstrates the evaluation of septal wall ruptures at 21 days. Statistical analysis revealed that $\mathrm{N}_{\text {sr }}$ was significantly larger in the DI group compared with the no-DI group with values of $165 \pm 63$ and $134 \pm 68(P=$ $0.006)$, respectively. The perimeters of the airways in the DI and no-DI groups at 21 days for which $A_{d}$ was evaluated were not different. However, compared with the no-DI group, $\mathrm{A}_{\mathrm{d}}$ was $11 \%$ lower in the DI group $(P=0.026)$.

\section{DISCUSSION}

Exacerbations constitute a significant component of the clinical manifestation of COPD (8a), becoming increasingly more frequent as the disease progresses (2). For example, in a large clinical study, patients with severe COPD characterized by the GOLD category IV, had a higher annual exacerbation rate (2.00) than those with more moderate COPD, having GOLD categories of III and II (1.34 and 0.85 , respectively) (14). Other studies showed that patients with a forced expiratory volume in $1 \mathrm{~s}$ (FEV1) $>60 \%$ predicted had an exacerbation rate of 1.6 per year as opposed to patients with FEV1 between $59 \%$ and $40 \%$ and those with FEV1 $<40 \%$ predicted having annual exacerbation rates of 1.9 and 2.3 , respectively $(5,30)$. Furthermore, patients who suffer from frequent exacerbations will likely continue to do so (9). Despite considerable effort, understanding of the irreversible nature of AECOPD is not complete.

In this study, we hypothesized that the increased mechanical forces that accompany an AECOPD event result in irreversible tissue deterioration, which in turn impairs function. Acute mechanical forces were delivered using DIs, defined as rapid inflation of the lung to $35 \mathrm{cmH}_{2} \mathrm{O}$ airway pressure. However, peak esophageal pressure during cough can exceed $200 \mathrm{cmH}_{2} \mathrm{O}$ (21); therefore, we consider our mechanical stimulation of the lung to be mild. Nevertheless, these acute increases in mechanical forces achieved by the frequent DIs did result in the following changes in structure and function: 1) large changes in the functional mechanical properties of the respiratory system such as FRC and compliance; and 2) noticeable structural changes in the parenchyma and airways occured only at 21 days after treatment. The former requires a careful analysis because the DIs also induce recruitments, whereas the latter suggests that in order for mechanical forces to be able to induce irreversible changes in lung structure, the ECM of the emphysematous lung should be sufficiently weakened.

The physiological variables (Fig. 1) including FRC, compliance, and hysteresivity increased with time due to the development of emphysema following PPE treatment as in previous studies $(11,16,27)$. The resistance decreased with time as in the tight-skin mouse (15); however, this is in contrast to observed changes in airway resistance in human COPD patients (43). One possibility is that the lung volumes in the normal and treated mice were different, and the measurements were taken at the same PEEP and not at the same lung volume (11).

The DIs significantly increased FRC and compliance both in the control and treated mice. To interpret these results, we first

Table 1. Mean values of alveolar diameters binned into groups of small, medium, and large

\begin{tabular}{|c|c|c|c|c|c|c|}
\hline & \multicolumn{2}{|c|}{ Small } & \multicolumn{2}{|c|}{ Medium } & \multicolumn{2}{|c|}{ Large } \\
\hline & DI & no DI & DI & no DI & DI & no DI \\
\hline 0 days & 17.9 & $18.2^{*}$ & 41.7 & $41.7 \#$ & 92.3 & $98.0^{*}$ \\
\hline 2 days & 27.4 & 27.4 & 142.3 & 141.6 & 329.1 & 335.1 \\
\hline 7 days & $28.1 * *$ & 27.6 & 147.0 & 147.0 & 339.9 & 353.0 \\
\hline 21 days & $27.6 *$ & 27.0 & $154.5^{* * * *}$ & 149.3 & 342.0 & 360.2 \\
\hline
\end{tabular}

Values of deep inspirations (DI) are in micrometers $(\mu \mathrm{m})$. The corresponding bins in the untreated control animals (0 days) are: 5-30 $\mu \mathrm{m}, 30-80 \mu \mathrm{m}$, and $80 \mu \mathrm{m}$; and in the treated animals, they are: 5-100 $\mu \mathrm{m}, 100-300 \mu \mathrm{m}$, and $300 \mu \mathrm{m}, * P<0.001, * * P=0.003, * * * P=0.007, \# P=0.015$. 

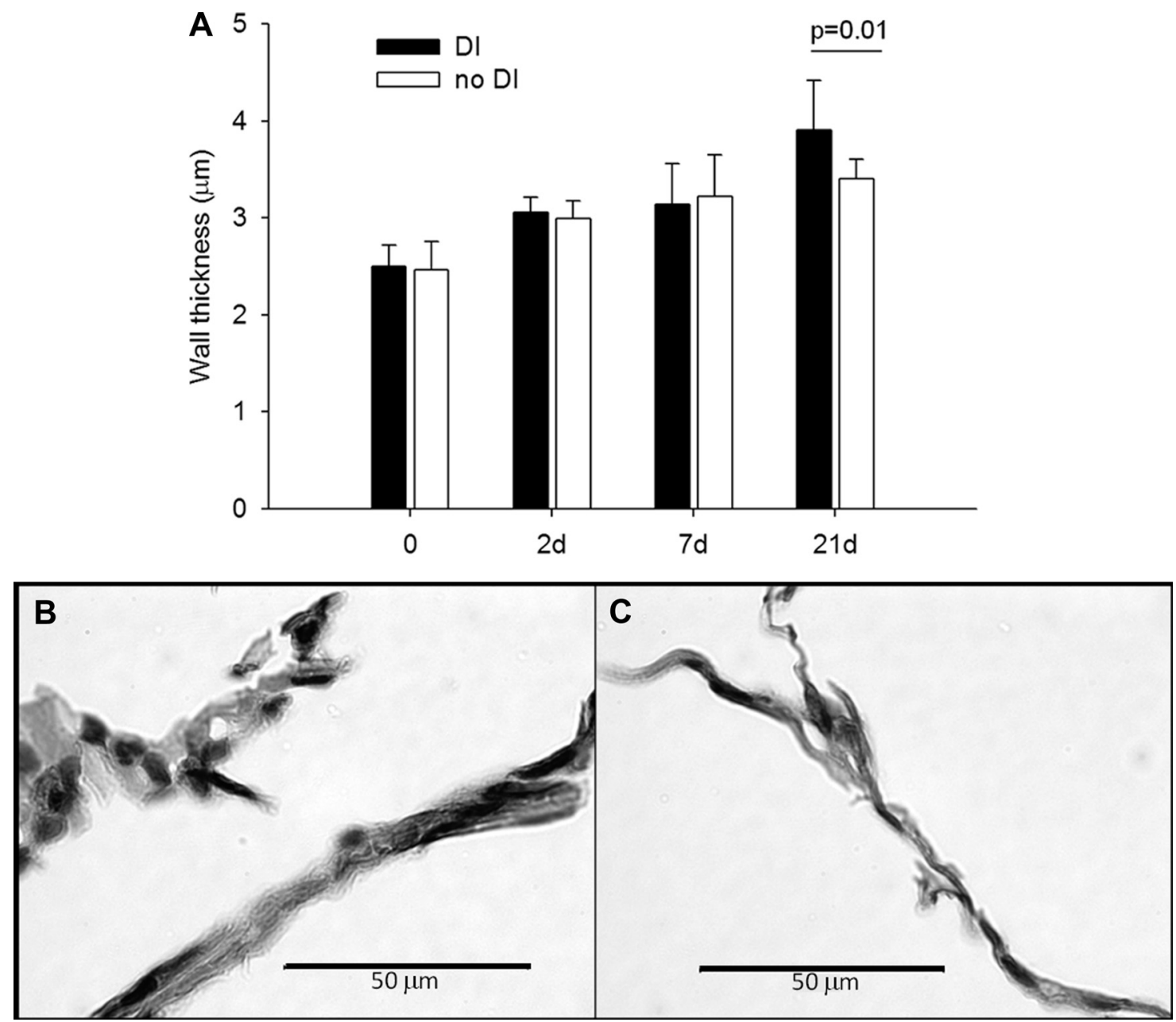

Fig. 4. Morphometric analysis of wall thickness $\left(\mathrm{W}_{\mathrm{t}}\right)$ of the airspaces. $A$ : mean and $\mathrm{SD}$ of $\mathrm{W}_{\mathrm{t}}$ as a function time and DI. PPE had a significant effect on $\mathrm{W}_{\mathrm{t}}(0$ vs. 2,7 , and 21 days; 21 vs. 2 and 7 days: $P<0.001)$. The DIs had a significant effect on $\mathrm{W}_{\mathrm{t}}$ at 21 days $(P<0.01)$. $B$ and $C$ : microstructural evidences of increased $\mathrm{W}_{\mathrm{t}}$ due to DIs 21 days after treatment. $B$ : hematoxylin and eosin staining with DIs, $C$ : hematoxylin and eosin staining with no-DI.

note that anesthetized mice in the supine position easily derecruit large regions of the lung (1). A single DI recruits some airspace regions that, over time, tend to collapse again. Repeated DIs lead to a steady state with a higher FRC depending on the time constant of recollapse relative to the time between DIs. There are at least three ways that compliance could increase in our experiments. First, when fibers inside a wall rupture, the wall becomes softer. If such microruptures occur in many walls, compliance will go up. Second, if a wall ruptures, then there is one less "spring" in the lung resisting inflation, and hence, compliance goes up. Finally, large stretches may induce surfactant release by type II cells (42), which would result in a lower surface tension and compliance can go up again. When compliance increases, the chest wall pulls the lung outward, and FRC goes up too. Taken together, in control mice in which no structural alterations were observed, changes in compliance are due to recruitment and possibly surfactant secretion. In the treated lung, the increase in compliance can be due to mechanical failure as well as recruitment and surfactant secretion. This analysis then suggests that the immediate effect of DIs on FRC and compliance is complicated by recruitment and possibly other processes, and from FRC and compliance alone it is difficult to deduce whether the DIs have caused any irreversible change in the lung during the 1 -h ventilation. Thus, a deeper understanding of the functional data requires a careful analysis of lung structure.

The progression of emphysema was accompanied by increases in both the mean alveolar airspace diameter (D) and its heterogeneity characterized by $\mathrm{D}_{2}$ (Fig. 3). Surprisingly, however, no effects of DIs could be detected on $\mathrm{D}_{2}$, a parameter highly sensitive to structural changes (31). The reason is that the subtle differences in structure due to the DIs could not be captured by a single number. Thus, in a more refined analysis, we combined D from all animals and grouped them into small, medium, and large size categories (Table 1). This analysis identified statistically significant differences between the no-DI and DI groups. Although the absolute differences were small, the statistical significances were very strong due to the large number $(>10,000)$ of airspaces in the calculations.

In the control animals, DIs decreased the sizes of the airspaces in all three airspace size categories. This may be related to the findings of Namati et al. (28) who observed that alveoli became smaller at end inspiration and proposed that this was due to alveolar recruitment in the mouse lung, which means that at higher inflation pressures similar to those in our DI protocol, secondary (daughter) alveoli suddenly pop open 


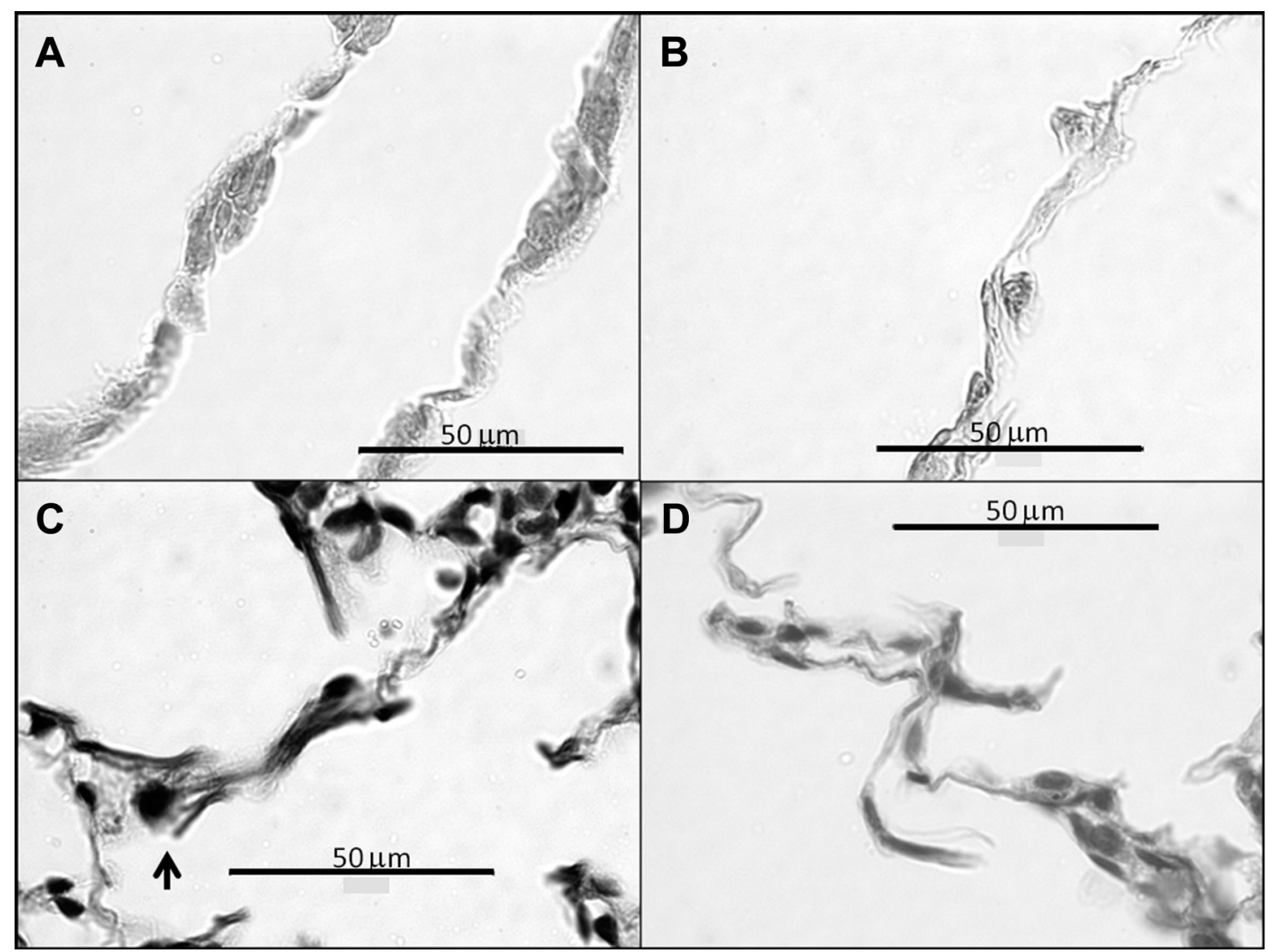

Fig. 5. Representative images of stained histological sections. A: Masson's trichrome staining for collagen, 21 days DI, $B$ : Masson's trichrome staining for collagen, 21 days no-DI, $C$ : modified Verhoeff's staining showing increased $\mathrm{W}_{\mathrm{t}}$ with stray elastin (arrow) that is a potential site of rupture, 21 days DI, $D$ : modified Verhoeff's staining, 21 days no-DI.

and inflate via the primary (mother) alveoli through the pores of Kohn. In contrast, in the treated animals, DIs generated larger D in the two smallest size categories suggesting that at the same fixation pressure, the DIs definitely increased airspace diameters. These results then imply that the septal walls of some small- and medium-sized airspaces became softer or some septal walls actually ruptured during ventilation with DIs. A softer tissue in turn represents plastic deformation as a consequence of microruptures inside the walls induced by the mechanical stresses of the DIs.

The microstructural changes caused by the DIs were most pronounced at 21 days. Indeed, while septal $\mathrm{W}_{\mathrm{t}}$ steadily increased with time (Fig. 4), the DIs caused a statistically significant increase only at 21 days. The increased thickness, which is a characteristic feature of severe AECOPD (1), is apparent on all three types of staining (Figs. 4 and 5). The

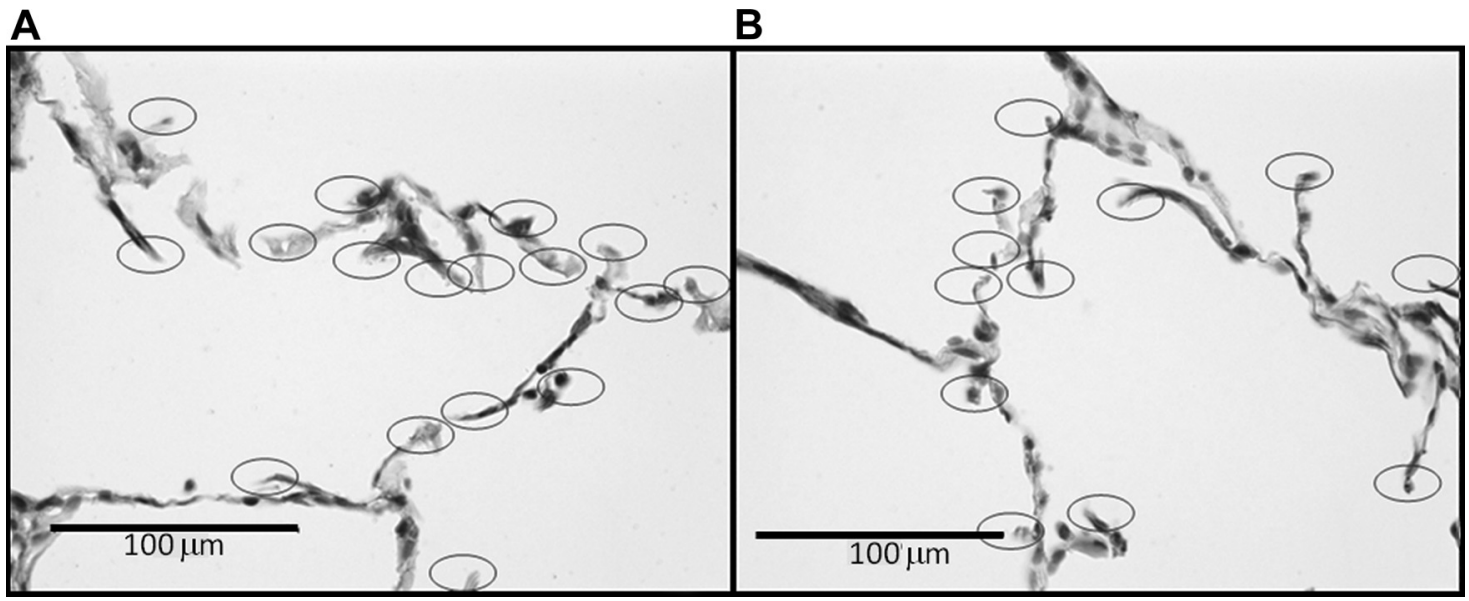

Fig. 6. Visualization of all alveolar septal end tips including possible alveolar ruptures due to DI on modified Verhoeff's stained sections. DI ( $A$ ) and no-DI ( $B$ ). Ellipses mark free septal ends. 
hematoxylin and eosin staining also shows more cell nuclei (Fig. 4B), a sign of inflammation similar to the increased neutrophils in the airways of COPD patients following an exacerbation (32). Additionally, the elastin staining suggests a disorganized fiber network in the wall with possible microruptures (Fig. 5C). These findings are consistent with a sudden deterioration of lung structure that accompanies AECOPD. We also need to point out that the increase in $\mathrm{W}_{\mathrm{t}}$ is accompanied by an increase in compliance in the DI group (Fig. 1B). Therefore, this is not an acute lung injury model in which compliance decreases. Also, the 1-h ventilation period is not enough for active cellular remodeling, hence the most likely reason for the wall thickening is capillary rupture leading to leakage and edema (41).

The fate of a septal wall in which microruptures do occur depends on several factors. Remodeling during the 1-h ventilation is not likely. However, depending on the magnitude of regional stresses, the wall can rupture. At 21 days, statistical analysis revealed that the total number of septal end-tips $\mathrm{N}_{\mathrm{sr}}$ was significantly larger in the DI group compared with the no-DI group. Similar to $\mathrm{N}_{\mathrm{sr}}$, alveolar $\mathrm{A}_{\mathrm{d}}$ around airways increased due to the DIs. In control animals, we did not see any evidence of ruptures, and hence the increase in FRC was caused by pure recruitment. On the other hand, at 21 days, the DI-induced increases in $\mathrm{N}_{\mathrm{sr}}$ and $\mathrm{A}_{\mathrm{d}}$ resulted in larger $\mathrm{D}$ (Table 1), and hence part of the increase in FRC and compliance must have resulted from ruptures. These changes in FRC and compliance represent irreversible decline in function following acute increase in mechanical forces on the parenchyma. Thus, these results provide evidence that our animal model does reproduce a number of features of AECOPD with irreversible changes in both structure and function. Furthermore, since we find evidence of $\mathrm{W}_{\mathrm{t}}$ and fiber and septal wall rupture only at 21 days, there exists a threshold in ECM remodeling below which acute increase in mechanical forces do not seem to induce irreversible changes.

The progression of emphysema alters the architecture of the connective tissue in the septal walls as a result of collagen and elastin remodeling $(23,25,39)$. As the ECM becomes progressively weaker, it is possible that DI-induced microruptures also occurred at earlier time points. For example, D increased for the smallest size category (Table 1) at 7 days. Such subtle changes in structure may not cause noticeable irreversible changes in function. However, when various ECM structures rupture, fragments of the corresponding molecules will be exposed. Both elastin (13) and proteoglycan (3) fragments are chemoattractant and hence the process of tissue breakdown by rupture can maintain and potentiate further inflammation, which is also characteristic of AECOPD (8a) and may contribute to the increased susceptibility of patients to infectioninduced inflammation. If a sufficient number of structural elements of the wall mechanically fail, the entire wall also ruptures, which can influence the distribution of low attenuation areas on computerized tomography images (38) and become clinically observable. Since the parenchyma is always under tensile stress, when an alveolar wall ruptures the stress the wall carried just before failure is redistributed among the neighboring walls. Consequently, some neighbors will experience an increased stress that unfolds new binding sites for enzymes such as elastase and increases the unbinding and cleaving rate (18). These mechanisms in turn result in a higher probability for the wall to mechanically fail. Thus, a single rupture can lead to a cascade of ruptures and serve as a positive feedback to potentiate further breakdown (37). This mechanism might help explain why previous AECOPDs increase the probability of future AECOPDs leading to the emergence of the frequent-exacerbation phenotype (14).

While our model constitutes a mouse model of AECOPD in terms of irreversible changes in structure and function, we acknowledge the limitations of the study. First, despite the fact that our animal model does not involve infections, many studies have confirmed that the mechanism that triggers AECOPD in humans is the viral or bacterial infection (33). Because of the differences in the anatomy and physiology of the mouse and human lungs, the contribution of atelectasis and recruitment to human AECOPD remains uncertain. The magnitude and spatial distribution of mechanical stresses in the mouse are different from those during human AECOPD. Additionally, the PPE treatment does not reproduce the immune response due to cigarette smoke, and the characteristics of ECM remodeling is different in the human case $(23,39)$. Hence the threshold in ECM remodeling that is necessary for mechanical forces to induce irreversible changes in function in mice, may be different in human COPD. Nevertheless, our animal model is flexible: various knockout or transgenic mouse models can be used to mimic the background remodeling of the ECM, and future studies could also combine DIs with infection models.

In summary, we have shown that exacerbation-like irreversible changes in structure and function can be induced by acute increases in mechanical forces in the absence of bacterial or viral infections as long as the lung ECM is sufficiently weak. Thus, it is possible that in humans, the increases in mechanical stresses on the emphysematous tissue associated with cough and difficulty in breathing are also the primary reason for the irreversible changes in AECOPD. While we acknowledge that infection is the likely cause of generating mechanical stresses, it is the balance between the abnormal remodeling and the amount and strength of mechanical stresses on the ECM that determines whether an exacerbation leads to irreversible decline in function or not. Our study also suggests that clinical treatment of AECOPD should minimize mechanical stresses, for example, by attenuating coughing or carefully choosing mechanical ventilation parameters if the patient needs to be ventilated.

\section{GRANTS}

This study was supported by National Heart, Lung, and Blood Institute grants HL-090757 and HL-098976, Hungarian Scientific Research Fund grant (OTKA) Grant 66700, and the Rosztoczy Foundation.

\section{DISCLOSURES}

No conflicts of interest, financial or otherwise are declared by the author(s).

\section{AUTHOR CONTRIBUTIONS}

Author contributions: M.V.S. and S.S. performed experiments; M.V.S., H.P., S.S., E.B.-S., and B.S. analyzed data; M.V.S., H.P., S.S., Z.H., E.B.-S., and B.S. interpreted results of experiments; M.V.S. prepared figures; M.V.S. and B.S. drafted manuscript; Z.H., E.B.-S., and B.S. conception and design of research; Z.H., E.B.-S., and B.S. edited and revised manuscript; B.S. approved final version of manuscript.

\section{REFERENCES}

1. Allen GB, Suratt BT, Rinaldi L, Petty JM, Bates JH. Choosing the frequency of deep inflation in mice: balancing recruitment against venti- 
lator-induced lung injury. Am J Physiol Lung Cell Mol Physiol 291: L710-L717, 2006.

2. Anzueto A. Impact of exacerbations on COPD. Eur Respir Rev 19: 113-118, 2010.

3. Cantor JO, Nadkarni PP. Hyaluronan: the Jekyll and Hyde molecule. Inflamm Allergy Drug Targets 5: 257-260, 2006.

4. Donaldson GC, Seemungal T, Jeffries DJ, Wedzicha JA. Effect of temperature on lung function and symptoms in chronic obstructive pulmonary disease. Eur Respir J 13: 844-849, 1999.

5. Donaldson GC, Seemungal TA, Bhowmik A, Wedzicha JA. Relationship between exacerbation frequency and lung function decline in chronic obstructive pulmonary disease. Thorax 57: 847-852, 2002.

7. Dubois AB, Botelho SY, Bedell GN, Marshall R, Comroe JH Jr. A rapid plethysmographic method for measuring thoracic gas volume: a comparison with a nitrogen washout method for measuring functional residual capacity in normal subjects. J Clin Invest 35: 322-326, 1956.

8. Garcia-Aymerich J, Serra Pons I, Mannino DM, Maas AK, Miller DP, Davis KJ. Lung function impairment, COPD hospitalisations and subsequent mortality. Thorax 66: 585-590, 2011.

8a.Global Initiative for Chronic Obstructive Lung Disease Global Strategy for the Diagnosis, Management, and Prevention of Chronic Obstructive Pulmonary Disease. http://www.goldcopd.org/uploads/users/files/GOLD_ Report_2011_Feb21.pdf.

9. Gompertz S, Bayley DL, Hill SL, Stockley RA. Relationship between airway inflammation and the frequency of exacerbations in patients with smoking related COPD. Thorax 56: 36-41, 2001.

10. Hamakawa H, Bartolak-Suki E, Parameswaran H, Majumdar A, Lutchen KR, Suki B. Structure-function relations in an elastase-induced mouse model of emphysema. Am J Respir Cell Mol Biol 45: 517-524, 2011.

11. Hantos Z, Adamicza A, Janosi TZ, Szabari MV, Tolnai J, Suki B. Lung volumes and respiratory mechanics in elastase-induced emphysema in mice. J Appl Physiol 105: 1864-1872, 2008.

12. Hantos Z, Daroczy B, Suki B, Nagy S, Fredberg JJ. Input impedance and peripheral inhomogeneity of dog lungs. J Appl Physiol 72: 168-178, 1992.

13. Houghton AM, Quintero PA, Perkins DL, Kobayashi DK, Kelley DG, Marconcini LA, Mecham RP, Senior RM, Shapiro SD. Elastin fragments drive disease progression in a murine model of emphysema. J Clin Invest 116: 753-759, 2006.

14. Hurst JR, Vestbo J, Anzueto A, Locantore N, Mullerova H, TalSinger R, Miller B, Lomas DA, Agusti A, Macnee W, Calverley P, Rennard S, Wouters EF, Wedzicha JA, Evaluation of COPD Longitudinally to Identify Predictive Surrogate Endpoints (ECLIPSE) Investigators. Susceptibility to exacerbation in chronic obstructive pulmonary disease. $N$ Engl J Med 363: 1128-1138, 2010.

15. Ito S, Bartolak-Suki E, Shipley JM, Parameswaran H, Majumdar A, Suki B. Early emphysema in the tight skin and pallid mice: roles of microfibril-associated glycoproteins, collagen, and mechanical forces. Am J Respir Cell Mol Biol 34: 688-694, 2006.

16. Ito S, Ingenito EP, Arold SP, Parameswaran H, Tgavalekos NT, Lutchen KR, Suki B. Tissue heterogeneity in the mouse lung: effects of elastase treatment. J Appl Physiol 97: 204-212, 2004.

17. Janosi TZ, Adamicza A, Zosky GR, Asztalos T, Sly PD, Hantos Z. Plethysmographic estimation of thoracic gas volume in apneic mice. $J$ Appl Physiol 101: 454-459, 2006.

18. Jesudason R, Sato S, Parameswaran H, Araujo AD, Majumdar A, Allen PG, Bartolak-Suki E, Suki B. Mechanical forces regulate elastase activity and binding site availability in lung elastin. Biophys $J$ 99: 3076$3083,2010$.

19. Kononov S, Brewer K, Sakai H, Cavalcante FS, Sabayanagam CR, Ingenito EP, Suki B. Roles of mechanical forces and collagen failure in the development of elastase-induced emphysema. Am J Respir Crit Care Med 164: 1920-1926, 2001.

20. Lakatos HF, Burgess HA, Thatcher TH, Redonnet MR, Hernady E, Williams JP, Sime PJ. Oropharyngeal aspiration of a silica suspension produces a superior model of silicosis in the mouse when compared to intratracheal instillation. Exp Lung Res 32: 181-199, 2006.

21. Lavietes MH, Smeltzer SC, Cook SD, Modak RM, Smaldone GC. Airway dynamics, oesophageal pressure and cough. Eur Respir J 11: 156-161, 1998.
22. Leith DE. Cough. Phys Ther 48: 439-447, 1968.

23. Lucey EC, Goldstein RH, Stone PJ, Snider GL. Remodeling of alveolar walls after elastase treatment of hamsters. Results of elastin and collagen mRNA in situ hybridization. Am J Respir Crit Care Med 158: 555-564, 1998.

24. Lutchen KR, Yang K, Kaczka DW, Suki B. Optimal ventilation waveforms for estimating low-frequency respiratory impedance. J Appl Physiol 75: 478-488, 1993.

25. Mercer RR, Crapo JD. Structural changes in elastic fibers after pancreatic elastase administration in hamsters. J Appl Physiol 72: 1473-1479, 1992.

26. Mishima M, Hirai T, Itoh H, Nakano Y, Sakai H, Muro S, Nishimura K, Oku Y, Chin K, Ohi M, Nakamura T, Bates JH, Alencar AM, Suki B. Complexity of terminal airspace geometry assessed by lung computed tomography in normal subjects and patients with chronic obstructive pulmonary disease. Proc Natl Acad Sci USA 96: 8829-8834, 1999.

27. Mouded M, Egea EE, Brown MJ, Hanlon SM, Houghton AM, Tsai LW, Ingenito EP, Shapiro SD. Epithelial cell apoptosis causes acute lung injury masquerading as emphysema. Am J Respir Cell Mol Biol 41: 407-414, 2009.

28. Namati E, Thiesse J, de Ryk J, McLennan G. Alveolar dynamics during respiration: are the pores of Kohn a pathway to recruitment? Am J Respir Cell Mol Biol 38: 572-578, 2008.

29. O'Donnell DE, Bertley JC, Chau LK, Webb KA. Qualitative aspects of exertional breathlessness in chronic airflow limitation: pathophysiologic mechanisms. Am J Respir Crit Care Med 155: 109-115, 1997.

30. Paggiaro PL, Dahle R, Bakran I, Frith L, Hollingworth K, Efthimiou J. Multicentre randomised placebo-controlled trial of inhaled fluticasone propionate in patients with chronic obstructive pulmonary disease. International COPD Study Group. Lancet 351: 773-780, 1998.

31. Parameswaran H, Majumdar A, Ito S, Alencar AM, Suki B. Quantitative characterization of airspace enlargement in emphysema. $J$ Appl Physiol 100: 186-193, 2006.

32. Qiu Y, Zhu J, Bandi V, Atmar RL, Hattotuwa K, Guntupalli KK, Jeffery PK. Biopsy neutrophilia, neutrophil chemokine and receptor gene expression in severe exacerbations of chronic obstructive pulmonary disease. Am J Respir Crit Care Med 168: 968-975, 2003.

33. Sapey E, Stockley RA. COPD exacerbations. 2: aetiology. Thorax 61: 250-258, 2006.

34. Seemungal TA, Donaldson GC, Bhowmik A, Jeffries DJ, Wedzicha JA. Time course and recovery of exacerbations in patients with chronic obstructive pulmonary disease. Am J Respir Crit Care Med 161: 1608 $1613,2000$.

35. Seemungal TA, Harper-Owen R, Bhowmik A, Jeffries DJ, Wedzicha JA. Detection of rhinovirus in induced sputum at exacerbation of chronic obstructive pulmonary disease. Eur Respir J 16: 677-683, 2000.

36. Stockley RA, O'Brien C, Pye A, Hill SL. Relationship of sputum color to nature and outpatient management of acute exacerbations of COPD 2000. Chest 136: e30, 2009.

37. Suki B, Lutchen KR, Ingenito EP. On the progressive nature of emphysema: roles of proteases, inflammation, and mechanical forces. Am J Respir Crit Care Med 168: 516-521, 2003.

38. Tanabe N, Muro S, Hirai T, Oguma T, Terada K, Marumo S, Kinose D, Ogawa E, Hoshino Y, Mishima M. Impact of exacerbations on emphysema progression in chronic obstructive pulmonary disease. Am J Respir Crit Care Med 183: 1653-1659, 2011.

39. Vlahovic G, Russell ML, Mercer RR, Crapo JD. Cellular and connective tissue changes in alveolar septal walls in emphysema. Am J Respir Crit Care Med 160: 2086-2092, 1999.

40. Wang D, Wang Y, Liu YN. Experimental pulmonary infection and colonization of Haemophilus influenzae in emphysematous hamsters. Pulm Pharmacol Ther 23: 292-299, 2010.

41. West JB. Pulmonary capillary stress failure. J Appl Physiol 89: 24832489, 2000.

42. Wirtz HR, Dobbs LG. Calcium mobilization and exocytosis after one mechanical stretch of lung epithelial cells. Science 250: 1266-1269, 1990.

43. Zamel N, Hogg J, Gelb A. Mechanisms of maximal expiratory flow limitation in clinically unsuspected emphysema and obstruction of the peripheral airways. Am Rev Respir Dis 113: 337-345, 1976. 